\title{
TRAFIC, A COMPUTER PROGRAM FOR CALCULATING THE RELEASE OF METALLIC FISSION PRODUCTS FROM AN HTGR CORE
}

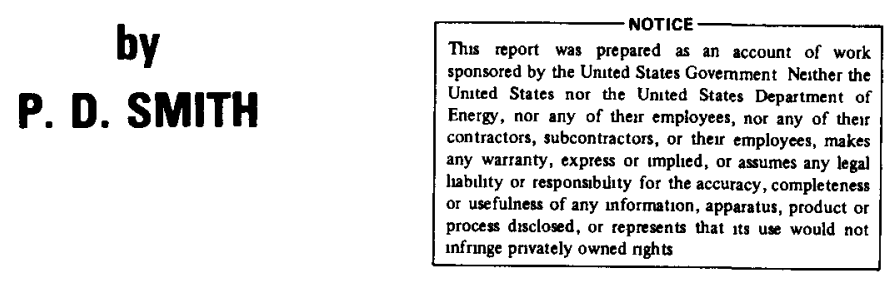

Prepared under

Contract EY-76-C-03-0167

Project Agreement No. 17

for the San Francisco Operations Office

Department of Energy

GENERAL ATOMIC PROJECT 3224

DATE PUBLISHED: FEBRUARY 1978

\section{GENERAL ATOMIC COMPANY}




\section{DISCLAIMER}

This report was prepared as an account of work sponsored by an agency of the United States Government. Neither the United States Government nor any agency Thereof, nor any of their employees, makes any warranty, express or implied, or assumes any legal liability or responsibility for the accuracy, completeness, or usefulness of any information, apparatus, product, or process disclosed, or represents that its use would not infringe privately owned rights. Reference herein to any specific commercial product, process, or service by trade name, trademark, manufacturer, or otherwise does not necessarily constitute or imply its endorsement, recommendation, or favoring by the United States Government or any agency thereof. The views and opinions of authors expressed herein do not necessarily state or reflect those of the United States Government or any agency thereof. 


\section{DISCLAIMER}

Portions of this document may be illegible in electronic image products. Images are produced from the best available original document. 


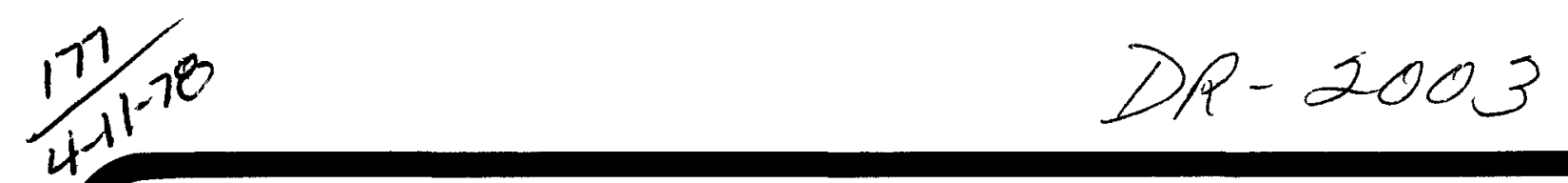

GA-A14721 UC-77

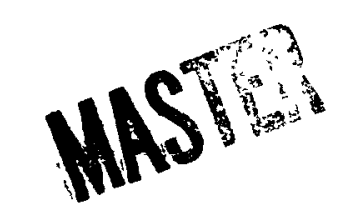

Doc. No. 903555

\title{
TRAFIC, \\ A COMPUTER PROGRAM FOR CALCULATING THE RELEASE OF METALLIC FISSION PRODUCTS FROM AN HTGR CORE
}

\author{
by \\ P. D. SMITH
}

Prepared under

Contract EY-76-C-03-1067

Project Agreement No. 17

for the San Francisco Operations Office

Department of Energy

DATE PUBLISHED: FEBRUARY 1978

\section{GENERAL ATOMIC COMPANY}




\section{NOTICE}

This report was prepared as an account of work sponsored by the United States Government. Neither the United States nor the Department of Energy, nor any of their employees, nor any of their contractors, subcontractors, or their employees, makes any warranty, express or implied, or assumes any legal liability or responsibility for the accuracy, completeness or usefulness of any information, apparatus, product or process disclosed, or represents that its use would not infringe privately owned rights.

Printed in the United States of America

Available from

National Technical Information Service

U.S. Department of Commerce

5285 Port Royal Road

Springfie1d, Virginia 22161

Price: Printed Copy $\$ 9.00$; Microfiche $\$ 3.00$ 
ABSTRACT

A special purpose computer program, TRAFIC, is presented for calculating the release of metallic fission products from an HTGR core. The program is based upon Fick's law of diffusion for radioactive species. One-dimensional transient diffusion calculations are performed for the coated fuel particles and for the structural graphite web. A quasi steady-state calculation is performed for the fuel rod matrix material. The model accounts for nonlinear adsorption behavior in the fuel rod gap and on the coolant hole boundary.

The TRAFIC program is designed to operate in a core survey mode; that is, it performs many repetative calculations for a large number of spatial locations in the core. This is necessary in order to obtain an accurate volume integrated release. For this reason the program has been designed with calculational efficiency as one of its main objectives.

A highly efficient numerical method is used in the solution. The method makes use of the Duhamel superposition principle to eliminate interior spatial solutions from consideration. Linear response functions relating the concentrations and mass fluxes on the boundaries of a homogeneous region are derived. Multiple regions are numerically coupled through interface conditions. Algebraic elimination is used to reduce the equations as far as possible. The prolem reduces to two nonlinear equations in two unknowns, which are solved using a Newton Raphson technique.

The TRAFIC program can be run in a stand-alone mode, where all data are input on cards, or it can be interfaced with the core physics and core performance codes now in use at General Atomic. In this latter application huge volumes of space and time-dependent thermal and particle performance data are automatically processed through data tape interfaces, and very little input is required of the user. 


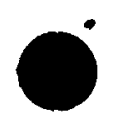


TABLE OF CONTENTS

PAGE

1. INTRODUCTION . . . . . . . . . . . . . . . . . . . . . . . . 1

2. THEORY . . . . . . . . . . . . . . . . . . . . . . 7

2.2 COATED PARTICLE RELEASE (COPAR) . . . . . . . . . . 12

2.2.1 COPAR Phase 1 Solution . . . . . . . . . . . 14

2.2.2 COPAR Phase 2 Solution . . . . . . . . . . . 20

2.2 .3 Other COPAR Features . . . . . . . . . . 25

2.3 FUEL ROD MODEL . . . . . . . . . . . . . . . . . 27

2.4 VAPOR PRESSURE RELATIONSHIPS . . . . . . . . . . . 32

2.5 GAP INTERFACE CONDITIONS . . . . . . . . . . . . . 37

2.6 GRAPHITE SLAB DIFFUSION MODEL . . . . . . . . . . . . 41

2.6.1 Phase 1 Slab Solution . . . . . . . . . . 44

2.6.2 Phase $2 \mathrm{~S} 1 \mathrm{ab}$ Solution ........... 45

2.7 COOLANT HOLE BOUNDARY . . . . . . . . . . . . . . . . 46

2.8 SOLUTION FOR NONLINEAR INTERFACE AND BOUNDARY CONDITIONS. 49

2.9 RELEASE AND INVENTORY EVALUATION . . . . . . . . . . . 52

2.10 MASS TRANSFER CORRELATION . . . . . . . . . . . . 53

2.11 FISSION YIELDS . . . . . . . . . . . . . . . 55

3. TRAFIC ORGANIZATION AND METHOD OF CALCULATION . . . . . . . . . 60

3.1 INPUT MODES . . . . . . . . . . . . . . . . 60

3.2 SURVEY DATA PROCESSING LOGIC . . . . . . . . . . 61

3.2.1 HTGR Geometry - Refueling Regions . . . . . . . 62

3.2.2 Spatial Positions in SURVEY . . . . . . . . . 68

3.2.3 Time History in SURVEY and TRAFIC . . . . . . . 74

3.2.4 Equilibrium Core Simulation . . . . . . . . . 79

3.3 TRAFIC FlOW CHART . . . . . . . . . . . . . . 83

4. INPUT INSTRUCTIONS . . . . . . . . . . . . . . . . . . 87

4.1 TRAFIC DECK SETUP . . . . . . . . . . . . . . 88

4.1.1 Basic Deck Structure . . . . . . . . . . . 88

4.1.2 Optional File Assignments . . . . . . . . 89 


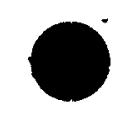




\section{TABLE OF CONTENTS (Continued)}

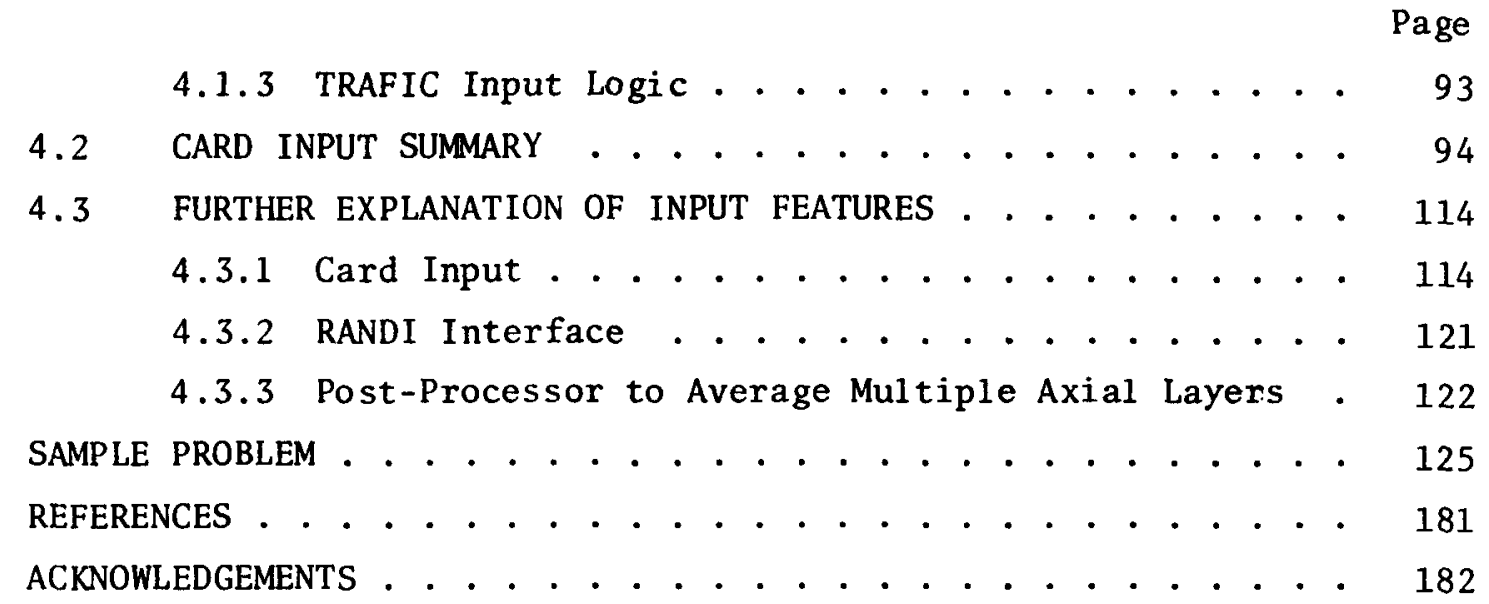




\section{INTRODUCTION}

This report presents a model for calculating the release of a single species of metallic fission product from the core of a High Temperature GasCooled Reactor (HTGR). The release process is generally governed by Fick's Law of diffusion for a radioactive species (Ref. 1). In addition, there are a number of complicating factors such as transport across a gap, non-linear sorption processes, and the modeling of the source from a collection of continuously failing particles, that must be considered. An exact solution of the nonlinear coupled equations involved in this process is a demanding task. The computational difficulties of the problem are further aggravated by the fact that thousands of repetitive calculations must be performed to obtain an accurate volume-integrated release from the core. In view of this, an essential feature of the present model is that it was formulated with computational efficiency as one of its main objectives. A second, equally important objective was that the model should realistically account for all important physical aspects of the problem. These conflicting goals have been met by developing a special-purpose program named TRAFIC (TRAnsport of Fission products In Core). TRAFIC takes advantage of a special HTGR geometry and some limiting physical assumptions to simplify the problem. It also employs a highly-efficient numerical solution method that is of general applicability to diffusion problems of this type. This report presents the theory behind the TRAFIC model, input instructions for the program, and the results of a sample run.

As an introduction to the problem at hand, the path taken by a fission product atom after it is born, as it migrates sequentially through several barriers in an HTGR core, will now be described. The modeling techniques employed at each stage will be briefly introduced. 
Upon direct birth from a nuclear fission, usually within the fueled kernel of a coated particle, a fission product atom is recoiled in a random direction with a characteristic kinetic energy. After a very short time the recoiled atom is slowed to rest at some distance from its initial birthplace. The recoll process is so rapid that it may be viewed as instantaneous. Hence, the effect of recoil is to change the spatial distribution of the direct fission source. A modified spatial distribution, termed the recoiled source shape, can be directly determined from the fission source shape as a function of the geometry and the material properties, both of which are independent of time.

The recoiled atom then migrates by a diffusion process through the kernel and one or more layers of a coated fuel particle. These layers have different physical properties, and the diffusion process proceeds at varying rates in different layers. There may also be sharp discontinuities in concentration at the particle layer interfaces caused by the different chemical affinities of the adjacent materials. In TRAFIC the process of time-dependent diffusion through the heterogeneous, multilayered particle is computed by a set of modular subroutines having the generic name COPAR (Ref. 2).

After release from a particle, a fission product atom enters the matrix material of the fuel rod. Here it is blended with the atoms released from all other particles in the same fuel rod. There will generally be two or more particle types (e.g., BISO and TRISO) in the rod. Furthermore, there are thousands of particles of each type, and the collection of particles in a rod experiences a space- and time-dependent history of temperature, burnup, and coating failure fraction. The COPAR source subroutine employs a birth pulse superposition technique to sum the release from all these particles. It considers all possible combinations of (a) birth in intact or failed particles, (b) times to failure, and (c) release from intact or failed particles. 
In the fuel rod matrix our atom begins another diffusion process in which it migrates through the matrix to the surface of the fuel rod. Strictly speaking, this is also a time-dependent diffusion problem. To solve it, one would have to perform a transient diffusion analysis with a space and time-dependent source rate. This calculation would require a disproportionate share of the computational effort of the model. On physical grounds this is not warranted, because it is known that diffusion in the matrix is relatively rapid, so the matrix resistance is not a controlling factor when compared to the other resistances in the problem. Therefore, TRAFIC makes the simplifying and conservative assumption that the diffusion coefficient in the matrix is a very large and, hence, that a quasi steady-state concentration profile is instantaneously developed in the fuel rod matrix. When this is done the partial differential equation in the fuel rod matrix is transformed to an integral mass balance equation, and the concentration profile in the matrix is known as a function of the history of the total source and the outgoing mass flux.

When the atom reaches the surface of the fuel rod, the next barrier to release is the helium-filled gap between the fuel rod and the surrounding structural graphite. The transport of an atom across the gap begins with evaporation of the atom from an adsorbed solid phase to a free vapor phase. Then the vapor atom must be transported across the gap by diffusion and convection. Finally, the vapor must be readsorbed on the opposite surface. In TRAFIC this process is conservatively modeled by assuming that the vapor pressure is equal on opposite sides of the gap and, furthermore, that the vapor pressure on either side is in equilibrium with the sorbed solid phase. Thus, it is assumed that all kinetic resistances in the gap are zero. Once an atom is desorbed as a vapor, it is assumed to be instantaneously availabl: for readsorption on the opposite side of the gap. This neglects any delay caused by diffusion through the gas in the gap.

It should be noted that the vapor pressure/sorption relationships employed in this gap transport model are generally nonlinear. This introduces nonlinear interface conditions in the system of coupled diffusion equations. 
After transport across the gap the atom is readsorbed on the fuel-hole surface of the structural graphite. From there it migrates by diffusion through the graphite to the coolant hole surface. The diffusion in the graphite is relatively slow, so the transient time-dependent diffusion equation must be solved in this region. A simplification is achieved by noting that the source rate is zero in the graphite. This means that the interior solution is a function only of the boundary conditions. The consequence of this is that the interior solution can be eliminated from consideration, and the Duhamel superposition principle can be used to account for the time-dependent boundary conditions. This makes possible a numerical solution method that is orders of magnitude faster than a direct, space-time solution.

When it reaches the coolant hole surface of the graphite, the fission product atom is again desorbed into the vapor phase. The desorption is governed by the same nonlinear vapor pressure relationships that are employed in the gap. At the coolant hole, however, the additional kinetic resistance due to diffusive mass transport through the boundary layer is considered. This takes the form of an empirical correlation between a mass transfer coefficient and some non-dimensional flow parameters of the coolant.

In summary, TRAFIC is a special-purpose program designed to calculate the transport of a metallic fission product species within the HTGR core. It considers the following transport paths in series:

1. Diffusive transport through multi-layered coated particles, both intact and failed;

2. Quasi-steady instantaneous transport through the fuel rod matrix;

3. Equilibrium vapor pressure transport, without kinetic resistance, In the fuel rod/graphite gap;

4. Diffusive transport through the graphite; 
5. Vapor pressure equilibrium at the coolant hole surface;

6. Kinetic resistance of the coolant hole boundary layer.

Transient diffusion calculations are performed in both the particles and the structural graphite. Both are accomplished by means of a superposition technique that eliminates the interior spatial solution from consideration. Nonlinear boundary conditions are considered on both the gap side and the coolant side of the graphite web.

TRAFIC performs these calculations in core survey mode, sampling a number of locations in the reactor core and volume integrating the release. Since the release is a highly nonlinear function of temperature, and since the temperature in an HTGR is an irregular function of time and position, a large number of locations must be sampled to obtain an accurate volume integrated release. The typical number of locations analyzed is seven per fuel element, multiplied by about 4000 elements in the core, divided by three for $120^{\circ}$ azimuthal symmetry, for a total of about 10,000. For each of these locations a time-dependent nonlinear diffusion calculation of about 100 time steps is performed as outlined above. It should be clear that calculational efficiency is essential in this application. TRAFIC has achieved an average running time of about two seconds per core location on the Univac 1108, but even this represents 5-6 hours of computing for a full core survey.

TRAFIC requires as input a general description of all the relevant material properties and how they vary with temperature and burnup. Then, for each space point analyzed, it requires a history of the fuel temperatures, the burnup, the fissions in each particle type, and the particle failure fractions. The large volume of historical data is automatically provided through a data tape interface with the THERM and PERFOR modules of the SURVEY core performance code*. One may also, by option, provide these data on cards, for "stand alone" evaluation of a few selected space points.

* SURVEY is a new core survey program for thermal and fuel performance analysis. A formal report on SURVEY, GA-A14869, is now in preparation. The calculational models of SURVEY are similar to those of its predecessor, TREVER (GA-A12985), but the data processing and the interfaces are improved. 
The following chapter presents the theory of the TRAFIC code. The equations governing each of the resistance mechanisms are presented sequentially, after which the overall solution strategy is discussed. A brief introduction to the organization of the TRAFIC code, explaining the logic of the core survey calculations, is presented in Chapter 3 . Chapter 4 then presents the input instructions, including both a summary of the input data in card-image format and some detailed explanations of various input features. Finally, the output from a typical sample problem involving an interface with the SURVEY code is presented in Chapter 5 . 


\section{THEORY}

This chapter presents the theory of the TRAFIC program. The following section contains a description of the geometry used in the calculation, showing the spatial arrangement of the release barriers. Then the equations governing all of the release barriers in turn will be presented. Finally, the overall solution strategy, in which the nonlinear interface equations are defined and solved by an iterative method, will be discussed.

\subsection{TRAFIC CALCULATIONAL GEOMETRY}

To perform the total core analysis, a geometry, or calculational cell, is defined which is representative of the HTGR core and which is repeated throughout the core. In TRAFIC the calculational cell is the smallest unit of symmetry in the HTGR core, a 30-60-90 triangle as shown below.

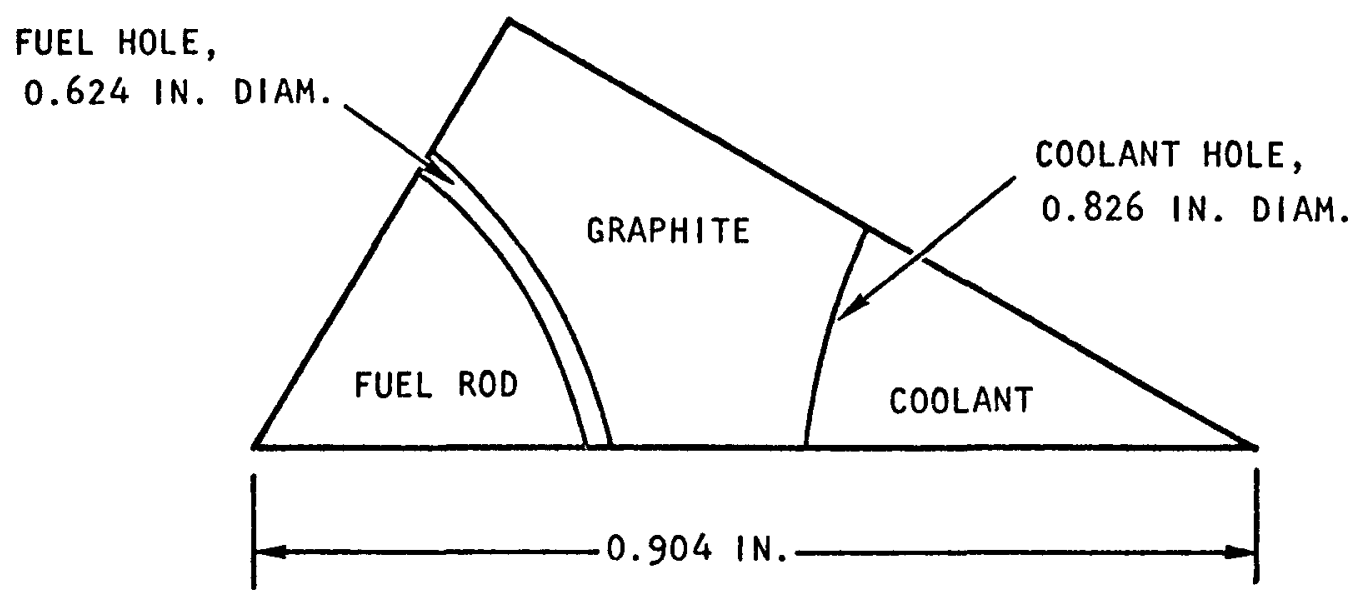

SMALLEST UNIT OF SYMMETRY IN HTGR CORE 
TRAFIC models the fuel rod in cylindrical coordinates, assuming the concentration distribution in the fuel rod is axisymmetric. Two-dimensional heat transfer calculations using the HEXT computer code (Ref. 3) have shown this to be a good approximation.

The graphite web, which in reality is a two-dimensional shape, is modeled in slab geometry. This is done by transforming the web into an "equivalent slab" having the same diffusive resistance as the actual shape. The dimensions of the equivalent slab are usually obtained by performing a two-dimensional heat transfer correlation with the aid of the HEXT code. The principle used is that the slab is equivalent if it has the same resistance to heat flow as the actual two-dimensional shape. This also provides an equivalent slab for mass diffusion because these two processes obey the same differential equation.* There are two unknowns in the slab dimensions, both of which affect the slab resistance: the cross sectional area and the thickness. The slab area is fixed equal to $1 / 12$ of the area of the coolant hole surface in order to preserve the proper convective mass transport characteristics at the coolant hole boundary. The thickness then immediately follows from the two-dimensional correlation. The graphite web along with an appropriate equivalent slab model is illustrated below.

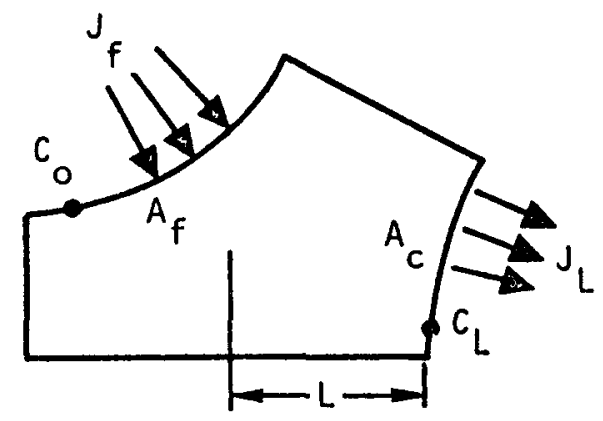

WEB GEOMETRY

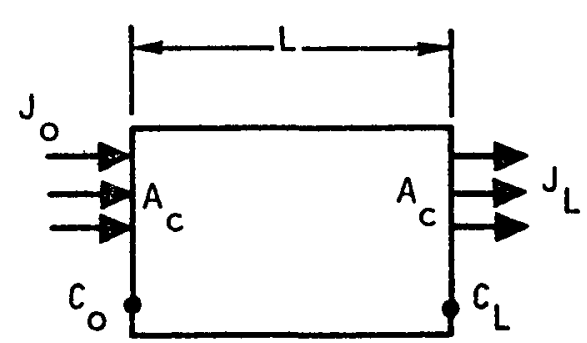

EQUIVALENT SLAB

WEB IDEALIZATION

* Strictly speaking, this is true only for a stable, non-decaying isotope. Analogous procedures can also be devised for decaying species. 
Since the release from particles is a strong function of temperature, and since the temperature varies radially in the fuel rod, TRAFIC has the option of subdividing the fuel rod into multiple annuli. When this is done the volume average temperature of each annulus is computed, and a local COPAR evaluation determines the source to that annulus. The sources in all of the annuli are then combined to compute the total source in the fuel rod.

In the actual two-dimensional web shape, the area on the fuel rod side (1/6 of the fuel hole area) is different from the area on the coolant hole side. Therefore, the equivalent slab has an incorrect area on the fuel rod side. TRAFIC accounts for this by adjusting the mass flux on the fuel rod side of the slab in such a way that the total mass flows are properly balanced. The way in which this is done will now be described.

Given a concentration of fission product $C_{o}$ on the fuel rod side of the slab and a concentration $C_{L}$ on the coolant hole side, the equivalent slab model will predict the mass flux $\mathrm{J}_{\mathrm{L}}$ on the coolant hole side of the slab, where the slab area is correct. On the fuel rod side, where the slab area is incorrect, the mass flux $\mathrm{J}_{0}$ predicted by the slab model is fictitious. However, the total mass flow,

$$
\dot{\mathrm{m}}=\mathrm{J}_{\mathrm{o}} \mathrm{A}_{\mathrm{c}},
$$

where $A_{c}$ is $1 / 12$ of the coolant hole area, is assumed to be correct. Consequently, the real mass flux emerging from the fuel rod is given by

$$
J_{f}=J_{0} \frac{A_{c}}{A_{f}},
$$

where $A_{f}$ is $1 / 6$ of the fuel rod surface area. Equation (2) is used 1ater to couple the solution in the slab region with the solution in the fuel region. 
An important part of the TRAFIC code, not shown in the previous sketches, is the coated fuel particle model. TRAFIC employs the COPAR program (Ref. 2) as a subroutine to compute the source from the particles to the fuel rod matrix. COPAR models the particle in the appropriate spherical geometry, using the actual dimensions and physical properties of the particle. These are defined in a general sense under control of user input, so the design and geometry of the particle is arbitrary. As an example of a typical particle, a TRISO particle is shown schematically below.

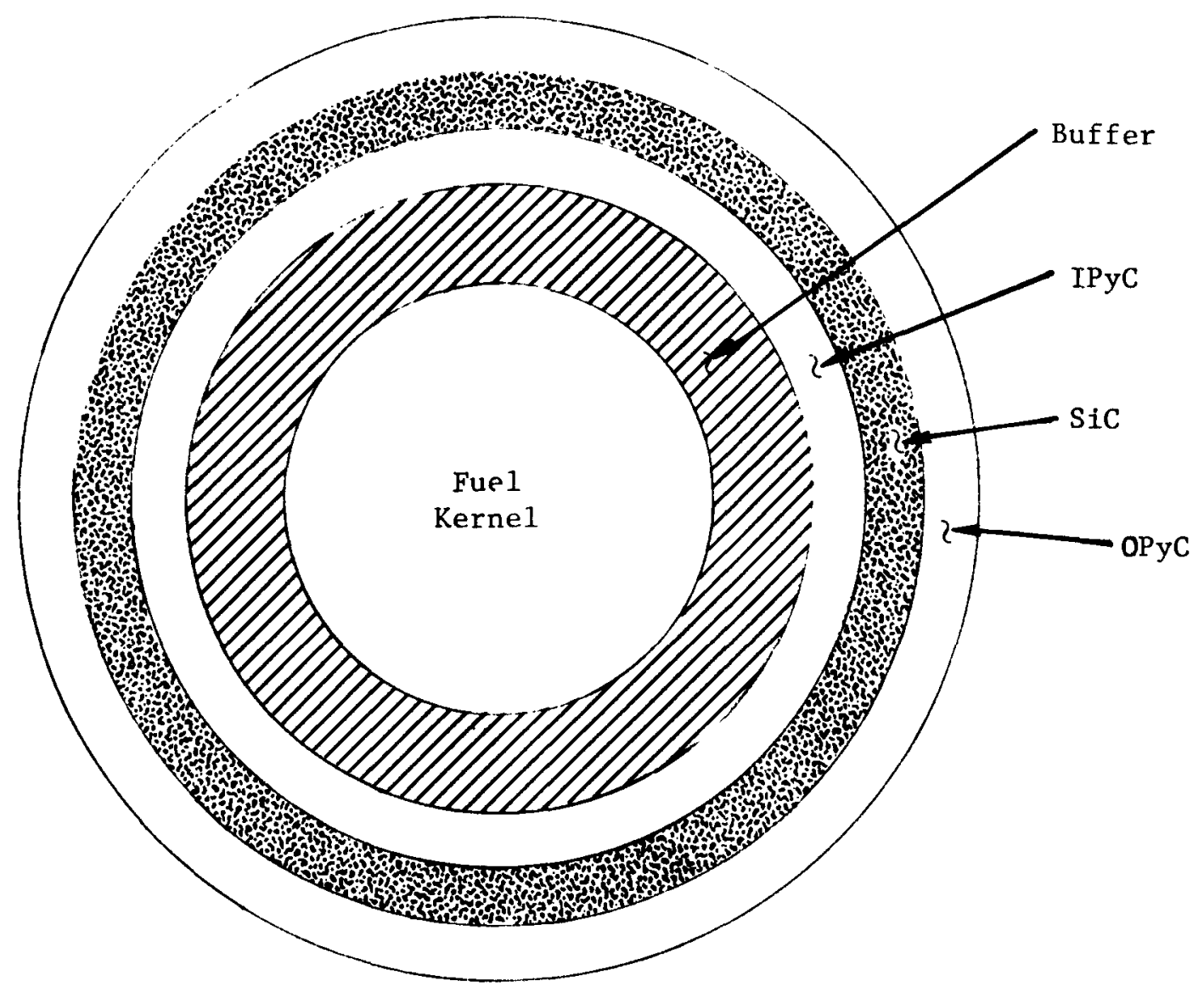

For background information, the various layers in a TRISO particle and their physical characteristics are described on the next page. 
1. Fuel Kernel - This is the innermost spherical region containing all of the fissile and fertile material, apart from a small contamination fraction. Diffusion through the kernel is the first barrier to release.

2. Buffer

- This is a porous and highly diffusive carbon layer designed to absorb recoil and prevent damage to the outer layers. It also serves as a volume reservoir for fission gases.

3. IPyC

- This is the "inner pyrocarbon" layer. It is impervious to gases but is relatively diffusive for metals.

4. SiC

- The silicon carbide layer is a dense and structurally rigid layer which serves as the primary barrier to metallic fission products. It also serves as a pressure vessel to retain gases and as a structural support for dimensional stability.

5. OPyC

- This is the "outer pyrocarbon" layer. It serves to protect the surface of the $\mathrm{SiC}$, and it also provides additional diffusive resistance.

A BISO particle, which is used only for fertile particles, is similar except that it does not have the SiC and OPyC layers. Having only the kernel and the IPyC as barriers to fission products, BISO's are relatively diffusive for metals.

The fission products released from the particles are assumed to act as a point source in the fuel rod matrix. The fuel rod matrix material is modeled as a homogeneous, "smeared" cylinder. Concentrations in the fuel matrix are measured in $\mu$ moles per $\mathrm{cm}^{3}$ of bulk fuel rod volume. For this reason the matrix material properties input to TRAFIC, particularly the density, must account for the assumed smearing of the material. 


\subsection{COATED PARTICLE RELEASE (COPAR)}

TRAFIC employs the two COPAR program modules, TABLE/REL and PART/REL (Ref. 2), as subroutines to compute the release of metallic fission products from a collection of coated particles. A detailed discussion of the theory behind these modules and their interface with the TRAFIC code is given in Ref. 2. This section summarizes the COPAR method and its implementation.

When computing the release from a collection of coated particles, one must consider several facts:

1. The problem is one of diffusion through an inhomogeneous medium of several layers.

2. More than one particle type (e.g., BISO and TRISO) is involved.

3. The collection of particles has a continuous, time-dependent history of fission birth, temperature, and failure fraction.

4. For a given history of fission birth and temperature, the release from all intact particles of a given type is the same, but the release from each failed particle depends on the time of failure. Each distinct fallure time is a separate case.

The implication of these facts is that the exact evaluation of release from a collection of intact and failed particles requires the superposition of many different cases, each one of which is a space- and time-dependent analysis involving inhomogeneous material properties and a time-dependent fission source. Thus, an exact evaluation of the particle release term is a task that could require a considerable amount of calculational effort.

Because of the obvious need for efficiency, some severe assumptions have been made in previous particle models. These include (a) ignoring spatial dependence, (b) ignoring time dependence, (c) assuming homogeneous properties, and (d) assuming $100 \%$ release after failure. An earlier particle 
release model in the first version of TRAFIC (Ref. 4) made the latter assumption. None of these simplifications can be fully justified, and some of them [(b) and (d)] are so conservative as to penalize the HTGR design.

The COPAR model was developed with the objective of efficiently calculating the particle release without making any unreasonable assumptions. This was achieved by means of a highly efficient numerical superposition technique that is based on physically plausible approximations. The model permits an accurate and efficient treatment of the following effects:

1. Transient time dependence

2. Spherical geometry spatial dependence

3. Kernel and multi-layer coatings

4. Spatially varying source

5. Recoil

6. Trapped fraction

7. Fickian diffusion

8. Radioactive decay

9. Step changes in concentration between layers

10. Coating failure

11. Evaporative boundary condition.

COPAR does this by means of a two-phase solution procedure. In phase 1 , some exact analytical solutions are computed, and the results are tabulated vs. a dimensionless time parameter. Phase 1 is done only once at the beginning of the calculation, possibly external to the TRAFIC code. In phase 2, a superposition analysis is performed in which a number of phase 1 solutions are evaluated by linear interpolation and superimposed. The superposition accounts for an arbitrary history of fission birth and failure fraction. An arbitrary history of temperature is embodied in the dimensionless time parameter. A summary of this method will now be presented. 


\subsubsection{COPAR PHASE 1 SOLUTION}

In phase 1, controlled by the TABLE/REL module (Ref. 2), COPAR solves the Fickian diffusion equation for a single species in spherical coordinates:

$$
\frac{\partial C(r, t)}{\partial t}=S(r, t)-\lambda C(r, t)+\frac{1}{r^{2}} \frac{\partial}{\partial r}\left[r^{2} D(r, t) \frac{\partial C}{\partial r}\right],
$$

where

$$
\begin{aligned}
& \mathrm{C}(\mathrm{r}, \mathrm{t}) \text { is a volume concentration }\left(\# / \mathrm{cm}^{3}\right), \\
& \mathrm{S}(\mathrm{r}, \mathrm{t}) \text { is a source rate }\left(\# / \mathrm{cm}^{3} \mathrm{sec}\right), \\
& \lambda \text { is the decay constant, } \\
& \mathrm{D}(\mathrm{r}, \mathrm{t}) \text { is the diffusion coefficient }\left(\mathrm{cm}^{2} / \mathrm{sec}\right), \\
& \mathrm{r} \text { is the radial coordinate }(\mathrm{cm}) \text {, and } \\
& \mathrm{t} \text { is the time coordinate. }
\end{aligned}
$$

The first step in the solution is to subdivide the multi-layered particle into thin spherical shell regions, each of which may be regarded as homogeneous with uniform properties. The time-dependent source, $S(r, t)$, will be removed from Eq. (3) and replaced by an initial condition birth pulse, B(r), applied at time zero. A subsequent superposition of birth-pulse solutions (in phase 2) will later be used to model a time-dependent source history. With these considerations $D(r, t)$ and $B(r)$ are assumed to be uniform in each shell, and Eq. (3) becomes

$$
\frac{\partial C(r, t)}{\partial r}=-\lambda C(r, t)+\frac{D(t)}{r}[r C(r, t)],(a \leq r \leq b) .
$$

The boundary conditions are tentatively assumed to be a constant concentration on the outside surface $(r=b)$ and a constant mass flux on the inside surface $(r=a)$,

$$
\begin{aligned}
& \left.C(r, t)\right|_{r=b}=C_{b}, \\
& -\left.D(t) \frac{\partial C(r, t)}{\partial r}\right|_{r=a}=J_{a} .
\end{aligned}
$$


The effect of the time-dependent variation of these boundary conditions will be considered later. The concentration and mass flux on the opposite sides will be found from the solution.

The initial conditions, as previously discussed, are assumed to be a uniform concentration $B$ applied at time zero:

$$
\left.C(r, t)\right|_{t=0}=B .
$$

The development now proceeds with the derivation of an analytic solution of Eqs. (4) through (7) in a thin spherical shell. The first step is to nondimensionalize the equation through suitable transformations. We define transformed independent variables

$$
\begin{aligned}
& x(r) \equiv \frac{r}{R}, \text { and } \\
& \rho(t) \equiv \frac{1}{R^{2}} \int_{0}^{t} D(\tau) d \tau,
\end{aligned}
$$

where $R$ is the outside radius of the particle. We further transform the dependent variable, $C$, to remove the decay term and the non-zero initial condition by defining

$$
U(r, t) \equiv r\left[e^{\lambda t} C(r, t)-B\right]
$$

Then Eq. ( $r$ ) can be written

$$
\frac{\partial U(x, \rho)}{\partial \rho}=\frac{\partial^{2} U(x, \rho)}{\partial x^{2}}
$$

Appropriate transformations to the boundary conditions (Ref. 2) can also be written as

$$
\left.U(x, \rho)\right|_{x=\frac{b}{R}}=U_{b} \text {, }
$$




$$
\left.G(x, p)\right|_{x=\frac{a}{R}}=G_{a} \text {, }
$$

where $G$ is defined as a transformed mass flux (Ref. 2). The transformed initial condition becomes

$$
\left.U(x, \rho)\right|_{\rho=0}=0 .
$$

Equations (11) through (14) are now in an elementary form, and the solution can be obtained by a standard analytical technique. Omitting the details, which are described in Ref. (2), the analytic solution can be written in the form

$$
\left.\begin{array}{l}
U(x, \rho)=f_{1}(x, \rho) G_{a}+f_{4}(x, \rho) U_{b}, \\
G(x, \rho)=f_{2}(x, \rho) G_{a}+f_{3}(x, \rho) U_{b} \cdot
\end{array}\right\}
$$

Evaluating this solution at the opposite boundaries, we have

$$
\left.\begin{array}{l}
U_{a}(\rho)=f_{1}\left(\frac{a}{R}, \rho\right) G_{a}+f_{4}\left(\frac{a}{R}, \rho\right) U_{b}, \\
G_{b}(\rho)=f_{2}\left(\frac{a}{R}, \rho\right) G_{a}+f_{3}\left(\frac{a}{R}, \rho\right) U_{b},
\end{array}\right\}
$$

Functions $\mathrm{f}_{1}$ through $\mathrm{f}_{4}$ may be viewed as "response functions", relating the response on one side of the shell to an assumed boundary condition on the other.

In actuality the assumed boundary conditions $G_{a}$ and $U_{b}$ are functions of time. For time-dependent boundary conditions we apply the Duhame1 superposition principle to Eq. (16). The result is 


$$
\begin{aligned}
U_{a}(\rho) & =\int_{0}^{\rho} f_{1}^{a}\left(\rho-\rho^{\prime}\right) \frac{d}{d \rho^{\prime}} G_{a}\left(\rho^{\prime}\right) d \rho^{\prime} \\
& +\int_{0}^{\rho} f_{4}^{a}\left(\rho-\rho^{\prime}\right) \frac{d}{d \rho^{\prime}} U_{b}\left(\rho^{\prime}\right) d \rho^{\prime}, \\
G_{b}(\rho) & =\int_{0}^{\rho} f_{2}^{b}\left(\rho-\rho^{\prime}\right) \frac{d}{d \rho^{\prime}} G_{a}\left(\rho^{\prime}\right) d \rho^{\prime} \\
& +\int_{0}^{\rho} f_{3}^{b}\left(\rho \rho^{\prime}\right) \frac{d}{d \rho^{\prime}} U_{b}\left(\rho^{\prime}\right) d \rho^{\prime}
\end{aligned}
$$

Thus, the solution to a partial differential equation in space and time is reduced to the solution of an integral equation in time alone. The interior spatial solution has been eliminated and replaced by boundary response functions. Note that all four of the boundary conditions, $U$ and $G$ on both sides of the shell, are unknown functions of time. These are to be found later by a simultaneous solution of the coupled multi-shell problem with the aid of interface and global boundary conditions. For the present, it is necessary to solve the integral equations (17) in a single-shell region. This is done by discretizing the time history and integrating Eq. (17) numerically. When this is done (Ref. 2) the final result is

$$
\left.\begin{array}{l}
U_{a}\left(\rho_{L}\right)=A_{1}^{L}+A_{2}^{L} G_{a}\left(\rho_{L}\right)+A_{3}^{L} U_{b}\left(\rho_{L}\right) \\
G_{b}\left(\rho_{L}\right)=A_{4}^{L}+A_{5}^{L} G_{a}\left(\rho_{L}\right)+A_{6}^{L} U_{b}\left(\rho_{L}\right)
\end{array}\right\}
$$

Here $A_{1}^{L}$ and $A_{4}^{L}$ are the results of a numerical integration [Eq. (17)] of all known quantities in the past history $\left(\rho_{\ell}<\rho_{L}\right) . A_{2}^{L}, A_{3}^{L}, A_{5}^{L}$, and $A_{6}^{L}$ are the remaining coefficients associated with the current unknowns. 
Eq. (18), in essence, is the result of an implicit forward integration of the partial differential equation (4) for a single-shell region. It describes the response of the unknown boundary conditions as linear functions of one another. Similar response equations can be derived, and the coefficients numerically evaluated, for each of the $n$ shell regions of a multi-layered particle. All of these response equations can then be combined with appropriate interface conditions and a global boundary condition to obtain the global, coupled solution.

The interface conditions are assumed to be a continuity of mass flux,

$$
\mathrm{J}_{\mathrm{b}}^{\mathrm{j}}=\mathrm{J}_{\mathrm{a}}^{\mathrm{j}+1}
$$

where $j$ is a shell index, and a step change in concentration,

$$
c_{b}^{j}=\phi_{j} c_{a}^{j+1}
$$

The $\phi^{\prime} s$, known as "partition factors", are input to the COPAR program as constants. This is a necessary limitation for the validity of the birth-pulse superposition that will be performed in phase $2^{*}$.

The boundary conditions on the outer boundary of shell $n$ (at $r=b_{n} \equiv R$ ) can be expressed in one of three optional ways.

1. Zero Concentration on Outer Boundary

$$
c_{b}^{n}=0
$$

\section{Evaporation into Vacuum with Linear Sorption}

$$
\mathrm{J}_{\mathrm{b}}^{\mathrm{n}}=\mathrm{h} \mathrm{c}_{\mathrm{b}}^{\mathrm{n}}
$$

\footnotetext{
*Note that TRAFIC also deals with a $\phi$ factor defining the interface condition in the gap between the fuel rod and the structural graphite. The assumption of contant $\phi$ will not be required in that case because the fuel rod gap is outside the superposition (or linear) region of the problem.
} 
3. Transfer to Fuel Rod Matrix and Subsequent Release

$$
\begin{aligned}
\mathrm{C}_{\mathrm{b}}^{\mathrm{n}} & =\phi_{\mathrm{n}} \mathrm{C}_{F M} \text {, with } \\
\frac{\mathrm{dC}_{\mathrm{FM}}}{\mathrm{dt}} & =\frac{4 \pi \mathrm{R}^{2}}{\mathrm{~V}_{F M}} \mathrm{~J}_{\mathrm{b}}^{\mathrm{n}}-\lambda \mathrm{C}_{F M}-\mathrm{R}_{F M} \mathrm{C}_{F M},
\end{aligned}
$$

where $C_{F M}$ is the concentration in the fuel rod matrix,

$\mathrm{V}_{\mathrm{FM}}$ is the matrix volume associated with one particle, and

$R_{F M}$ is a release constant from the matrix to the outside.

These equations and their transformation into the appropriate non-dimensional form are discussed in more detail in Ref. 2. A general feature of each of these options is that the boundary conditions are linear and homogeneous in the two functions, $C_{b}^{n}(t)$ and $J_{b}^{n}(t)$. This is a prerequisite for the phase 2 superposition. Furthermore, note that all three of these options can ultimately be expressed in the form of a linear equation,

$$
\mathrm{U}_{\mathrm{b}}^{\mathrm{n}}+\mathrm{A}_{1} \mathrm{G}_{\mathrm{b}}^{\mathrm{n}}=\mathrm{z}_{2}
$$

The complete system of linear equations for the multi-layered particle consists of the two Eqs. (18) for each shell region, Eqs. (19) and (20) for each interface, and Eq. (25) for the outer boundary. One of the Eqs. (18) disappears for the innermost spherical kernel region due to a requirement of symmetry at $r=0$. The final systems of equations consists of $4(n-1)+2$ linear equations in the same number of unknowns. Half of these can be eliminated algebraically. The remaining $2(n-1)+1$ equations are solved numerically using the Cholesky method of forward elimination and back substitution. The details are given in Ref. 2 .

In summary, the phase 1 solution consists of solving the heterogeneous diffusion problem for a unit birth pulse applied as an initial condition at time zero. The solution proceeds by marching forward in time. At each 
time step, the program loops over shell regions, and for each shell the program numerically evaluates the Duhamel integrals in Eq. (17). This serves to define the coefficients $A_{1}$ through $A_{6}$ in Eq. (18). These response equations are then combined with equations representing the interface and boundary conditions. The combined simultaneous system of linear equations is then solved to obtain the unknown interface and boundary conditions at the end of the time step. These include both concentrations and mass fluxes. The mass fluxes are time integrated to obtain the total release from the particle and also from the kernel. The final results of the phase 1 analysis consist of the fractional releases from the particle and from the kernel tabulated as a function of a particleaveraged dimensionless time parameter, termed $\rho_{\text {eff }}$. These tabulated functions are then employed in the phase 2 superposition described in the next section.

\subsubsection{COPAR PHASE 2 SOLUTION}

In phase 2, controlled by the PART/REL module (Ref. 2) COPAR superimposes a number of birth pulse solutions to obtain a combined solution for a collection of particles with a continuous history of fission birth and coating failure fraction. The way in which this is done is summarized below.

\section{Parameterization}

Two representative birth-pulse solutions are obtained in phase 1 . One is for an always-intact particle, and the second is for an always-failed particle. The "failure" is modeled by increasing the diffusion coefficient, $D$, in all coating layers that are designated as failed. The reason for selecting these two "base cases" will be apparent later.

The key assumption in the phase 2 superposition is that the fractional release of an impulse birth from either an always-intact or an always-failed particle can be paratemeterized as a function of a single independent variable, termed "effective dimensionless time", $\rho_{\text {eff }}$. This quantity is defined in terms of an effective homogeneous diffusion, $D_{\text {eff }}$, that would 
give the same diffusive resistance as the actual inhomogeneous particle, At any point in time $t$ the value of $D_{\text {eff }}$ is given by

$$
\frac{R}{\sqrt{D_{\text {eff }}(t)}}=\sum_{j=1}^{n} \frac{\Delta r_{j}}{\sqrt{D_{j}(t)}} .
$$

Now if the spatial shape of $D(r, t)$ is independent of time, i.e.,

$$
D(r, t)=\bar{D}(r) \cdot f(t)
$$

it can be shown that the spatial solution of the differential equation (1) is a unique function of a single dimensionless time parameter,

$$
\rho_{\text {eff }}(t)=\frac{1}{R^{2}} \int_{0}^{t} D_{\text {eff }}(\tau) d \tau
$$

The solution is not a unique function of $\rho_{\text {eff }}$ if the ratio of any two $D_{j}$ 's is arbitrarily time-dependent. This is clearly the case when failure occurs in selected coating layers. For this reason, one parameterized solution is insufficient to describe the transition from the intact to the failed state. Instead, an approximate procedure based on shifting from an alwaysintact to an always-failed solution is used. This will be described later.

Another situation in which the $D$ ratios may be time-dependent can occur when $D$ is a function of temperature and the temperature is a function of time. It is currently assumed that

$$
D_{j}(t)=D_{o_{j}} e^{-Q_{j} / R T(t)} .
$$

If the Q's are different, then the ratio of the D"s will be temperaturedependent. COPAR ignores this variation, assuming that it is a second order effect. 
The approach taken in COPAR is to determine a single spatial shape of $\mathrm{D}_{j}$ at a specified nominal temperature, TNOM. The phase 1 tabulations are based on a computed $\rho_{\text {eff }}$ in which this constant spatial shape of $D_{j}$ is implicit. In the phase 2 superposition the history of $\rho_{\text {eff }}$ is computed using Eqs. (26) and (28), taking the actual space-time variation of $D$ into account. The assumption is made that the true solution and the phase 1 solution are equal at the same value of $\rho_{\text {eff }}$. The error in this approximation depends on the actual variation of the $D$ ratios. This can be checked by using the stand-alone COPAR program [COPAR/STAL, Ref. (2)] to do a direct solution for some representative cases. Then a conservative value of TNOM can be selected that gives a reasonable fit to the true solution.

The parameterization technique described here greatly simplifies the evaluation of impulse release fractions when performing the phase 2 superposition. Having tabulated the phase 1 release fractions as functions of $\rho_{\text {eff }}$, the phase 2 evaluation is accomplished by a linear interpolation in a precomputed table. This avoids the time consuming Duhamel integrations and matrix inversions that would be needed in a direct solution.

\section{Failure Transition}

In the PART/REL module the transition from the intact to the failed state is approximated by transferring from the always-intact to the alwaysfailed release functions. The transfer is achieved by calculating a shift in the dimensionless time, after which the failed-state solution is evaluated at the shifted time. The amount of the shift is chosen so as to preserve the inventory in the kernel at the time of failure. At times of equal kernel inventory, the coating inventory in the intact solution is higher than the coating inventory in the failed solution. Thus, when transferring from the intact to the failed solution the resulting reduction of coating inventory causes an instantaneous jump in the particle release. This jump is an approximation to the rapid burst release that actually occurs after coating failure. The approximate shifted solution conservatively 
overestimates the burst release because, in truth, a reduction of $D$ will not cause an instantaneous response. The approximate shifted solution approaches the direct solution asymptotically from above, and, if the reduction of $\mathrm{D}$ is great enough, the rate of approach is quite rapid. Once again, the validity of this approximation can be checked by employing the COPAR/STAL program to account for the actual variation of $D$. An example is shown in Ref. 2 .

For the purpose of illustration we adopt a simplified notation and omit some of the tedious details in Ref, 2. Consider a particle that fails at time point $m$ following a birth pulse in time step $\ell$ (which starts at time point $\ell-1)$. A pseudo origin of the failed-state $\rho$ at the time of failure, termed $\rho$, is computed by equating kernel inventories, i.e.,

$$
\mathrm{f}_{\mathrm{k}}^{\mathrm{F}}\left(\rho_{\ell \mathrm{m}}^{I F}\right)=\mathrm{f}_{\mathrm{k}}^{I}\left(\rho_{\mathrm{m}}^{I}-\rho_{\ell-1}^{I}\right) \text {, }
$$

where $f_{k}$ is the fractional release from the kernel,

and I,F denote "intact" and "failed", respectively.

The shifted failed-state $\rho$ at time point $n$ after failure is given by

$$
\rho_{\ell m n}^{F}=\rho_{\ell m}^{I F}+\sum_{k=m+1}^{\mathfrak{n}} \Delta \rho_{k}^{F}
$$

Finally, the post-fallure particle release from a birth pulse $\Delta B_{\ell}$ is given by

$$
\Delta \mathrm{R}_{\ell \mathrm{mn}}=\Delta \mathrm{B}_{\ell} \mathrm{f}_{\mathrm{p}}^{\mathrm{F}}\left(\rho_{\ell \mathrm{mn}}^{\mathrm{F}}\right)
$$




\section{Superposition of Birth Pulses}

The phase 2 superposition consists of summing the contribution of a series of birth pulses to simulate the release from a continuous birth history. The summation also accounts for a collection of particles with a time-dependent history of failure fraction. All unique combinations of birth time, failure time, and release time must be considered. Again adopting a simplified notation, the final result of the summation is

$$
\begin{aligned}
\mathrm{R}_{\mathrm{n}}^{\mathrm{TOT}} & =\left(1-\mathrm{F}_{\mathrm{n}}\right) \sum_{\ell=1}^{\mathrm{n}} \mathrm{B}_{\ell} \mathrm{f}_{\mathrm{p}}^{\mathrm{T}}\left(\rho_{\mathrm{n}}^{\mathrm{I}}-\rho_{\ell-1}^{\mathrm{I}}\right) \\
& +\sum_{\mathrm{m}=1}^{\mathrm{n}} \Delta \mathrm{F}_{\mathrm{m}} \sum_{\ell=1}^{\mathrm{m}} \mathrm{B}_{\ell} \mathrm{f}_{\mathrm{p}}^{\mathrm{F}}\left(\rho_{\ell \mathrm{mn}}^{\mathrm{F}}\right) \\
& +\sum_{\ell=1}^{\mathrm{n}} \mathrm{F}_{\ell} \mathrm{B}_{\ell} \mathrm{f}_{\mathrm{p}}^{\mathrm{F}}\left(\mathrm{o}_{\mathrm{n}}^{\mathrm{F}}-\rho_{\ell-1}^{\mathrm{F}}\right)
\end{aligned}
$$

where $F_{n}$ is the failure fraction at the start of time step $n$, $\Delta \mathrm{F}_{\mathrm{m}} \equiv \mathrm{F}_{\mathrm{m}}-\mathrm{F}_{\mathrm{m}-1}$,

and $B_{\ell}$ is the total birth in all particles during time step $\ell$.

The first term in (33) is the contribution from always-intact particles. The second term, a double sum, is the contribution from all particles that fail between birth and release. The third term is the contribution from all particles that were failed at the time of birth.

An optional procedure exists in PART/REL for collapsing all birth pulses prior to failure into a single, effective pulse. This reduces the double sum in (33) to a single sum, and it greatly improves the calculational efficiency 
without having a significant impact on the accuracy. The details of this procedure are explained in Ref. 2. In summary, the option is defined as follows:

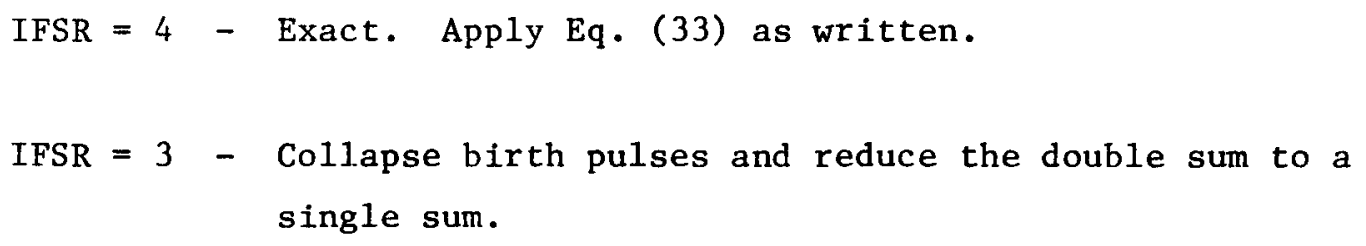

\subsubsection{OTHER COPAR FEATURES}

A few other features of COPAR that will affect a user's understanding of the problem and his input to the code will be briefly explained in this section.

\section{$\underline{\text { Recoil Model }}$}

After fission birth, the direct fission source is assumed to recoil isotropically a constant distance, $d_{R}$, from its point of origin. A user specifies $d_{R}$ and the shape of the direct source, $B_{j}(j=1,2, \ldots, n)$, as input to the program. COPAR internally calculates the recoiled source shape, $\mathrm{RB}_{j}$. This modified source shape serves as the initial condition in the phase 1 direct solution. The method for doing this recoil calculation is discussed in Ref, 2. Most users will not be interested in these details, but there is one fact that should be made clear. After recoil, all of the birth that remains in any shell region is assumed to be uniformly distributed in that region. This is a prerequisite for the assumption of a spatially uniform initial condition in each shell. The consequence of this is that the spatial resolution of the recoiled source shape will be lost unless the user takes the care to specify sufficiently thin regions near the outer boundary of the fuel kernel. In practice it is probably sufficient to specify one or more thin regions in the kernel material but to ignore the error in the highly diffusive buffer region. 


\section{Trapped Fraction Model}

COPAR has an optional "trapped fraction" model as described below. The purpose of the model is to account for empirically observed delay mechanisms that are not diffusive in nature. The model can be effectively bypassed by setting all the input parameters equal to zero.

After the direct source is recoiled, a certain fraction of the recoiled source is assumed to be initially immobile, unavailable for diffusion. This "initial trapped fraction", TFI, is given by the empirical formula,

$$
\operatorname{TFI}=\left[\mathrm{TF}_{0}-\mathrm{TF}_{1} \cdot \operatorname{FIMA}(t)\right] \mathrm{e}^{\mathrm{TF} / \mathrm{T}(\mathrm{t})},
$$

where FIMI is the burnup (fissions per initial metal atom),

$\mathrm{T}$ is the temperature $\left({ }^{\circ} \mathrm{K}\right)$,

and $\mathrm{TF}_{0}, \mathrm{TF}_{1}$, and $\mathrm{TF}_{2}$ are constants, all greater than or equal zero, input to the program.

For times beyond the initial birth pulse, Eq. (34) is reevaluated as a non-increasing function of time. Any decrease in trapped fraction, or untrapping, leads to an incremental amount of source at that time. This is representative of an annealing process.

\section{Accounting for Radioactive Decay}

The derivations for the phase 1 direct solution contained a radioactive decay term in the transformation, Eq. (10). Thus, in principle, the method can account for decay in the phase 1 release function tabulation. In practice, however, it is simpler to ignore decay in phase 1 and to account for decay by an after-the-fact correction in phase 2 . The way in which this is done is explained in Ref. 2. The point is mentioned here so that a TRAFIC user will not be confused by the absence of any decay effect in the phase 1 tabulation. 
The use of the IFSR option to control the collapsing of birth pulses was previously mentioned on page 25. Some additional IFSR options are also available for further improving the efficiency. These involve bypassing the diffusion calculation in certain sitautions by assuming either $100 \%$ or zero release. By these means the COPAR model may be reduced to the form of some earlier particle release models, e.g., those in the original TRAFIC code (Ref. 4). This may be desirable for comparing new and old results. There may also be situations where these approximations are valid, or possibly conservative, and their adoption will have the benefit of reducing computer costs. A summary of the various IFSR choices is given in the input instructions on page 115.

\subsection{FUEL ROD MODEL}

In the fuel rod and in the structural graphite regions, TRAFIC solves a modified form of Fick's law that includes an additional term representing diffusion due to a temperature gradient. This term was omitted from the COPAR model (Section 2.2) for three reasons, First, an additional parameter would have substantially increased the amount of tabulated data needed to describe the parameterized release functions. Second, at the time of the COPAR development there was no evidence that the thermal gradient effect was important. Finally, the temperature gradients within a coated particle are small. In the fuel rod and in the structural graphite regions, however, the thermal gradient term was included because, although the magnitude of the effect was unknown, it was desired to evaluate some limiting cases.

The transport of fission products in all cases must satisfy conservation of mass,

$$
\frac{\partial C(r, t)}{\partial t}=S(r, t)-\lambda C(r, t)-\vec{\nabla} \cdot \vec{J}(r, t)
$$


The modified form of Fick's Law, with an additional thermal gradient term, is

$$
J(r, t)=-D(r, t) \quad \vec{\nabla} C(r, t)-K(r, t) C(r, t) \vec{\nabla} T(r, t)
$$

where $J$ is the mass flux,

$D$ is the usual diffusion coefficient,

$\mathrm{K}$ is a thermal gradient diffusion coefficient,

and

$\mathrm{T}$ is the temperature $\left({ }^{\circ} \mathrm{K}\right)$.

The diffusion coefficient $D$ is assumed to be given as a function of temperature by

$$
D(r, t)=D_{0} e^{-Q / R T(r, t)}
$$

By performing a detailed thermodynamic analysis of the thermal diffusion process, it can be shown that the thermal diffusion coefficient $K$ in Eq. (36) can be esitmated by

$$
K(r, t)=\frac{D(r, t) Q^{*}}{y R T^{2}(r, t)},
$$

where $y \equiv e+\frac{f}{T}$,

is a constant in the adsorption versus vapor pressure relationship (to be introduced 1ater in Section 2.4), and where $Q^{*}$ is the activation energy (heat of transport) for thermal diffusion. In theory (Ref. 5), the activation energy $Q *$ can assume an absolute value ranging from zero to the activation energy for diffusion in a concentration gradient. Thus,

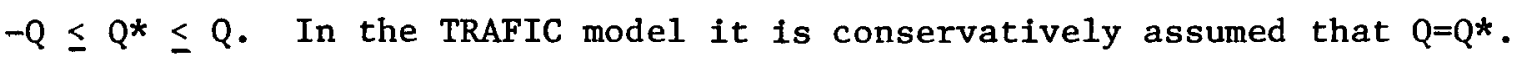
This gives the maximum possible driving force for release. Some additional input parameters to the program, termed FFUDGE and GFUDGE, may be used in parametric studies as multiplying factors to modify the thermal gradient effect in the fuel rod and the structural graphite, respectively. 
Substituting (38) into (36), the modified Fick's law becomes

$$
\vec{J}(r, t)=-D(r, t)\left[\vec{\nabla} C(r, t)+\frac{Q^{*}}{y R T^{2}} \vec{\nabla} T(r, t) \cdot C(r, t)\right] .
$$

As previously mentioned on P. 3, the diffusion equation in the fuel rod, with its space and time-dependent source term, would be tedious to solve. This is avoided by making a conservative assumption that $D$ is very large in the fuel rod, and the mass flux $\mathrm{J}$ is limited by other resistances. With this assumption Eq. (39) can be approximated as

$$
\vec{\nabla} C(r, t)+\frac{Q^{*}}{y R T^{2}} \vec{\nabla} T(r, t) C(r, t)=\frac{\vec{J}}{D} \approx 0 .
$$

Eq. (40) can be used to solve for the spatial shape of the concentration profile in the fuel rod. To do this we first assume that the temperature in the fuel rod is a parabolic function of radius, given by

$$
T(r)=T_{\epsilon}-\left(T_{E}-T_{f}\right)\left(\frac{r}{r_{f}}\right)^{2},
$$

where $\quad T_{G}$ is the fuel rod centerline temperature,

$T_{f}$ is the fuel rod surface temperature, and

$r_{f}$ is the radius of the fuel rod.

Eq. (41) is an exact solution of the heat conduction equation in cylindrical coordinates under conditions of spatially uniform heat generation rate and thermal conductivity. In view of Eq. (41), we have

$$
\vec{\nabla} \cdot T(r, t)=\frac{\partial}{\partial r} T(r, t)=\frac{-2 r\left(T_{€}-T_{f}\right)}{r_{f}{ }^{2}} \text {. }
$$

We further assume that the temperature difference across the fuel rod is small compared to the average fuel temperature. Then we can replace the temperature $\mathrm{T}$ in the denominator of Eq. (40) by the volume averaged value,

$$
\vec{T}=\frac{T_{€}+T_{f}}{2}
$$


Substituting (42) and (43) into Eq. (40) results in the ordinary differential equation in $r$ :

$$
\frac{\partial}{\partial r} C(r, t)-2 \psi(t) r C(r, t)=0,
$$

where

$$
\psi(t) \equiv \frac{4 Q *\left(T_{E}-T_{f}\right)}{y R r_{f}^{2}\left(T_{E}+T_{f}\right)^{2}} .
$$

Tentatively assuming that a known concentration, $C_{f}(t)$, is given as a boundary condition on the surface of the fuel $\operatorname{rod}\left(r=r_{f}\right)$, the solution to Eq. (44) is

$$
C(r, t)=C_{f}(t) \exp \left[\psi\left(r^{2}-r_{f}^{2}\right)\right] \quad .
$$

Finally, one can volume integrate Eq. (46) to obtain the volume-averaged concentration, $\bar{C}$, in the fuel rod. This leads to the following relationship between the fuel surface concentration, $C_{f}$, and the average concentration, $\bar{c}$ :

$$
C_{f}(t)=\bar{C}(t)\left(\frac{\psi(t) r_{f}^{2}}{1-e^{-\psi(t) r_{f}^{2}}}\right)
$$

Eq. (47) defines a spatial shape factor which will later be used to modify calculated values of $\bar{C}$.

Now, we return to the mass balance equation, (35). Integration Eq. (35) over the volume of the fuel rod and then dividing by the volume, we obtain

$$
\frac{d \bar{C}(t)}{d t}=\bar{S}(t)-\lambda \bar{C}(t)-\left(\frac{2}{r_{f}}\right) J_{f}(t),
$$

where $\bar{C}$ and $\bar{S}$ are volume-averaged quantities, and $J_{f}$ is the mass flux emerging from the fuel rod surface. 
For coupling the fuel rod solution to the downstream graphite web region, we use Eq. (2) to eliminate the fuel rod mass $f l u x, J_{f}$, in favor of the mass flux, $J_{0}$, into the fuel rod side of the equivalent graphite slab. Noting that

$$
\frac{A_{c}}{A_{f}}=\frac{2 \pi r_{c} / 12}{2 \pi r_{f} / 6}=\frac{r_{c}}{2 r_{f}} \text {, }
$$

Eq. (21), (48), and (49) combine to give

$$
\frac{d \bar{C}(t)}{d t}=\bar{S}(t)-\lambda \bar{C}(t)-\frac{r_{c}}{r_{f}^{2}} J_{o}(t) .
$$

The solution of Eq. (50) is achieved by tentatively assuming that the source rate $\bar{S}$ and the mass flux $J_{0}$ are known functions of time. Assuming zero initial conditions and employing a birth pulse superposition method, the solution is

$$
\bar{c}(t)=e^{-\lambda t} \int_{0}^{t}\left[\bar{S}(\tau)-\frac{r_{c}}{r_{f}{ }^{2}} J_{0}(\tau)\right] e^{\lambda \tau} d \tau \text {. }
$$

The volume-averaged concentration, $\bar{c}(t)$, can be eliminated in favor of the fuel rod surface concentration, $C_{f}(t)$, by substituting $E q .(47)$ into Eq. (51), giving

$$
C_{f}(t)=\left(-\frac{\psi(t) r_{f}^{2}}{-\psi(t) r_{f}^{2}}\right) e^{-\lambda t} \int_{0}^{t}\left[\bar{s}(\tau)-\frac{r_{c}}{r_{f}{ }^{2}} J_{o}(\tau)\right] e^{\lambda \tau} d \tau .
$$

The solution now proceeds by discretizing the time dependence and numerically integrating Eq. (52) with the aid of the trapezoidal rule. The volume-averaged source rate $\vec{S}(\tau)$ is a known function of time, obtained by volume integrating the COPAR particle release rate over a number of annular regions in the fuel rod. The mass $f l u x J_{0}(\tau)$ is known for all times $t_{i}(i<n)$ in the past history, but it is unknown at the current solution time, $t=t_{n}$. The same can be said of the fuel rod surface concentration, $C_{f}$. 
Based on these considerations, one can ultimately derive from Eq. (52)

the expression

$$
C_{f}\left(t_{n}\right)=\left[\frac{\psi\left(t_{n}\right) r_{f}^{2}}{1-e^{-\psi\left(t_{n}\right) r_{f}^{2}}}\right]\left[D_{1}^{n}+D_{2}^{n} J_{o}\left(t_{n}\right)\right] \text {. }
$$

The coefficient $D_{1}^{n}$ includes the contribution of all known terms in the past history, including source rates and mass fluxes, to the integral in Eq. (52). The coefficient $D_{2}^{n}$ is the remaining factor associated with the current unknown, $J_{0}\left(t_{n}\right)$.

Equation (53) is the final form of the quasi-steady fuel rod solution. The combination of this with other aspects of the TRAFIC model will be considered later.

\subsection{VAPOR PRESSURE RELATIONSHIPS}

The next resistance barrier to be considered is the gap between the fuel rod and the graphite web. Here, and also on the coolant hole side of the web, the analysis depends on certain vapor pressure relationships. These are discussed in this section.

It is assumed in TRAFIC that the solid phase concentration of a fission product and its gas phase vapor pressure are in a state of equilibrium. When this is the case, the vapor pressure, p (atm.), and the solid phase concentration per unit mass, $C$ ( $\mu$ moles/gram), are uniquely related to one another by empirical equations known as "sorption isotherms". These relationships are nonlinear and functions of temperature, so one may write

$$
p=p(C, T)
$$


Note that the concentration $C$ in Eq. (54) is a number per unit mass, whereas the concentration $\mathrm{C}$ in the diffusion equation [e.g., Eq. (3)] is a number per unit volume. These two measures of concentration are related by

$$
C\left[\frac{\mu \text { moles }}{g}\right]=\frac{C\left[\mu \text { moles } / \mathrm{cm}^{3}\right]}{\rho\left[\mathrm{g} / \mathrm{cm}^{3}\right]} \text {, }
$$

where $\rho$ is the density of the graphite material. The mass concentration was adopted for expressing the sorption isotherms because mass is easier to measure than volume. The volume concentration is required for expressing the leakage term as a vector divergence in the diffusion equation.

The sorption isotherms are commonly measured in two ranges of concentration. For very small concentrations, where competition for sorption sites can be neglected, the sorption is said to be in the "Langmuir" or linear range, i.e.,

$$
\mathrm{p}_{\ell}=\mathrm{K}_{\ell}(\mathrm{T}) \mathrm{C},
$$

where $\mathrm{K}_{\ell}$ is a constant of proportionality that depends on temperature. The second range is the "Freundlich" or nonlinear range. Here, owing to the competition for sorption sites, the pressure increases as a higher-than-linear function of concentration,

$$
P_{f}=K_{f}(T) c^{m(T)}
$$

where $m$ is an exponent greater than 1. The parameters $k_{f}$ and $m$ are found experimentally by correlating $\ln (p)$ vs. $\ln (C)$, fitting the data with the empirical model,

$$
\ln p_{f}=\left(a+\frac{b}{T}\right)+\left(e+\frac{f}{T}\right) \ln C
$$

Then Eq. (58) can be re-expressed in the form

$$
p_{f}=e^{\left(a+\frac{b}{T}\right)} c e^{\left(e+\frac{f}{T}\right)},
$$

which is the same form as (57), although less general. 
The Langmuir and Freundlich isotherms, Eqs. (56) and (59), will both be straight lines when plotted on log-log paper. The intersection of these lines is an experimental parameter called the "transition concentration", $C_{\mathrm{TR}}$. This is the concentration where, by definition, the vapor pressures calculated using the Langmuir and Freundich parameters will be equal. Equating Eqs. (56) and (59) gives

$$
K_{\ell}(T) C_{T R} \equiv e^{\left(a+\frac{b}{T}\right)} C_{T R}^{\left(e+\frac{f}{T}\right)},
$$

or

$$
K_{\ell}(T)=e^{\left(a+\frac{b}{T}\right)} C_{T R}^{\left(e+\frac{f}{T}-1\right)}
$$

Substituting (61) into (56) then gives

$$
\mathrm{p}_{\ell}=e^{\left(\mathrm{a}+\frac{\mathrm{b}}{\mathrm{T}}\right)} \mathrm{C}_{\mathrm{TR}}^{\left(\mathrm{e}+\frac{\mathrm{f}}{\mathrm{T}}-1\right)} \mathrm{c} .
$$

Thus, the Langmuir and the Freundlich isotherms employ the same materialdependent parameters, with the additional parameter $\mathcal{C}_{\text {TR }}$ relating the two.

In general, $\mathcal{C}_{\mathrm{TR}}$ may be a function of temperature. The above derivations, and all those that follow, are valid when this is the case. However, TRAFIC presently assumes that $C_{T R}$ is a constant, so no functional relationship is implied.

It should be noted that the transition described above is not always observed in the laboratory and that for some species all of the available data may be in the Freundlich range. When this is the case the transition concentration is conservatively assumed to be the lowest concentration at which any measurements have been made. As shown in the sketch at the top of the next page, this is conservative because it probably overestimates the vapor pressure, hence overpredicts fission product release, for concentrations less than the assumed $C_{T R}$. 


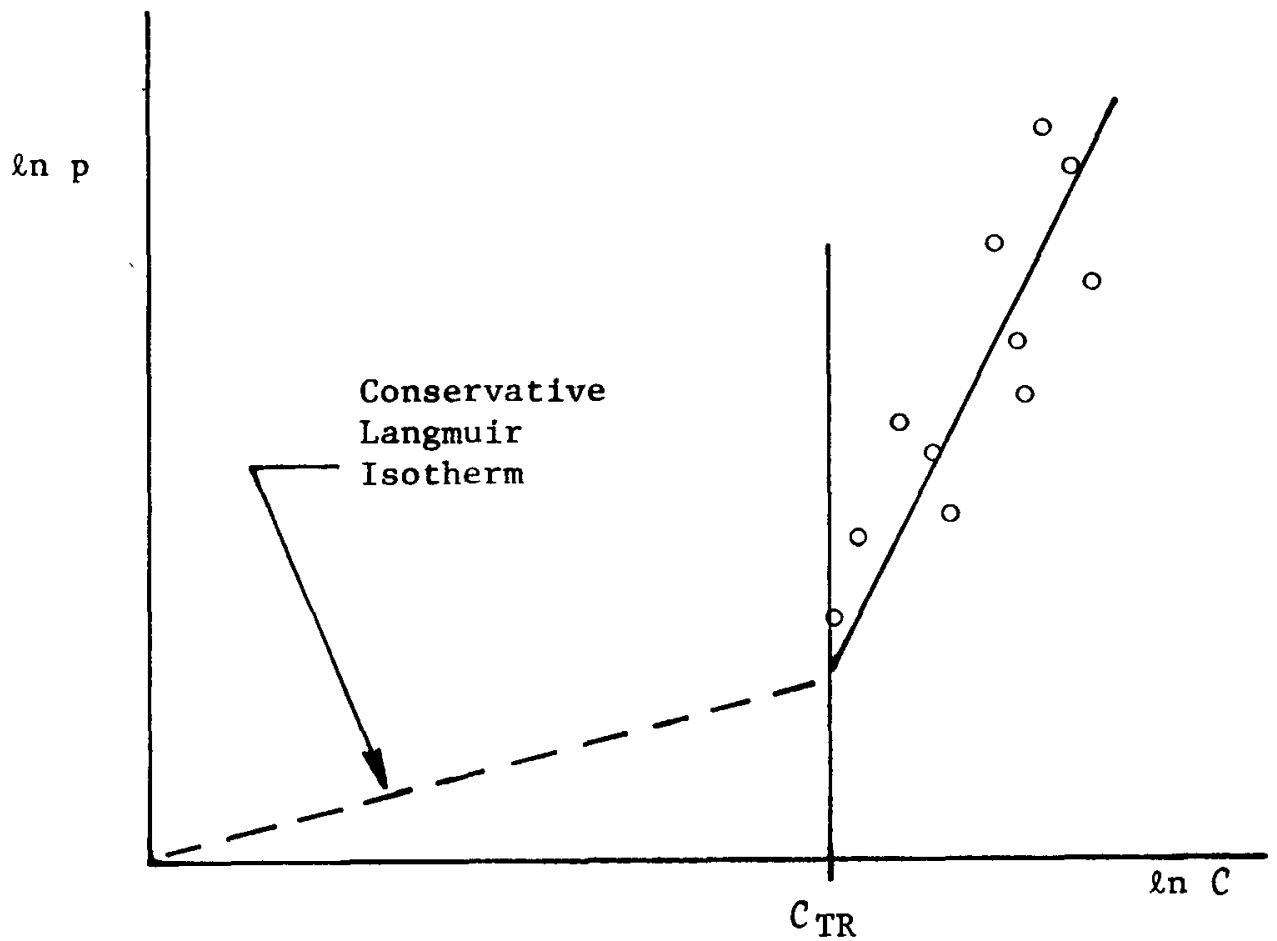

In cases where a definite transition is experimentally observed, then the transition concentration is found by solving for the intersection.

In the early days of fission product analysis at General Atomic it was customary to employ Eq. (62) (the Langmuir isotherm) when $C$ was less than $C_{T R}$ and Eq. (59) (the Freundlich isotherm) whenever $\mathcal{C}$ was greater than $C_{T R}$. There are two reasons why this practice is no longer followed. First, as can be seen from the sketch above, this causes a discontinuity in the slope of $p(C)$ at the point of transition. This, in turn, can cause a lack of convergence in the Newton Raphson iteration used in solving for the nonlinear interface or boundary conditions. A guess on one side of the "knee" that is extrapolated to the other side can cause a perpetual oscillation. Clearly, the function $p(C)$ must have a smooth transition with continuous derivatives to prevent this. A second factor which must be considered is that the 
actual experimental data observed in the vicinity of the transition are generally above the intersection point, as shown schematically below.

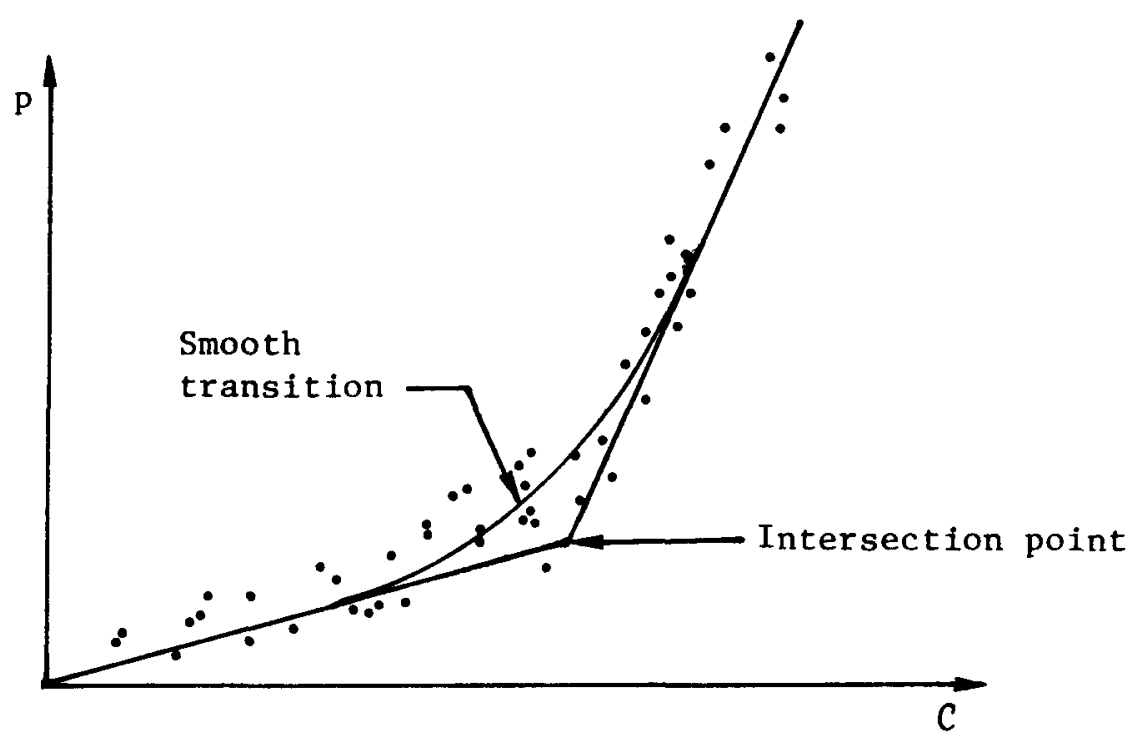

A smooth function that is generally consistent with experimental observations is the sum of the isotherms,

$$
\mathrm{p}=\mathrm{p}_{\ell}+\mathrm{p}_{\mathrm{f}}
$$

or

$$
\mathrm{p}=\mathrm{e}^{\left(\mathrm{a}+\frac{\mathrm{b}}{\mathrm{T}}\right)}\left[\mathcal{C}_{\mathrm{TR}}^{\left(\mathrm{e}+\frac{\mathrm{f}}{\mathrm{T}}-1\right)} \mathrm{C}+\mathrm{C}^{\left(\mathrm{e}+\frac{\mathrm{f}}{\mathrm{T}}\right)}\right]
$$


This is the expression now used in TRAFIC. A simplified notation that will shorten future derivations is achieved by defining

$$
\begin{aligned}
& x(T) \equiv a+\frac{b}{T}, \text { and } \\
& y(T) \equiv e+\frac{f}{T} \text {. }
\end{aligned}
$$

Then Eq. (64) can be written

$$
\mathrm{p}=\mathrm{e}^{\mathrm{x}}\left(\mathrm{C}_{\mathrm{TR}}^{\mathrm{y}-1} \mathrm{C}+\mathrm{C}^{\mathrm{y}}\right)
$$

The next section, 2.5, deals with the application of this equation in calculating the interface conditions. Section 2.7 describes a similar application for the coolant hole boundary condition.

\subsection{GAP INTERFACE CONDITIONS}

The fuel rod solution, Eq. (53), is a linear expression relating $\mathrm{C}_{\mathrm{f}}$, the fuel rod surface concentration, to $J_{0}$, the mass flux entering the graphite web. Continuity of mass flux $J$ across the gap was tacitly assumed in deriving this expression. The object of the present section is to complete the coupling by deriving an expression

$$
C_{f}\left(t_{n}\right)=C_{f}\left(C_{o}\left(t_{n}\right)\right)
$$

relating the concentrations on the fuel rod surface $\left(C_{f}\right)$ and the inner graphite surface $\left(C_{0}\right)$. A unique function of form (68) is possible only if there is no kinetic resistance in the gap, i.e., the mass flux $J_{0}$ does not enter into the expression. In principle it would not create any mathematical problems to include some kinetic resistance in the gap, but in practice this is not done owing to a lack of experimental data. Instead, the conservative assumption is adopted that the vapor pressures on both sides of the gap are equal and in equilibrium. This permits one to derive an implicit relationship,

$$
P=P_{f}\left(C_{f}, T_{f}\right)=P_{g}\left(C_{o}, T_{g}\right),
$$


where $f$ and $g$ refer to the fuel rod side and the graphite side of the gap, respectively. Substituting the particular form of the vapor pressure relationship, Eq. (67), into Eq. (69) we have

$$
p=e^{x_{f}}\left(C_{T_{f}}^{y_{f}-1} C_{f}+C_{f}^{y_{f}}\right)=e^{x} g\left(C_{T R}{ }_{g}^{y_{g}^{-1}} C_{o}+C_{o}{ }^{y_{g}}\right)
$$

Since expression (70) is nonlinear in both $C_{f}$ and $C_{o}$, it is not possible to algebraically solve for one as a function of another. For a particular numerical value of $\mathcal{C}_{o}$, however, one can numerically solve for $\mathcal{C}_{f}$ using Newton's method. Still, explicit evaluation of $C_{f}$ is not the object. What is required is a functional relationship of the form (68) so that one can formulate and solve a system of simultaneous equations for the state at $t_{n}$.

Since the desired system of equations includes Eq. (68), and the system is therefore nonlinear, our attention must be directed to solving the system once it is formulated. The method employed in TRAFIC is to linearize all nonlinear equations by a first order Taylor expansion about the best possible guess. Then a solution of the linearized equations will serve to project the solution to a better guess. This is a multi-variable (vector) analogue of Newton's method. Thus, the object is to derive from Eq. (70) a linearized form

$$
c_{f}^{i}=c_{f}^{i-1}+\left(\frac{\partial C_{f}}{\partial C_{o}}\right)^{i-1}\left(c_{o}^{i}-c_{o}^{i-1}\right)
$$

where $i$ is an iteration counter. Parameters in Eq. (71) with a superscript i-1 are known or can be numerically evaluated from the results of the last iteration. Parameters with superscripts $i$ are the unknown $C_{f}$ and $C_{o}$ for the current iteration. 
Equation (71) can also be rearranged to the more conventional linear form

$$
C_{f}^{i}=A_{3}^{i-1}+A_{4}^{i-1} C_{0}^{i}, *
$$

where

$$
A_{4}^{i-1}=\left(\frac{d_{f}}{d_{0}}\right)^{i-1}
$$

and

$$
A_{3}^{i-1}=C_{f}^{i-1}-A_{4}^{i-1} C_{c}^{i-1}
$$

Eq. (72) is the final form of the gap interface equation. The object now is to derive expressions for the coefficients, $A_{3}$ and $A_{4}$.

Since Eq. (70) cannot be directly solved for $\mathrm{C}_{\mathrm{f}}$ as a function of $\mathrm{C}_{\mathrm{o}}$, it is not possible to explicitly differentiate $C_{f}\left(C_{o}\right)$ as Eq. (73) would imply. However, by implicit differentiation using the chain rule

$$
\frac{\mathrm{dC}_{\mathrm{f}}}{\mathrm{dC}_{\mathrm{o}}}=\frac{\frac{\mathrm{dp}}{\mathrm{dC}}}{\frac{\mathrm{dp}}{\mathrm{dC}_{\mathrm{f}}}}=\frac{\frac{\mathrm{dp}}{\mathrm{dC}} \frac{\mathrm{dC_{o }}}{\mathrm{dC_{o }}}}{\frac{\mathrm{dp}}{\mathrm{dC}_{f}} \frac{\mathrm{dC}_{\mathrm{f}}}{\mathrm{dC}_{\mathrm{f}}}},
$$

or, invoking Eq. (55) for the fuel and graphite,

$$
\frac{\mathrm{dC}_{\mathrm{f}}}{\mathrm{dC}}=\left(\frac{\rho_{\mathrm{f}}}{\rho_{\mathrm{g}}}\right)\left(\frac{\frac{\mathrm{dp}}{\mathrm{d} \mathrm{C}_{\mathrm{o}}}}{\frac{\mathrm{dp}}{\mathrm{d} \mathrm{C}_{\mathrm{f}}}}\right)
$$

\footnotetext{
*Subscripts 3 and 4 are used here because TRAFIC is coded this way. Also, the derivations dealing with the simultaneous equations (Section 2.8) use this notation. Subscripts 1 and 2 apply to the coolant hole side.
} 
Then Eq. (70) can be differentiated and the results substituted into Eq. (76), giving

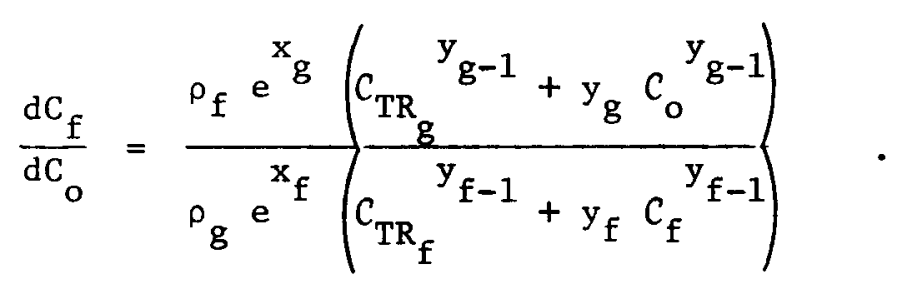

The logic for evaluating all of the required coefficients will now be outlined :

1. Given a guess $\mathrm{C}_{0}^{i-1}$, evaluate

$$
c_{0}^{i-1}=\frac{c_{o}^{i-1}}{\rho_{g}} \text {, }
$$

and then from the right hand side of Eq. (70) evaluate $p^{i-1}$.

2. Given $p^{i-1}$, solve the left hand side of $E q(70)$ for $C_{f}^{i-1}$ using Newton's method.

3. Evaluate $\left(\mathrm{dC}_{\mathrm{f}} / \mathrm{dC}_{\mathrm{o}}\right)^{i-1}$ from Eq, (77), thereby defining $\mathrm{A}_{4}^{i-1}$ (Eq. (73))

4. Evaluate $C_{f}^{i-1}=C_{f}^{i-1} \rho_{f}$. Then from Eq. (74),

$$
A_{3}^{i-1}=C_{f}^{i-1} \rho_{f}-A_{4}^{i-1} C_{o}^{i-1}
$$

This completes the definition of the gap interface equation, Eq. (72). 


\subsection{GRAPHITE SLAB DIFFUSION MODEL}

It will be recalled that the COPAR model (Section 2.2) employed a superposition principle at two stages of the analysis. The first stage was the Duhamel superposition [Eq. (17)] used to account for the timedependent boundary conditions in a single thin-shell region. The second stage, applied after the simultaneous solution for the multi-layer particle, was a birth-pulse superposition [Eq. (33)] used to account for the timedependent source. Note that we were able to combine layers and get to the second stage only because the differential equation was linear throughout the particle. We could take advantage of this fact to eliminate the unknown interior boundary conditions and eventually obtain a complete coupled solution for a multilayered particle based on known, external boundary conditions.

Now, as discussed in the previous section, the boundary conditions for the equivalent graphite slab are nonlinear and unknown. Therefore, we can proceed no farther with this model than the Duhamel superposition stage. We can derive a set of linear response functions relating the unknown boundary conditions, analogous to Eq. (18). These form a part of the system of nonlinear simultaneous equations that govern the TRAFIC model at each point in time. There is no need to perform a second stage of superposition because the source term is zero inside the graphite. Therefore, the interior solution depends only on the unknown boundary conditions.

The above discussion has hopefully put the graphite slab model in perspective. We will now proceed with a brief discussion of the slab solution. Begin with Eq. (35) for the conservation of mass. Assuming that the source term $S$ is zero and writing the equation in slab geometry 
we have

$$
\frac{\partial C(x, t)}{\partial t}=-\lambda C(x, t)-\vec{\nabla} \cdot J(x, t),
$$

where, by analogy with Eq. (39),

$$
\vec{J}(x, t)=-D(x, t)\left[\vec{\nabla} C(x, t)+\frac{Q^{*}}{y R T^{2}} \vec{\nabla} T(x, t) \cdot C(x, t)\right] .
$$

We now make some simplifications that will reduce Eqs. (80) and (81) to a single second order equation having constant coefficients. First, it is assumed (as with the fuel rod) that the temperature difference across the slab is small compared with the temperature itself. Then

$$
\begin{aligned}
T(x, t) & \approx T(t) \\
D(x, t) & \approx D(t) \\
\nabla T(x, t) & \approx \frac{\Delta T(t)}{L}
\end{aligned}
$$

where $\overline{\mathrm{T}}$ is the average temperature,

$\Delta \mathrm{T}$ is the temperature difference (assuming quasi-steady-state), and

$L$ is the thickness of the equivalent slab.

With these approximations we eliminate the spatial dependence of the coefficients, and Eq. (81) becomes

$$
\frac{\partial C}{\partial t}=D(t) \frac{\partial^{2} C}{\partial x^{2}}+\alpha(t) \frac{\partial C}{\partial x}-\lambda C
$$

where

$$
\alpha(t) \equiv \frac{D(\bar{T}) Q^{*} \Delta T(t)}{\operatorname{yRT}(t)^{2} L}
$$


The next step is to nondimensionalize Eq. (83). Defining

$$
\begin{aligned}
\xi & \equiv \frac{x}{L}, \\
\rho(t) & \equiv \frac{1}{L^{2}} \int_{0}^{t} D(\tau) d \tau, \\
\beta(t) & =\frac{L \alpha(t)}{D(t)}, \text { and } \\
\gamma(t) & =\frac{\lambda L^{2}}{D(t)},
\end{aligned}
$$

Eq. (83) can be written

$$
\frac{\partial C(\xi, \rho)}{\partial \rho}=\frac{\partial^{2} C}{\partial \xi^{2}}+\beta \frac{\partial C}{\partial \xi}-\gamma C
$$

where, in genera1, $\beta$ and $\gamma$ are functions of time.

The approximation is now made that $\beta$ and $\gamma$ are independent of time, given by their time-averaged values. Then Eq. (89) reduces to one of constant coefficients, and the analytic solution depends on only four parameters: $\rho, \xi, \beta$, and $\gamma$. The parameters $\rho$ (a dimensionless time parameter) and $\xi$ (a dimensionless $x$ coordinate) vary continuously, but $\beta$ and $\gamma$ are now constants. The motivation for assuming constant $B$ and $\gamma$ is that this permits a closed form parameterized solution to be obtained, thereby facilitating a very rapid numerical evaluation. Without this approach it would be necessary to solve a space-time partial differential equation for each different local region analyzed by TRAFIC. But by parameterizing the solution and employing the Duhamel superposition principle (to be described later) it is possible to adopt a two-phase solution technique, greatly reducing the overall calculational effort. This two-phase solution technique, somewhat analogous to that already explained for COPAR, will now be described. 


\subsubsection{PHASE 1 SLAB SOLUTION}

The phase 1 slab solution is based on the tentative assumption that the boundary conditions are independent of $\rho$. The boundary conditions are arbitrarily taken to be a concentration, $\mathrm{C}_{0}$, on the fuel rod side of the slab (at $\xi=0$ ) and a transformed mass $f l u x, J_{L} L / D$, on the coolant side of the slab (at $\xi=1$ ). Thus, we assume that

$$
\begin{gathered}
\left.C(\rho, \xi)\right|_{\xi=0}=C_{0} \text {, and } \\
\left.\frac{J_{L}(f, \xi) L}{D(t)}\right|_{\xi=1}=\frac{J_{L} L}{D(t)},
\end{gathered}
$$

are both independent of $\rho$.

With this assumption an analytic solution to Eq. (89) can be derived. Omitting the details, which are given in Ref. 6 , the analytic solution takes the form

$$
C(\xi, \rho, \beta, \gamma)=F_{1}(\xi, \rho, \beta, \gamma) C_{0}+F_{2}(\xi, \rho, \beta, \gamma) \frac{J_{L} L}{D}
$$

Using the analytic expressions $F_{1}$ and $F_{2}$ one can evaluate the concentration and the mass flux on the boundaries opposite to the given boundary conditions. The results take the form

$$
\left.\begin{array}{l}
C_{L}(\rho, \beta, \gamma)=G_{1}(\rho, \beta, \gamma) C_{0}+G_{2}(\rho, \beta, \gamma) \frac{J_{L} L}{D} \\
\frac{J_{0} L}{D}(\rho, \beta, \gamma)=H_{1}(\rho, \beta, \gamma) C_{0}+H_{2}(\rho, \beta, \gamma) \frac{J_{L} L}{D} .
\end{array}\right\}
$$


The four funcitons $G_{1}, G_{2}, H_{1}$, and $H_{2}$ (more precisely, the integrals of these functions, as explained in Ref. 6) are evaluated in advance and tabulated at discrete values of $\rho, \beta$, and $\gamma$. This completes the phase 1 solution. Thereafter, in phase 2 , these functions can be efficiently evaluated by linear interpolation in the precomputed tables.

\subsubsection{PHASE 2 SLAB SOLUTION}

In phase 2, TRAFIC accounts for the effect of time varying boundary conditions by applying the Duhamel superposition principle to the basic solution, Eq. (93). Dropping the $B$ and $\gamma$ arguments for convenience, the results are

$$
\left.\begin{array}{l}
C_{L}(\rho)=\int_{0}^{\rho} G_{1}\left(\rho-\rho^{\prime}\right) \frac{d_{0}}{d \rho^{\prime}} d^{\prime}+\int_{0}^{\rho} G_{2}\left(\rho-\rho^{\prime}\right) \frac{d}{d \rho^{\prime}}\left(\frac{J_{L} L}{D}\right) d \rho^{\prime} \\
\frac{J_{0} L}{D}(\rho)=\int_{0}^{\rho} H_{1}\left(\rho-\rho^{\prime}\right) \frac{d_{o}}{d \rho^{\alpha}} d \rho^{\prime}+\int_{0}^{\rho} H_{2}\left(\rho-\rho^{\prime}\right) \frac{d}{d \rho^{\prime}}\left(\frac{J_{L} L}{D}\right) d \rho^{\prime} \cdot
\end{array}\right\}
$$

As with the COPAR solution for a thin-shell region, these integrals are evaluated numerically, and one obtains an implicit set of linear equations relating the boundary conditions at any point in time. The final results, analogous to $\mathrm{Eq} .(18)$, are

$$
\left.\begin{array}{l}
C_{L}\left(\rho_{n}\right)=B_{1}^{n}+B_{2}^{n} C_{o}\left(\rho_{n}\right)+B_{3}^{n}\left(\frac{L}{D_{n}}\right) J_{L}\left(\rho_{n}\right) \\
J_{0}\left(\rho_{n}\right)=B_{4}^{n}+B_{5}^{n}\left(\frac{D_{n}}{L}\right) C_{0}\left(\rho_{n}\right)+B_{6}^{n} J_{L}\left(\rho_{n}\right)
\end{array}\right\}
$$

These two linear equations, relating the four unknown boundary conditions on either side of the slab, are later combined with the nonlinear interface and boundary equations to solve for the coupled state at time $t_{n}$. 


\subsection{COOLANT HOLE BOUNDARY}

The equation for the coolant hole boundary condition is derived, as was the gap interface condition (Section 2.5), by considering the vapor pressure equilibrium at the solid-gas interface. There are two differences here: first, one does not have the difficulty of solving for conditions on the opposite side; second, the kinetic resistance of the boundary layer is considered.

By analogy with Eqs. (69) and (70), the vapor pressure on the coolant hole side of the slab is given by

$$
\begin{aligned}
& p=p_{g}\left(C_{L}, T_{L}\right), \text { or } \\
& p=e^{x_{g}^{L}}\left(C_{T R_{g}} y_{g-1}^{L} C_{L}+C_{L}^{y_{g}^{L}}\right),
\end{aligned}
$$

where $C_{L}$ is the concentration per unit mass of graphite on the coolant hole side,

and $\quad x_{g}^{L}$ and $y_{g}^{L}$ are the graphite properties evaluated by Eqs. (65) and (66) at the temperature $T_{L}$ on the coolant hole side.

As before, the concentration per unit mass is related to the concentration per unit volume by

$$
c_{L}=\frac{C_{L}}{\rho_{g}} \text {. }
$$


Given the vapor pressure, $p$, one can convert this to a gas phase volumetric concentration, $\mathrm{C}_{\mathrm{a}}$, by the ideal gas law

$$
C_{a}=\frac{10^{6} p}{R T_{L}}
$$

where $\quad C_{a}$ is the concentration inside the boundary layer [umoles $\left./ \mathrm{cm}^{3}\right]$,

$\mathrm{p}$ is the vapor pressure [atm],

$\mathrm{T}_{\mathrm{L}}$ is the graphite wall temperature $\left[{ }^{\circ} \mathrm{K}\right]$,

$\mathrm{R}=82.06\left[\mathrm{~cm}^{3} \mathrm{~atm} / \mathrm{mole}{ }^{\circ} \mathrm{K}\right]$, and

$10^{6}$ converts from moles to $\mu$ moles.

The kinetic resistance of the boundary layer is modeled by an empirical mass transfer correlation,

$$
J_{L}\left(t_{n}\right)=H\left(t_{n}\right)\left[C_{a}\left(t_{n}\right)-C_{\infty}\left(t_{n}\right)\right],
$$

where $\mathrm{H}$ is an empirical function of varlous dimensionless flow parameters, and $\mathrm{C}_{\infty}$ is the "free stream" or mixed mean concentration in the coolant, assumed to be given.

Through Eqs. (96) and (98), it can be seen that Eq. (99) reduces to a nonlinear relationship between $J_{L}$ and $C_{L}$. In general, the relationship can be written

$$
J_{L_{n}}=H\left[C_{a}\left(C_{L_{n}}\right)-C_{\infty}\right]
$$


As was the case with the nonlinear interface conditions, the solution of the coupled TRAFIC equations is achieved by a Newton Raphson iteration. At each stage of the iteration Eq. (100) is linearized by a Taylor series expansion about the latest guess (i-1). By analogy with Eq. (72), the linearization is achieved by letting

$$
C_{a}^{i}\left(C_{L_{n}}\right)=A_{1}^{i-1}+A_{2}^{i-1} C_{L_{n}}^{i}
$$

where

$$
A_{2}^{i-1}=\left(\frac{d_{a}}{d C_{L}}\right)^{i-1}
$$

and

$$
A_{1}^{i-1}=C_{a}^{i-1}-A_{2}^{i-1} C_{L_{n}}^{i-1}
$$

The derivative in $\mathrm{Eq} .(102)$ is given by the chain rule:

$$
\frac{\mathrm{dC}_{\mathrm{a}}}{\mathrm{dC}_{\mathrm{L}}}=\left(\frac{\mathrm{dc}}{\mathrm{dp}}\right)\left(\frac{\mathrm{dp}}{\mathrm{dC}_{L}}\right)\left(\frac{\mathrm{dC}_{\mathrm{L}}}{\mathrm{dC}_{\mathrm{L}}}\right)
$$

By differentiating Eqs. (98), (96), and (97)) in turn, one finally obtains

$$
\frac{\mathrm{dC}_{\mathrm{a}}}{\mathrm{dC}_{\mathrm{L}}}=\left(\frac{10^{6}}{\mathrm{RT}_{\mathrm{L}}}\right)\left\{\mathrm{e}^{\mathrm{x}_{\mathrm{g}}^{\mathrm{L}}}\left[\mathrm{C}_{\mathrm{TR}_{\mathrm{g}}} \mathrm{y}_{\mathrm{g}}^{\mathrm{L}-1}+\left(\mathrm{y}_{\mathrm{g}}^{\mathrm{L}}-1\right) \mathrm{C}_{\mathrm{L}}^{\mathrm{y}_{\mathrm{g}}^{\mathrm{L}}-1}\right]\right\}\left(\frac{1}{\rho_{\mathrm{g}}}\right) \cdot
$$

The logic for evaluating the required coefficients is as follows:

1. Given a guess $C_{L}^{i-1}$, evaluate $c_{L}^{i-1}$ using Eq. (97);

2. Evaluate the derivative $\left(A_{2}^{i-1}\right)$ from Eq. (105);

3. Evaluate the constant $\left(A_{1}^{i-1}\right)$ from Eq. (103).

Then, substituting the linearized equation (101) into Eq. (100), the final linearized form of the coolant hole boundary condition is

$$
J_{L_{n}}^{i}=H\left[A_{1}^{i-1}+A_{2}^{i-1} C_{L_{n}}^{i}-C_{\infty}\right]
$$




\subsection{SOLUTION FOR NONLINEAR INTERFACE AND BOUNDARY CONDITIONS}

In summary, the five equations to be solved by TRAFIC at each time, $t_{n}$, are as follows:

Steady-state Mass Balance in Fuel Rod

$$
\mathrm{C}_{\mathrm{f}_{\mathrm{n}}}=\chi^{\mathrm{n}}\left(\mathrm{D}_{1}^{\mathrm{n}}+\mathrm{D}_{2}^{\mathrm{n}} \mathrm{J}_{\mathrm{o}}\right)
$$

Nonlinear Gap Interface Condition

$$
c_{f_{n}}=c_{f}\left(c_{o_{n}}\right)
$$

Ref. Eq. (68)

and its linearization at iteration $i$,

$$
c_{f_{n}}^{i}=A_{3}^{i-1}+A_{4}^{i-1} C_{o_{n}}^{i}
$$

Ref.Eq. (72)

Two Equations for Diffusion in Graphite Web

$$
\left.\begin{array}{l}
C_{L_{n}}=B_{1}^{n}+B_{2}^{n} C_{0}^{n}+B_{3}^{n}\left(\frac{L}{D_{n}}\right) J_{L_{n}} \\
J_{o_{n}}=B_{4}^{n} \frac{D_{n}}{L}+B_{5}^{n} \frac{D_{n}}{L} C_{0}+B_{6}^{n} J_{L_{n}} \cdot
\end{array}\right\}
$$

Ref . Eq. (95)

\section{Nonlinear Evaporation Boundary Condition}

$$
\mathrm{J}_{\mathrm{L}_{\mathrm{n}}}=\mathrm{H}\left[\mathrm{C}_{\mathrm{a}}\left(\mathrm{C}_{\mathrm{L}_{\mathrm{n}}}\right)-\mathrm{C}_{\infty}\right] \text {, }
$$

Ref. Eq. (100)

and its linearization at iteration $i$,

$$
J_{L_{n}}^{i}=H\left[A_{1}^{i-1}+A_{2}^{i-1} C_{L_{n}}^{i}-C_{\infty}\right]
$$

Ref. Eq. (106) 
In TRAFIC these equations are solved using the Newton Raphson method. In a loop over iterations 1 , the coefficients $A_{1}^{i-1}$ through $A_{4}^{i-1}$ are evaluated based on the most recent guess, $C_{0}^{i-1}$ and $C_{L}^{i-1}$. Then the system of five linear equations is projected to the state at the next iteration. The solution of the five linear equations can be achieved by algebraic elimination as follows.

Substituting Eq. (106) into Eq. (95) 1 , eliminating the 1 and $n$ subscripts for brevity, we have

$$
\begin{gathered}
\mathrm{C}_{\mathrm{L}}=\mathrm{B}_{1}+\mathrm{B}_{2} \mathrm{C}_{\mathrm{o}}+\mathrm{B}_{3}\left(\frac{\mathrm{L}}{\mathrm{D}}\right) \mathrm{H}\left[\mathrm{A}_{1}+\mathrm{A}_{2} \mathrm{C}_{\mathrm{L}}-\mathrm{C}_{\infty}\right] . \\
\text { Similarly, substituting Eq. (106) into Eq. (95) }{ }_{2} \text { gives } \\
\mathrm{J}_{0}=\mathrm{B}_{4}\left(\frac{D}{\mathrm{~L}}\right)+\mathrm{B}_{5} \frac{\mathrm{D}}{\mathrm{L}} \mathrm{C}_{0}+\mathrm{B}_{6} \mathrm{H}\left[\mathrm{A}_{1}+\mathrm{A}_{2}-\mathrm{C}_{\infty}\right] .
\end{gathered}
$$

Now substitute Eq. (107) and (72) into Eq. (53), giving

$$
A_{3}+A_{4} C_{0}=x\left(D_{1}+D_{2}\left\{B_{4}\left(\frac{D}{L}\right)+B_{5}\left(\frac{D}{L}\right) C_{0}+B_{6} H\left[A_{1}+A_{2} C_{L}-C_{\infty}\right]\right\}\right) .
$$

Equations (107) and (109) are now two linear equations in two unknowns, $C_{0}$ and $\mathrm{C}_{\mathrm{L}}$.

Define $\quad x_{1} \equiv 1-B_{3} \frac{L}{D} H A_{2}$, and

$$
\mathrm{x}_{2} \equiv \mathrm{B}_{1}+\mathrm{B}_{3} \frac{\mathrm{L}}{\mathrm{D}} \mathrm{H}\left(\mathrm{A}_{1}-\mathrm{C}_{\infty}\right) \text {. }
$$

Then, after rearranging terms, Eq. (107) becomes

$$
x_{1} C_{L}-B_{2} C_{0}=x_{2} \text {. }
$$

50 


$$
\begin{aligned}
\text { Define } \quad \mathrm{x}_{3} \equiv \mathrm{A}_{4}-\chi \mathrm{D}_{2} \mathrm{~B}_{5}\left(\frac{\mathrm{D}}{\mathrm{L}}\right), \\
\mathrm{x}_{4} \equiv-\chi \mathrm{D}_{2} \mathrm{~B}_{6} \mathrm{HA}_{2}, \text { and } \\
\mathrm{x}_{5} \equiv-\mathrm{A}_{3}+\chi\left\{\mathrm{D}_{1}+\mathrm{D}_{2}\left[\mathrm{~B}_{4}\left(\frac{D}{\mathrm{~L}}\right)+\mathrm{B}_{6} H\left(\mathrm{~A}_{1}-\mathrm{C}_{\infty}\right)\right]\right\} .
\end{aligned}
$$

Then Eq. (109) can be written

$$
x_{3} C_{0}+x_{4} C_{L}=x_{5}
$$

Finally, the simultaneous solution of (112) and (116) gives

$$
\begin{aligned}
& C_{0}=\frac{x_{5}-\frac{x_{4} x_{2}}{x_{1}}}{x_{3}+\frac{x_{4} B_{2}}{x_{1}}} \text {, and } \\
& C_{L}=\frac{x_{2}+B_{2} C_{0}}{x_{1}} \text {. }
\end{aligned}
$$

This completes the solution in a typical iteration. The iteration continues until successive values of $C_{0}$ and $C_{L}$ are sufficiently close. 


\subsection{RELEASE AND INVENTORY EVALUATION}

Having solved for the state of concentration and mass flux on all material interfaces, including the exterior boundary, we have all of the information we need to calculate the inventory of fission products in any of the material regions. TRAFIC evaluates the total mass transferred between regions by integrating the mass flux with respect to time at all material interfaces. The integration must account for the decay of the fission product after it flows past the interface. Considering the release to the coolant as a typical example, we have

$$
R_{c}(t)=A_{c} \int_{0}^{t} e^{-\lambda(t-\tau)} J_{L}(\tau) d \tau,
$$

where

$\mathrm{R}_{\mathrm{c}}$ is the integrated release inventory accounting for decay,

$A_{c}$ is the area of the coolant hole surface,

$\lambda$ is the decay constant,

$\mathrm{J}_{\mathrm{L}}$ is the mass flux at the coolant hole surface,

$t$ is the current time, and

$\tau$ is a time in the past history.

The integration, Eq. (119), is reduced to a recursive formula by a minor manipulation. Defining an adjusted mass flux,

$$
J_{L}^{*}(\tau) \equiv e^{\lambda \tau} J_{L}(\tau),
$$

Eq. (119) reduces to

$$
R_{L}(t)=A_{c} e^{-\lambda t} \int_{0}^{t} J_{L}^{*}(\tau) d \tau
$$


By discretizing in time and integrating with the trapezoidal rule, Eq. (121) becomes

$$
R_{c}\left(t_{n}\right)=A_{c} e^{-\lambda t_{n}}\left[R_{c}\left(t_{n-1}\right)+\frac{1}{2}\left(J_{L_{n}}^{*}+J_{L_{n-1}}^{*}\right)\left(t_{n-1}-t_{n}\right)\right] .
$$

Similar formulas are used to compute inventories in the other spatial regions such as the particles, the fuel rod, and the graphite web.

\subsection{MASS TRANSFER CORRELATION}

The mass transfer coefficient $H[\mathrm{~cm} / \mathrm{sec}]$ in $\mathrm{Eq} .(100)$ is computed from an empirical correlation based on dimensionless coolant flow parameters. The correlation presently used (Ref. 7) is

$$
\mathrm{H}=.023 \frac{\mathrm{D}_{\mathrm{He}}}{\mathrm{d}_{\mathrm{c}}} \mathrm{Re}^{.83} \mathrm{Sc}^{.44},
$$

where $D_{H e}$ is the diffusion coefficient of the diffusing species in the helium coolant at a given temperature and pressure $\left[\mathrm{cm}^{2} / \mathrm{sec}\right]$.

$d_{c}$ is the diameter of the coolant hole $(\mathrm{cm})$,

Re is the Reynolds number [see Eq. (125)], and

Sc is the Schmidt number [see Eq. (126)].

The diffusion coefficient of a metallic fission product in helium is assumed to be given (Ref. 8) by

$$
D_{\mathrm{He}}=\mathrm{D}_{\mathrm{o}_{\mathrm{He}}}\left(\frac{\mathrm{P}_{\mathrm{o}}}{\mathrm{p}}\right)\left(\frac{\mathrm{T}_{\mathrm{c}}}{\mathrm{T}_{\mathrm{o}}}\right)^{\mathrm{DGAS}}
$$

where

$$
\begin{aligned}
\mathrm{D}_{\mathrm{O}_{\mathrm{He}}} & \text { is the diffusion coefficient at standard temperature and pressure, } \\
\mathrm{p}_{\mathrm{O}} & =\text { standard pressure }(1 \mathrm{~atm}) \\
\mathrm{P} & =\text { coolant pressure }(\mathrm{atm}) \\
\mathrm{T}_{\mathrm{O}} & =\text { standard temperature }\left(273^{\circ} \mathrm{K}\right) \\
\mathrm{T}_{\mathrm{C}} & =\text { coolant temperature }\left({ }^{\circ} \mathrm{K}\right) \text {, and } \\
\text { DGAS } & \text { is an input parameter (usually } 1.65) .
\end{aligned}
$$


The dimensionless numbers in Eq. (122) are defined by

$$
\begin{array}{ll}
\operatorname{Re} \equiv \frac{d_{c} v \rho}{\mu} & \text {, and } \\
S c & \equiv \frac{\mu}{\rho D_{H e}} \quad,
\end{array}
$$

where $v$ is the flow velocity $[\mathrm{cm} / \mathrm{sec}]$,

$\rho$ is the coolant density $\left[\frac{\mathrm{g}}{\mathrm{cm}^{3}}\right]$,

$\mu$ is the coolant viscosity $[\mathrm{g} / \mathrm{cm} \mathrm{sec}]$.

The expression for Re that is actually programmed into the TRAFIC code is somewhat different from the above because it involves a mass flow rate, $\dot{m}$, instead of a velocity, $v$, and because it contains numerous units conversions. In particular, since

$$
\dot{\mathrm{m}}=\frac{\rho \mathrm{v} \pi \mathrm{d}_{\mathrm{c}}{ }^{2}}{4},
$$

then an expression for Re involving consistent units would be

$$
\operatorname{Re}=\frac{4 \dot{m}}{\pi d_{c}^{\mu}}
$$

Details of the units conversions are documented in the listing of the code. 


\subsection{FISSION YIELDS}

TRAFIC requires that the accumulated number density of fissions in NPART particle types be input as a function of time. In general, these fissions may be occurring in any of several fissile or converted fertile nuclides. The average yield of a given fission product depends on which nuclide is fissioning. Therefore, in order to compute the total fission product source rate in any given particle, it is necessary to partition the total number of fissions among the different fissioning nuclides in a particle. For cases in which there is only one fissionalbe nuclide per particle (e.g., U-235 in TRISO particles and Th-232 in BISO particles, as in the high-enriched LHTGR designs), the partitioning is trivial. In general, however, one must account for mixed materials in a particle (e.g., in the Fort St. Vrain reactor or in low-enriched cycles). The procedure for doing this in TRAFIC is explained in this section.

The method currently employed in TRAFIC to partition the fissions is valid for a maximum of two fissionable nuclides and two particle types. The total fissions in each of two particle types are assumed to be partitioned among two nuclides, one labeled fissile and one labeled fertile. For the sake of convenience, the symbol " $U$ " will be used for fissile material, and the symbol "Th" will be used for fertile material. Separating the fissions by nuclide, we have

$$
\begin{aligned}
& \Delta \mathrm{f}^{\mathrm{l}}=\Delta \mathrm{f}_{\mathrm{U}}^{\mathrm{l}}+\Delta \mathrm{f}_{\mathrm{Th}}^{\mathrm{l}}, \\
& \Delta \mathrm{f}^{2}=\Delta \mathrm{f}_{\mathrm{U}}^{2}+\Delta \mathrm{f}_{\mathrm{Th}}^{2},
\end{aligned}
$$

where $\Delta \mathrm{f}$ is an incremental number of fissions, and 1,2 refer to the particle type. 
Assuming that each nuclide sees an identical neutron flux environment, regardless of the particle in which it resides, we can write

$$
\begin{aligned}
& \frac{\Delta \mathrm{f}_{\mathrm{U}}^{2}}{\Delta \mathrm{f}_{\mathrm{U}}^{\mathrm{I}}}=\frac{\mathrm{U}_{2}}{\mathrm{U}_{1}}, \\
& \frac{\Delta \mathrm{f}_{\mathrm{Th}}^{2}}{\Delta \mathrm{f}_{\mathrm{Th}}^{\mathrm{I}}}=\frac{\mathrm{Th}_{2}}{\mathrm{Th}_{1}},
\end{aligned}
$$

where $U$ and Th as stand-alone symbols refer to the number of atoms of $U$ or Th, and the subscripts 1 and 2, again, refer to particle type. Note that if $U$ is enriched uranium, and if $U_{1}$ and $U_{2}$ have the same enrichment, we may define $U$ to mean the number of atoms of all isotopes, including $U-238$. If the enrichments are different, then $U$ must refer only to the fissile isotope, $\mathrm{U}-235$.

By simultaneously solving Eqs. (129) through (132) one obtains

$$
\Delta \mathrm{f}_{\mathrm{Th}}^{\mathrm{l}}=\frac{\Delta \mathrm{f}_{1}-\left(\frac{\mathrm{U}_{1}}{\mathrm{U}_{2}}\right) \Delta \mathrm{f}_{2}}{1-\left(\frac{\mathrm{U}_{1}}{\mathrm{U}_{2}}\right)\left(\frac{\mathrm{Th}_{2}}{\mathrm{Th}_{1}}\right)},
$$

then

$$
\begin{aligned}
& \Delta \mathrm{f}_{\mathrm{U}}^{\mathrm{l}}=\Delta \mathrm{f}^{\mathrm{l}}-\Delta \mathrm{f}_{\mathrm{Th}}^{\mathrm{l}}, \\
& \Delta \mathrm{f}_{\mathrm{Th}}^{2}=\left(\frac{T h_{2}}{T h_{1}}\right) \Delta \mathrm{f}_{\mathrm{Th}}^{\mathrm{l}}, \\
& \Delta \mathrm{f}_{\mathrm{U}}^{2}=\Delta \mathrm{f}^{2}-\Delta \mathrm{f}_{\mathrm{Th}}^{2} .
\end{aligned}
$$


TRAFIC performs an internal reorganization of the particle type numbers to ensure that $\mathrm{U}_{2}$ and $\mathrm{Th}_{1}$ are both greater than zero. This is indirectly controlled by an option, *

$$
\begin{aligned}
& \text { IUTH }_{i} \equiv 0 \text { if particle } i \text { is predominantly Th, } \\
& \text { IUTH }_{i} \equiv 1 \text { if particle } i \text { is predominantly } U,
\end{aligned}
$$

with the restriction $\mathrm{IUTH}_{1} \neq \mathrm{IUTH}_{2} \cdot$ By this option a local numbering scheme (internal to TRAFIC and unknown to the user) is defined by which particle 1 is the "predominantly fertile" particle and particle 2 is the "predominantly fissile" particle. This local numbering scheme is used in the derivations that follow.

Equations (133) through (136) contain two ratios, $\mathrm{U}_{1} / \mathrm{U}_{2}$ and $\mathrm{Th}_{2} / \mathrm{Th}_{1}$.

The most convenient form of input is to specify these quantities not as ratios between particles, but as ratios of nuclides within a given particle. There are, in fact, three independent ratios of the four quantities in question, and the two required ratios can be derived from these three. The three ratios that are input to TRAFIC are

$$
\begin{aligned}
& \left(\frac{\mathrm{U}}{\mathrm{Th}}\right)_{1}, \\
& \left(\frac{\mathrm{Th}}{\mathrm{U}}\right)_{2}, \text { and } \\
& \left(\frac{\mathrm{Th}}{\mathrm{U}}\right)_{\mathrm{TOT}} \equiv \frac{\mathrm{Th}_{1}+\mathrm{Th}_{2}}{\mathrm{U}_{1}+\mathrm{U}_{2}}
\end{aligned}
$$

These three ratios are all defined as one variable name called RATIOP. RATIOP is a (Th/U) ratio for a fissile particle or the smeared total, and it is a $(U / T h)$ ratio for a fertile particle.

* The option IUTH is normally provided on the SURVEY/THERM data tape, but it may also be input by the user in a stand-alone TRAFIC calculation. 
From the definition $(137)_{3}$ and some minor manipulations, it can be shown that

$$
\left(\frac{\mathrm{U}_{1}}{\mathrm{U}_{2}}\right)=\left(\frac{\mathrm{U}}{\mathrm{Th}}\right)_{1}\left[\frac{\left(\frac{\mathrm{Th}}{\mathrm{U}}\right)_{\mathrm{TOT}}-\left(\frac{\mathrm{Th}}{\mathrm{U}}\right)_{2}}{1-\left(\frac{\mathrm{U}}{\mathrm{Th}}\right)_{1}\left(\frac{\mathrm{Th}}{\mathrm{U}}\right)_{\text {TOT }}}\right],
$$

then

$$
\left(\frac{\mathrm{Th}_{2}}{\mathrm{Th}_{1}}\right)=\frac{\left(\frac{\mathrm{U}}{\mathrm{Th}}\right)_{1}\left(\frac{\mathrm{Th}}{\mathrm{U}}\right)_{2}}{\left(\frac{\mathrm{U}_{1}}{\mathrm{U}_{2}}\right)} \quad\left[\mathrm{U}_{1} \neq 0\right]
$$

If $\mathrm{U}_{1}=0$, then $\mathrm{U}_{2}=\mathrm{U}_{\mathrm{TOT}}$, and the program employs the alternate expression,

$$
\left(\frac{\mathrm{Th}_{2}}{\mathrm{Th}}\right)=\frac{\left(\frac{\mathrm{Th}}{\mathrm{U}}\right)_{2}}{\left(\frac{\mathrm{Th}}{\mathrm{U}}\right)_{\mathrm{TOT}}-\left(\frac{\mathrm{Th}}{\mathrm{U}}\right)_{2}} \quad\left[\mathrm{U}_{1}=0\right]
$$

Having partitioned the fissions by the above procedure, the average fission yield in particle $i$ is given by

$$
\mathrm{Y}_{\mathrm{avg}}^{i}=\frac{\Delta \mathrm{f}_{U}^{\mathrm{i}} \cdot \mathrm{Y}_{U}+\Delta \mathrm{f}_{\mathrm{Th}}^{i} \cdot \mathrm{Y}_{\mathrm{Th}}}{\Delta \mathrm{f}^{i}}
$$

It should be noted that the nuclide number ratios (137) that are input to TRAFIC are specified as the values at the beginning of a fuel load, and they are held constant throughout the fuel load. In reality these three ratios are time-dependent because different nuclides burn at different rates. However, one should remember that these input ratios are only a means to an end. The ultimate use of these quantities is to determine the partitioning between particles of a single nuclide type, i.e., to evaluate Eqs. (138) and 
(139). The assumption that these derived ratios are constant is quite reasonable. Therefore, the time-dependence of the input ratios is irrelevant. They will vary in such a way as to preserve the constant nature of the desired end result. 


\section{TRAFIC ORGANIZATION AND METHOD OF CALCULATION}

This section briefly explains certain aspects of the organization and the method of calculation in the TRAFIC code. This information will help a user to understand the way in which the program actually calculates certain results of interest, and it will aid in the interpretation of those results.

\subsection{INPUT MODES}

TRAFIC is designed to operate in three input modes. In the "stand-alone" mode, all input data are read from cards. In the "survey" mode much of the input data are obtained by reading the thermal (THERM) and the fuel performance (PERFOR) output tapes of the SURVEY code. SURVEY computes time histories of temperatures, coolant flows, numbers of fissions, particle failure fractions, etc., for a large number of spatial locations in the reactor. In the survey mode all of this information is automatically interfaced with TRAFIC. Separate TRAFIC input is needed only for a sma1l amount of material property data. In the third mode of input, all data that would normally be read from the SURVEY tapes are read instead from a catalogued data file. The data in the file are generated by a previous survey-mode TRAFIC run in which the SURVEY data have (by option) been written by TRAFIC into the file. The catalogued file input option can be used for performing repetitive calculations with the same historical data, as might be done in a sensitivity study. This avoids the need to mount the tapes and to read the data for unwanted spatial locations. The stand-alone input option is useful for checking out the TRAFIC code using simple problems and for comparing TRAFIC with other codes. But by far the most useful mode of input is the survey mode. The survey type of calculation, with its obvious need for an efficient model, was the main motivation for the TRAFIC development. 
Regardless of the input mode, essentially the same data are read from whatever source is appropriate. Thereafter, the calculations proceed according to the same logic. Once the program enters the calculation phase, the mode of input is indistinguishable. The output is the same in any case.

The remaining discussion in this chapter is presented from the viewpoint of the survey mode of calculation.

\subsection{SURVEY DATA PROCESSING LOGIC}

TRAFIC begins its calculations with an initialization phase in which all data that are independent of spatial position in the reactor core are input to the code and/or initialized. These data include material properties, geometry, the phase 1 COPAR tabulations, calculation options, printing and sorting options, etc. Then the controlling subroutine enters a DO loop over spatial positions in the core. For each spatial position (or local point) selected, TRAFIC performs a tine-dependent diffusion calculation according to the method described in Chapter 2 of this report. The output from this local point calculation can either be printed in detail as a function of time (by option), or some of the data can be saved in arrays for further processing, sorting, and summarizing in end-of-run output tables. The data that are printed in the detailed time history include

1. Time-step index and end-of-step time

2. Concentrations at material interfaces

3. Mass fluxes at material interfaces

4. " $\phi$ factor" (ratio of concentrations) at the gap

5. Tota1 production in particles

6. Particle release fractions

7. Inventories in particles, fuel rod, and graphite

8. Release to the coolant. 
The data that are saved for the end-of-run summaries include only the inventories and the release to the coolant. These results are saved and sorted according to fuel block index, reload segment, and year. They are tabulated in the summary printout in the following ways:

1. For each reload segment, an ordered list of the inventories and the releases for all fuel blocks in the segment at the time of each reload.

2. For each reload segment, the total inventory and release for the segment at the end of each year.

3. An "equilibrium core mockup" in which the results of 2 are redisplayed to simulate an equilibrium core (see Section 3.2.4).

4. "Total core" summaries (actually, the results for one axial 1ayer) by reload and year.

The preceding paragraph was a rather brief summary description of the TRAFIC code output, To really understand the operation of the code, it is necessary to consider in detail what space points are analyzed, how the results for many points are combined, what is the nature of the time and reload history, etc. These details are discussed in the following subsections.

\subsubsection{HTGR GEOMETRY - REFUELING REGIONS}

The logic of the SURVEY code is intimately related to the geometry of the HTGR core and the fuel management scheme. In order to understand the manner in which the spatial survey locations and the time history are related, it is necessary to consider the geometrical pattern in which the fuel elements are zoned and refueled. This will now be explained. 
The HTGR core consists of a large number ( 4000 ) of fuel elements in the shape of hexagonal prisms. There are two types of elements: "standard elements" contain a repeating pattern of fuel holes and coolant holes over most of their area; "control elements" are similar except that they contain three large holes, two for the control rod pair and one for the reserve shutdown material.

The elements of any type are stacked vertically into "columns". A column extends through the entire length of the core, and it typically consists of eight fuel elements plus plenum elements and replaceable reflectors.

The columns, in turn, are organized into "refueling regions", A typical refueling region consists of seven columns. The central column in such a region consists of control elements. The six peripheral columns consist of standard elements. The coolant flow through a seven-column region is controlled by an individual flow control valve. Owing to the control rod and the flow control function, these regions are also designated as "control regions" or "flow regions". However, it is their designation as refueling regions that is important in a TRAFIC analysis.

In addition to the seven-column refueling regions, there are also a number of refueling regions with fewer than seven columns located around the periphery of the core. These do not necessarily contain control rods and flow control valves.

The HTGR is periodically (e.g., annually) reloaded with fresh fuel. At each reload a fraction of the fuel elements (e.g., 1/4) is replaced, and the remaining fuel elements are left in position. All elements that are replaced at any point in time constitute a "reload segment". The number of reload segments in the core at any time is the inverse of the fraction that is replaced in a reload (e.g., 4). Each reload segment consists of a number of separate refueling regions. These are scattered in a regular pattern across 
the radial plane of the core. See Figs. 1 and 2 for an example. The pattern is designed so that no two adjacent refueling regions are in the same segment. This is done to minimize power peaking.

Refueling regions and reload segments are significant in a TRAFIC analysis for a number of reasons. First, whenever a segment is reloaded, the fuel blocks in that region contain fresh fuel, so all fission product concentrations, inventories, etc., must be initialized to zero. Each separate reload at each fuel block location is a unique TRAFIC problem. On the other hand, the TRAFIC analysis proceeds with real time, not time since reload, as the pacing independent variable. Different segments are reloaded at different times, and it is necessary to keep track of these and to consider what the entire core, which contains fuel of different ages, is doing at any point in time. Another reason for considering segments as separate entities has to do with distinguishing the contribution of each segment to the total core release. This information is useful from a design standpoint in order to determine optimum fuel management strategies. The segment inventory information may also be useful for reprocessing studies.

Reload segments are given two designations. A letter symbol (e.g., $A, B, C, D)$ is used to designate the geometrical configuration of all fuel elements in a segment. The configuration is unique, i.e., it does not change with time. A number (e.g., 1, 2, 3, .., n) is used to designate the actual reload sequence. Each batch of fuel has a unique number. For example, initially an HTGR core might contain segments 1-4 in positions A-D respectively. At the first reload, segment 1 in position $A$ is replaced by segment 5 . At the second reload, segment 2 in position $B$ is replaced by segment 6 . This sequence continues until all four positions have been reloaded, and the cycle then repeats itself indefinitely. A schematic example of this is shown in Fig. 3. 


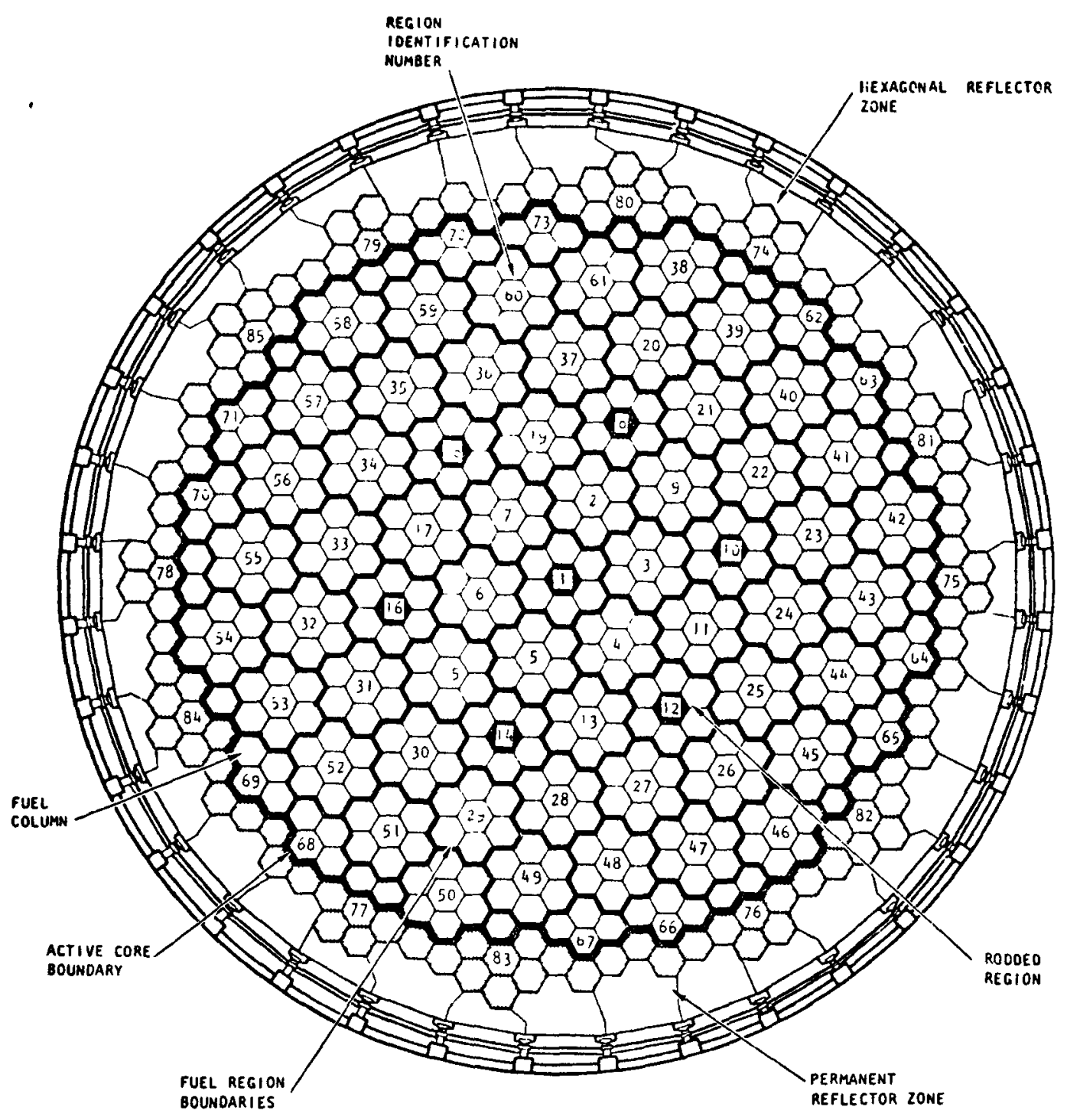

Fig. 1. 3000-MW(t) core plan 


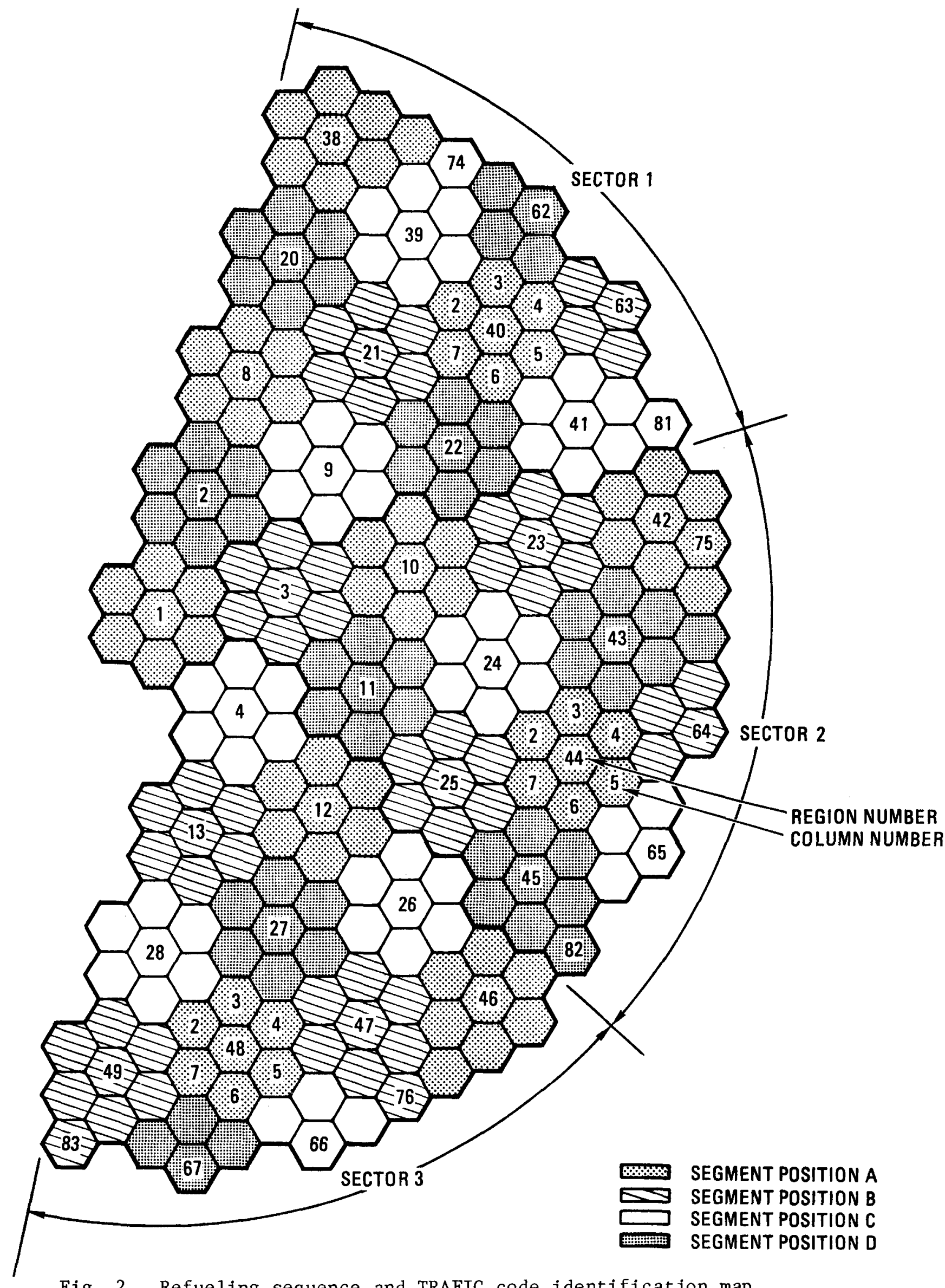

Fig. 2. Refueling sequence and TRAFIC code identification map. 


\begin{tabular}{|c|c|c|c|c|c|c|c|}
\hline $\begin{array}{l}\text { FUEL } \\
\text { LOAD }\end{array}$ & $\begin{array}{l}\text { YEAR OF } \\
\text { OPERATION }\end{array}$ & $\begin{array}{l}\text { TIME } \\
\text { POINT }\end{array}$ & $\operatorname{DIME}_{\text {DAYS }}$ IN & \multicolumn{4}{|c|}{ SEGMENT POSITIONS } \\
\hline & & & & A & 8 & c & D \\
\hline $\begin{array}{l}\text { INITIAL } \\
\text { CORE }\end{array}$ & 1 & $\begin{array}{c}1 \\
2 \\
3 \\
4 \\
5 \\
6 \\
7 \\
8 \\
9 \\
10 \\
11\end{array}$ & $\begin{array}{r}0 \\
5 \\
25 \\
50 \\
100 \\
150 \\
200 \\
225 \\
250 \\
270 \\
292\end{array}$ & SEGMENT 1 & SEGMENT 2 & SEGMENT 3 & SEGMENT 4 \\
\hline $\begin{array}{c}\text { RELOAD } \\
1\end{array}$ & 2 & $\begin{array}{l}\text { SAME AS } \\
\text { IN } \\
\text { YEAR }\end{array}$ & $\begin{array}{l}\text { SAME AS } \\
\text { IN } \\
\text { YEAR I }\end{array}$ & SEGMENT 5 & SEGMENT 2 & SEGMENT 3 & SEGMENT 4 \\
\hline $\begin{array}{l}\text { RELOAD } \\
2\end{array}$ & 3 & $"$ & " & SEGMENT 5 & SEGMENT 6 & SEGMENT 3 & SEGMENT 4 \\
\hline $\begin{array}{c}\text { RELOAD } \\
3\end{array}$ & 4 & " & " & SEGMENT 5 & SEGMENT 6 & SEGMENT 7 & SEGMENT 4 \\
\hline $\operatorname{RELOAD}_{4}$ & 5 & " & " & SEGMENT 5 & SEGMENT 6 & SEGMENT 7 & SEGMENT 8 \\
\hline $\begin{array}{c}\text { RELOAD } \\
5\end{array}$ & 6 & 11 & " & SEGMENT 9 & SEGMENT 6 & SEGMENT 7 & SEGMENT 8 \\
\hline $\begin{array}{l}\text { RELOAD } \\
6\end{array}$ & 7 & "1 & 11 & SEGMENT 9 & SEGMENT 10 & SEGMENT 7 & SEGMENT 8 \\
\hline
\end{tabular}

Fig. 3. Segment and time point identification chart for TRAFIC study. 


\subsubsection{SPATIAL POSITIONS IN SURVEY}

The SURVEY program has a number of optional sequences for sampling the spatial positions in an HTGR core. There are also a number of optional formats in which the output data can be written on tape. One of these sequences, and one fixed data tape format, has been selected as "standard" in order to facilitate the interface with other codes such as TRAFIC. In order to avoid dealing with a complicated set of options, TRAFIC has been programmed so that it operates only with the standard sequence and the standard format. These features will now be briefly explained.

SURVEY subdivides the core both axially and radially according to a set of indices defined below.

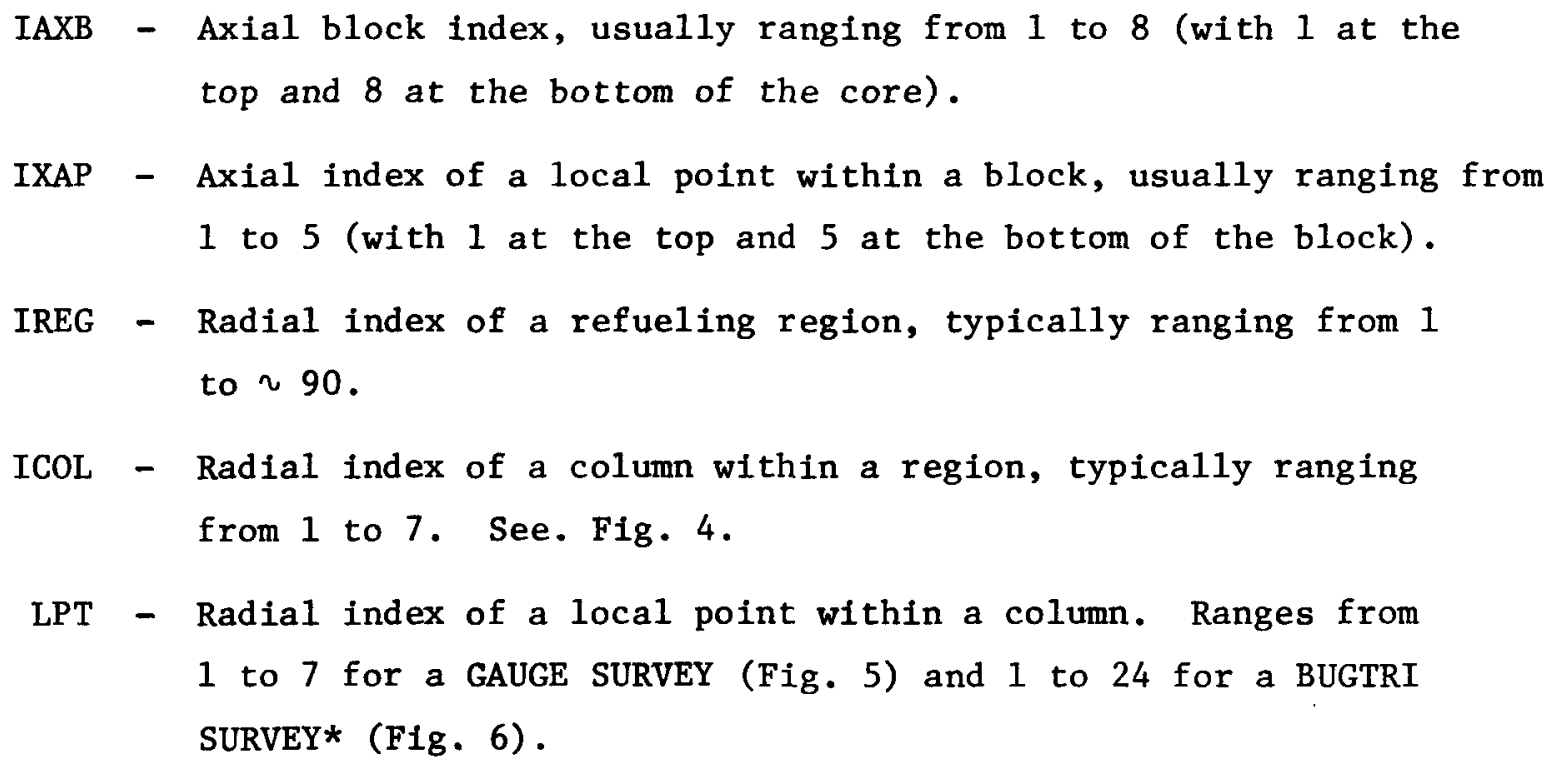

*GAUGE (Ref. 9) and BUGTRI (Ref. 10) are two neutron diffusion and core depletion codes used for core design studies. GAUGE is a coarse mesh code, and BUGTRI is a fine mesh code. 


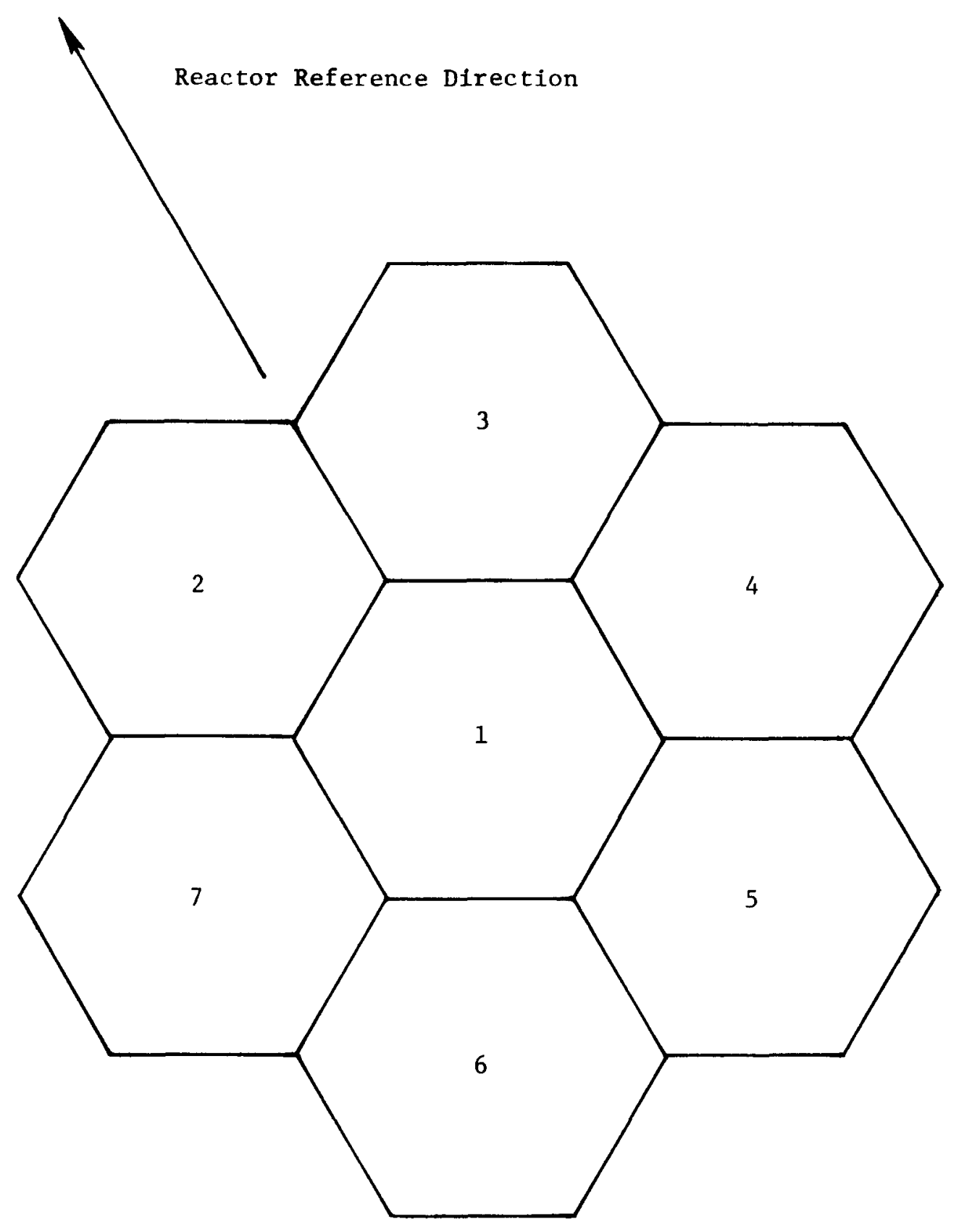

Fig. 4. Column numbering in refueling region 


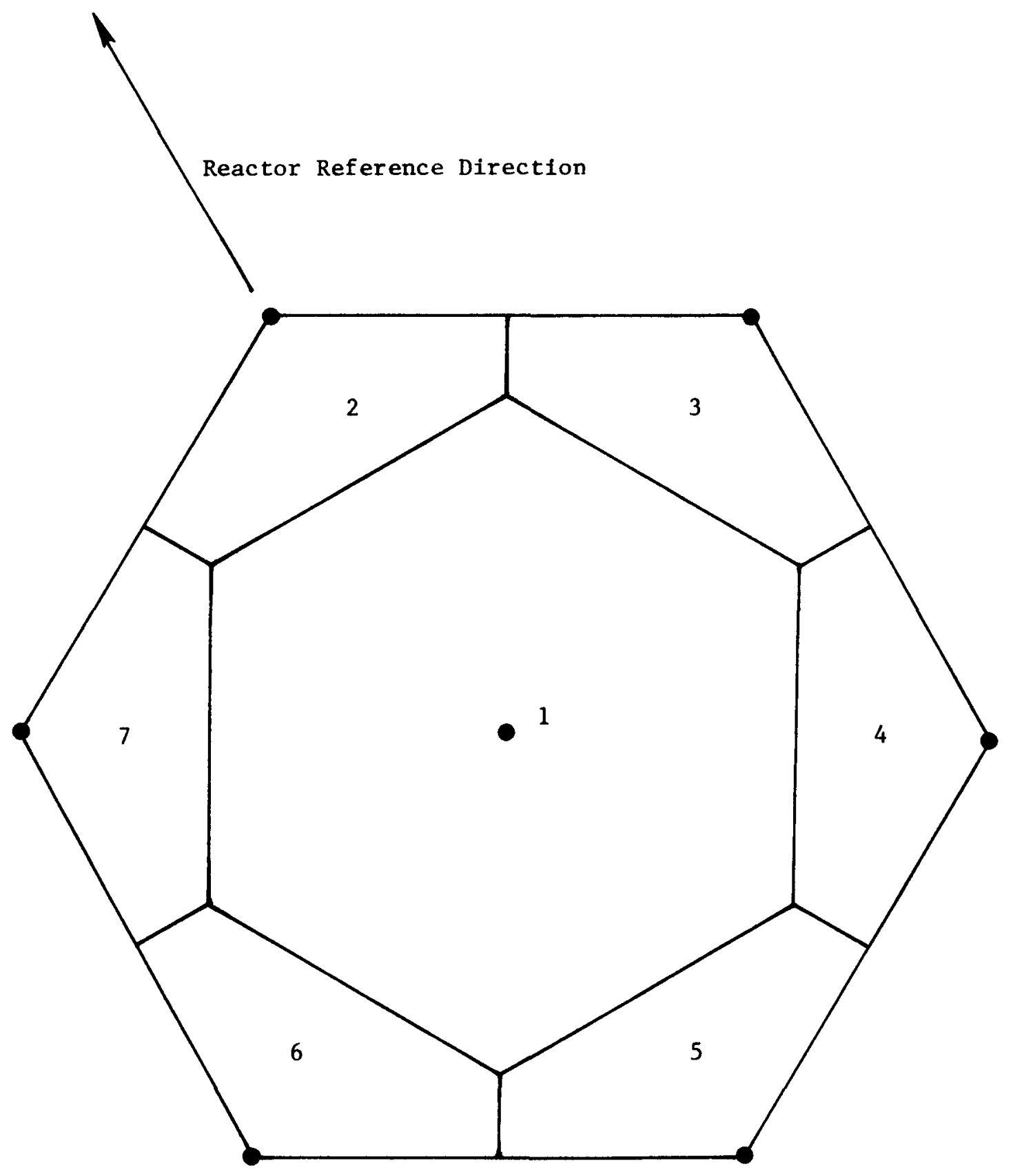

Fig. 5. Loca1 point numbering for GAUGE/SURVEY. 


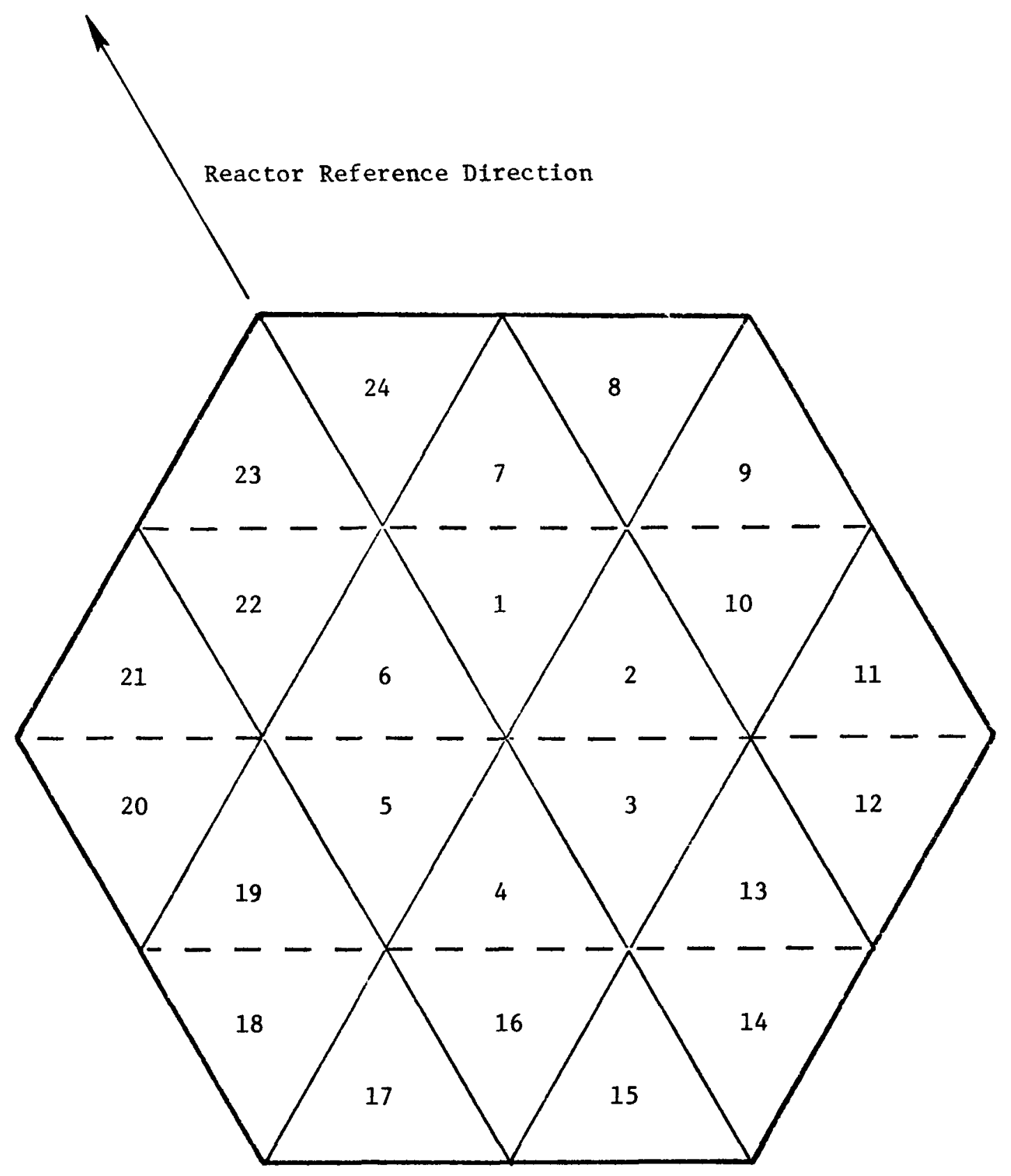

Fig. 6. Local point numbering for BUG/SURVEY. 
The standard survey sequence is to select a single axial plane, i.e., one value of IAXB and one value of IAXP, and to sample all regions, all columns, and all local points on a symmetrical part of that plane. For example, Fig, 2 shows the regions and columns involved in a $180^{\circ}$ symmetry analysis of a typical HTGR.

The usual practice in a SURVEY/TRAFIC analysis is to do a separate run for each of the 8 axial block layers in the core and to subsequently combine the results of the 8 layers with a postprocessing code. More will be said about this postprocessing code in Section 4.3.3. For each axial layer analyzed, the usual practice is to chose the lowermost axial position on the block (e.g., IAXP = 5) for the analysis. This position has the highest temperatures, hence the highest fission product release. TRAFIC assumes that whatever conditions are input to the code for a given radial position are uniformly spread over the entire axial height of a block. Thus, in assuming the worst conditions in a block exist at every axial location, this approach is guaranteed to be conservative. Note that the alternative approaches of using axially averaged block conditions, or perhaps conditions at the center location (e.g., IAXP $=3$ ), are not necessarily more accurate. This is because the fission product release is a highly nonlinear function of temperature, and the release will be dominated by the hotter regions. The only way to ensure accurate results is to analyze several axial positions and do a proper numerical integration.

The local radial points in a column, designated by LPT, have certain assumed spatial positions. These are oriented in accordance with the SURVEY numbering scheme, which is shown in Figs. 5 and 6 . The local positions are points at which the neutron fluxes are calculated in the core physics codes. A hypothetical unit cell element (see sketch on p. 7) is assumed to exist at each of these locations, even though it is obvious, especially for the seven GAUGE points, that no fuel rods or coolant holes actually exist at precisely these locations. The idea behind this model is that conditions at a local point are representative of conditions "somewhere in the vicinity" of the point. 
Results calculated with such a hypothetical unit cell can be volume integrated to obtain average or cumulative results for the total block. The volume integration in TRAFIC is done as follows. First, when performing calculations at any local point, the concentrations and mass fluxes in the unit cell are computed in an "exact" sense. The local mass fluxes are then multiplied by the total coolant hole area in the block. This gives a block-normalized release rate, i.e., the release rate from a complete block if all local points in the block, both radial and axial, were to have the same conditions as the point in question. Then the volume integrated release can be obtained by a weighted sum,

$$
R_{i}=\sum_{j=1}^{n} w_{j} R_{i j},
$$

where

$$
w_{j}=\frac{v_{j}}{v_{\text {TOT }}}
$$

is the volume fraction of local point $j$, and $R_{i f}$ is the block normalized release of locat point $j$ in block $i$. The weight factors are fixed by SURVEY as follows:

For a GAUGE SURVEY

$$
\begin{aligned}
& W_{1}=\frac{1}{2} \quad(\text { the centra1 point) } \\
& W_{2}, \ldots, W_{7}=1 / 12 \text { (the peripheral points). }
\end{aligned}
$$

These are the same factors used in GAUGE for the power normalization.

For a BUGTRI SURVEY

$$
\mathrm{w}_{1}, \ldots, \mathrm{w}_{24}=1 / 24 \text {. }
$$

Al1 triangular regions have the same area. 


\subsubsection{TIME HISTORY IN SURVEY AND TRAFIC}

The time history in SURVEY and TRAFIC is subdivided into a sequence of time steps in a rather peculiar way, the purpose of which is to ensure that time-dependent rate processes such as fission product release are modeled in a conservative manner. This section explains the way in which the timedependent input data are defined and communicated between SURVEY and TRAFIC. When preparing input for a stand-alone analysis, a user should use a similar technique.

GAUGE output, and hence the power data input to SURVEY, is provided at a series of time points which shall herein be termed "tape times". Using these tape-time powers, along with thermal properties calculated at these same times, SURVEY performs a thermal analysis and calculates temperatures for the coolant, the graphite, and the fuel. Thus, temperatures are computed only at the discrete tape times. These temperatures must then be used to calculate several history-dependent phenomena such as kernel migrations, particle failures, fission product release, and stresses. For these purposes it is necessary to deduce from the discrete temperature values a continuous operating history. A physically reasonable approximation would be to let the temperatures vary linearly between the tape time points. However, all of the history-dependent models in SURVEY, including TRAFIC, require that the temperatures be held constant during each calculational step. Therefore, it is necessary to choose an equivalent step-wise function.

The technique used in SURVEY to define the stepwise temperature variation is to subdivide each time interval between successive tape times into two half intervals. The temperature during each half interval is assumed to be constant, equal to the temperature at the adjacent tape time. This scheme, and the reason it is conservative, is illustrated on the next page. 


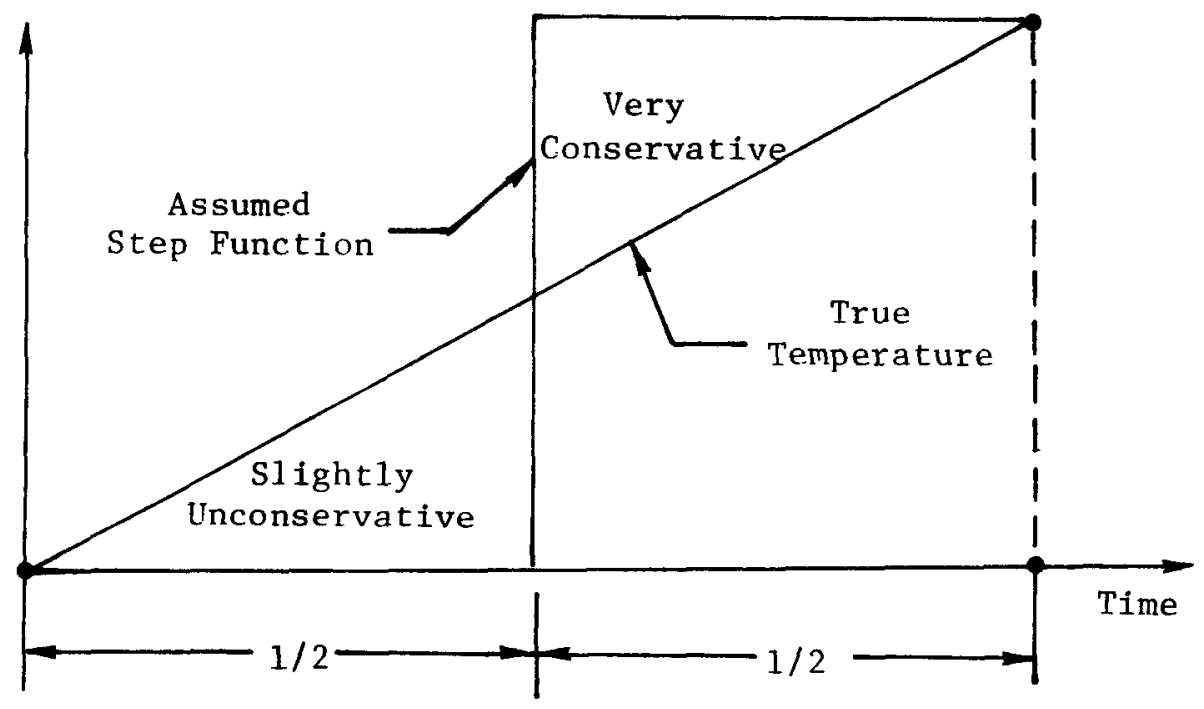

This results in a conservative analysis because the rate processes involved (which are invariably detrimental) are nonlinear with temperature, and they occur at a disproportionately faster rate at the higher temperature. The integrated response over the assumed stepwise temperature history is always greater than the integrated response for a piecewise linear temperature history.

This method of subdividing intervals is awkward because it means that a modified sequence of time steps and time points must be used in the analysis. A SURVEY or TRAFIC time step is defined as the time interval over which temperature is assumed to be constant, i.e., the interval between successive "mid-time" points. Thus, the fission product release parameters computed by TRAFIC are evaluated only at the mid times, and these times do not correspond to the tape times at which the powers and temperatures were originally determined.

In view of the awkward situation, one might be tempted to use a simpler approach in which the time intervals were left alone but the temperatures were averaged during the interval. In general, this gives unconservative results because the integrated response due to the average temperature is less than the integrated response due to a linearly varying temperature. 
The time step halving procedure described above becomes inapplicable when the tape time interval includes a reactor shutdown. This is because GAUGE calculates the operating conditions at full power on either side of the shutdown, so a uniform application of the time step halving procedure would not account for the period of zero power and reduced temperatures. Therefore, a special rule is applied at the beginning and the end of each power period. A time step at the beginning of a power period begins at the first tape time in the period and steps forward to the next mid-time. A time step at the end of a power period begins at the mid-time and steps forward to the last tape time in the period. The complete time step transformation for a typical SURVEY/TRAFIC operating history, including a shutdown, is shown in Fig. 7.

Owing to the modified history of time steps, some of the variables computed by SURVEY at the tape time points must be adjusted before they can be used by TRAFIC. The temperatures, of course, are defined at the tape time points, and they are assumed to be constant throughout the TRAFIC time step intervals. The same can be said about any other variable, such as a heat flux or a coolant flow, that can be considered as existing unchanged over a period of time. However, certain other variables must be defined at specific points in time, because it is their difference over an interval that affects the TRAFIC solution. Variables of this type include accumulated fissions, burnup, and particle failure fractions. These variables must be translated from the tape time values computed by SURVEY to the mid-time values needed by TRAFIC. The procedure for doing this differs for each of the three variables mentioned above, and it will now be explained individually. 
Fig. 7 Typical SURVEY/TRAFIC Operating History

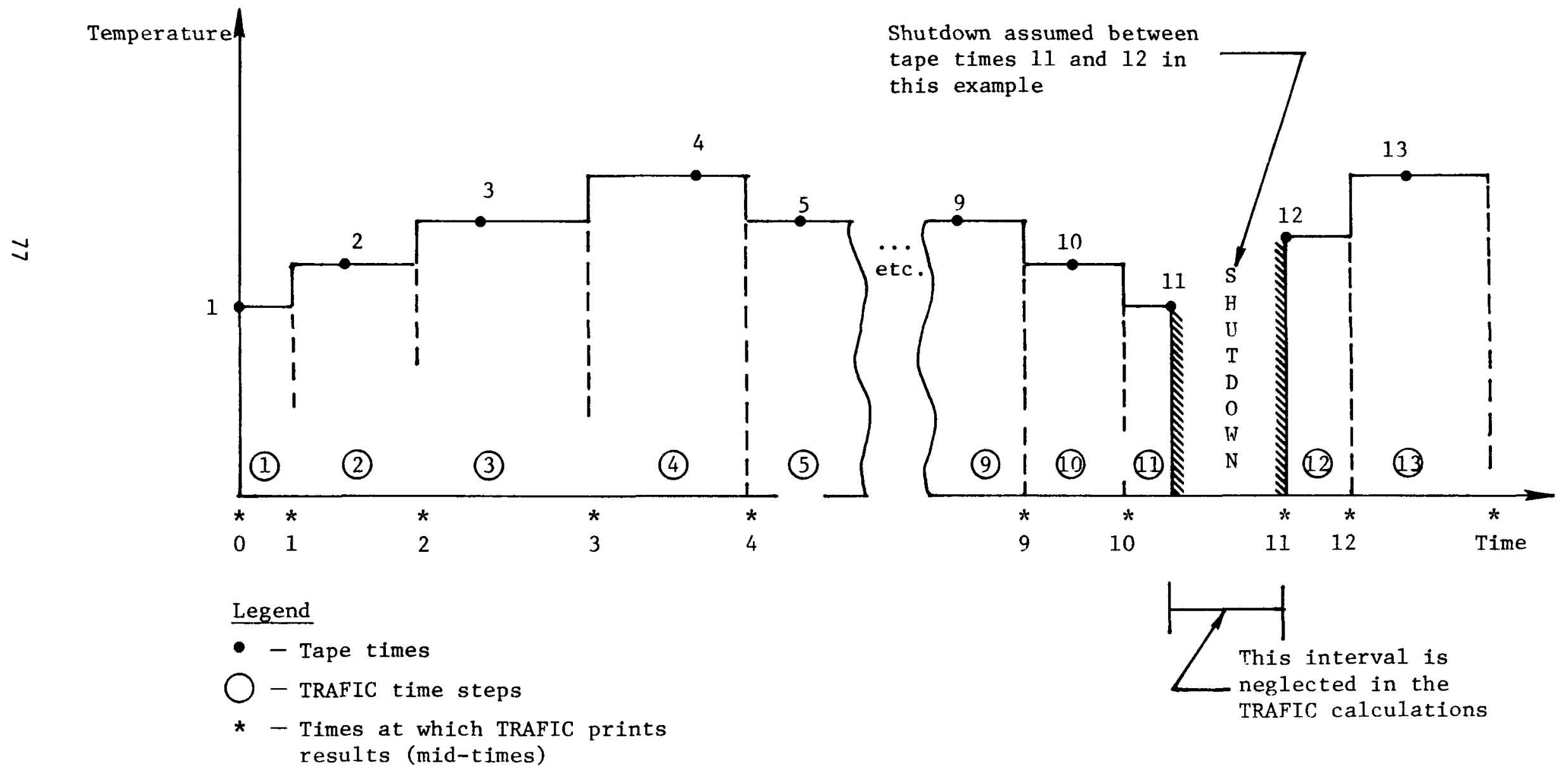




\section{Accumulated Fissions}

The input data required by TRAFIC are the accumulated fissions at the end of each TRAFIC time step. These are the mid-times for a typical SURVEY time step, and they are the tape times for the last time step in each power period (e.g., year). The accumulated fissions are translated internally by the SURVEY code, and they are written on the THERM output tape in the form required by TRAFIC. Users of the SURVEY/TRAFIC combination need not be concerned with the time step conversion. Users of the stand-alone TRAFIC will have to carefully lay out their time steps and be sure that the fissions are being properly defined.

\section{Burnup}

The input data required by TRAFIC are the values of burnup (FIMA) at the tape time points. These are converted by interpolation within the TRAFIC code to values at the start and end of the TRAFIC time steps.

\section{Failure Fractions}

The input data required by TRAFIC are the failure fractions at the tape time points. These are converted within TRAFIC to the failure fractions at the start and end of each TRAFIC time step. A second conversion is made within the COPAR phase 2 solution, in which the point values of failure fraction are used to define an incremented fallure fraction at the start of each TRAFIC time step.

All other variables that are input as functions of time are specified at the tape time points and assumed to be constant throughout each TRAFIC time step. 


\subsubsection{EQUILIBRIUM CORE SIMULATION}

The usual mode of calculation in SURVEY (hence TRAFIC) is to follow a core burnup study beginning at the first, all-fresh fuel load of a reactor. This is called the start-up mode. The burnup study usually proceeds for a sufficient number of years that near the end of the study the core is close to being in a state of equilibrium. Equilibrium is defined as that repetitive state where every reload in a given segment location is "typical" in the sense that metal loadings, powers, and temperatures follow the same history. Furthermore, similar segment locations (e.g., B, C, D) are indistinguishable in a shifted time frame.

In some applications of TRAFIC, such as computing the cumulative metal plateout over the 40-year lifetime of a plant, it is desirable to determine the fission product release rate from an equilibrium core. The results can then be extrapolated for any period. Unfortunately, the core depletion codes do not permit a direct determination of the equilibrium cycle, so one must begin with a startup analysis and approach equilibrium in an approximate manner. This section describes how this is done and how TRAFIC results for a simulated equilibrium core are computed.

The usual burnup period for a GAUGE startup study is seven years for a core having four segments refueled annually. An example of such a burnup is shown in Fig. 3, p. 67, Considering the fact that the first four reload segments contain fuel that is not typical of equilibrium, it is clear that a seven-year burnup has not, in truth, reached equilibrium. Nevertheless, experience has shown that the results do not change much after seven years, so the last four years of the seven-year burnup may be regarded as typical. In general, the procedure used in a SURVEY analysis is to perform a startup calculation and to assume that the last NSEG ( $\equiv$ number of segments) years are typical of an equilibrium core. 
For an equilibrium core study it is desired to follow the history of a typical fuel load in each of the reload segments. In the last NSEG years of a burnup study, only one of the segments will see a full-residence burnup in that period. The others will be reloaded at some time in the period. But, if these segments really were in equilibrium, then the missing years at the end of the last reload would have the same power history as the same number of years before the last reload. Thus, it is assumed that the unknown power history beyond the end of the burnup study can be simulated by translating the supposedly similar years forward in time, as shown below.

\section{Equilibrium Core Simulation}

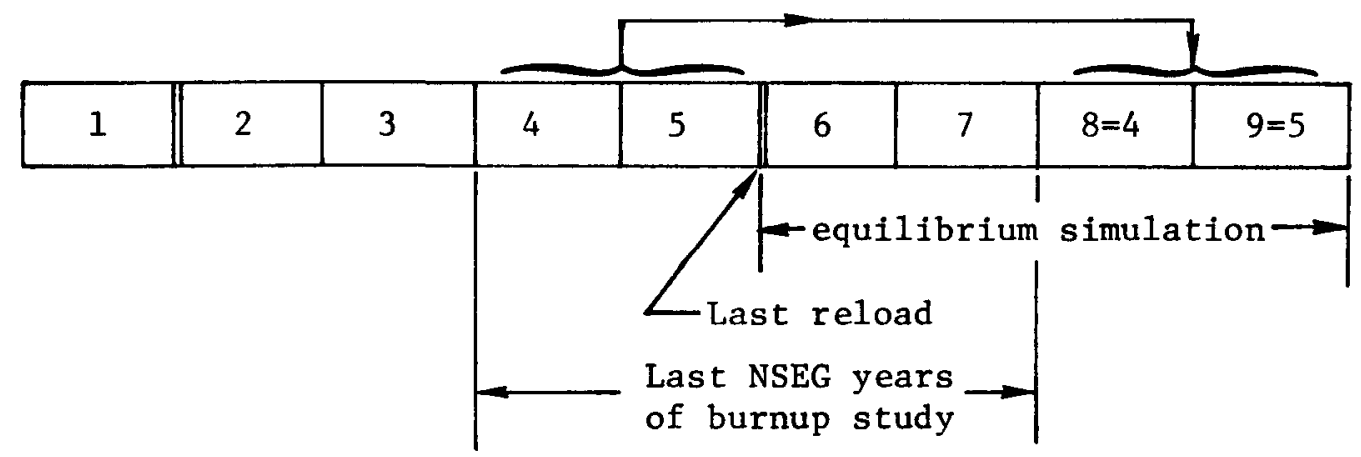

There are two distinct ways in which TRAFIC can be used to perform an equilibrium core simulation. The first is to let SURVEY do the power translation so as to provide TRAFIC with simulated equilibrium core input data. The second is to operate both SURVEY and TRAFIC in startup mode, then let TRAFIC do an analogous translation of its output data. The results with these approaches could be substantially different, and it is worth discussing the approaches in more depth to explain why.

The first method, to let SURVEY do the equilibrium simulation, provides the most accurate and consistent results. The temperatures, burnups, and particle failure fractions are all calculated in SURVEY by history-dependent models involving various rate processes. In the SURVEY equilibrium simulation the powers, the neutron fluxes, and the incremental FIMA's are translated in time. All other time-dependent variables are derived from these, and they are evaluated according to physical laws that control them. Parameters such 
as irradiation strains, thermal conductivities, gap width, and kernel migration distances, are all history-dependent, and they respond as continuous functions of time. When these data are input to TRAFIC, the fission product release is also calculated consistently using the appropriate history-dependent model.s.

In the second method the SURVEY and TRAFIC analyses are both performed in the startup mode. When the startup study is completed, the fission product release rates are translated in time to simulate an equilibrium core. An example of the way this is done is shown schematically below.

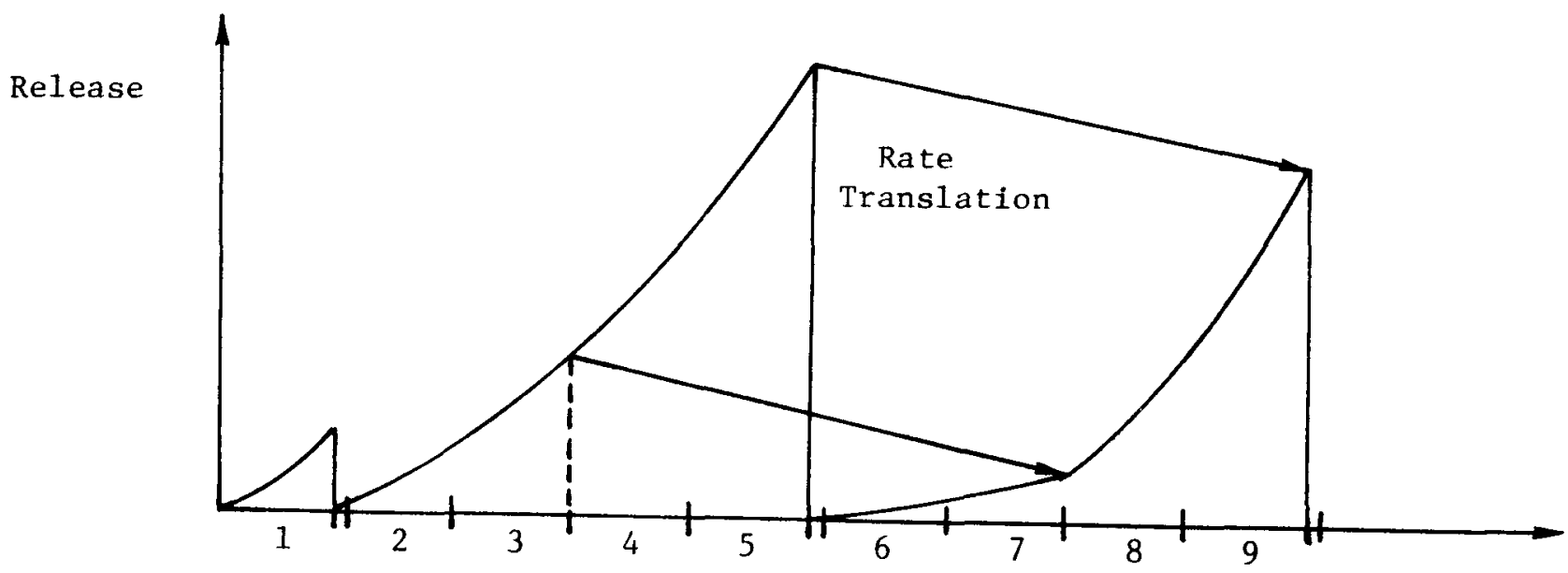

Note that the calculated release rates are still discontinuous, but in truth they should be continuous. For example, years 2 and 3 may have large particle failure fractions, whereas years 6 and 7 may not. Thus, one must use this method with caution. 
Considering the problem outlined above, a user may wonder what benefit there could be in simulating equilibrium by this approximate procedure. The answer is that a user frequently wants the startup results in any case. If the translation discontinuity should fortuitously be small, then an equilibrium simulation can also be obtained free of charge. The TRAFIC output in a startup analysis provides both the startup results and the simulated equilibrium results on a yearly basis, printed one above the other on the same page*. It is a simple matter for a user to check the translation discontinuity. If it is too large, he may elect to rerun the case using the first approach, i.e., beginning with a SURVEY equilibrium run.

\footnotetext{
* Note that the simulated equilibrium results are always given in a startup analysis, and no action on the part of the user (other than to request summary printout) is required to obtain them.
} 


\subsection{TRAFIC FLOW CHART}

The preceding sections have explained the details of the spatial survey and the calculational method of the TRAFIC code. The present section summarizes all of this by means of an abbreviated flow chart showing the logical sequence of the calculations. 


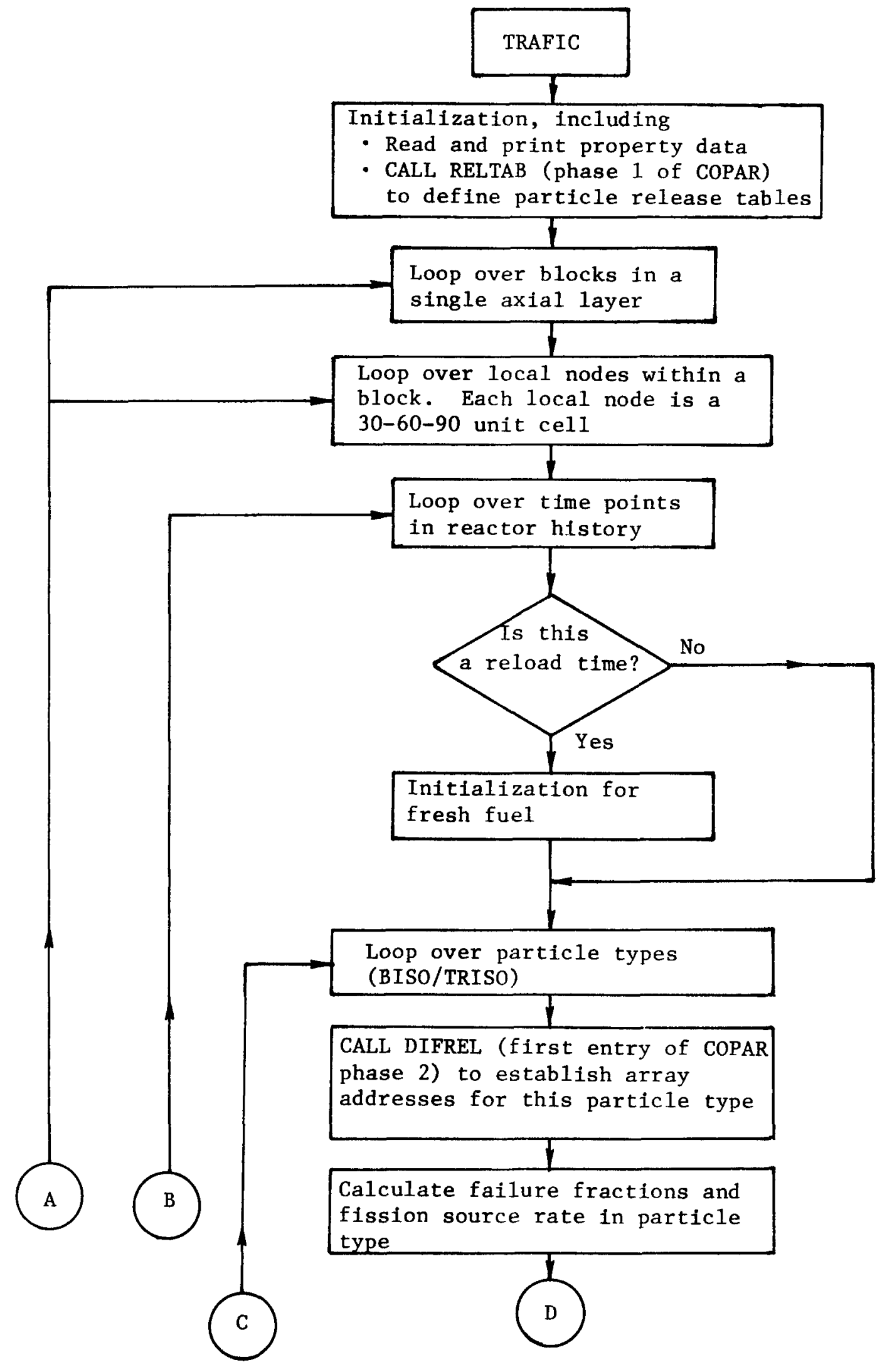




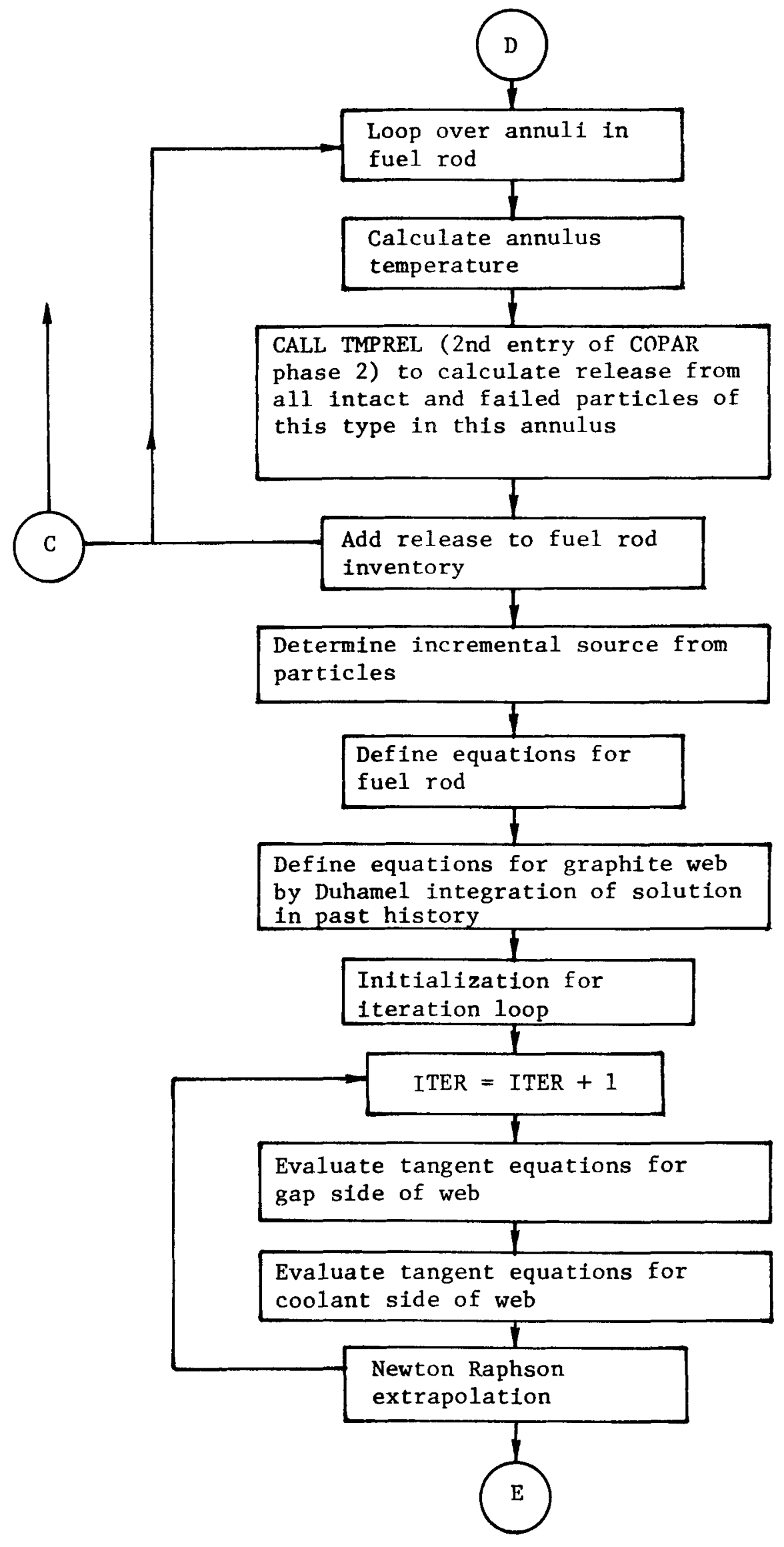




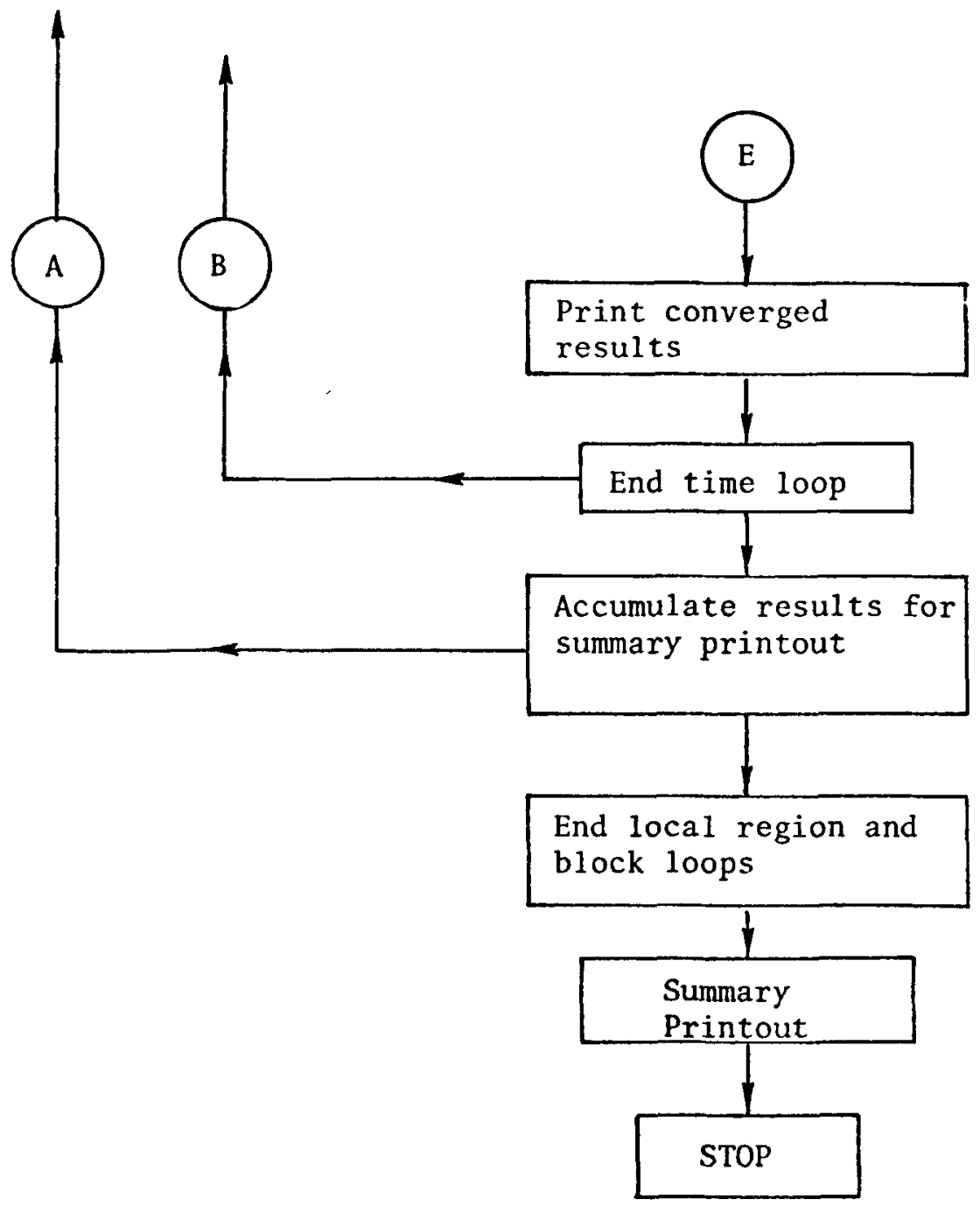




\section{INPUT INSTRUCTIONS}

This chapter contains input instructions for the TRAFIC code. Section 4.1 explains the deck setup for a TRAFIC run. Section 4.2 contains a summary of the card input in card image format. For a user who is already familiar with the program, these summary descriptions will be self explanatory. In some cases references are made to other parts of the report for a more detailed explanation. Section 4.3 contains some further information on a few items that may not be obvious in the card image summaries.

The latest version of TRAFIC, the one documented in this report, is called TRAFIC*VERIO. This version differs from some earlier ones in that it includes a cleaned-up version of the COPAR code (Ref. 2), and it employs the most recently developed method for solving the nonlinear interface and boundary equations (described in Section 2.8). The version designations of TRAFIC (i.e., VERIO) correspond to similar designations for a compatible version of the SURVEY code. From time to time it becomes necessary to update the SURVEY code, and these updates are frequently accompanied by a change in format of the output data tapes. Whenever this happens a corresponding compatible version of TRAFIC is also created. In most cases this does not involve changing either the method of calculation in TRAFIC or the contents of the card input. If changes to these items do occur, they will be documented in an internal memo. 


\section{I TRAFIC DECK SETUP}

4.1.1 BASIC DECK STRUCTURE

The following is the basic deck structure for a typical TRAFIC*VERIo run.

\begin{tabular}{|c|c|}
\hline DASG , A & TRAFIC*VERIO \\
\hline$\nabla C O P Y$ & TRAFIC*VERIO ., I \\
\hline DFREE & TRAFIC*VERIO. \\
\hline DPRT, T & \\
\hline DASG & $20, \mathrm{D} / 10000 / / 150000$ \\
\hline$\nabla A S G, A$ & DIFFEQ *DATA 3 \\
\hline DUSE & $21 .$, DIFFEQ*DATA3. \\
\hline$\nabla A S G$ & $22, \mathrm{D} / 10000 / / 150000$ \\
\hline
\end{tabular}

Tptional tape and/or file assignments for the following:

a) COPAR phase 1 tables

b) Therma1 and performance data

c) Output for the RANDI Code.

See Section 4.1.2 for details.

DXQT TRAFICMAP

$\left[\begin{array}{l}\text { TRAFIC*VERIO data cards. } \\ \text { See Section } 4.2 \text {. }\end{array}\right.$

$\nabla P M D, R E L$

Note that units 20,21 , and 22 must always be assigned as indicated. Unit 21 , which is equated to a catalogued file named DIFFEQ*DATA3, contains the phase 1 parameterized solution for the equivalent graphite slab model in TRAFIC. Unit 20 is a temporary word-addressable file used to hold the DIFFEQ*DATA3 data in a form more convenient for ready access. Unit 22 is a temporary word-addressable file used for data sorting prior to printing the end-of-run summary tables.

In addition to the above, which are always required, there may be a number of file assignments that depend on user-controlled options. These are described in the next section, 4.1.2. 
The TRAFIC data cards indicated above are summarized in Section 4.2. Note that these include as a subset the COPAR input data read by TABLE/REL, the program module used to generate the phase 1 COPAR tables. The logic employed by TRAFIC to read the card input is somewhat complicated. It contains a number of nested DO 1oops, and it depends on a number of options. A brief description of this input logic is given in Section 4.1.3.

\subsubsection{OPTIONAL FILE ASSIGNMENTS}

Optional file assignments may be required for
a) COPAR phase 1 tables,
b) Thermal and performance data, and
c) Output for the RANDI code.

These three classifications are considered separately below.

\section{COPAR Phase 1 Tables}

An option called IRFT on TRAFIC Card C2 (TABLE/REL Card 2) is used to control the calculation and the input or output of the COPAR phase 1 tables. The meaning of this option is summarized below.

IRFT $>0$ Calculate tables and write them on logical unit IRFT for subsequent retrieval (when IRFT $<0$ in a later run).

IRFT $=0$ Calculate tables but do not write them on a file.

IRFT < 0 Do not calculate tables. Instead, read them from logical unit |IRFT|. For this option to work, a previous run with IRFT >0 and the same file assignment for $\mid$ IRFT $\mid$ must have been made.

Each of these options will cause a set of tables for the given particle type to be stored in a COMMON block. From these core storage locations the tables are later employed in the phase 2 superposition analysis. 
Whenever IRFT $\neq 0$, a file must be assigned either for writing the data or reading the data. As explained in Ref. 2, this file may be either a temporary file or a catalogued file. However, a temporary file has no advantage in a TRAFIC application, since IRFT $=0$ would achieve the same results. Therefore, a TRAFIC user should assign this unit only as a catalogued file. The purpose of this file is to avoid repetition of the phase 1 COPAR calculations when successive TRAFIC runs are done with the same particle types, the same diffusing species, and the same range of temperatues. The format of the file assignment is typically

DASG , AX YOUR*COPARFILE//WKEY

VUSE $\quad$ n. , YOUR*COPARFILE.

where $\quad \mathrm{n}=|\mathrm{IRFT}|$.

If more than one distinct value of $\mathrm{n}$ is used (i.e., different IRFT options are specified for different particle types), then an additional file assignment is required for each additional $n$.

\section{Thermal and Performance Data}

If ICARD $=0$ on Card 1, al1 thermal and performance data are on cards, and no files need be assigned.

If ICARD $=1$ or 2 , the input to TRAFIC is from the two SURVEY output tapes. These must be assigned as

$$
\begin{aligned}
& \text { Unit } 13 \text { - THERM tape, and } \\
& \text { Unit } 14 \text { - PERFOR tape. }
\end{aligned}
$$

Typical tape assignments take the form

$\nabla A S G, T \quad n, U,---$

where $\mathrm{n}$ is the unit number (13 or 14 in this case), and ---- is the four digit tape reel number. 
If $\operatorname{ICARD}=2$, then the SURVEY input to TRAFIC will be reproduced, condensed if possible, and written on a catalogued file for future use. Then, in addition to the above two tapes, a catalogued file must be assigned as

Unit 10 - Write file for SURVEY data.

The form of the assign statement is usually

DASG, AX YOUR*SURVEYFILE//WKEY

VUSE $10 .$, YOUR*SURVEYFILE.

The $\mathrm{x}$ option is for exclusive use, and the WKEY is an optional write key.

If $\operatorname{ICARD}=3$, then TRAFIC reads al1 its thermal and performance data from the file that was previously written as unit 10. This time, however, the file is labeled as unit 13. Thus we have

$$
\text { Unit } 13 \text { - Read file for SURVEY data, }
$$

and the form of the assign statement is usually

DASG,A YOUR*SURVEYFILE

DUSE 13., YOUR*SURVEYFILE.

The $\mathrm{x}$ option and the write key are unnecessary in this instance. 


\section{Output for the RANDI Code}

If certain combinations of options are appropriately set by the user (see Section 4.3.2) then the TRAFIC code will calculate release constants for input to the RANDI code (Ref. 11). These can be written on a catalogued file assigned as unit 24. If this file is to be written, then the form of the assign statement is usually

$\nabla A S G$, AX $\quad$ YOUR*RANDIFILE//WKEY

VUSE 24 , YOUR*RANDIFILE.

Note that successive TRAFIC runs for different axial layers write into the same file at different starting locations. See Section 4.3 .3 for instructions as to how this data file must be processed prior to RANDI input.

In summary, a complete list of all possible optional file assignments, together with the options that control them, is given below. Catalogued file names, of course, are arbitrarily chosen by the user. The names used here are only examples.

\section{Optional File Assignments}

\section{Assignment}

DASG, AX YOUR*COPARFILE//WKEY

VUSE n., YOUR*COPARFILE.

VAST, T 13, U, - - -

VASG, T $14, \mathrm{U},----$

DASG, AX YOUR*SURVEYFILE//WKEY

VUSE 10., YOUR*SURVEYFILE.

DASG,A YOUR*SURVEYFILE

DUSE 13 ., YOUR*SURVEYFILE.

DASG, AX YOUR*RANDIFILE//WKEY

DUSE 24., YOUR*RANDIFILE.

\section{Option}

IRFT $\neq 0$

(n. $=\mid$ IRFT $\mid$ )

TCARD $=I$ or 2

ICARD $=2$ only

ICARD $=3$ on $1 \mathrm{y}$

RANDI output file to be written. See Section 4.3.2. 


\subsubsection{TRAFIC INPUT LOGIC}

The order in which theTRAFIC *VERIO data cards are read is described below.

Cards 1 and 2

$\left.\begin{array}{l}\text { Card CO } \\ \text { DO I }=1 \text {,NPART (from Card CO) } \\ \text { Cards } \mathrm{Cl}-\mathrm{Cl2}\end{array}\right\} \begin{aligned} & \text { COPAR } \\ & \text { Input }\end{aligned}$

Cards 3-26

DO $K=1$, NZCALC (from Card 13)

DO $\mathrm{L}=1$, (NREG or NRCALC) (see Card 21)

Card 27

DO $M=1, \mathrm{NCOL}$ ( NCOL $=1$, if NRCALC > 0 ; or

$=$ number of colums in region $\mathrm{L}$, if NRCALC $=0$ )

DO N=1, NLPT (NLPT $=1$, if NPCAL on Card $21=-1$; or

$=$ number of local points, if $\mathrm{NPCAL}=0$; or

$=$ NPCAL, if NPCAL >0)

Card 28

DO I=1,NPART+1 (from Card 12)

Card 29

DO I=1,NPART (from Card 12)

Card 30

Cards 31-37

DO I=1, NPART (from Card 12)

Card 38

DO $I=1$, NPART (from Card 12)

Card 39

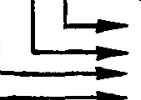


4.2 CARD INPUT SUMMARY

A summary of the TRAFIC card input (including the COPAR input) is given on the following pages. 


\begin{tabular}{|c|c|c|}
\hline Word & 1 & \\
\hline Column & $1-6$ & \\
\hline Format & I6 & \\
\hline $\begin{array}{c}\text { Card } \\
1\end{array}$ & $\begin{array}{l}\text { Type of } \\
\text { input/output }\end{array}$ & $\begin{aligned} \text { ICARD } & =0, \text { card input only. } \\
& =1 \text {, input from SURVEY thermal and performance tapes. } \\
& =2 \text {, input from SURVEY tapes, write on output file. } \\
& =3 \text {, input from file generated when ICARD }=2 . \\
& \text { See pp. } 90-91 \text { for file designations. }\end{aligned}$ \\
\hline Symbol & ICARD & \\
\hline
\end{tabular}

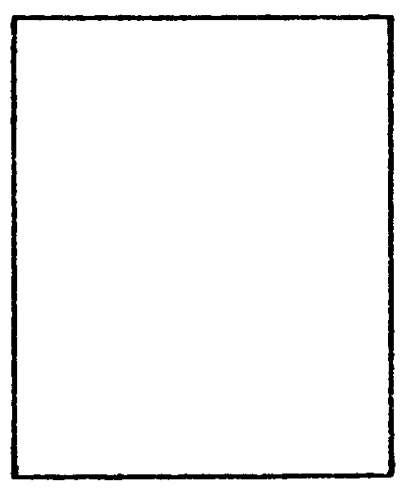

ư

\begin{tabular}{|c|c|}
\hline Word & $1-12$ \\
\hline Column & $1-72$ \\
\hline Format & $12 \mathrm{~A} 6$ \\
\hline $\begin{array}{c}\text { Card } \\
2\end{array}$ & Title. Any alphanumeric data in columns $1-72$. \\
& \\
& \\
\hline Symbo1 & PTITLE \\
\hline
\end{tabular}

Read only if

ICARD $=0$.

If ICARD $\neq 0$,

title will be

read from

SURVEY tape. 


\begin{tabular}{|c|c|c|c|}
\hline Word & 1 & & \\
\hline Colum & $1-6$ & & \\
\hline Format & I6 & & \\
\hline $\begin{array}{l}\text { Card } \\
\text { C0 }\end{array}$ & $\begin{array}{l}\text { Number of } \\
\text { particle types } \\
(\leq 2)\end{array}$ & NOTE : & $\begin{array}{l}\text { For each particle type the table can either be calculated in } \\
\text { this run or read from a catalogued file which was generated } \\
\text { in a previous run. This is controlled by the IRFT option on } \\
\text { Card } 2 \text {. Note also that COPAR has a limit of NPART }=4 \text {, but the } \\
\text { TRAFIC limit of } 2 \text { supercedes this. }\end{array}$ \\
\hline Symbol & NPART & & \\
\hline
\end{tabular}

Cards 1 - 12 are to be repeated in a loop over NPART particle types.

\begin{tabular}{|c|c|}
\hline Word & $1-14$ \\
\hline Column & $1-80$ \\
\hline Format & $13 \mathrm{~A} 6, \mathrm{~A} 2$ \\
\hline \multirow{3}{*}{ Card $\mathrm{Cl}$} & $\begin{array}{l}\text { Any alphanumeric title in column } 1-80 \\
\text { (Usually pertaining to the present particle type) }\end{array}$ \\
\hline Symbol & TITLE \\
\hline
\end{tabular}

\section{Always}

required for

each particle

type.

\begin{tabular}{|c|c|c|c|c|c|}
\hline Word & $\overline{1}$ & 2 & $\overline{3}$ & 4 & Continued below \\
\hline Column & $1-6$ & $7-12$ & $13-18$ & $19-24$ & \\
\hline Format & I6 & $\overline{\mathrm{I} 6}$ & I6 & $\overline{I 6}$ & \\
\hline $\begin{array}{c}\text { Card } \\
\text { C2 }\end{array}$ & $\begin{array}{l}\text { Number of } \\
\text { shell regions } \\
\text { in model } \\
(\max .8)\end{array}$ & $\begin{array}{l}\text { Region index } \\
\text { of outermost } \\
\text { region in } \\
\text { fuel kernel }\end{array}$ & $\begin{array}{l}\text { Number of } \\
\text { time points } \\
\text { per decade } \\
\text { in long table } \\
\text { (See p. 115) }\end{array}$ & $\begin{array}{l}\text { Boundary } \\
\text { condition } \\
\text { option } \\
1,2 \text {, or } 3 \\
\quad \rightarrow\end{array}$ & 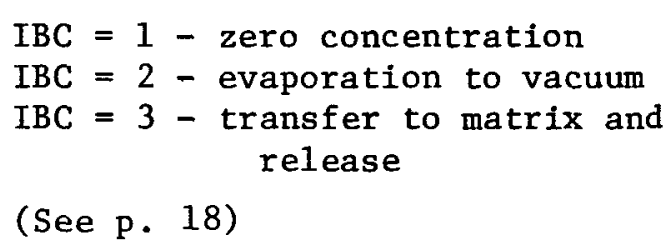 \\
\hline Symbol & NREG & NKERN & NTC & IBC & \\
\hline
\end{tabular}

Always
required for
each particle
type.

COPAR Input 


\begin{tabular}{|c|c|c|c|c|c|}
\hline Word & 5 & 6 & 7 & 8 & \\
\hline Column & $25-30$ & $31-36$ & $37-42$ & $43-48$ & \\
\hline Format & I6 & 16 & 16 & 16 & \\
\hline $\begin{array}{l}\text { Card C2 } \\
\text { Cont'd }\end{array}$ & $\begin{array}{l}\text { Intact/failed } \\
\text { state release } \\
\text { option - } 0,1 \text {, } \\
2,3,4 \\
\text { See p. } 115 .\end{array}$ & $\begin{array}{l}\text { Release func- } \\
\text { tion table } \\
\text { index } \\
\text { See p. } 89 .\end{array}$ & $\begin{array}{l}\text { Number of } \rho \\
\text { time points } \\
\text { in short } \\
\text { tables } \\
\text { See p. } 115 .\end{array}$ & $\begin{array}{l}\text { Print option } \\
\text { for long } \\
\text { tables }- \\
0=\text { no } \\
1=\text { yes }\end{array}$ & \\
\hline Symbo 1 & IFSR & IRFT & NTRHO & IPRINT & \\
\hline
\end{tabular}

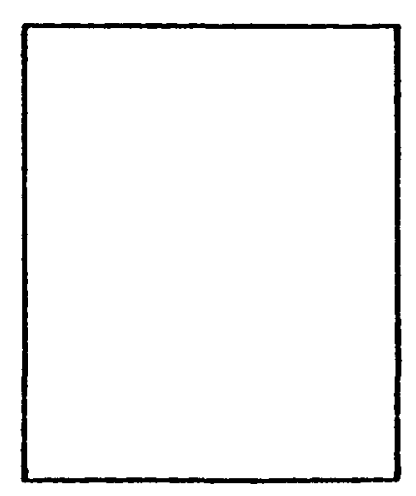

SKIP CARDS C3-C12 IF IRFT<0.

SKIP CARDS C3-C11 IF IFSR=0 and IRFT $\geq 0$.

\begin{tabular}{|c|c|c|c|c|c|}
\hline Word & 1 & 2 & 3 & 4 & \\
\hline Column & $1-12$ & $13-24$ & $25-36$ & $37-48$ & \\
\hline Format & $12 \mathrm{X}$ & E12.6 & E12.6 & E12.6 & \\
\hline $\begin{array}{l}\text { Card } \\
\text { C3 }\end{array}$ & Not used. & $\begin{array}{l}\text { Max. time } \\
\text { since birth } \\
\text { for release } \\
\text { evaluation } \\
\text { (days) }\end{array}$ & $\begin{array}{l}\text { Leng th of } \\
\text { smallest } \\
\text { time step in } \\
\text { histories to } \\
\text { be analyzed } \\
\text { (days) }\end{array}$ & $\begin{array}{l}\text { Length of } \\
\text { nominal time } \\
\text { step in } \\
\text { histories to } \\
\text { be analyzed } \\
\text { (days) }\end{array}$ & $\begin{array}{l}\text { See p. } 116 \text { for further } \\
\text { explanation of TMAXD, TMIND, } \\
\text { TNOMD. }\end{array}$ \\
\hline Symbol & & TMAXD & TMIND & TNOMD & \\
\hline
\end{tabular}

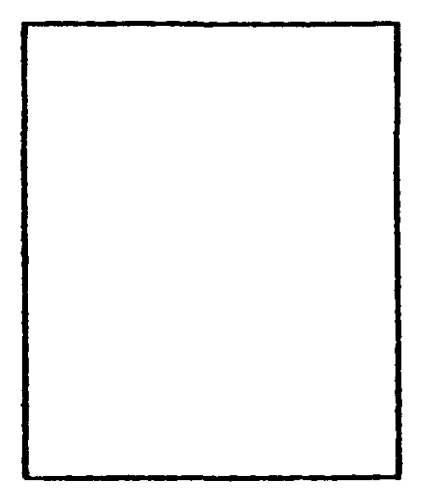

\begin{tabular}{|c|c|c|c|c|}
\hline Word & 1 & 2 & 3 & \\
\hline Column & $1-12$ & $13-24$ & $25-36$ & \\
\hline Format & E12.6 & E12.6 & E12.6 & \\
\hline $\begin{array}{l}\text { Card } \\
\text { C3a }\end{array}$ & $\begin{array}{l}\text { Maximum temp- } \\
\text { erature in } \\
\text { histories to } \\
\text { be analyzed }\end{array}$ & $\begin{array}{l}\text { Minimum temp- } \\
\text { erature in } \\
\text { histories to } \\
\text { be analyzed }\end{array}$ & $\begin{array}{l}\text { Nominal temp- } \\
\text { erature in } \\
\text { histories to } \\
\text { be analyzed }\end{array}$ & $\begin{array}{l}\text { All temperatures in }{ }^{\circ} \mathrm{C} \text {. See p. } 116 \\
\text { for further explanation of } \\
\text { TMAXC, TMINC, TNOMC. }\end{array}$ \\
\hline Symbol & TMAXC & TMINC & TNOMC & \\
\hline
\end{tabular}

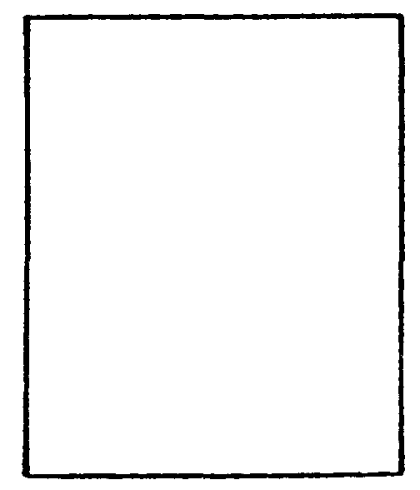




\begin{tabular}{|c|c|c|c|c|c|}
\hline Word & 1 & 2 & 3 & 4 & \\
\hline Column & $1-12$ & $13-24$ & $25-36$ & $37-48$ & \\
\hline Format & E12.6 & E12.6 & $E 12.6$ & $E 12.6$ & \\
\hline $\begin{array}{l}\text { Card } \\
\text { C4 }\end{array}$ & $\begin{array}{l}\text { Fission } \\
\text { product recoil } \\
\text { distance } \\
\quad(\mathrm{cm} .)\end{array}$ & $\begin{array}{l}\text { Effective mass } \\
\text { transfer coef- } \\
\text { ficient. } \\
\text { See Eq. ( } 22) \\
\text { IBC = } 2 \text { only }\end{array}$ & $\begin{array}{l}\text { Release con- } \\
\text { stant from } \\
\text { matrix. } \\
\text { See Eq. (24) } \\
\text { IBC = } 3 \text { only }\end{array}$ & $\begin{array}{l}\text { Volume of } \\
\text { matrix asso- } \\
\text { ciated with } \\
\text { one particle } \\
I B C=3 \text { only }\end{array}$ & \\
\hline Symbol & RDIST & HMASS & RCMAT & VOLMAT & \\
\hline
\end{tabular}

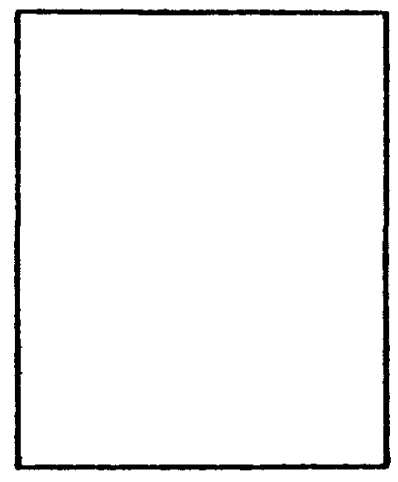

\begin{tabular}{|c|c|c|c|c|c|}
\hline Word & 1 & 2 & & NREG & \\
\hline Column & $1-12$ & $13-24$ & & & \\
\hline Format & E12.6 & E12.6 & & E12.6 & $(6 \mathrm{E} 12,6)$ \\
\hline $\begin{array}{l}\text { Card } \\
\text { C5 }\end{array}$ & $\begin{array}{l}\text { Outer radius } \\
\text { of first } \\
\text { region } \\
\qquad(\mathrm{cm})\end{array}$ & $\begin{array}{l}\text { Outer radius } \\
\text { of second } \\
\text { region } \\
\qquad(\mathrm{cm})\end{array}$ & etc. & $\begin{array}{l}\text { Outer radius of } \\
\text { last region } \\
(\mathrm{cm})\end{array}$ & \\
\hline Symbo1 & $R(1)$ & $\mathrm{R}(2)$ & & $\mathrm{R}$ (NREG) & \\
\hline
\end{tabular}

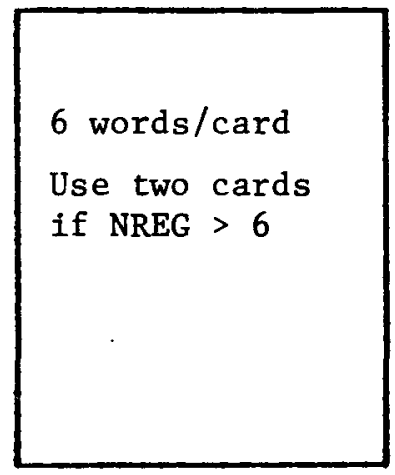

\begin{tabular}{|c|c|c|c|c|c|}
\hline Word & 1 & 2 & & NREG & \\
\hline Column & $1-12$ & $13-24$ & & & \\
\hline Format & E12.6 & E12.6 & $\ldots$ & E12.6 & $(6 \mathrm{E} 12.6)$ \\
\hline $\begin{array}{l}\text { Card } \\
\text { C6 }\end{array}$ & $\begin{array}{l}\text { Fission birth } \\
\text { density in } \\
\text { region } 1 \\
\text { before recoil } \\
\text { (非/volume) }\end{array}$ & $\begin{array}{l}\text { Fission birth } \\
\text { density in } \\
\text { region } 2 \\
\text { before recoil } \\
\text { (\#/volume) }\end{array}$ & etc. & $\begin{array}{l}\text { Fission birth } \\
\text { density in } \\
\text { region NREG } \\
\text { before recoil } \\
\text { (\#/volume) }\end{array}$ & $\begin{array}{l}\text { Note: This is unnormalized } \\
\text { birth density. Program nor- } \\
\text { malizes so that total birth } \\
\text { is 1.0. Units are arbitrary. }\end{array}$ \\
\hline Symbol & $B(1)$ & $B(2)$ & & $\mathrm{BCNREC}$ & \\
\hline
\end{tabular}

6 words/card

Use two cards

if NREG > 6 


\begin{tabular}{|c|c|c|c|c|c|}
\hline Word & 1 & 2 & $\ldots$ & NREG & \\
\hline Column & $1-12$ & $13-24$ & $\ldots$ & & \\
\hline Format & E12.6 & E12.6 & $\ldots$ & E12.6 & \\
\hline $\begin{array}{l}\text { Card } \\
\text { C7 }\end{array}$ & $\begin{array}{l}\text { Partition } \\
\text { coefficient }(\phi) \\
\text { for region } 1\end{array}$ & $\begin{array}{l}\text { Partition } \\
\text { coefficient }(\phi) \\
\text { for region } 2\end{array}$ & etc. & $\begin{array}{l}\text { Partition } \\
\text { coefficient }(\phi) \\
\text { for last } \\
\text { region }\end{array}$ & $\begin{array}{l}\phi \equiv \mathrm{C}_{\mathrm{b}}^{\mathrm{i}} / \mathrm{C}_{\mathrm{a}}^{\mathrm{i}+1} \\
\text { Note: Always input NREG } \\
\text { values. Last (NREG) value } \\
\text { is used only if IBC }=3 \text {. }\end{array}$ \\
\hline Symbol & PHI(1) & PHI(2) & $\ldots$ & PHI (NREG) & \\
\hline
\end{tabular}

6 words/card

Use two cards

if NREG > 6

\begin{tabular}{|c|c|c|c|c|c|}
\hline Word & 1 & 2 & & NREG & \\
\hline Column & $1-12$ & $13-14$ & $\ldots$ & & \\
\hline Format & E12.6 & E12.6 & $\ldots$ & E12.6 & \\
\hline $\begin{array}{l}\text { Card } \\
\text { C8 }\end{array}$ & $\begin{array}{l}D_{\text {o for intact }} \\
\text { state in } \\
\text { region } 1 \\
\left(\mathrm{~cm}^{2} / \mathrm{sec}\right)\end{array}$ & $\begin{array}{l}\text { Do for intact } \\
\text { state in } \\
\text { region } 2 \\
\left(\mathrm{~cm}^{2} / \mathrm{sec}\right)\end{array}$ & etc. & $\begin{array}{l}D_{\text {O for intact }} \\
\text { state in } \\
\text { region NREG } \\
\left(\mathrm{cm}^{2} / \mathrm{sec}\right)\end{array}$ & $\begin{array}{l}\text { Note: } \\
\qquad \mathrm{D}_{\mathrm{I}}=\mathrm{D}_{\mathrm{O}_{\mathrm{I}}} \mathrm{e}^{-\mathrm{Q}_{\mathrm{I}} / \mathrm{RT}} \\
\mathrm{T} \text { has units of }\left[{ }^{\circ} \mathrm{K}\right]\end{array}$ \\
\hline Symbol & $\operatorname{DZI}(1)$ & $\mathrm{DZI}(2)$ & & DZI (NREG) & \\
\hline
\end{tabular}

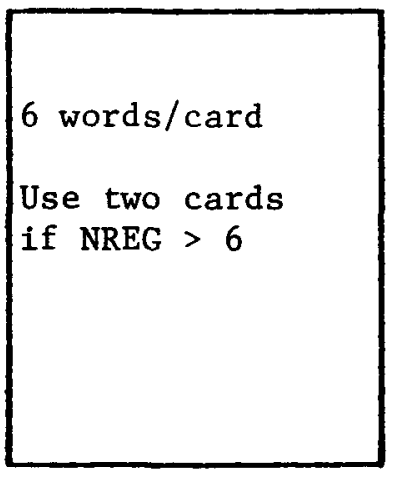

\begin{tabular}{|c|c|c|c|c|c|}
\hline Word & 1 & 2 & & NREG & \\
\hline Column & $1-12$ & 13-24 & & & \\
\hline Format & E12.6 & E12.6 & $\ldots$ & E12.6 & \\
\hline $\begin{array}{l}\text { Card } \\
\text { C9 }\end{array}$ & $\begin{array}{l}\text { Activation } \\
\text { energy for } \\
\text { intact state in } \\
\text { region } 1\end{array}$ & $\begin{array}{l}\text { Activation } \\
\text { energy for } \\
\text { intact state in } \\
\text { region } 2\end{array}$ & etc. & $\begin{array}{l}\text { Activation } \\
\text { energy for } \\
\text { intact state in } \\
\text { region NREG }\end{array}$ & $\begin{array}{l}\text { Note: Q (activation energy) } \\
\text { has units of } \\
\text { [calories/gram mole] }\end{array}$ \\
\hline Symbol & OI(1) & $Q I(2)$ & & QI (NREG) & \\
\hline
\end{tabular}

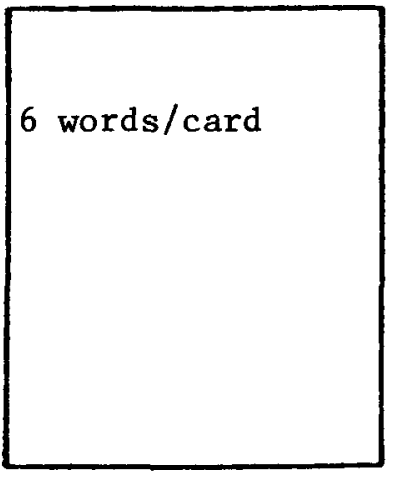




\begin{tabular}{|c|c|c|c|c|c|}
\hline Word & 1 & 2 & $\ldots$ & NREG & \\
\hline Column & $1-12$ & $13-24$ & $\ldots$ & & \\
\hline Format & $E 12.6$ & E12.6 & $\ldots$ & E12.6 & \\
\hline $\begin{array}{l}\text { Card } \\
\text { C10 }\end{array}$ & \multicolumn{2}{|c|}{$\begin{array}{l}\text { Failed state } D_{0} \text { for each region. } \\
\text { Card } c 8 .\left(\mathrm{cm}^{2} / \mathrm{sec}\right)\end{array}$} & \multicolumn{2}{|c|}{ Analogous to } & $\begin{array}{l}\text { Note: } \\
\qquad D_{F}=D_{o_{F}} e^{-Q_{F} / R T}\end{array}$ \\
\hline Symbol & DZF (1) & $\operatorname{DZF}(2)$ & $\cdots$ & DZF (NREG) & \\
\hline
\end{tabular}

6 words/card

Use 2 cards if

NREG > 6

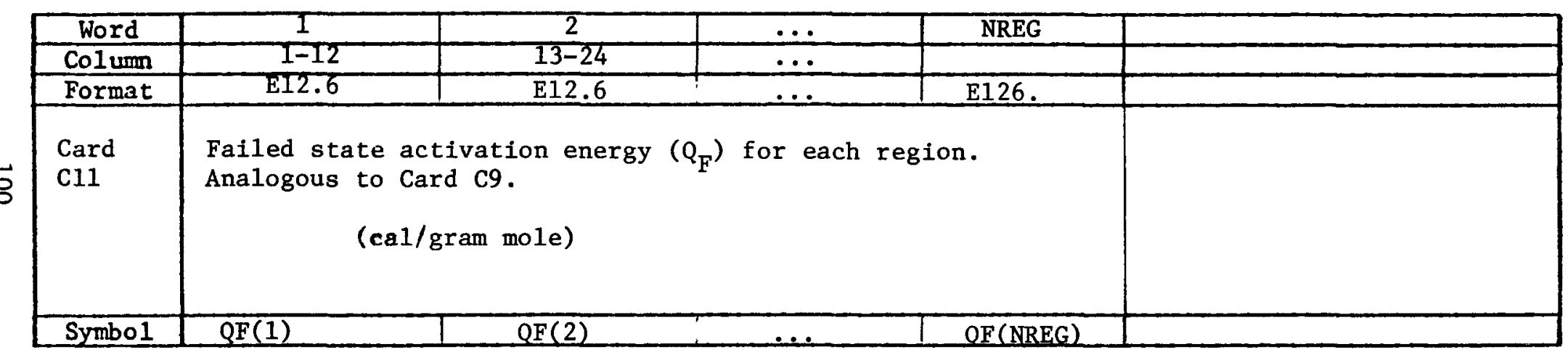

6 words/card

Use 2 cards if NREG > 6

\begin{tabular}{|c|c|c|c|c|}
\hline Word & 1 & 2 & 3 & \\
\hline Column & $1-12$ & $13-24$ & $25-36$ & \\
\hline Format & E12.6 & E12.6 & E12.6 & \\
\hline $\begin{array}{l}\text { Card } \\
\text { Cl2 }\end{array}$ & $\begin{array}{l}\text { Parameter } \mathrm{TF}_{0} \\
\text { in } \mathrm{Eq} .(34)\end{array}$ & $\begin{array}{c}\text { Parameter } \mathrm{TF}_{1} \\
\text { in Eq. }(34) \\
\left(\frac{\text { atoms }}{\text { fission }}\right)\end{array}$ & $\begin{array}{l}\text { Parameter } \mathrm{TF}_{2} \\
\text { in Eq. }(34) \\
\left({ }^{\circ} \mathrm{K}\right)\end{array}$ & \\
\hline Symbol & TFO & TF1 & TF2 & \\
\hline
\end{tabular}


Graphite Diffusion Properties

\begin{tabular}{|c|c|c|c|c|c|c|}
\hline Word & 1 & 2 & 3 & 4 & 5 & \\
\hline Column & $1-12$ & $13-24$ & $25-36$ & $37-48$ & $49-60$ & \\
\hline Format & E12.6 & E12.6 & $\mathrm{E} 12.6$ & E12.6 & E12.6 & \\
\hline $\begin{array}{c}\text { Card } \\
3\end{array}$ & $\begin{array}{l}\text { Reference } \\
\text { temperature } \\
\text { for graphite } \\
\text { diffusion } \\
\text { coefficient } \\
\left({ }^{\circ} \mathrm{C}\right)\end{array}$ & $\begin{array}{l}\text { Activation } \\
\text { energy for } \\
\text { diffusion in } \\
\text { graphite } \\
\text { (cal/gmole) }\end{array}$ & $\begin{array}{l}\text { Diffusion } \\
\text { coefficient in } \\
\text { graphite at } \\
\text { temp = TBASE } \\
\left(\mathrm{cm}^{2} / \mathrm{sec}\right)\end{array}$ & $\begin{array}{l}\text { Effective } \\
\text { diffusion } \\
\text { thickness of } \\
\text { equivalent } \\
\text { slab } \\
(\mathrm{cm})\end{array}$ & $\begin{array}{l}\text { Fission product } \\
\text { decay half-life }\end{array}$ & $\begin{array}{l}\text { See p. } 117 \text { for } \\
\text { further explan- } \\
\text { ation }\end{array}$ \\
\hline Symbol & TBASE & EBASE & DBASE & XLDIFG & THALF & \\
\hline
\end{tabular}

Always required.

Graphite Sorption Properties

\begin{tabular}{|c|c|c|c|c|c|c|}
\hline Word & 1 & 2 & 3 & 4 & 5 & 6 \\
\hline Column & $1-12$ & $13-24$ & $25-36$ & $37-48$ & $49-60$ & $61-72$ \\
\hline Format & E12.6 & E12.6 & E12.6 & E12.6 & E12.6 & EI2.6 \\
\hline $\begin{array}{l}\text { Card } \\
4\end{array}$ & $\begin{array}{l}\text { "a" in } \\
\text { Eq. (64) for } \\
\text { graphite }\end{array}$ & $\begin{array}{l}\text { "b" in } \\
\text { Eq. (64) for } \\
\text { graphite } \\
\left({ }^{\circ} \mathrm{K}\right)\end{array}$ & $\begin{array}{l}\text { "e" in } \\
\text { Eq. (64) for } \\
\text { graphite } \\
\text { (formerly "c") }\end{array}$ & $\begin{array}{l}\text { "f" in } \\
\text { Eq. (64) for } \\
\text { graphtie } \\
\text { (formerly "d") } \\
\quad\left({ }^{\circ} \mathrm{K}\right)\end{array}$ & $\begin{array}{l}C_{\text {TR }} \text { in } \\
\text { Eq. (64) for } \\
\text { graphite } \\
\text { ( } \mu \text { moles/g) }\end{array}$ & $\begin{array}{l}\text { Density } \rho \text { in } \\
\text { Eq. (55) for } \\
\text { graphite } \\
\quad\left(\mathrm{g} / \mathrm{cm}^{3}\right)\end{array}$ \\
\hline Symbol & $\overline{\mathrm{ACPG}}$ & $\overline{\mathrm{BCPB}}$ & $\overline{\mathrm{CCPG}}$ & $\overline{\mathrm{DCPG}}$ & CTRANG & RHOG \\
\hline
\end{tabular}

Fuel Rod Sorption Properties

\begin{tabular}{|c|c|c|c|c|c|c|}
\hline Word & 1 & 2 & 3 & 4 & 5 & 6 \\
\hline Column & $1-12$ & $13-24$ & $25-36$ & $37-48$ & $49-60$ & $61-72$ \\
\hline Format & E12.6 & E12.6 & E12.6 & E12.6 & E12.6 & E12.6 \\
\hline $\begin{array}{l}\text { Card } \\
5\end{array}$ & \multicolumn{6}{|c|}{$\begin{array}{l}\text { A11 fuel rod sorption properties are analogous to those defined } \\
\text { in Card } 4 \text { for graphite. Note that RHOF must be defined as a smeared density, } \\
\mathrm{g} / \mathrm{cm}^{3} \text { of fuel rod volume. The other sorption properties are on a mass basis. }\end{array}$} \\
\hline Symbol & $\mathrm{ACPF}$ & $\mathrm{BCPF}$ & $\mathrm{CCPF}$ & DCPF & CTRANF & $\mathrm{RHOF}$ \\
\hline
\end{tabular}


Coolant Diffusion and Mass Transfer Data

\begin{tabular}{|c|c|c|c|c|c|}
\hline Word & 1 & 2 & 3 & 4 & \\
\hline Column & $1-12$ & $13-24$ & $25-36$ & $37-48$ & \\
\hline Format & E12.6 & E12.6 & E12.6 & E12.6 & \\
\hline $\begin{array}{c}\text { Card } \\
6\end{array}$ & $\begin{array}{l}\text { Coolant } \\
\text { pressure p in } \\
\text { Eq. (124) } \\
\quad(\text { atm) }\end{array}$ & $\begin{array}{l}\mathrm{D}_{\mathrm{O}_{\mathrm{He}}} \text { in } \\
\mathrm{Eq} \cdot(124) \\
\left(\mathrm{cm}^{2} / \mathrm{sec}\right)\end{array}$ & $\begin{array}{l}\text { Exponent in } \\
\text { Eq. (124) }\end{array}$ & $\begin{array}{l}\text { Fission } \\
\text { product } \\
\text { concentration } \\
C_{\infty} \text { in } \\
\text { Eq. }(100) \\
\left(\mu \mathrm{moles} / \mathrm{cm}^{3}\right)\end{array}$ & $\mathrm{D}_{\mathrm{He}}=\mathrm{D}_{\mathrm{O}_{\mathrm{He}}}\left(\frac{\mathrm{P}_{\mathrm{o}}}{\mathrm{P}}\right)\left(\frac{\mathrm{T}_{\mathrm{c}}}{\mathrm{T}_{\mathrm{o}}}\right)^{\text {DGAS }}$ \\
\hline Symbol & PGAS & PGASO & $\overline{\text { DGAS }}$ & CCHANL & \\
\hline
\end{tabular}

Yields

\begin{tabular}{|c|c|c|c|c|c|c|}
\hline Word & 1 & 2 & & & & \\
\hline Column & $1-12$ & $13-24$ & & & & \\
\hline Format & E12.6 & E12.6 & & & & \\
\hline $\begin{array}{c}\text { Card } \\
7\end{array}$ & $\begin{array}{l}\text { Yield of } \\
\text { fission product } \\
\text { from fertile } \\
\text { material }\end{array}$ & $\begin{array}{l}\text { Yield of } \\
\text { fission product } \\
\text { from fissile } \\
\text { material }\end{array}$ & NOTE: & $\begin{array}{l}\text { These } \\
\text { of th } \\
\text { parti } \\
\text { The m } \\
29\end{array}$ & $\begin{array}{l}\text { are yields of } \\
\text { e particle in } w \\
\text { cle types are c } \\
\text { aterial mix is }\end{array}$ & $\begin{array}{l}\text { given material, regardless } \\
\text { hich it resides. The } \\
\text { pntrolled by IUTH on Card } 20 . \\
\text { controlled by RATIOP on Card }\end{array}$ \\
\hline Symbol & YIELDT & YIELDS & & & & \\
\hline
\end{tabular}

Misc.

\begin{tabular}{|c|c|c|c|c|c|}
\hline Word & 1 & 2 & 3 & 4 & 5 \\
\hline Column & $1-12$ & $13-24$ & $25-36$ & $37-42$ & $43-48$ \\
\hline Format & E12.6 & E12.6 & E12.6 & I6 & $I 6$ \\
\hline $\begin{array}{c}\text { Card } \\
8\end{array}$ & $\begin{array}{l}\text { Particle } 1 \\
\text { Matrix } \\
\text { contamination } \\
\text { fraction }\end{array}$ & $\begin{array}{l}\text { Particle } 2 \\
\text { Matrix } \\
\text { contamination } \\
\text { fraction }\end{array}$ & $\begin{array}{l}\text { Ratio of } \\
\text { surface to } \\
\text { average fission } \\
\text { rate in fuel } \\
\text { rod }\end{array}$ & $\begin{array}{l}\text { Number of } \\
\text { annular } \\
\text { subdivisions } \\
\text { in fuel rod }\end{array}$ & $\begin{array}{l}\text { Option to continue calcula- } \\
\text { tions if iteration fails to } \\
\text { converge: } \\
=0 \text {, call MERR } \\
=1 \text {, skip to next space } \\
\text { point }\end{array}$ \\
\hline Symbol & FFC (1) & $\mathrm{FFC}(2)$ & RODSAF & NRDIV & IGOON \\
\hline
\end{tabular}


IF ICARD $\neq 0$, skip Cards $9-13$

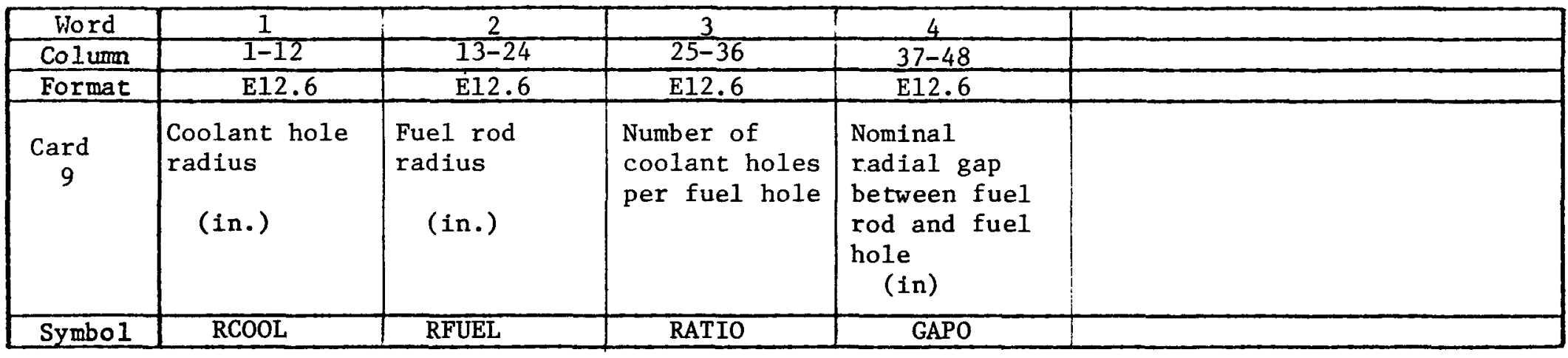

If ICARD $\neq 0$, data on cards 9-14 are read from SURVEY

tapes

\begin{tabular}{|c|c|c|c|c|c|c|}
\hline Word & 1 & 2 & 3 & 4 & 5 & 6 \\
\hline Column & $1-12$ & $13-24$ & $25-36$ & $37-48$ & $49-60$ & $61-72$ \\
\hline Format & E12.6 & E12.6 & E12.6 & $E 12.6$ & E12.6 & E12.6 \\
\hline $\begin{array}{c}\text { Card } \\
10\end{array}$ & $\begin{array}{l}\text { Fraction of } \\
\text { active core } \\
\text { height that } \\
\text { is fueled in } \\
\text { control } \\
\text { column }\end{array}$ & $\begin{array}{l}\text { + Ditto for } \\
\text { standard } \\
\text { column }\end{array}$ & $\begin{array}{l}\text { Active fuel } \\
\text { height in } \\
\text { a control } \\
\text { block } \\
\quad \text { (in.) }\end{array}$ & $\begin{array}{l}\text { \& Ditto for } \\
\text { standard } \\
\text { block }\end{array}$ & $\begin{array}{l}\text { Number of } \\
\text { fuel holes } \\
\text { in a control } \\
\text { block }\end{array}$ & $\begin{array}{l}\text { \& Ditto for } \\
\text { standard } \\
\text { block }\end{array}$ \\
\hline Symbo1 & HFUEL (1) & HFUEL (2) & HBLOK (1) & $\operatorname{HBLOK}(2)$ & XNHOLE (1) & XNHOLE (2) \\
\hline
\end{tabular}

\begin{tabular}{|c|c|c|c|c|c|c|}
\hline Word & 1 & 2 & 3 & 4 & 5 & 6 \\
\hline Column & $1-12$ & $13-24$ & $25-30$ & $31-36$ & $37-42$ & $43-48$ \\
\hline Format & E12.6 & E12.6 & I6 & I6 & I6 & I6 \\
\hline $\begin{array}{c}\text { Card } \\
11\end{array}$ & $\begin{array}{l}\text { Coefficient } \\
\text { in coolant } \\
\text { viscosity } \\
\text { Eq. (146) } \\
\text { (see p. 118) }\end{array}$ & $\begin{array}{l}\text { Exponent } \\
\text { in coolant } \\
\text { viscosity } \\
\text { Eq. (146) } \\
\text { (see p. 118) }\end{array}$ & $\begin{array}{l}\text { Number of } \\
\text { years (fuel } \\
\text { irradiation } \\
\text { periods) in } \\
\text { burnup study }\end{array}$ & $\begin{array}{l}\text { Number of } \\
\text { years resi- } \\
\text { dency of fuel } \\
\text { before reload } \\
\text { (typical) }\end{array}$ & $\begin{array}{l}\text { Number of } \\
\text { regions } \\
\text { analyzed, } \\
\text { e.g., in a } \\
\text { symmetry sec- } \\
\text { tion of the } \\
\text { core }\end{array}$ & $\begin{array}{l}\text { Number of } \\
\text { axial block } \\
\text { layers in core. }\end{array}$ \\
\hline Symbol & EMUO & EMU & NYR & NCYCLE & NREG & NLAYER \\
\hline
\end{tabular}




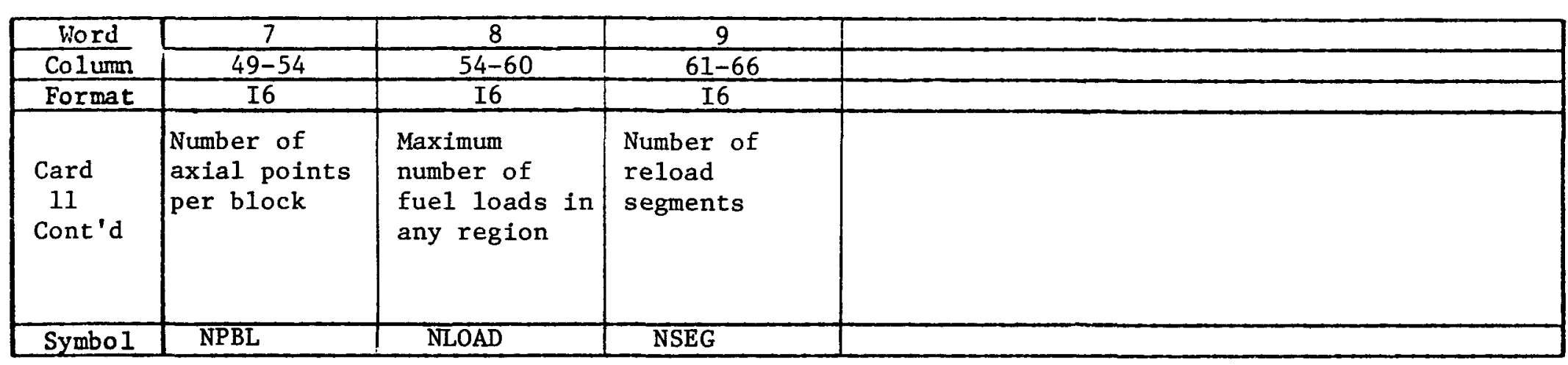

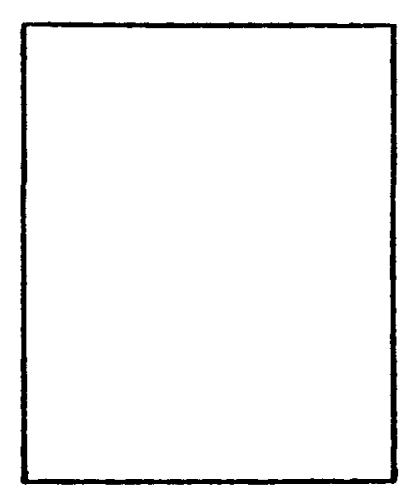

\begin{tabular}{|c|c|c|c|c|c|}
\hline Word & 1 & 2 & 3 & 4 & \\
\hline Column & $1-12$ & $13-18$ & $19-24$ & $25-30$ & \\
\hline Format & $\overline{E 12.6}$ & I6 & I6 & I6 & \\
\hline $\begin{array}{c}\text { Card } \\
12\end{array}$ & $\begin{array}{l}\text { Weighting } \\
\text { factor for } \\
\text { centra1 point } \\
\left(W_{1} \text { in }\right. \\
\text { Eq. }(128)) .\end{array}$ & $\begin{array}{l}\text { Number of } \\
\text { equivalent } \\
\text { coolant holes } \\
\text { in variably } \\
\text { orificed } \\
\text { regions }\end{array}$ & $\begin{array}{l}\text { Number of } \\
\text { local points } \\
\text { per hex: } \\
7 \text { - GAUGE } \\
24 \text { - BUG }\end{array}$ & $\begin{array}{l}\text { Number of } \\
\text { particle types } \\
(\leq 2)\end{array}$ & $\begin{array}{l}\text { Note: Set NPART }=\text { NPART } \\
\text { on Card } C_{0} \text {. This dual defini- } \\
\text { tion is a carryover from } \\
\text { SURVEY. }\end{array}$ \\
\hline Symbo1 & WTFAC & $\overline{\mathrm{NEQH}}$ & NPHX & NPART & \\
\hline
\end{tabular}

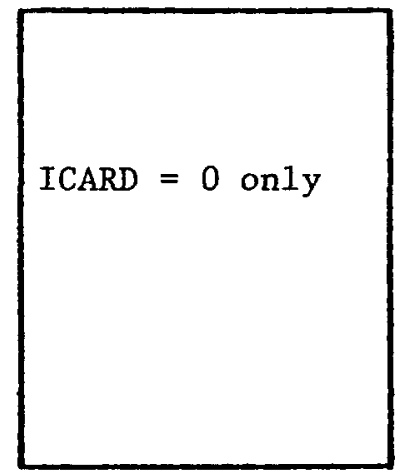

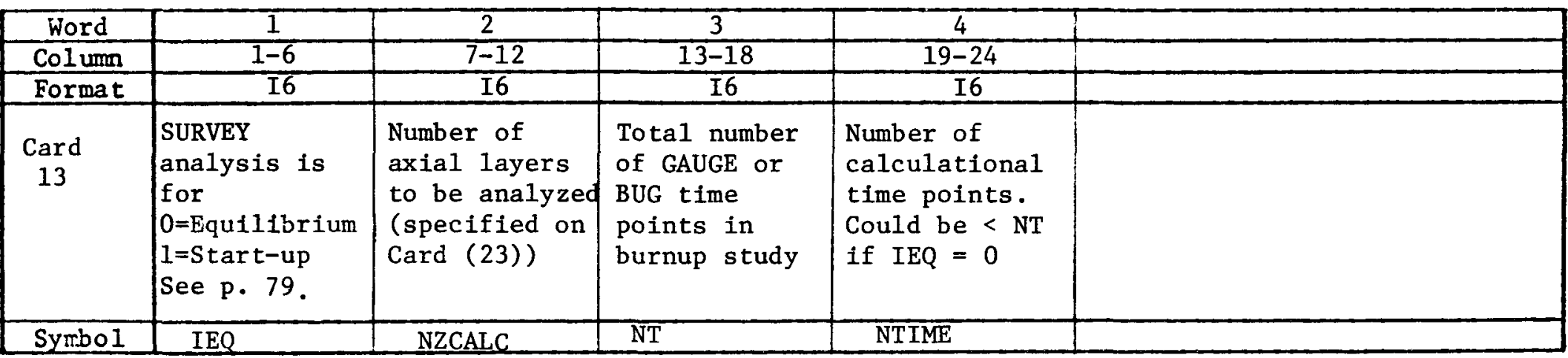

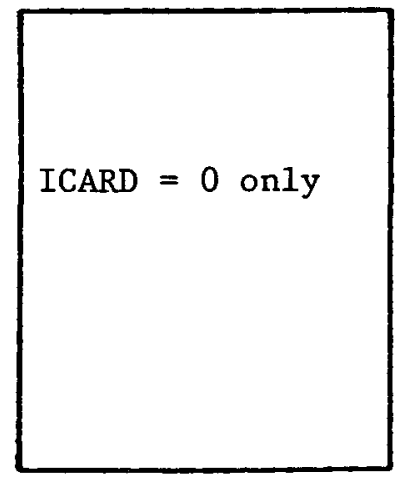




\begin{tabular}{|c|c|c|c|c|c|}
\hline Word & 1 & 2 & 3 & & \\
\hline Column & $1-6$ & $7-12$ & $13-18$ & & \\
\hline Format & I6 & I6 & I6 & & \\
\hline $\begin{array}{c}\text { Card } \\
14\end{array}$ & $\begin{array}{l}\text { Number of } 10 g \\
\text { p tabulations } \\
\text { in DIFFEQ } \\
\text { table }\end{array}$ & $\begin{array}{l}\text { Number of } 10 g \\
\gamma \text { tabulations } \\
\text { in DIFFEQ } \\
\text { table }\end{array}$ & $\begin{array}{l}\text { Number of log } \\
\beta \text { tabulations } \\
\text { in DIFFEQ } \\
\text { table }\end{array}$ & $\begin{array}{l}\mathrm{NR}=49 \\
\mathrm{NG}=9 \\
\mathrm{NB}=9\end{array}$ & $\begin{array}{l}\text { in present version of code. } \\
\text { (See p. } 118 \text { for explanation.) }\end{array}$ \\
\hline Symbol & NR & $\overline{\mathrm{NG}}$ & $\overline{\mathrm{NB}}$ & & \\
\hline
\end{tabular}

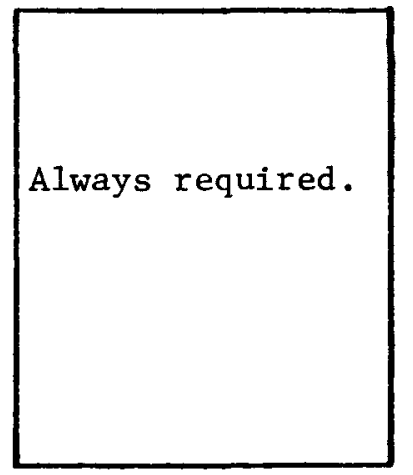

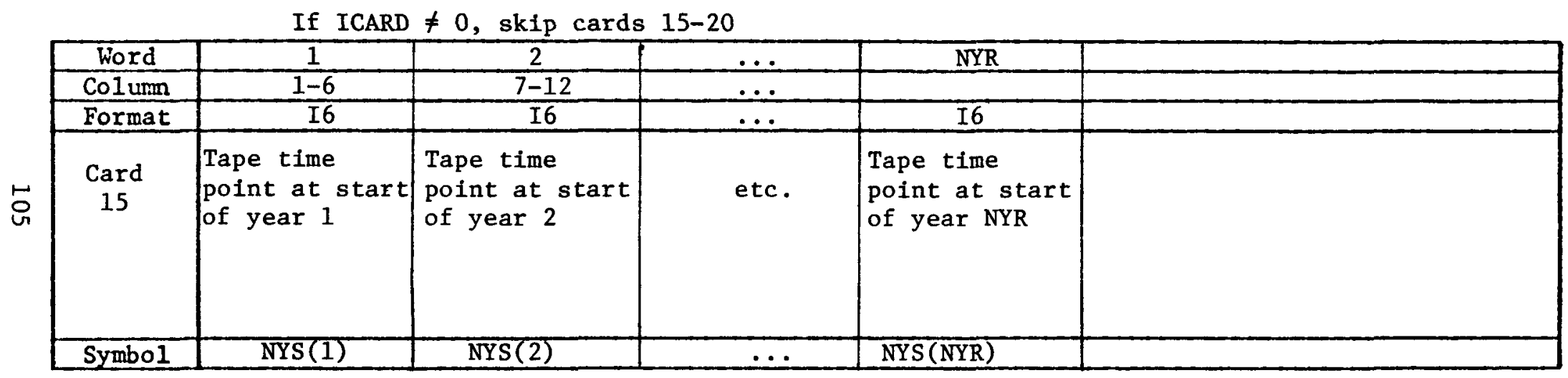

Format 12I6.
Use additional
cards if NYR > 12

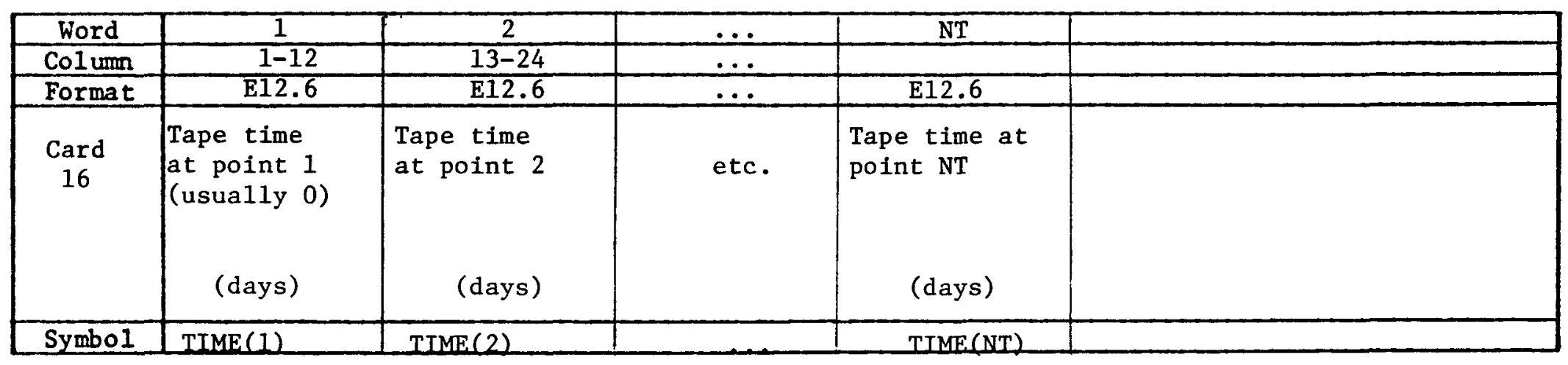

Format $6 \mathrm{E} 12.6$
NT/6 cards
required.




\begin{tabular}{|c|c|c|c|c|c|}
\hline Word & 1 & 2 & ‥ & NREG & \\
\hline Column & $1-6$ & $7-12$ & $\ldots$ & & \\
\hline Format & I6 & I6 & $\ldots$ & I6 & \\
\hline $\begin{array}{c}\text { Card } \\
17\end{array}$ & $\begin{array}{l}\text { Number of } \\
\text { columns in 1st } \\
\text { region of } \\
\text { survey }\end{array}$ & $\begin{array}{l}\text { Number of } \\
\text { columns in } 2 \text { nd } \\
\text { region of } \\
\text { survey }\end{array}$ & etc. & $\begin{array}{l}\text { Number of } \\
\text { columns in } \\
\text { last region } \\
\text { of survey }\end{array}$ & $\begin{array}{l}\text { See Card } 19 \text { for the corres- } \\
\text { pondence between these NREG } \\
\text { regions and the "global" } \\
\text { numbering of the reactor core. }\end{array}$ \\
\hline Symbol & NCPR(1) & NCPR (2) & $\ldots$ & NCPR (NREG) & \\
\hline
\end{tabular}

\begin{tabular}{|c|c|c|c|c|c|}
\hline Word & 1 & 2 & & NREG & \\
\hline Column & $1-6$ & $7-12$ & & & \\
\hline Format & I6 & I6 & & I6 & \\
\hline $\begin{array}{c}\text { Card } \\
18\end{array}$ & $\begin{array}{l}\text { Reload segment } \\
\text { number of } 1 \mathrm{st} \\
\text { region of } \\
\text { survey }\end{array}$ & $\begin{array}{l}\text { Reload semgnet } \\
\text { number of } 2 \mathrm{nd} \\
\text { region of } \\
\text { survey }\end{array}$ & etc. & $\begin{array}{l}\text { Reload segment } \\
\text { number of } \\
\text { last region of } \\
\text { survey }\end{array}$ & $\begin{array}{l}\text { Note: Use numbers } 1,2,3,4 \text { to } \\
\text { correspond to positions } A, B, C, D \\
\text { respectively. See } \\
\text { Section } 3.2 .1 \text {. }\end{array}$ \\
\hline Symbol & NREL (1) & NREL (2) & $\ldots$ & NREL (NREG) & \\
\hline
\end{tabular}

Format $12 \mathrm{I} 6$.

NREG/12 cards required.

Format 1216 .

Reactor region Note: These global region

etc. number

numbers are used in the code

corresponding for identification purposes.

to last region Their use permits a partial

of survey.

core survey. 


\begin{tabular}{|c|c|c|c|c|}
\hline Word & $I$ & 2 & & \\
\hline Column & $1-6$ & $7-12$ & & \\
\hline \multicolumn{5}{|l|}{ Format } \\
\hline $\begin{array}{c}\text { Card } \\
20\end{array}$ & $\begin{array}{l}\text { Predominant } \\
\text { material in lst } \\
\text { particle } \\
0=\text { fertile } \\
1=\text { fissile }\end{array}$ & $\begin{array}{l}\text { Predominant } \\
\text { material in 2nd } \\
\text { particle } \\
0=\text { fertile } \\
1=\text { fissile }\end{array}$ & Note: & $\begin{array}{l}\text { If there are two particles, then it is required } \\
\text { that IUTH(1) } \neq \text { IUTH( } 2 \text {. See Section } 2.11 \text { for } \\
\text { more information about fissile and fertile } \\
\text { particles. }\end{array}$ \\
\hline Symbol & $\overline{\text { IUTH (1) }}$ & IUTH(2) & & \\
\hline
\end{tabular}

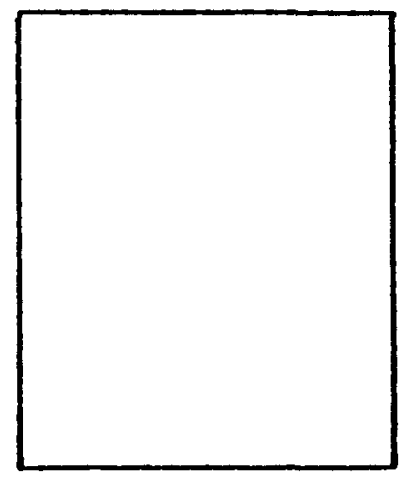

\begin{tabular}{|c|c|c|c|c|}
\hline Word & 1 & 2 & 3 & 4 \\
\hline Column & $1-6$ & $7-12$ & $13-18$ & $19-24$ \\
\hline Format & I6 & I6 & 16 & I6 \\
\hline $\begin{array}{c}\text { Card } \\
21\end{array}$ & $\begin{array}{l}\text { Kinetic solution } \\
\text { type } \\
0=\text { transient } \\
1=\text { steady state }\end{array}$ & $\begin{array}{l}\text { Number of } \\
\text { substeps per } \\
\text { TRAFIC time } \\
\text { step. }\end{array}$ & $\begin{array}{l}\text { 0, analyze all regions/ } \\
\text { columns in each layer. } \\
>0 \text {, analyze NRCALC region/ } \\
\text { column combinations in each } \\
\text { layer. }\end{array}$ & $\begin{array}{l}-1 \text {, column average survey } \\
0 \text {, survey all local pts. } \\
\text { in column } \\
>0 \text {, analyze the NCALC local } \\
\text { points on Card } 24 .\end{array}$ \\
\hline Symbol & ISTEAD & NSUB & NRCALC & NCALC \\
\hline
\end{tabular}

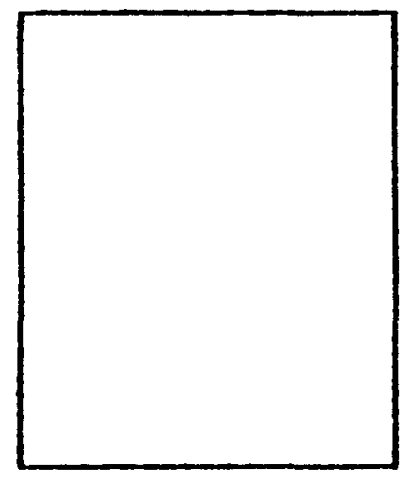

\begin{tabular}{|c|c|c|}
\hline Word & 5 & 6 \\
\hline Column & $25-30$ & $31-36$ \\
\hline Format & I6 & 16 \\
\hline $\begin{array}{l}\text { Card } \\
21 \\
\text { cont'd }\end{array}$ & $\begin{array}{l}0, \text { print all results. } \\
>0 \text {, print the NPRINT region/column } \\
\text { combinations on Card } 25 .\end{array}$ & $\begin{array}{l}\text { If release constants are to be calculated for RANDI } \\
\text { (See p. } 121 \text { for conditions) } \\
0=\text { Do not print them, } \\
1 \text { = Print them, } \\
2 \text { = Print and punch them. }\end{array}$ \\
\hline Symbol & NPRINT & KREL \\
\hline
\end{tabular}

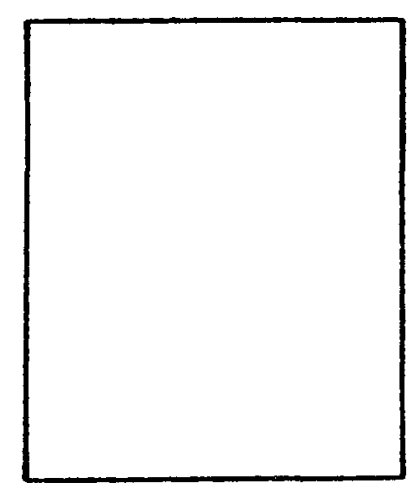


Read Card 22 only if ICARD $<3$ and NRCALC $>0$ on Card 21

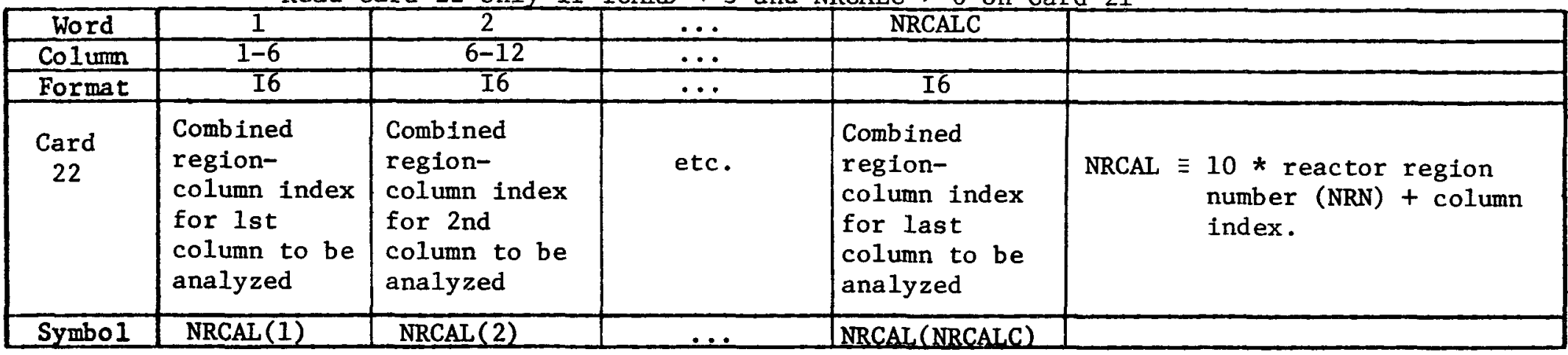

Formerly 1216

NRCALC $/ 12$ cards required.

Read Card 23 only if ICARD $=0$.

\begin{tabular}{|c|c|c|c|c|c|}
\hline Word & 1 & 2 & $\ldots$ & NZCALC & \\
\hline Column & $1-6$ & $7-12$ & & & \\
\hline Format & I6 & I6 & $\ldots$ & $I 6$ & \\
\hline $\begin{array}{c}\text { Card } \\
23\end{array}$ & $\begin{array}{l}\text { Combined } \\
\text { block-point } \\
\text { index for lst } \\
\text { layer to be } \\
\text { analyzed }\end{array}$ & $\begin{array}{l}\text { Combined } \\
\text { block-point } \\
\text { index for 2nd } \\
\text { layer to be } \\
\text { analyzed }\end{array}$ & etc. & $\begin{array}{l}\text { Combined } \\
\text { block-point } \\
\text { index for last } \\
\text { layer to be } \\
\text { analyzed }\end{array}$ & $\begin{aligned} \text { NZCAL } \equiv & 10 * \text { axial block } \\
& \text { number (IAXB) }+ \text { axial } \\
& \text { point index (IAXP) }\end{aligned}$ \\
\hline Symbol & NZCAL (1) & NZCAL (2) & $\ldots$ & NZCAL (NZCALC) & \\
\hline
\end{tabular}

See Card 13 for NZCALC.

NZCALC $/ 12$ cards required.

Format 1216

NCALC $/ 12$ cards required. in-plane local points

being surveyed.

\begin{tabular}{|c|c|c|c|c|c|}
\hline Word & 1 & 2 & $\ldots$ & NCALC & \\
\hline Column & $1-6$ & $7-12$ & $\ldots$ & & \\
\hline Format & I6 & I6 & $\ldots$ & I6 & \\
\hline $\begin{array}{l}\text { Card } \\
24\end{array}$ & $\begin{array}{l}\text { lst local } \\
\text { point. }\end{array}$ & $\begin{array}{l}\text { 2nd local } \\
\text { point. }\end{array}$ & etc. & $\begin{array}{l}\text { Last local } \\
\text { point. }\end{array}$ & $\begin{array}{l}\text { List of in-plane local points } \\
\text { to be analyzed for each column } \\
\text { being surveyed. }\end{array}$ \\
\hline Symbol & NPCAL (1) & NPCAL (2) & 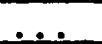 & NPCAL (NCALC) & \\
\hline
\end{tabular}

Format $12 \mathrm{I} 6$.
NCALC/12 cards
required.


Read Card 25 only if ICARD $<3$ and NPRINT>0 on Card 21.

\begin{tabular}{|c|c|c|c|c|c|}
\hline Word & 1 & 2 & & NPRINT & \\
\hline Column & $I-6$ & $7-12$ & & & \\
\hline Format & $I 6$ & I6 & & I6 & \\
\hline $\begin{array}{c}\text { Card } \\
25\end{array}$ & $\begin{array}{l}\text { Combined } \\
\text { region-column } \\
\text { index for lst } \\
\text { printout }\end{array}$ & $\begin{array}{l}\text { Combined } \\
\text { region-column } \\
\text { index for 2nd } \\
\text { printout }\end{array}$ & etc. & $\begin{array}{l}\text { Combined } \\
\text { region-column } \\
\text { index for last } \\
\text { printout }\end{array}$ & $\begin{aligned} \mathrm{NRCP} \equiv & 10 * \text { reactor region } \\
& \text { index (NRN) } \\
& + \text { column index. }\end{aligned}$ \\
\hline Symbol & NRCP (1) & NRCP (2) & $\ldots$ & NRCP(NPRINT) & \\
\hline
\end{tabular}

Format 1216

NPRINT/12 cards required.

\begin{tabular}{|c|c|c|c|c|c|c|}
\hline Word & 1 & 2 & 3 & 4 & 5 & \\
\hline Column & $1-12$ & $13-24$ & $25-36$ & $37-48$ & $49-60$ & \\
\hline Format & E12.6 & E12.6 & E12.6 & E12.6 & E12.6 & \\
\hline $\begin{array}{c}\text { Card } \\
26\end{array}$ & $\begin{array}{l}\text { Multiplication } \\
\text { factor for } \\
\text { fertile par- } \\
\text { ticle fission } \\
\text { product } \\
\text { release }\end{array}$ & $\begin{array}{l}\text { Multiplication } \\
\text { factor for } \\
\text { fissile par- } \\
\text { ticle fission } \\
\text { product } \\
\text { release }\end{array}$ & $\begin{array}{l}\text { Multiplication } \\
\text { factor for } \\
\text { fission product } \\
\text { decay constant } \\
\lambda\end{array}$ & $\begin{array}{l}\text { Multiplication } \\
\text { factor for } \\
\text { effect of ther- } \\
\text { mal gradient } \\
\text { diffusion in } \\
\text { fuel rod }\end{array}$ & $\begin{array}{l}\text { Multiplication } \\
\text { factor for } \\
\text { effect of ther- } \\
\text { mal gradient } \\
\text { diffusion in } \\
\text { graphite web }\end{array}$ & $\begin{array}{l}\text { Used for } \\
\text { sensitivity } \\
\text { studies. } \\
\text { See p. } 119 \\
\text { for explan- } \\
\text { ation. }\end{array}$ \\
\hline Symbol & BFUDGE & TFUDGE & DFUDGE & FFUDGE & GFUDGE & \\
\hline
\end{tabular}

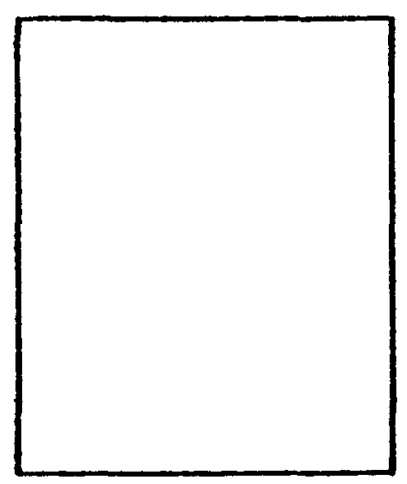

Cards 27-39 are read in a loop over NZCALC axial layers. Inside the axial loop is a loop over either NREG regions or NRCALC region/column combinations. See diagram on p. 93.

\begin{tabular}{|c|c|c|c|c|c|}
\hline Word & 1 & 2 & & NTIIE & \\
\hline Column & $1-6$ & $7-12$ & & & Definitions of NRLD \\
\hline Format & I6 & I6 & $\ldots$ & I6 & \\
\hline $\begin{array}{c}\text { Card } \\
27\end{array}$ & $\begin{array}{l}\text { Time point } \\
\text { indicator } \\
\text { for first tape } \\
\text { time }\end{array}$ & $\begin{array}{l}\text { Time point } \\
\text { indicator } \\
\text { for 2nd tape } \\
\text { time }\end{array}$ & etc. & $\begin{array}{l}\text { Time point } \\
\text { indicator } \\
\text { for last tape } \\
\text { time }\end{array}$ & $\begin{array}{l}0=\text { typical midyear point } \\
1=\text { start of reload } \\
2=\text { start of year, not } \\
\\
\text { reload } \\
3=\text { end of reload } \\
4=\text { end of year, not reload }\end{array}$ \\
\hline Symbol & NRLD(1) & NRID(2) & $\ldots$ & NRLD (NTIME) & \\
\hline
\end{tabular}

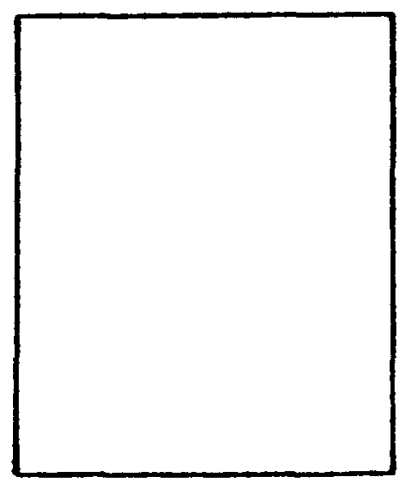


Cards 28-39 are read within a loop over all columns in this region or one region/column. Within the column loop is a loop over local points in the column. See p. 93.

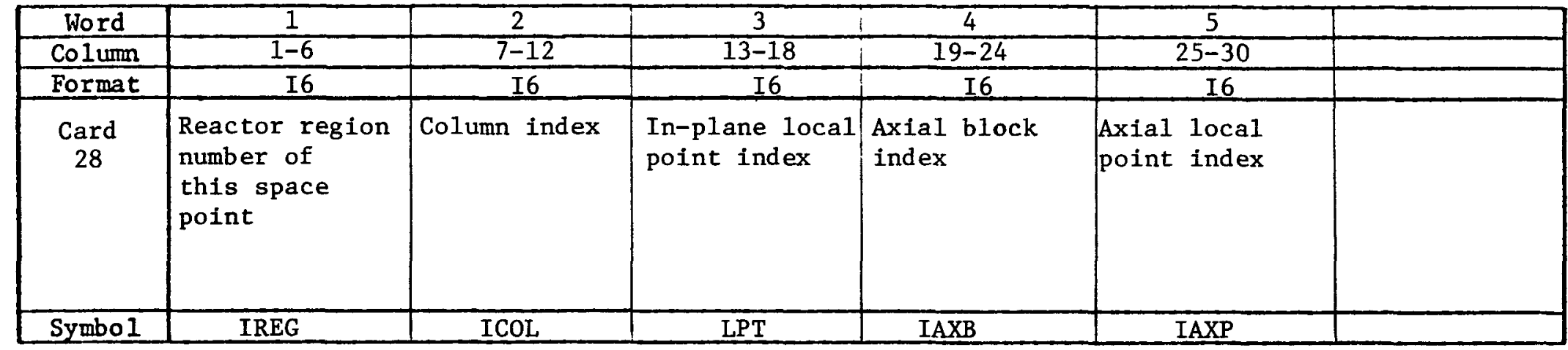

Identifying card for each in-plane local point.

NLOAD/6 cards required.

See Section 2.11 for explanation of RATIOP.
*Note: From this point hence a simplified format and array notation is used. The index I denotes the word sequence on the card. In this example (Card 30), I ranges from 1 to NTIME. A standard 6-word format such as that shown on Card 16 is used. initial heavy metal atom) NTIME tape time points.

\begin{tabular}{|c|c|c|}
\hline Word & 1 - NTIME & \\
\hline \multicolumn{3}{|l|}{ Col umn } \\
\hline Format & $6 \mathrm{E} 12.6$ & \\
\hline $\begin{array}{c}\text { Card } \\
30\end{array}$ & $\begin{array}{l}\text { Burnup (FIMA-fissions per } \\
\text { initial heavy metal atom) in } \\
\text { particle type } J \text { at each of } \\
\text { NTIME tape time points. }\end{array}$ & $\begin{array}{l}\text { *Note: From this point hence a simplified format and } \\
\text { array notation is used. The index I denotes the word } \\
\text { sequence on the card. In this example (Card 30), I } \\
\text { ranges from } 1 \text { to NTIME. A standard 6-word format such } \\
\text { as that shown on Card } 16 \text { is used. }\end{array}$ \\
\hline Symbol & (BURNUP $(I, J), I=1, N T I M E)$ & \\
\hline
\end{tabular}

NTIME $/ 6$ cards required.

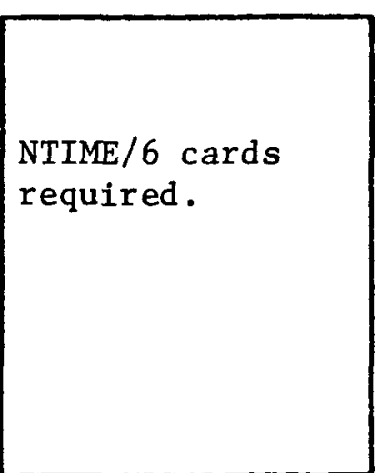




\begin{tabular}{|c|l|l|}
\hline Word & \multicolumn{1}{|c|}{ l-NTIME } & \\
\hline Column & \multicolumn{1}{|c|}{ 6E12.6 } & \\
\hline Format & \multicolumn{1}{|c|}{} \\
\hline $\begin{array}{c}\text { Card } \\
31\end{array}$ & $\begin{array}{l}\text { Flow in a single coolant } \\
\text { channel. (I bm/hr) }\end{array}$ & Values are at tape times. Ref. Section 3.2.3. \\
& & \\
\hline Symbol & (FLOW(I), I=1,NTIME) & \\
\hline
\end{tabular}

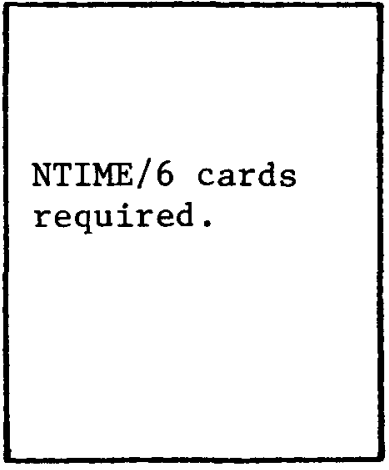

\begin{tabular}{|c|c|c|}
\hline Word & 1-NTIME & \\
\hline Column & & \\
\hline Format & 6E12.6 & \\
\hline $\begin{array}{c}\text { Card } \\
32\end{array}$ & $\begin{array}{l}\text { Heat flux at the coolant } \\
\text { hole surface. } \\
\text { Btu }\end{array}$ & Values are at tape times. \\
\hline & $\left(h r f t^{2}\right)$ & \\
\hline Symbol & (QFLUX(I), I $=1$, NTIME) & \\
\hline
\end{tabular}

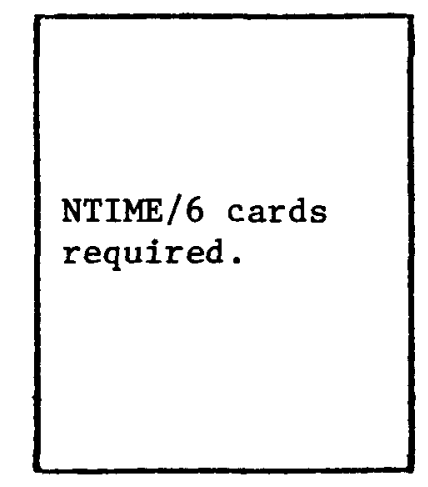

\begin{tabular}{|c|c|c|}
\hline Word & 1-NTIME & \\
\hline Column & 6E12.6 & \\
\hline Format & Values are at tape times \\
Card & Coolant temperature & \\
33 & $\left({ }^{\circ} \mathrm{F}\right)$ & \\
& & \\
\hline Symbol & (TCOOL(I).I=1,NTIME) & \\
\hline
\end{tabular}

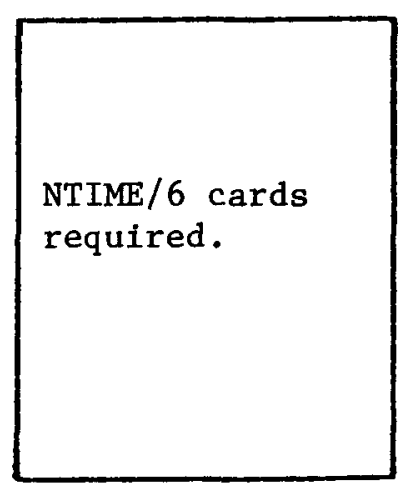




\begin{tabular}{|c|c|c|}
\hline Word & 1-NTIME & \\
\hline Column & & \\
\hline Format & $6 \mathrm{E} 12.6$ & \\
\hline $\begin{array}{c}\text { Card } \\
34\end{array}$ & $\begin{array}{l}\text { "Minimum" graphite } \\
\text { temperature, defined as } \\
\text { averaged over coolant hole } \\
\text { surface } \\
\qquad\left({ }^{\circ} \mathrm{F}\right)\end{array}$ & Values are at tape times \\
\hline Symbol & (TGMIN(I), I=1, NTIME) & \\
\hline
\end{tabular}

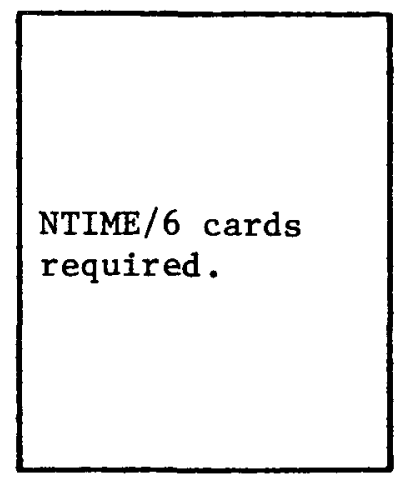

\begin{tabular}{|c|c|c|}
\hline Word & I-NTIME & \\
\hline \multicolumn{3}{|l|}{ Column } \\
\hline Format & $6 \mathrm{E} 12.6$ & \\
\hline $\begin{array}{c}\text { Card } \\
35\end{array}$ & $\begin{array}{l}\text { "Maximum" graphite } \\
\text { temperature, defined as } \\
\text { average over fuel hole } \\
\text { surface } \\
\qquad\left({ }^{\circ} \mathrm{F}\right)\end{array}$ & Values are at tape times. \\
\hline Symbo1 & $(\operatorname{TGMAX}(I), I=1$, NTIME) & \\
\hline
\end{tabular}

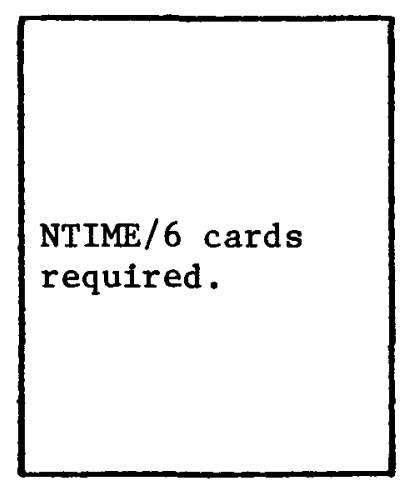

\begin{tabular}{|c|c|c|}
\hline Word & 1-NTIME & \\
\hline Column & 6E12.6 & \\
\hline Format & "Minimum" fuel rod \\
Card & $\begin{array}{c}\text { temperature, defined as } \\
\text { average over fuel rod surface } \\
\left({ }^{\circ} \mathrm{F}\right)\end{array}$ & Values are at tape times. \\
\hline Symbol & (TFMIN(I), I=1,NTIME) & \\
\hline
\end{tabular}

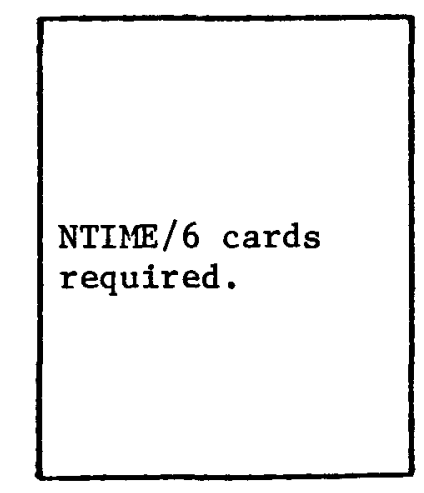




\begin{tabular}{|c|c|c|}
\hline Word & 1-NTIME & \\
\hline Column & 6E12.6 & \\
\hline Format & Maximum fuel rod temperature & \\
\hline $\begin{array}{c}\text { Card } \\
37\end{array}$ & $\begin{array}{c}\text { (value at centerline) } \\
\left({ }^{\circ} \mathrm{F}\right)\end{array}$ & \\
& & \\
\hline Symbo1 & (TFMAX (I), I=1,NTIME) & \\
\hline
\end{tabular}

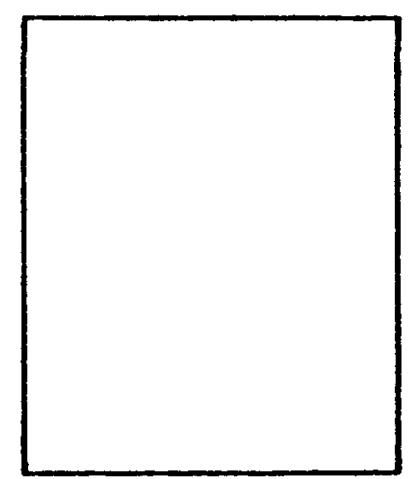

Card 38 is repeated in a loop over J=1,NPART particle types.

\begin{tabular}{|c|c|c|}
\hline Word & 1-NTIME & \\
\hline \multicolumn{3}{|l|}{ Column } \\
\hline Format & $6 \mathrm{E} 12.6$ & \\
\hline \multirow[t]{2}{*}{$\begin{array}{c}\text { Card } \\
38\end{array}$} & $\begin{array}{l}\text { Accumulated smeared fission } \\
\text { density in particle } \mathrm{J} \\
\text { fissions }\end{array}$ & $\begin{array}{l}\text { Values are at TRAFIC end-of-step time points (usually } \\
\text { mid-time points, except at end of year). See Section } \\
3.2 .3 \text {. }\end{array}$ \\
\hline & $\mathrm{cm}^{3}$ of fuel rod & Note: Must be zeroed when fresh fuel is loaded. \\
\hline Symbol & $($ FISSAC $(I, J), I=1$, NTIME $)$ & \\
\hline
\end{tabular}

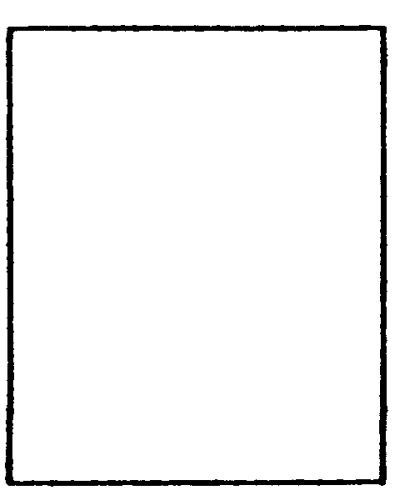

Card 39 is repeated in a loop over $J=1$, NPART particle types

\begin{tabular}{|c|c|c|}
\hline Word & \multicolumn{1}{|c|}{ 1-NTIME } & \\
\hline Column & \multicolumn{1}{|c|}{ 6E12.6 } & \\
\hline Format & Total failure percentage & Values are at tape times. \\
Card & of partical type $\mathrm{J}$. & $\begin{array}{l}\text { Note: Do not include initial contamination fraction. } \\
\text { Initia1 contamination, unlike failure, is assumed to } \\
\text { have } 100 \% \text { release. See FFC on Card } 8 .\end{array}$ \\
& $(\%)$ & \\
\hline Symbol & (FAILIT(I,J) $\mathrm{I}=1$, NTIME) & \\
\hline
\end{tabular}

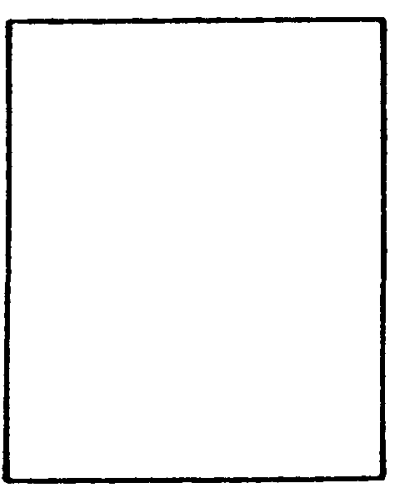




\subsection{FURTHER EXPLANATION OF INPUT FEATURES}

\subsubsection{CARD INPUT}

This section presents some supplemental information that will further explain certain aspects of the card input described in Section 4.2. The details given below are listed in the order in which the data appear on the cards. Input variables that are not mentioned here should either be selfexplanatory or should have explanations referenced elsewhere in the text.

\section{Card $1-$ ICARD}

The ICARD option controls the input mode, i.e., the way in which the timedependent survey data are defined. A description of the input modes is presented in Section 3.1. Section 4.1.2, page 90, contains a summary of al1 tape and file assignments that are required for the various ICARD options.

\section{Card $\mathrm{C}_{0}-$ NPART}

Note that NPART on Card $\mathrm{C}_{0}$ and NPART on Card 12 should be the same and should both be $\leq 2$. These dual definitions are a carryover due to the interface of TSORT, SURVEY, COPAR, and TRAFIC. A11 of these codes require that NPART be defined. Some of them use NPART for different purposes, e.g., defining dimensions, reading input data, or calculational loops.

\section{$\underline{\text { Card } \mathrm{C}_{2}}$}

NREG - The number of shell regions includes the innermost solid sphere and the outer hollow shells. The limit of 8 is a requirement for printout purposes. 


\begin{abstract}
NKERN - The only reason for setting NKERN > 1 is to account for the local depletion at the kernel surface caused by recoil. Then the outer kernel regions should be sufficiently thin (compared to RDIST on Card C4) to capture the local effect.
\end{abstract}

NTC - This controls the accuracy and the cost of the direct COPAR solution. The solution first proceeds with NTC as the basis of the time stepping, and a "long table" is generated. Then NTRHO is used to select certain values from the long table and construct a shorter table. The short table is the one finally used as input to the phase 2 COPAR calculation. NTC $=20$ is recommended.

IBC - The options 1,2 , and 3 correspond to cases $1,2,2$, and 3 . on page 18 .

IFSR - This option is summarized below.

IFSR Option

\begin{tabular}{|c|c|c|c|}
\hline IFSR & $\begin{array}{c}\text { Intact State } \\
\text { Release }\end{array}$ & $\begin{array}{c}\text { Failed State } \\
\text { Release } \\
\text { Computing } \\
\text { Time (sec) }\end{array}$ \\
\hline 0 & None & Instantaneous & 0.10 \\
\hline 1 & Diffusion $^{\mathrm{b}}$ & Instantaneous & 0.15 \\
\hline 2 & None & Diffusion & 0.16 \\
\hline 3 & Diffusion & $\begin{array}{c}\text { Diffusion } \\
\text { (Birth pulses before } \\
\text { failure collapsed) }\end{array}$ & 0.32 \\
\hline 4 & Diffusion & Diffusion & 1.50 \\
\hline
\end{tabular}

a. UNIVAC 1110; history having 48 time steps.

b. Unless otherwise noted, the diffusion calculations are performed by superimposing the solutions for all unique, birth-to-failure-torelease histories. Considerable gains in efficiency can be achieved, with no appreciable loss of accuracy, by collapsing the birth pulses prior to failure in the case of IFSR $=3$. 
IFSR controls the calculational efficiency of the phase 2 birth pulse superposition by means of a series of increasingly more rigorous approximations. IFSR $=4$ is most rigorous. IFSR $=3$ is recommended. Earlier versions of TRAFIC employed a model that was equivalent to setting IFSR $=0$ for TRISO particles and IFSR $=1$ for BISO particles. For more information on the details of these approximations, see Ref. 2 .

IRFT - This option controls the input, the output, and the file assignments required in the COPAR phase 1 table generation. An explanation of this option is given in Section 4.1.2, p. 89 .

NTRHO - See comments above for the NTC option. A value of 100 is recommended.

\section{Card C3 - TMAXD, TMIND, TNOMD}

TMAXD is the maximum time in days of an irradiation history. This is combined with the maximum value of $\mathrm{D}_{\text {eff }}$ (at the maximum temperature) to determine the upper bound of $\rho_{\text {eff }}[\operatorname{Ref} . \mathrm{Eq} .(28)]$ in the long table. Similarly, the minimum time, TMIND, is combined with the minimum $\mathrm{D}_{\text {eff }}$ (at the minimum temperature) to obtain a possible lower bound of $\rho_{\text {eff }}$ in the long table. This lower bound may then be modified based on considerations of accuracy and particle heterogeneity.

TNOMD is a nominal time step size. This parameter is used in a procedure to correct the COPAR birth pulse solution for the effect of a birth pulse having finite width. See Ref. 2 for details.

\section{Card C3A - TMAXC, TMINC, TNOMC}

The maximum temperature (TMAXC) and minimum temperature (TMINC) are used along with the maximum and minimum times to determine the limits of $\rho$ in the long table. The nominal temperature, TNOMC, is used to define the spatial 
shape of $D(r)$ on which the entire tabulated solution is based. It also defines a nominal value of $D_{\text {eff }}$, which is used to compute the value of $\rho_{\text {eff }}$ as a function of time.

\section{$\underline{\text { Card } 3}$}

The diffusion coefficient in the graphite is given by the following equation:

$$
D(T)=\operatorname{DBASE} * \operatorname{EXP}\left[\frac{\mathrm{EBASE}}{\mathrm{R}} *\left(\frac{1}{\mathrm{TBASE}+273}-\frac{1}{\mathrm{~T}+273}\right)\right] \text {, }
$$

where DBASE is the value of $\mathrm{D}\left(\mathrm{cm}^{2} / \mathrm{sec}\right)$ at reference temperature TBASE. EBASE is the activation energy ( $\mathrm{cal} / \mathrm{g} \mathrm{mole}$ )

$R$ is the gas constant $\left(1.986 \mathrm{cal} / \mathrm{g}\right.$ mole $\left.{ }^{\circ} \mathrm{K}\right)$, TBASE is the reference temperature $\left({ }^{\circ} \mathrm{C}\right)$,

and $\mathrm{T}$ is the temperature of the web $\left({ }^{\circ} \mathrm{C}\right)$.

The variable XLDIFG is the value of $L$ defining the effective thickness of the graphite $s l a b$. See sketch on $p .8$. It can be computed by a 1-D vs. 2-D correlation using the heat conduction equation. The HEXT code (Ref. 3) is usually used for this. See p. 8 for explanation.

\section{Card 8 - FFC (1), FFC (2)}

The matrix contamination fraction is a fraction of the fissionable material that is assumed to reside outside the coated particles. This fraction of the fission product yield is assumed to be instantaneously released from the particles and available for diffusion in the fuel rod matrix. Note that this is not the same as an initial failure fraction, because (depending on the COPAR option IFSR) 100\% release from failed particles is not necessarily assumed. 


\section{Card 8 - RODSAF, NRDIV}

RODSAF is used to account for the effect of flux depression (self-shielding) in the fuel rod. The fission source rate in the fuel rod is assumed to have a parabolic shape,

$$
S(r)=S_{\text {avg }}\left[(2-R O D S A F)+2\left(\text { RODSAF-1) }\left(\frac{r}{r_{f}}\right)\right]^{2},\right.
$$

where

$$
\begin{aligned}
& S(r) \text { is the source rate density at radius } r \text {, } \\
& S_{\text {avg }} \text { is the average } S \text { in the fuel rod, } \\
& \text { RODSAF is a parameter in the range } 1 \leq \operatorname{RODSAF} \leq 2 \text {, and } \\
& r_{f} \text { is the outer radius of the fuel rod. }
\end{aligned}
$$

The fuel rod is subdivided into NRDIV annular regions of equal $\Delta r$, and the above equation is integrated over the annulus to obtain the average source rate in each annulus.

\section{Card 11 - EMUO, EMU}

The viscosity in the helium coolant is assumed to be given by

$$
\nu=\text { EMUO } *\left(\mathrm{~T}_{\text {cool }}\right)^{\mathrm{EMU}},
$$

where $\nu$ is the viscosity $[\mathrm{g} \mathrm{mole} / \mathrm{cm} \mathrm{sec}]$, and $\mathrm{T}_{\text {cool }}$ is the coolant temperature $\left({ }^{\circ} \mathrm{K}\right)$. This is converted to a mass basis by

$$
\mu\left[\frac{\mathrm{g}}{\mathrm{cm} \sec }\right]=\nu\left[\frac{\mathrm{g} \text { mole }}{\mathrm{cm} \sec }\right] \times\left[\frac{4.003 \mathrm{~g}}{\mathrm{~g} \text { mole }}\right],
$$

and the value of $\mu$ is used in Eqs. (125) and (126) to compute the dimensionless flow parameters $R_{e}$ and $S_{c}$. 
Card $14-N R, N G$, NB

For time-independent boundary conditions, the boundary response functions $G$ and $\mathrm{H}$ [Eq. (93)] for the graphite slab are a function of the three parameters $\rho, \gamma$, and $\beta$ (see p. 43). These functions, or rather their indefinite integrals, are tabulated as a 3-dimensional array for discrete values of $10 \mathrm{~g}$ $\rho, \log \gamma$, and $\log \beta$. The variables $N R, N G$, and NB define the dimensions of this table. An external program called DIFFEQ is used to calculate the response functions and write them on a catalogued file. Thereafter they remain fixed for all TRAFIC runs. The numerical range of the three parameters is wide enough to cover all possible cases.

\section{Card 26}

The parameters on this card are used to arbitrarily modify (fudge) the importance of certain effects in a TRAFIC analysis. By selectively varying these one can calculate partial derivatives that are used in an uncertainty analysis (sensitivity study) such as the AIPA study (Ref. 12). For three of these factors, i.e.,

$$
\begin{aligned}
& \text { BFUDGE - fertile particle release, } \\
& \text { TFUDGE - fissile particle release, and } \\
& \text { DFUDGE - decay constant, }
\end{aligned}
$$

the nominal value of the effect is achieved by setting the factor to 1.0. The values of BFUDGE, TFUDGE, and DFUDGE should always be $\geq 0$ for the results to have physical meaning.

The two factors associated with thermal diffusion, i.e.,

FFUDGE - thermal diffusion in fuel rod, and

GFUDGE - thermal diffusion in graphite, 
are used to multiply the activation energy Q* in Eq. (29). As explained on p. 28, TRAFIC employs the conservative assumption that $Q *=Q$. The physically admissible range of $Q *$ is

$$
-Q \leq Q^{*} \leq Q
$$

This implies that

$$
-1 \leq\left\{\begin{array}{l}
\text { FFUDGE } \\
\text { GFUDGE }
\end{array}\right\} \leq 1
$$

Thus, a factor of FFUDGE or GFUDGE $=1.0$ gives a conservative analysis of the thermal gradient effect, a factor of 0 . gives a nominal analysis with no thermal diffusion effect, and a factor of -1 . gives an unconservative analysis with diffusion against the thermal gradient.

\section{Card 27 - NRLD}

The definitions of NRLD given on p. 109 are probably self explanatory. However, it should be noted that the term "year" in these definitions really means "fuel irradiation period". This is the interval between reactor reloads, i.e., the interval between planned shutdowns for refueling. The actual length of time is arbitrary, controlled by TIME on Card 16. The term "reload" in these definitions refers to those points in time where the particular fuel block is reloaded, whereas "year" refers to a reload anywhere in the reactor.

The "years" are significant in the irradiation history description because these are the times when the typical time interval halving procedure is modified. The "reloads" are significant because these are the times when fresh fuel is introduced, and a number of historical parameters are initialized by the program. See Section 3.2.3 for a complete description of the time history. 


\subsubsection{RANDI INTERFACE}

TRAFIC*VER10 is capable of calculating fission product release constants, which can be used as input to the RANDI code (Ref. 11). These consist of release constants from the intact fertile particles, the failed fertile particles, the failed fissile particles, matrix contamination, and the graphite web.* These data will be calculated in TRAFIC and written into unit 24, providing for an automated interface with RANDI, provided that the following combination of conditions is properly satisfied The TRAFIC run must be a full core survey (possibly of a symmetrical part) because RANDI performs a full core analysis. A maximum of one axial layer in the survey (the standard mode) is permitted in each run. A postprocessing code (see Section 4.3.3) is later used to collapse the layers and obtain core average results. Finally, the RANDI interface is possible only if a startup analysis is being performed, because this is the assumed mode of operation in RANDI. RANDI does its own equilibrium core simulation after the startup phase.

The specific TRAFIC options that control the RANDI interface are described below. The release constants will be written on unit 24 (see Section 4.1.2) if:

a) all regions and columns (on the tapes or the input cards) are being analyzed (NRCALC $=0$ on Card 21),

b) Calculations are performed for all local points and/or for all column average points (NCALC $\leq 0$ on Card 21),

c) only one axial layer is being analyzed (NZCALC = 1 on Card 13), and

d) a start-up core (as opposed to an equilibrium core) is being analyzed (IEQ $=1$ from the SURVEY tapes, or on Card 13).

\footnotetext{
*Note that these release "constants" are time dependent, and their use in RANDI
} properly accounts for the transient nature of metallic fission product release. 
It is also possible for TRAFIC to print and punch the release constants. This will occur if conditions (b) and (d) on the previous page are satisfied and, in addition,

e) KREL $=1$ on Card 21 (print), or KREL $=2$ on Card 21 (print and punch).

Note that the release constants will be printed for information only, but not written on unit 24 and not used for a RANDI interface, if either of conditions (a) or (c) are violated. In other words, one may obtain printout, but there will be no RANDI interface, if TRAFIC performs a less-than-complete layer survey or if TRAFIC performs calculations for more than one layer.

\subsubsection{POST-PROCESSOR TO AVERAGE MULTIPLE AXIAL LAYERS}

The RANDI code requires, for each lsotope, the data from NBLC axial layers, where NBLC is the number of fuel blocks per column in the core being analyzed. This means that TRAFIC*VER10 must be run NBLC times for each isotope. The same catalogued file (one file for each isotope) should be assigned to unit 24 for all of these NBLC runs. The data for any given axial layer is positioned in the file in a unique, separate location. The starting address of the data block is calculated in TRAFIC from the size of the data block and from the index IAXB, input either on Card 28 or from the SURVEY data tape. Thus, the NBLC axtal layers can be run in any order, and the data for the layers will be appropriately positioned in the file. After all desired layers have been run, the file for that isotope is full and ready for postprocessing.

This procedure is repeated $\mathrm{N}$ times, where $\mathrm{N}$ is the number of metallic isotopes being used as "reference nuclides" in the RANDI input. Usually $\mathrm{N}=2$ for the nuclides strontium and cesium. RANDI will simulate the behavior of the other metal nuclides based on the calculated behavior of these two. In any case, after all $\mathrm{N}$ of the data files are full, the actual postprocessing can begin. 
The function of the postprocessing code is to collect the data from the $\mathrm{N}$ isotope files, to calculate axially averaged release constants for each of the $\mathrm{N}$ isotopes, and to write all of these results on a single output file, ready for input to RANDI. This postprocessor is a small undocumented program named RANDAT. It is located in the catalogued file PROC*RANDAT, and it can be run with the following deck setup.

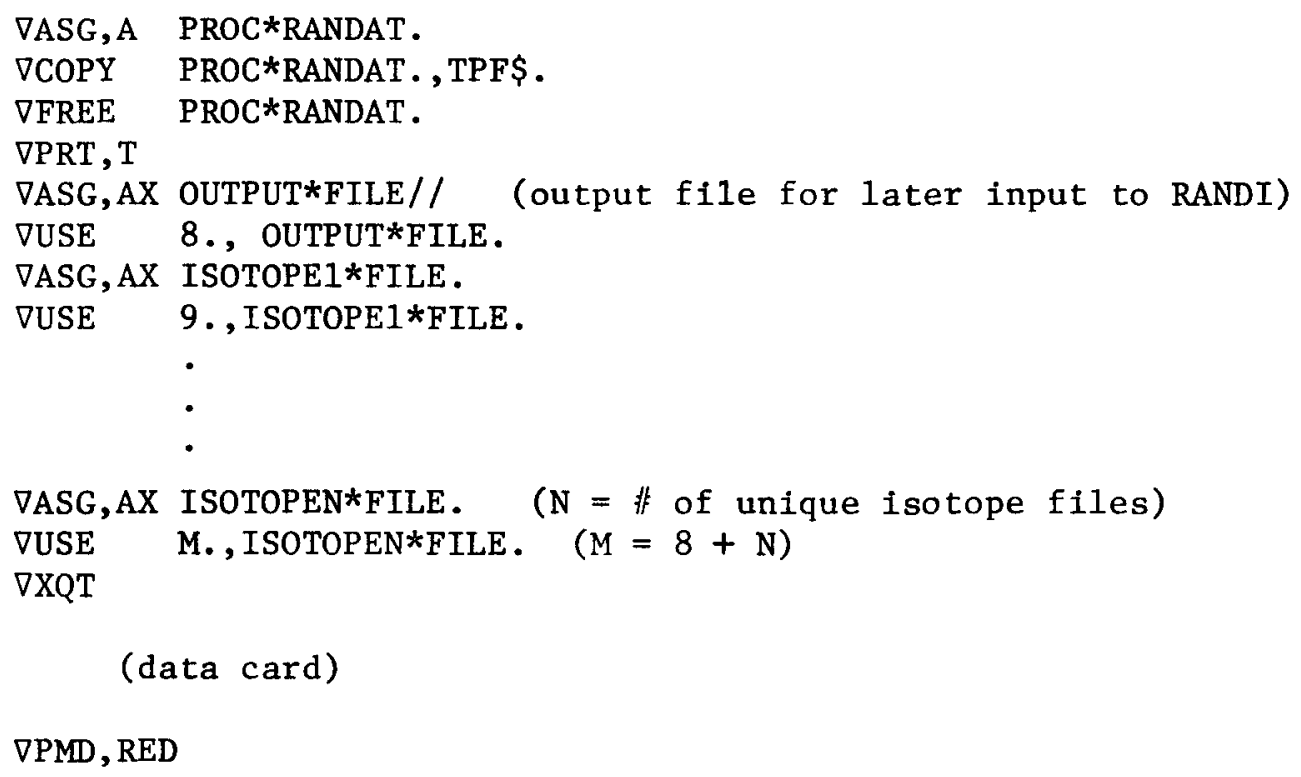

The one and only data card read by RANDAT is of the following format:

\begin{tabular}{|c|c|c|c|c|}
\hline Card & Word 非 & Format & Name & Description \\
\hline 1 & 1 & I6 & NBLK & $\begin{array}{l}\text { The number of axial blocks in the core }(=\text { the } \\
\text { number of data blocks on each input file). }\end{array}$ \\
\hline & 2 & I6 & NSPC & $\begin{array}{l}\text { The number of unique species analyzed }(=\text { the } \\
\text { number of input files, N). }\end{array}$ \\
\hline
\end{tabular}


Presently, the code is limited to
a) 104 time steps,
b) 4 reload segments,
c) 2 fuel particles, and
d) 2 species (the present RANDI 1 imit).

To change any of these limits, please see the custodian. 


\section{SAMPLE PROBLEM}

On the following pages is a sample run of TRAFIC, performed in the usual core survey mode. The card input for this case is stored in an element called SAMPLEDATA, which, in turn, is stored in the TRAFIC*VER10 program file. The data tapes for this case were generated by a SURVEY*VER10 analysis of a medium size HTGR core called the VHTR. This analysis was done to study the feasibility of a preliminary design in a process heat application. The temperatures, and hence the fission product release, are higher than in the reference HTGR lead plant design. These results are given only as a typical example of a TRAFIC calculation, and they should not be interpreted as representative of HTGR designs in general. 
ajó, TRAF jCoverzo.

$040200000000 \quad \ldots \quad \ldots \ldots$

CERT I THLFT OUEPID.

FLPpURz7RT.I RL72-8 11/16/77 23:16157

THAFIC VEETIOCLI FLEHENT TABLF

o name

VERSTON TYPE DATE

ARSOLUTE - 15 DATE 75

TIME SEO " SIZE-PRE, TEXT ICYCLE WOROI PSRMOOE LOCATION

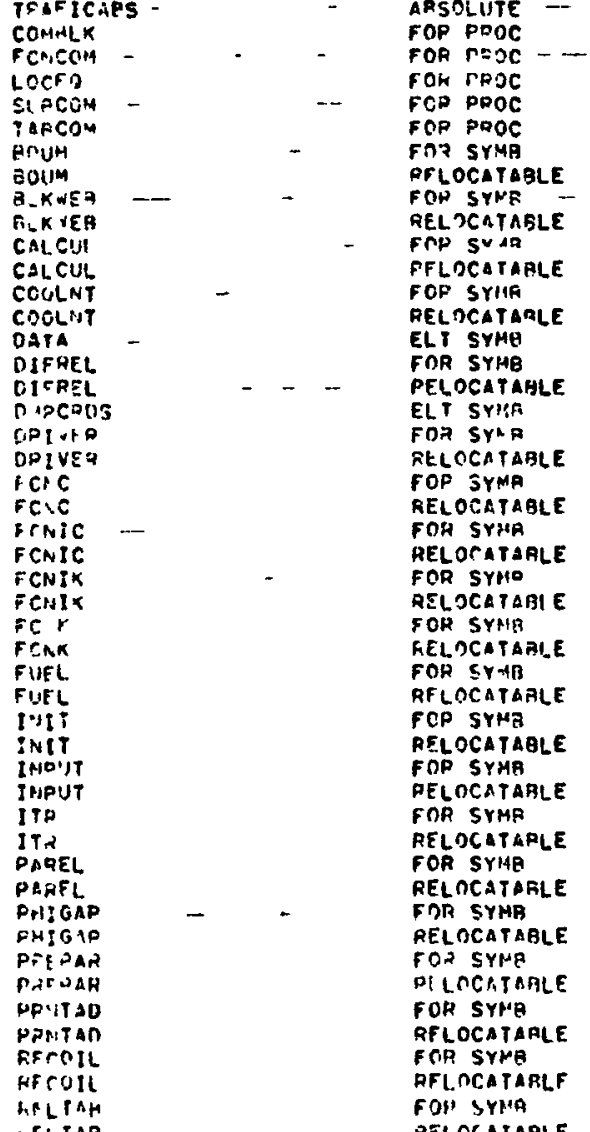

it 19108108

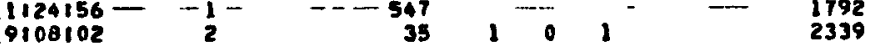

Nov $77 \quad 19108194$

19108105
19108106

15 NOV 77 19108106

15 NOV 77 19100:09

$\begin{array}{rr}-7 & -7 \\ 1910 k 110- & -1\end{array}$

19100114

15 Nov $77 \quad 19108319$

19108128

is nov 77 1916a129

19108132

15 nOV 77 19800136

PELOCATAHLE 15 NOY 77 1916Ri36

15 NOV $77 \quad 2980814$

15 NOV 77 i0108140

i5 nOY 77 19100148

15 NoV 77 10inois!

\begin{tabular}{l}
15 NOV 77 \\
15 NOY 77 \\
19108153 \\
\hline
\end{tabular}

$\begin{array}{ll}15 & \text { Nov } 77 \\ 15 & 19108154 \\ 19 & 108155\end{array}$

5 NOV $77 \quad 39: 09: 57$

NOV $77 \quad 19109100$

$\begin{array}{llll}\text { GFLOCATARLE } & 15 \text { NOY } 77 & 19169102 \\ \text { CP SYHE } & 15 \text { NOV } 77 & 19109103\end{array}$

IS NOV 77 19109105

15 NOY $77 \quad 19: 09210$

15 nov 77 191091?0

HoV $77 \quad 19809122$

NoV $77 \quad 19809127$

15 noY $77 \quad 19109135$

is nov $77 \quad 19109137$

15 NOY 77 igiogis

vov 77 i91198145

NOV $77 \quad 19109147$

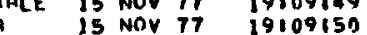

$\begin{array}{lll} & \\ \text { OHI SYMA } & \text { is NOV } 77 & 19109151 \\ 77 & 19109156\end{array}$

10109156
19110107

$2+198$

$199.50--1-\ldots$

$\begin{array}{r}31 \\ 131 \\ 100\end{array} 50-1-$

2

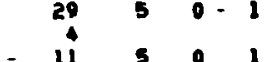

$\begin{array}{rrrr}11 & 5 & 0 & 2414 \\ -95 & 5 & 2943 \\ -2 & -94 & 2949\end{array}$

2950
$2-5$

$\begin{array}{rrrrr}2 & 5 & 0 & 1 & 3121 \\ 28 & 5 & 0 & 1\end{array}$

2
$-\quad 3$

$\begin{array}{lll}39 & 5\end{array}$

$\begin{array}{llll}24 & 5 & 0 & 1\end{array}$

30
7 50

7
-13001

$\begin{array}{llll}13 & & & \\ 32 & 5 & 0 & 1\end{array}$

$\begin{array}{llll}70 & 5 & 0 & 1\end{array}$

20
15
216

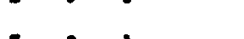

29

25.

501

$39-$

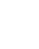

64501

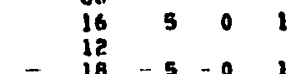

$\begin{array}{llll}18 & -5 & -0 & 1\end{array}$

25

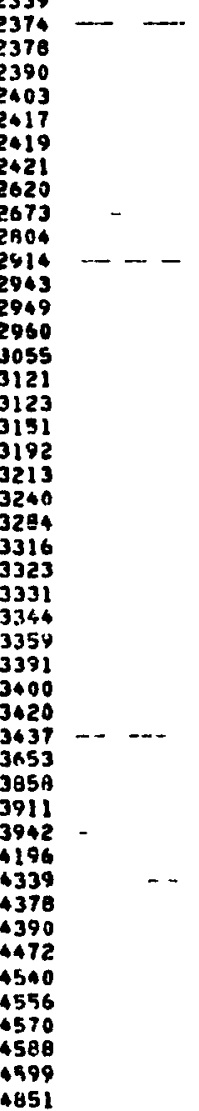




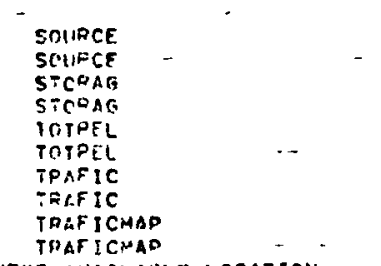

\begin{tabular}{|c|c|c|c|}
\hline $\begin{array}{l}\text { FOR SYMA } \\
\text { RELOCATAOLE } \\
\text { FOQ SYYA } \\
\text { RELOCATAALE } \\
\text { FOR SYMR } \\
\text { PCLOCATARLE } \\
\text { FOR SYHA } \\
\text { RELOCATARLE } \\
\text { MAP SYHE } \\
\text { ABSOLUTE }\end{array}$ & $\begin{array}{l}15 \text { NOV } \\
15 \text { NOV } \\
15 \text { NOV } \\
15 \text { NOV } \\
15 \text { NOV } \\
15 \text { NOV } \\
15 \text { NOV } \\
15 \text { NOV } \\
15 \text { NOV } \\
15 \text { NOV }\end{array}$ & $\begin{array}{l}77 \\
77 \\
77 \\
77 \\
77 \\
77 \\
77 \\
77 \\
77 \\
77\end{array}$ & $\begin{array}{l}19110110 \\
19110116 \\
19110117 \\
19110119 \\
19110125 \\
19110136 \\
19110142 \\
19110153 \\
19110156 \\
19111128\end{array}$ \\
\hline
\end{tabular}

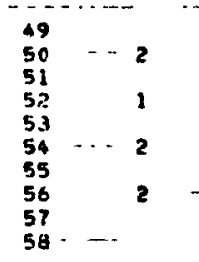

ASSEMELEE PROCEOURE TADLE EMPTY

COAOL PHOCEMIRE TARLE EMPTY

FORTAAN PROCEDURE TABLE

\begin{tabular}{|c|c|c|c|}
\hline $\begin{array}{l}\text { O NAME } \\
\text { COAHLK } \\
\text { SUGCOM }\end{array}$ & $\begin{array}{r}\text { LOCATION } \\
65494 \\
66972\end{array}$ & $\begin{array}{l}\text { LINK } \\
2 \\
5\end{array}$ & $\begin{array}{l}\text { O NAME } \\
\text { FCNCOM } \\
\text { PAACOM }\end{array}$ \\
\hline
\end{tabular}

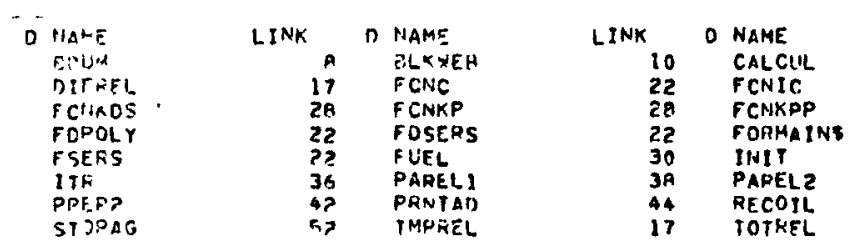

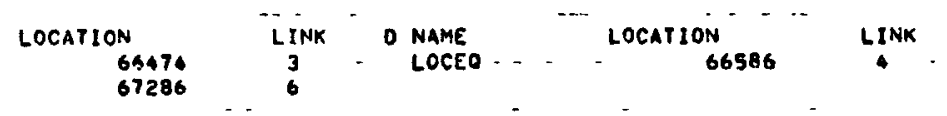

LINK DNAME
12 CALCZ

$\begin{array}{ll}12 & \text { CALCL } \\ 24 & \text { FCNIK } \\ 26 & \text { FCNKS } \\ 20 & \text { FPLT } \\ 32 & \text { IMPIS } \\ 33 & \text { PHIGAP } \\ 46 & \text { RFLTAB }\end{array}$

$\begin{array}{rrrr}\text { LINK } & \text { O NAME } & \cdots & \text { IINK } \\ 12 & \text { COOLNT } & & \text { LINK } \\ 26 & \text { FCNKDP } & & 14 \\ 28 & \text { FOPLI } & & 28 \\ 22 & \text { FPOLY } & & 22 \\ 22 & & 22 \\ 34 & \text { INPIIT } & -\cdots & 34 \\ 80 & \text { PREPAR } & & 42 \\ 48 & \text { SOURCE } & - & 50 \\ 56 & & & \end{array}$

-ASE 20,0/1OBORO/1150000

TASEMA OIFEERTIATA3.

SUSE ?l, ,DIFFEODDATA3.

sASO 22,0/100000//150000

vasgiax coparotaflem

-USE O, , COPAR TARLE.

SACO.T $24 ., F$

DAsB, 13,U,TROT

a450, 14,11,7945

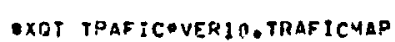




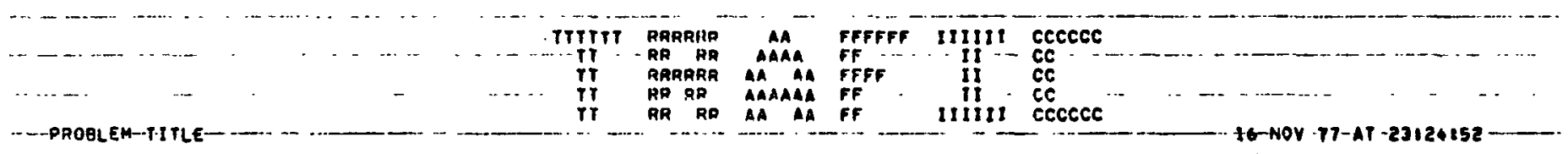

CORE-SURVEY RUN FOR TRAFIC-VALIOATION

... MAIN INPITT IS- FROM SURVEY TAPES ON UNITS.13 ANO 14- 


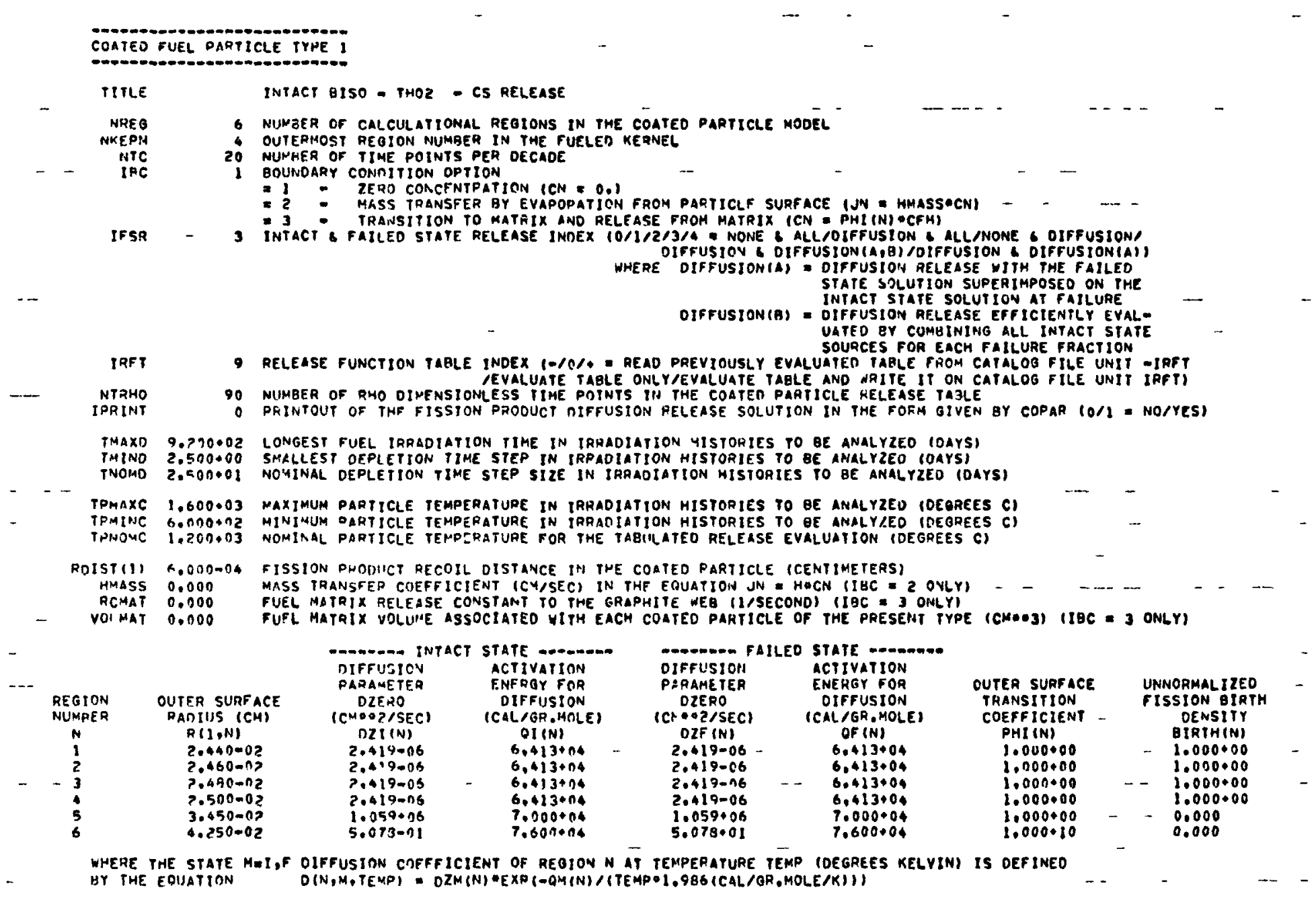




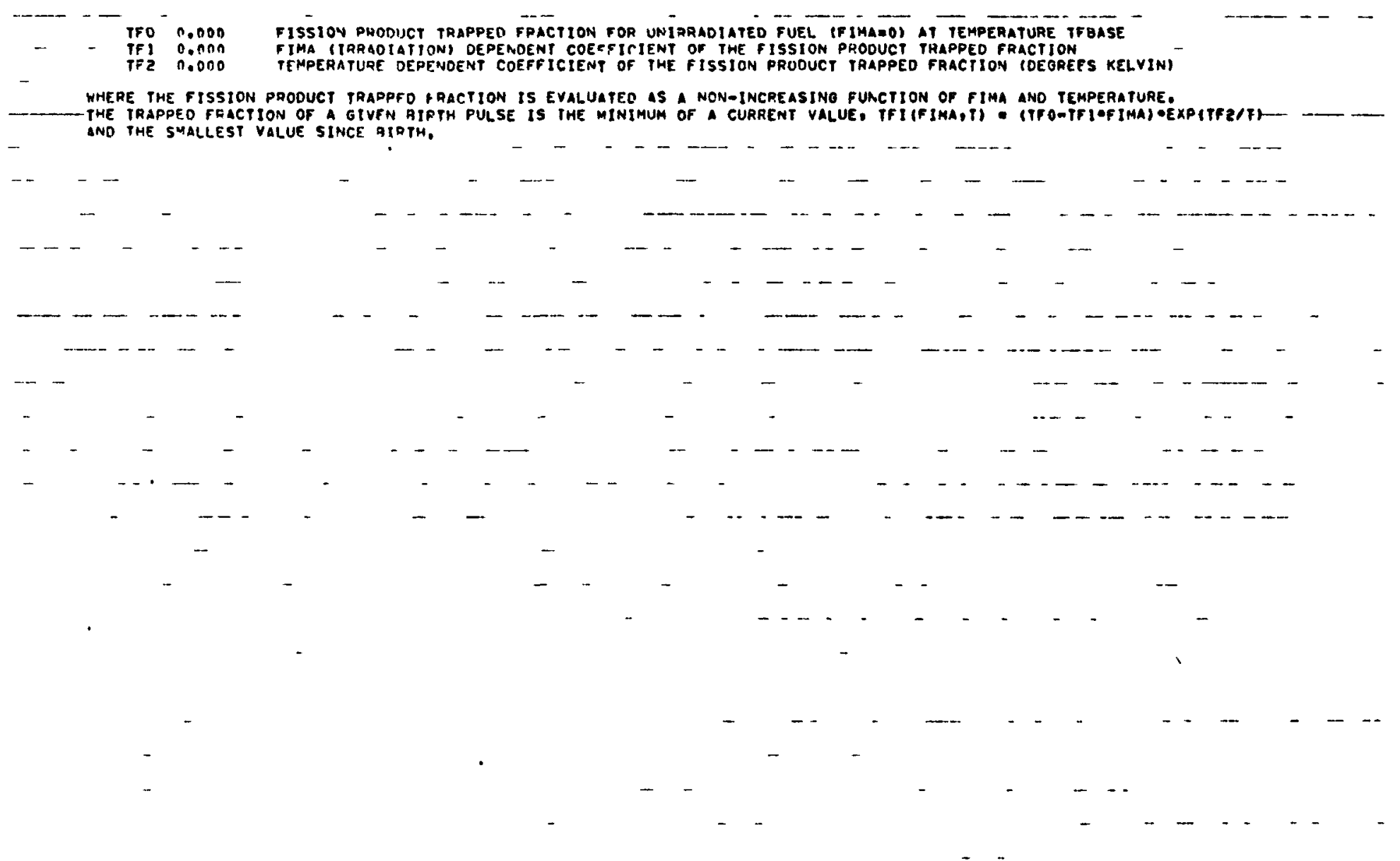


- - table of papameters for evaluating fission product release fróm coateo fuel particle irpe i im its intät and falleo states

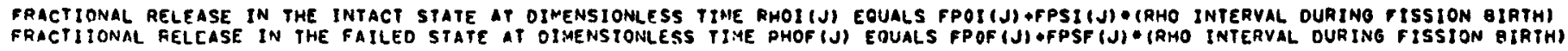

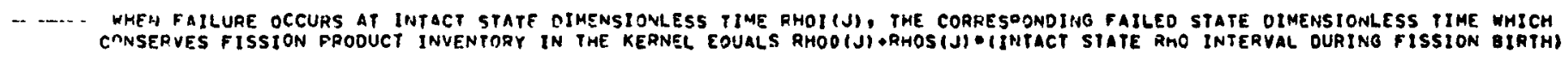

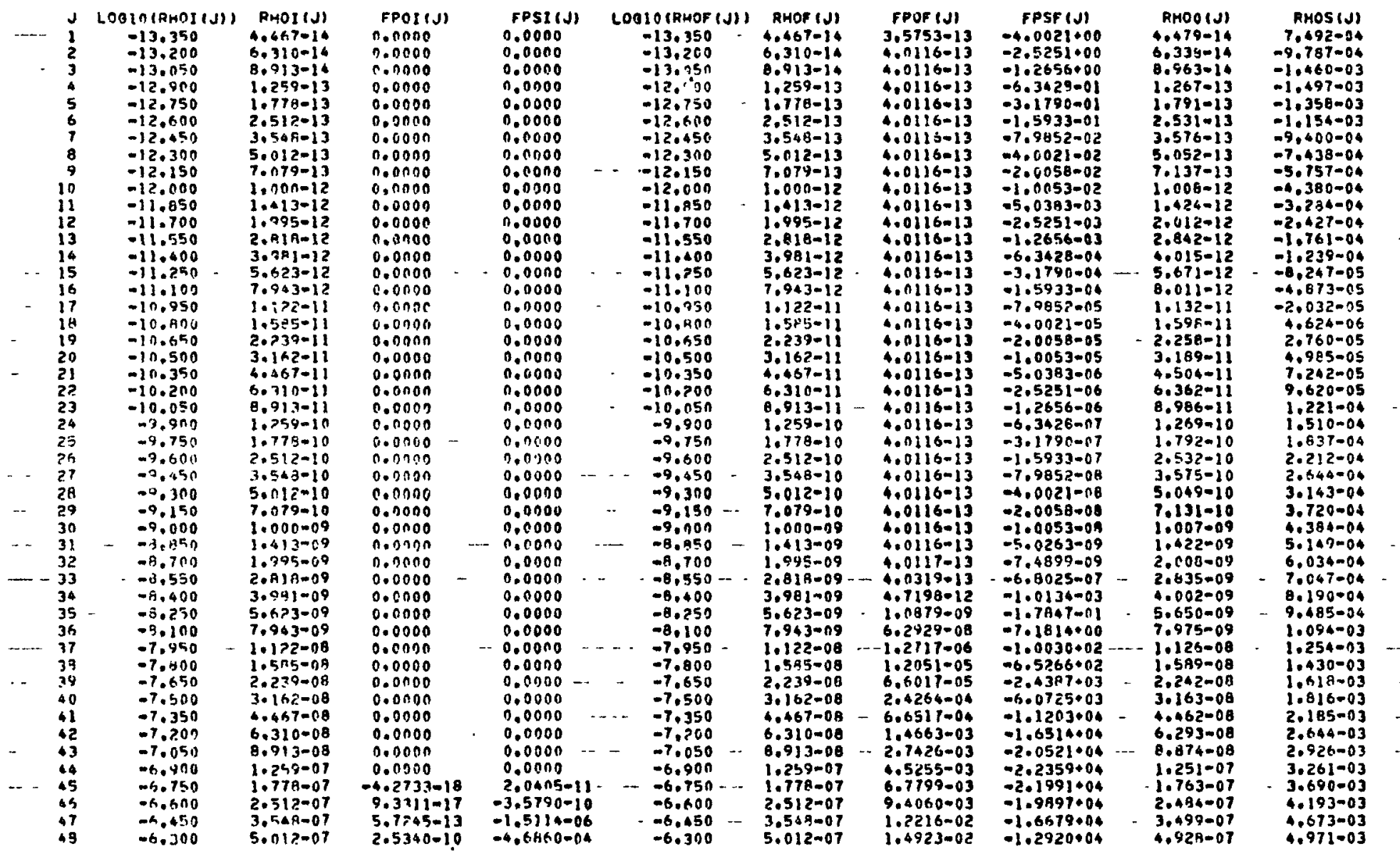




$\begin{array}{ccccccccc} & & & & \\ 0\end{array}$




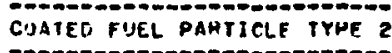

\section{conser}

TITLE INTACT thISO - UCz - CS RELEASE

NOEG O NUMAER OF CALCIULATIONAL REOTONS IN THE COATED PARTICLE MODEL

NKEPM

O OUTERAOST PEGTON NUHPER IN THE FUELED KERNEL PARTICLE MODEL

O NUMBER OF TIME POINTS PER DECADE

COUNDARY CONOITION OPIIDN

- 1 - ZEPO CMNCENTHATION ICN a 0.1

$\cos$

IFSA

- INTRCT FTANSITION TO HATRIX AND RELEASE FROM MATRIX (CM. PHI (N) OCFM")

0/3/2/3/4 " NONE BALL/OIFFUSION \& ALL/NONE G OIFFUSION/,

WMERE OIFFUSIONIA - DIFFUSION RELEASE WITH THE FAlLED

STATE SOLUTION SUPERIMPOSED ON THE

DIFFUSIONIBI = OIFFUSION RELEASE EFFICIENTLY EVAL-

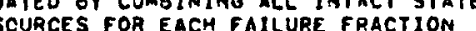

IAFT

- RELEASE FUNCTION TABLE INDEX IO/O/. EREA PREVIOUSLY EVALUATED JABLE FAOM CATALOO FILE UNIT -IAFT

NTRHO

- NUMEER OF RHO nIMENSIOMLESS TIME POINTS IN TME COATEO PARTICLE RELEASE TAPLE

IPOINT

PRIMTOLT OF THE FISSION PRGDUCT OIFFUSION RELEASE SOLUTION IN THE FORM GIVEN BY COPAR $10 / 2$ = NO/YES)

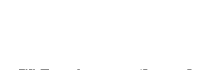


$-\quad-$

T TFO 0.000

FISSION PROUUCT TRAPPEO FRACTION FOR UNIPRADIATEO FUEL (FIMAEOT AT TEMPERATURE TFBASE

FIMA IIRPADIATIONI DFPENDENT COEFF ICIENT OF PME FISSION PHOOUCT TRAPPEO FRACTION
TEMPERA TURF DFPENDFNT COEFFICIENT OF THE FISSION PRODUCT TRADPED PRACTION (DEGREES KELVINI

WMERE THE FISSION PQODUCT THAPDEU FPACTION IS EVALUATEO AS NOV-IHCREASING FUNCTION OF FIHA ANO TEMPERATURE.

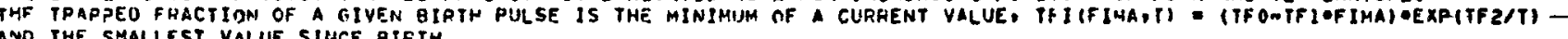

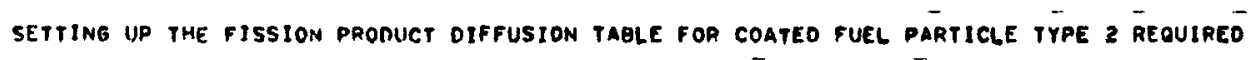

.126 SECONOS

$-$

CARD 3 I DIFFUSION AYO DECAY PARAMETERS

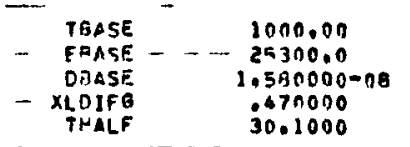

ReFE DENCE TEMPERATUPE (OEGREES C)

DIFFUSTON ACTIVATION ENERGY (CALORIES/GRAM MOLE)

DIFFUSION COEFFICIENT IN THE GRAPHITE MATERIAL AT TEMPERATURE TBASE (CMA 2 ASEC)

NIFFUSICN DISTANCE THROUGH THE GRAPHITE (CM)
PAOIOACTIVE DECAY HALF LIFE OF THE FISSICN PRODUCT ISOTOPE (VEAR)

THE TEMPEAATUPE DEPENDENT DIFFUSION COEFFICIENT IN THE FUEL OR GAAPMITE HATERIAL IS DEFINED GY

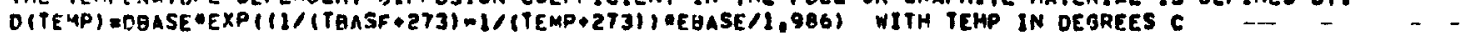

- caro 4 i-vapor paessure vs F.p.concentration parameters for the graphite material

\begin{tabular}{|c|c|}
\hline $\begin{array}{r}\text { ACPS } \\
\text { BCPO } \\
\text { CPPS } \\
\text { DCPG } \\
\text { CTRANG } \\
\text { PHOG }\end{array}$ & $\begin{array}{r}7.09000 \\
-2760000 \\
-5100000 \\
1170000 \\
1300000 \\
1.72000\end{array}$ \\
\hline & \\
\hline
\end{tabular}

aOSORPTION COEFFICIENT a FOR THE GRAPHITE MATERIAL ADSCRPTION COEFFICIENT B FOR PME GRAPHITE MATEATAL ADSORPTION COEFEICIENT D FOR THE GRAPPHTE MATERIAL THE OAAPHE TROM LANG DENSITY OF THE GRAPHITE MATERIAL (ORAMSICMOESI

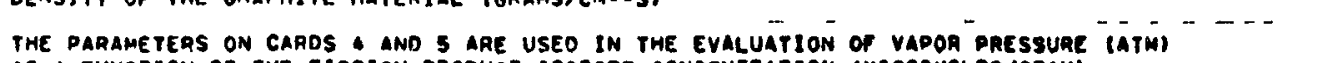

AS FINCTION OF TME EISSION PRODUCT ISOTOPE CONCEMTRATION (MICROMOLESIGRAM

$P=X$ OCONCAOY
(CONCDCTRANI FREUNDLICH BEHAYIOA) HHERE $X=E X P(A+B / T E M P(X))$

OH PaX OCOMCOCTRAN*O(Y-1) (CONCECTRANI LANGMIUR REHAVIOR)

$Y=C+D / T E M P(K)$

CARD 5 I VAPOR PRFSSUAE VS F.P. CONCENTRATION PARAMETERS GOR IME FUEL MatriX material

$\begin{array}{rr}\text { ACFF } & 8.39000 \\ \text { OCPF } & -3930000 \\ \text { CCPF } & -50000 \\ \text { DCFF } & 1100.00 \\ \text { CTRANF } & 4.00000 \\ \text { RHOF } & .286000\end{array}$

AOSORPTION COEFFICIENT A FOR THE FUEL MATRIX MATERIAL

ADSORPTION COEFFICIENT O FOR THE FUEL MATRIX MATERIAL

AJSOPPTION COEFFICIENT C FOR THE FUEL MATAIX MATERIAL

TRANSITION F.P. CONCENTRATIOH FOH CHANGE FROM LANGHIUR TO FREUNOLICH BEHAVIOR (MICROMOLES/GRAM)

DENSITY OF THE FUEL MATRIX MATERIAL IGRAMSICMOAJI

CARD 6 I HELIUM CODLANT PARAMETERS

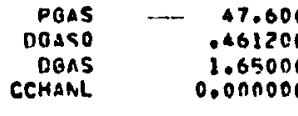

PRESSURE OF THE HELIUM COOLANT (ATM)

APONENT IN THF HEL IIJM COOLANT DIFFUSION COEFFICIENT EOUATION

作

THE TEMPERATURE OEPENDENT HELIUM OIFFUSION COEFFICIFNT AND VISCOSITY ARE OEF INED OY :

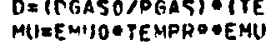

ARE IN UNITS OF DEOREES KELYIN AND RANKINE, RESPECIIVELY,

GARN? YIELOS 


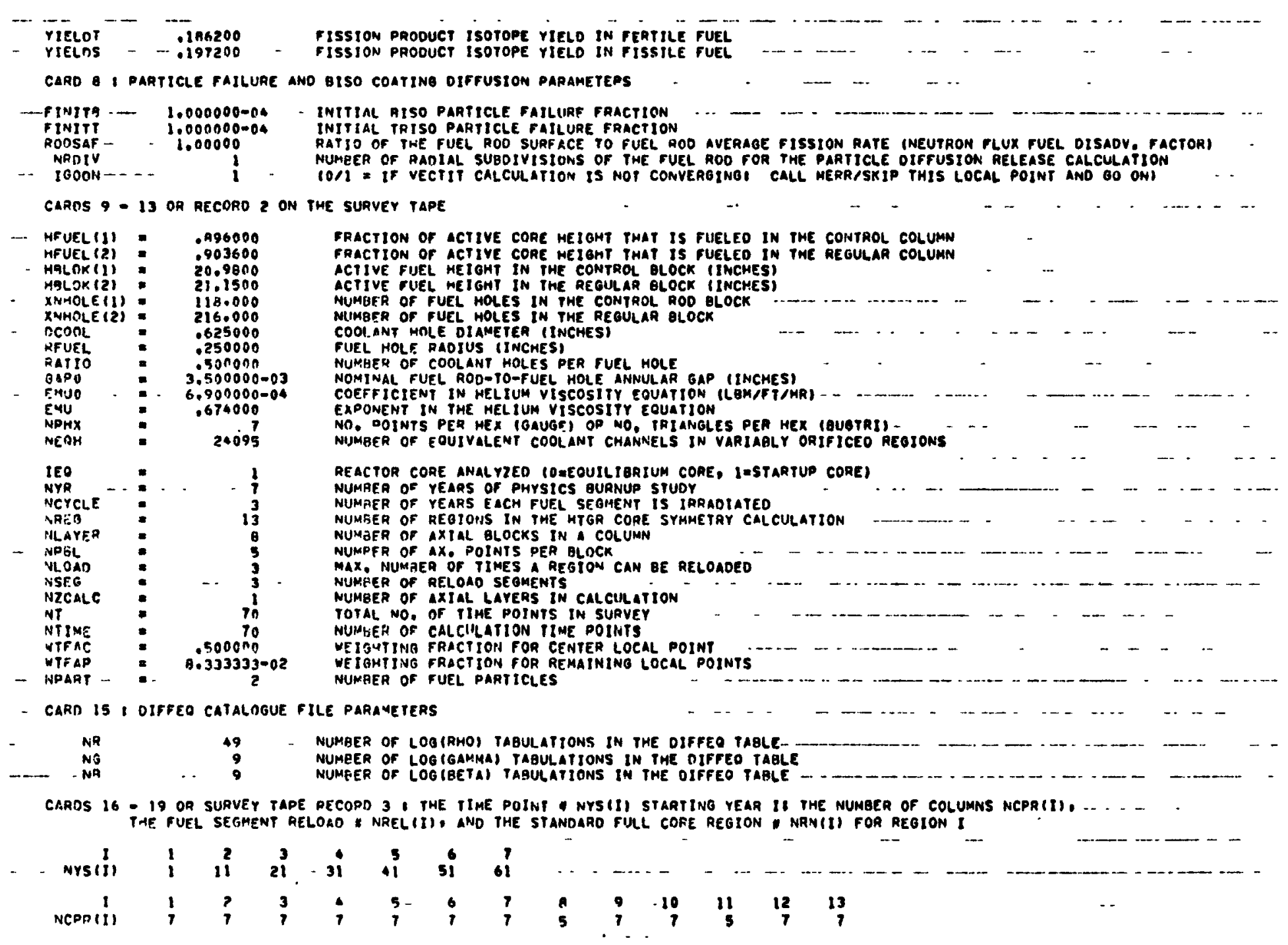




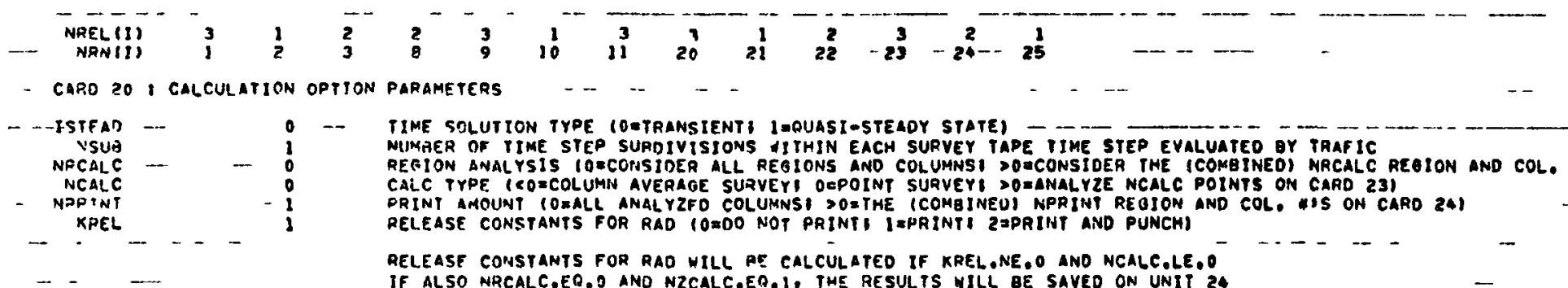

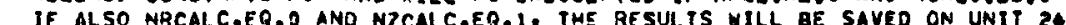

calculations will de peffopmeo for all aegtons ano columas

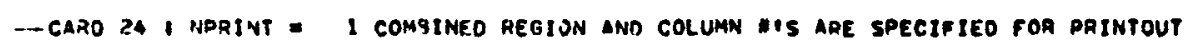

NRCP III 54

- CAND 25 I ParametFa aOJUSTMENT factors for the trafic analysis

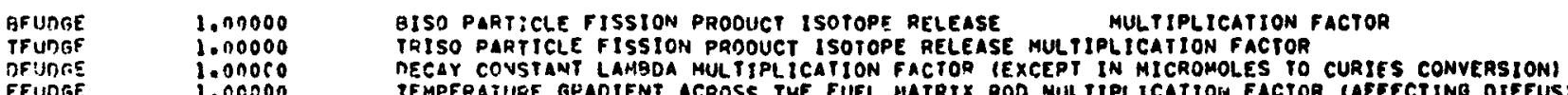

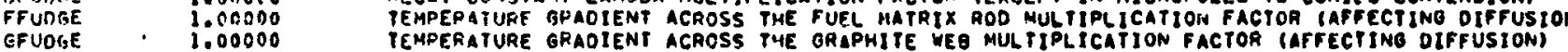

SUPVEY TAPE TIME POINT DESCRIPTIONS FOR 70 TIME POINTS (YR PT.),

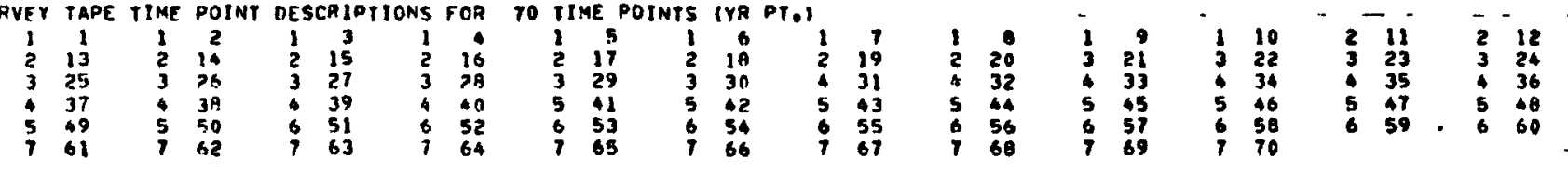

USING 54AD OF 21262 LOCATIONS OF THE A MRRAY 


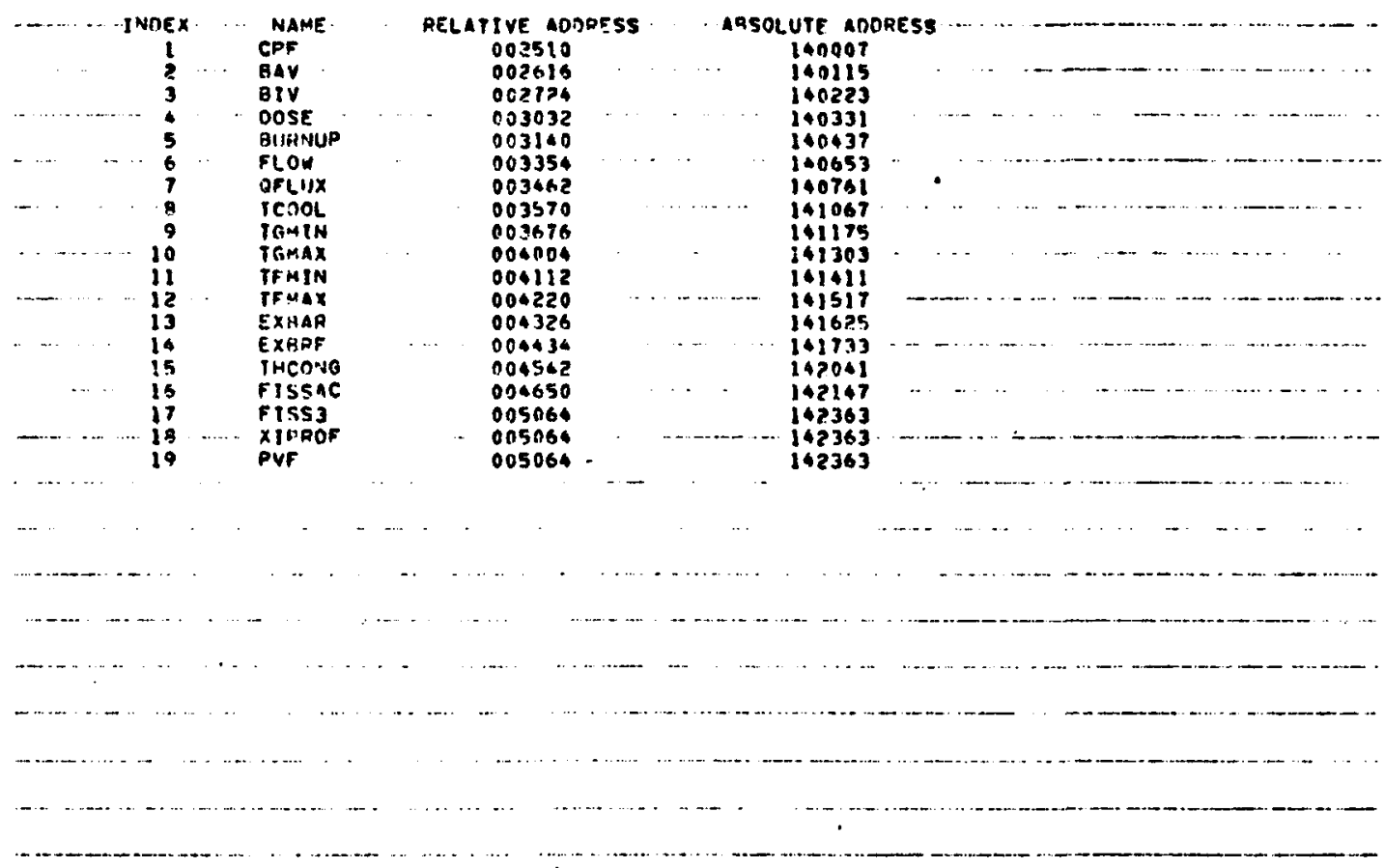




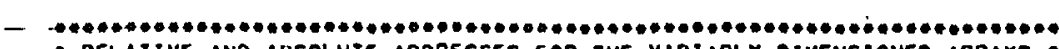

DRLATIVE AND ABSDLUTE AODRESSES FOR THE VARIABLY OIMENSIONEO ARRAYS :

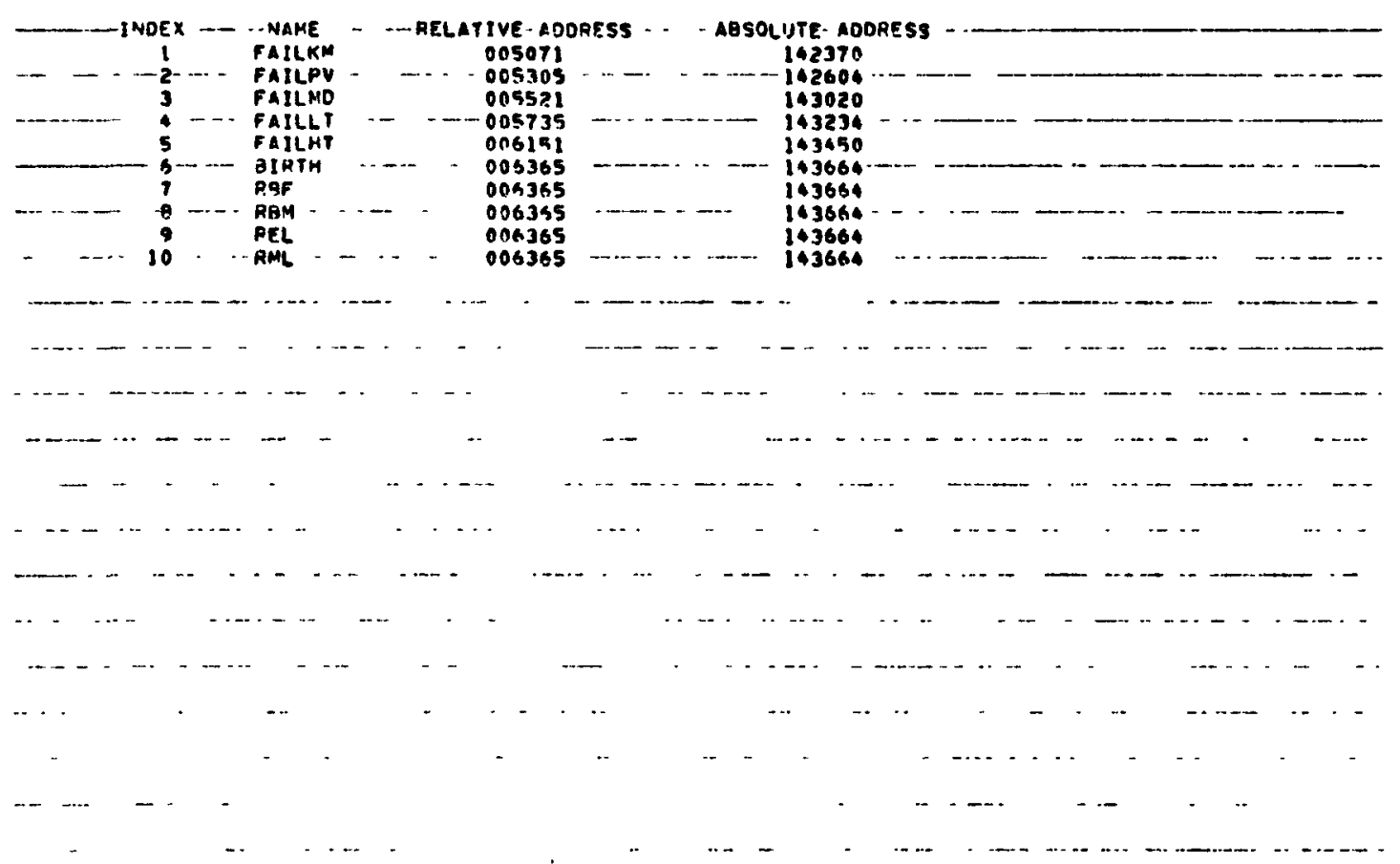




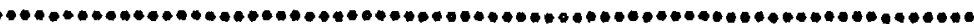
- RELATIVE AND AASOLUTE ADDRESSES FOQ THE VARIABLY OIMENSIONEO IRRAYS

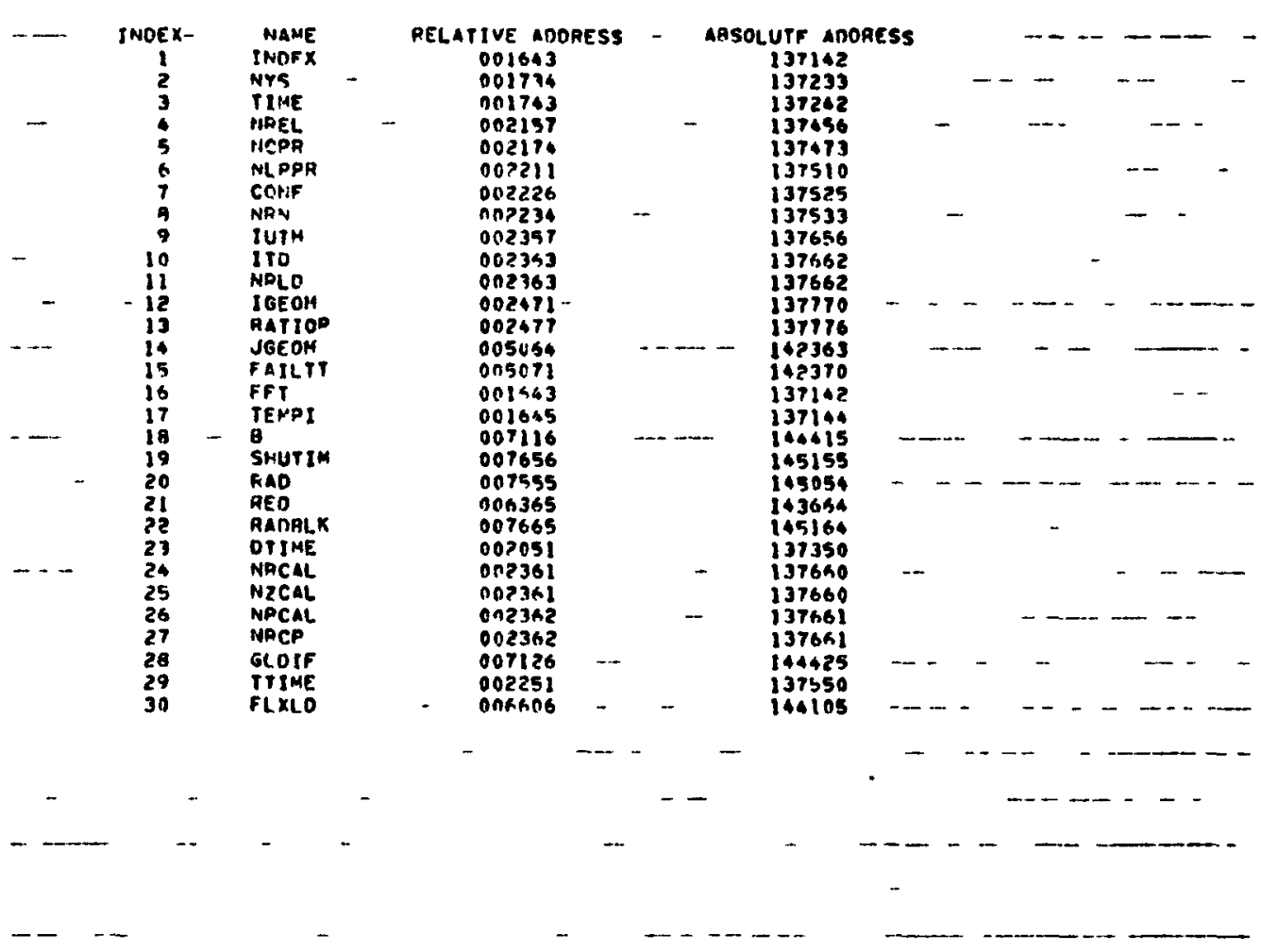




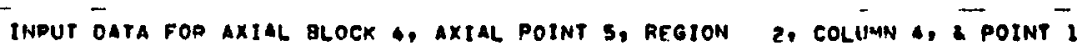

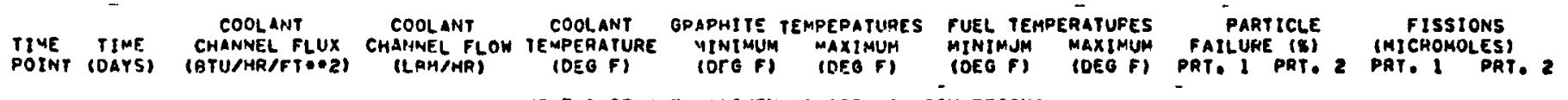

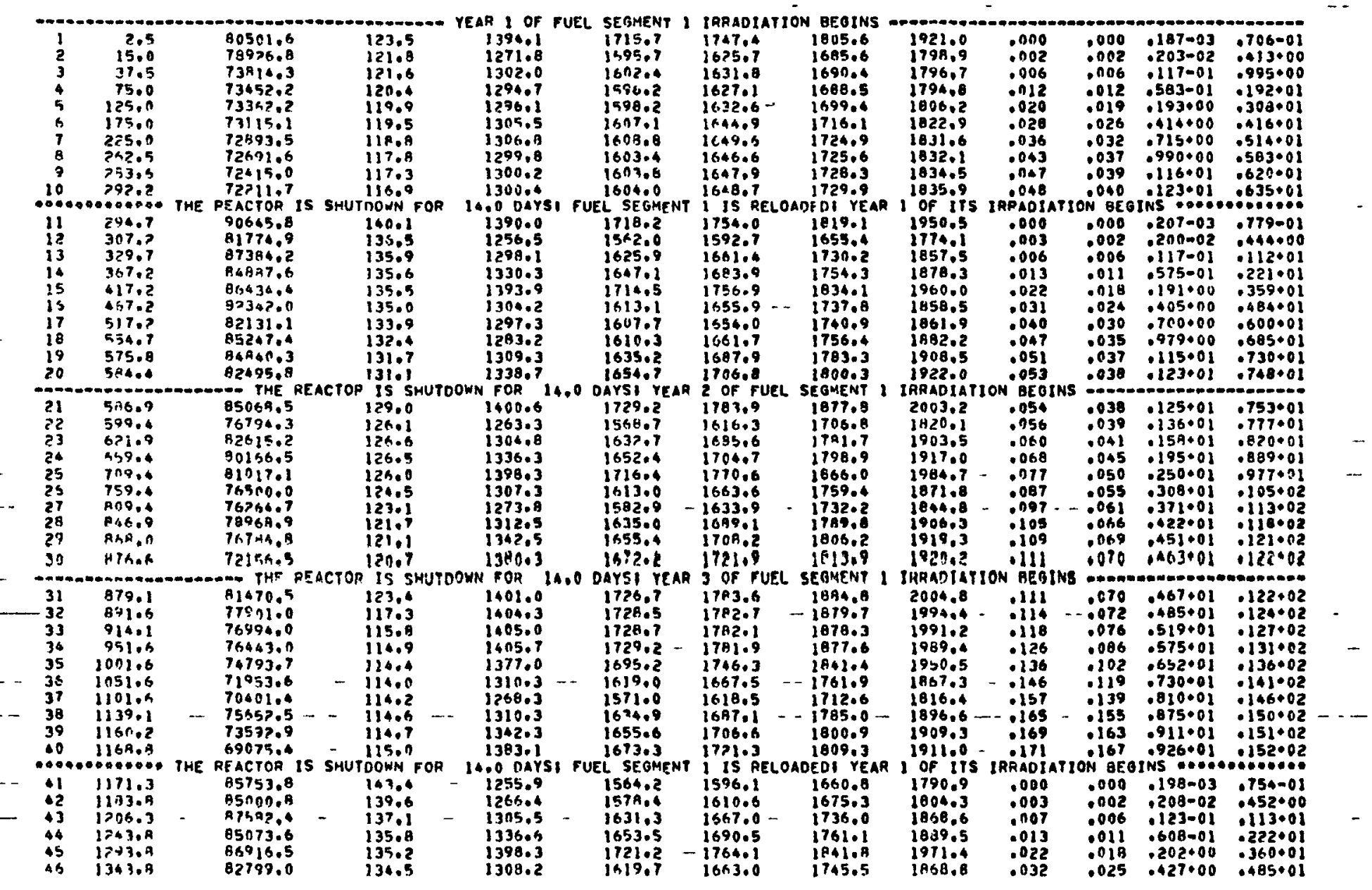




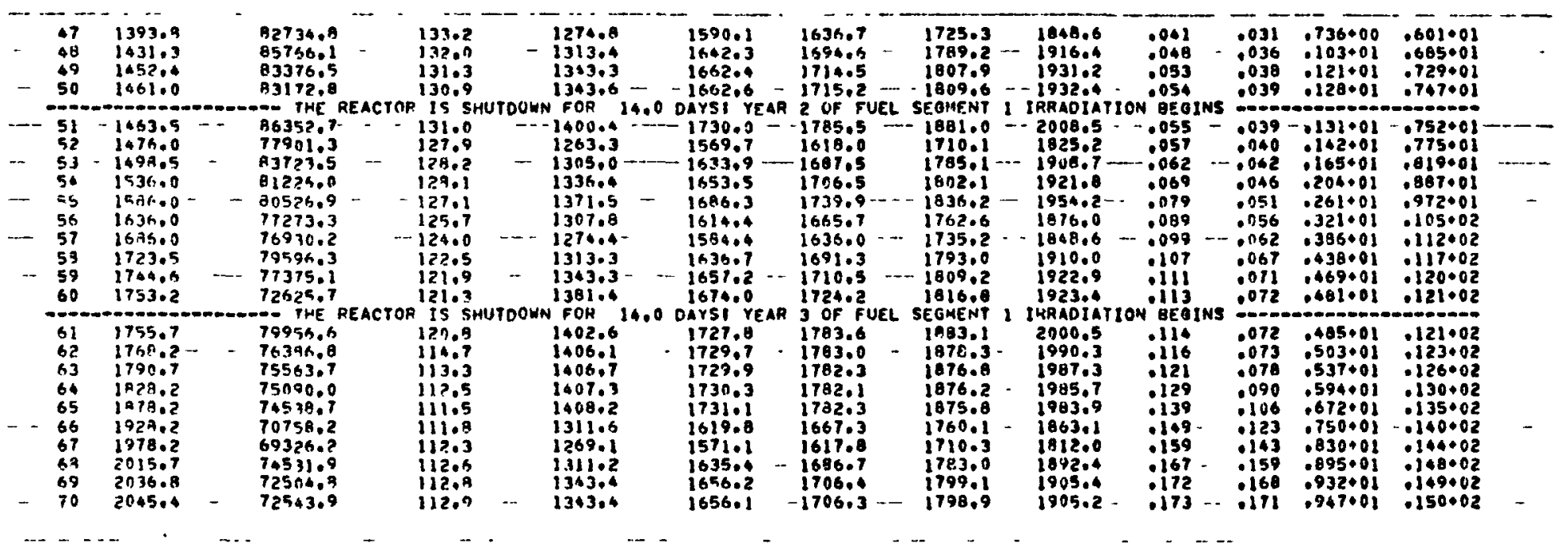




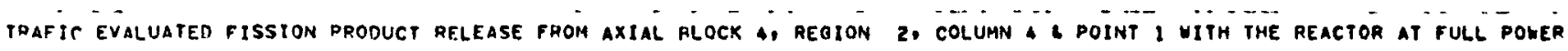

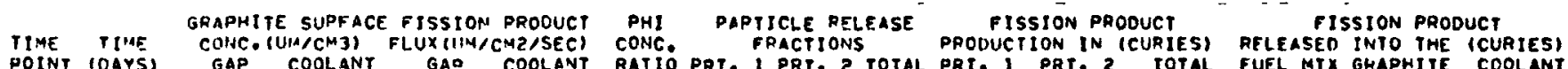

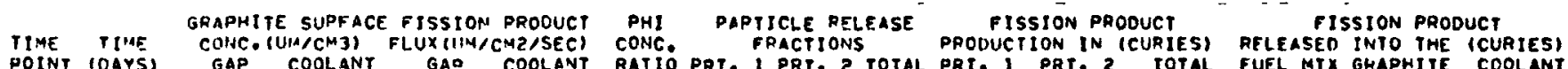

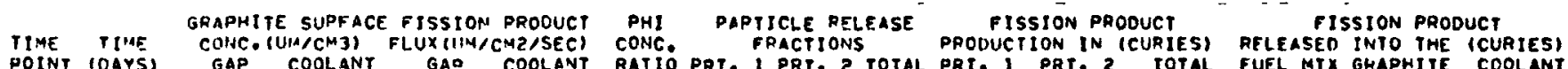

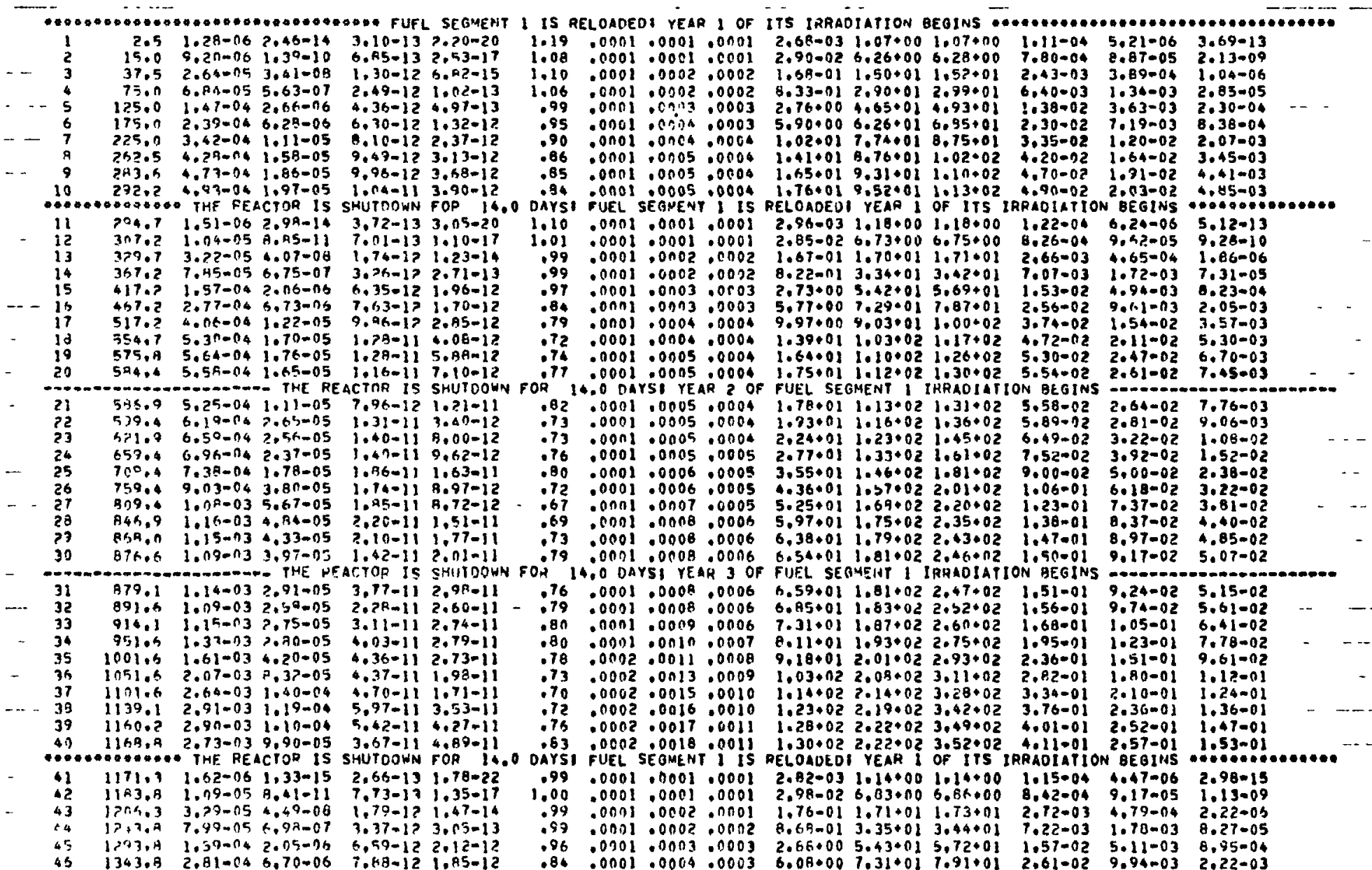




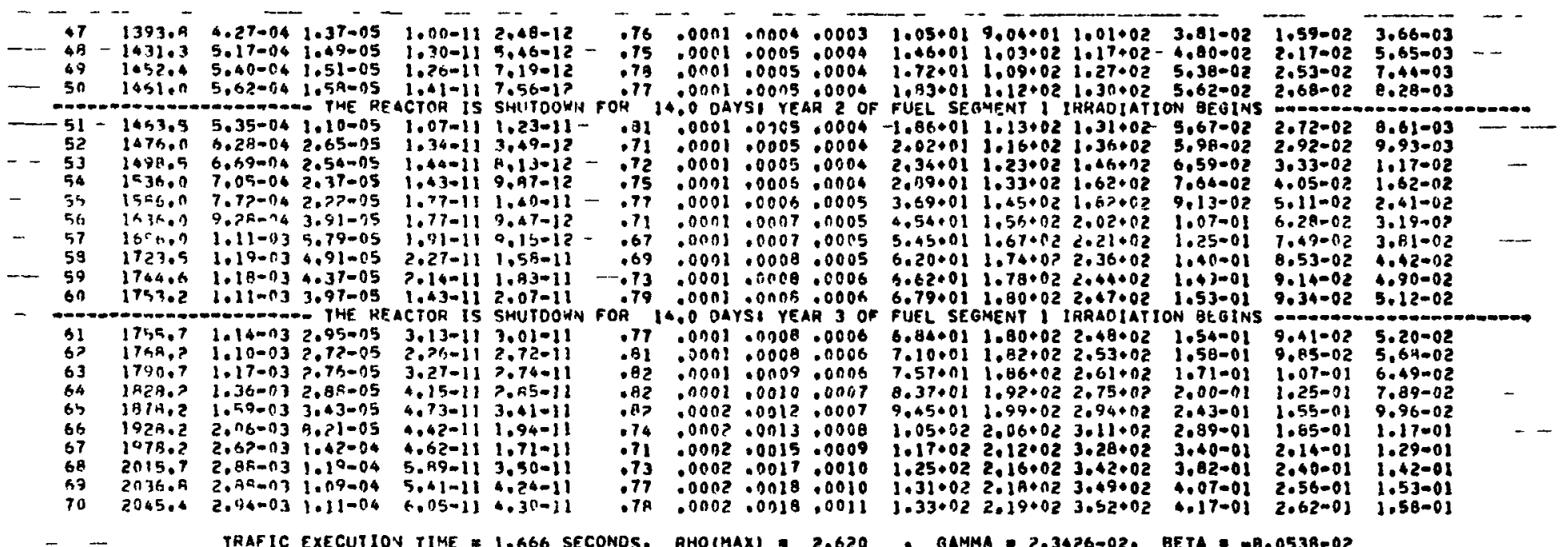

TRAFIC EXECUTION TIME $=1.666$ SECONOS, RHO(MAX) $=2.620$

GAMMA $=2.3426-02$, BETA $=-0.0538-02$

$$
-
$$


INPUT DATA FOR AXIAL BLOCK 4, AXIAL POINT 3, REOION 2 , COLUMN A, DOINT 2 COOLAVT COOLANT COOLANT GPAPHITE TEMPERATURES FUEL TEMPERATURES PARTICLE FISTIONS

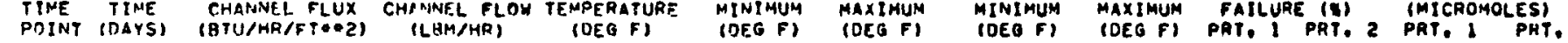

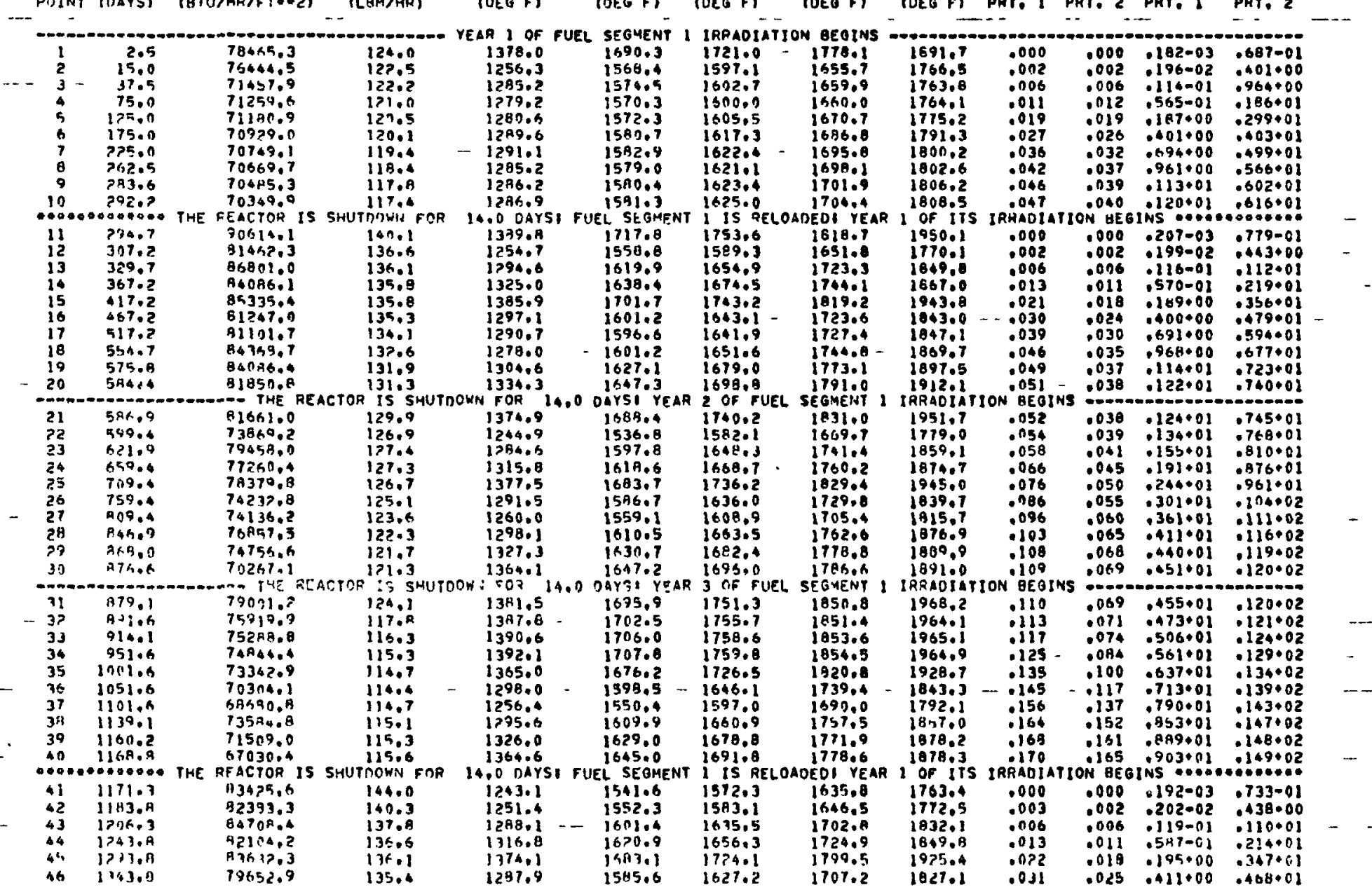




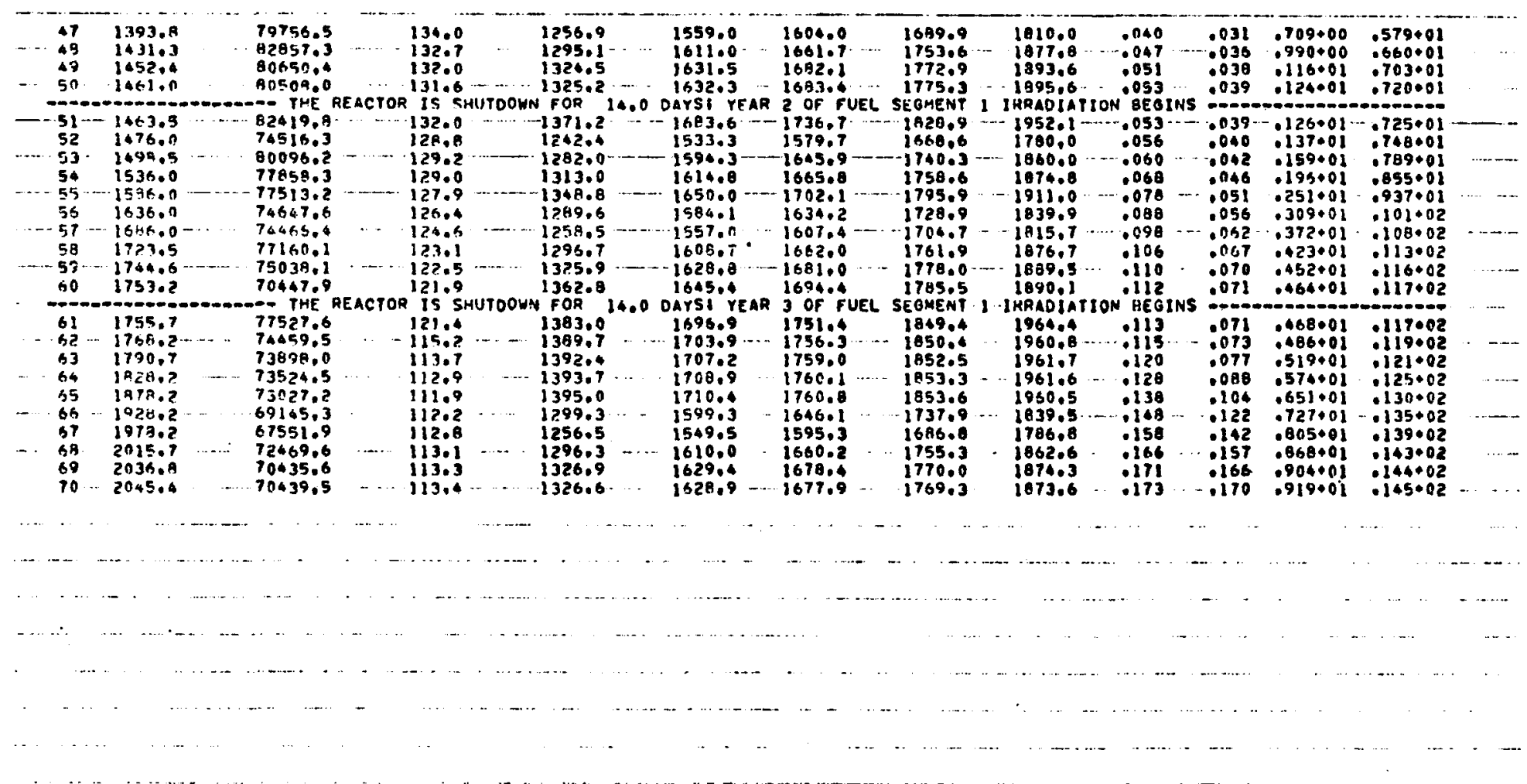


TRAFIC EVALUATED FISSION PRODUCT RELEASE FROM AXIAL RLOEK a, REgION 2 , COLUHA A POINT 2 WITH THE REACTOR AT FULL POWER GPADHITE SURFACE FISSION PPODUCT PHI PARTICLF RELEASE FISSTON PROOUCT PRI FISSION PRODUCI

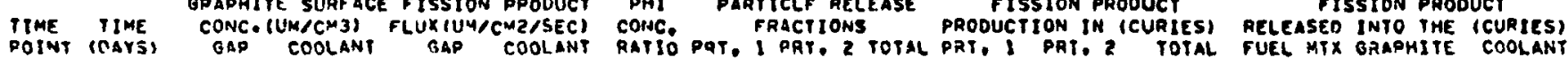

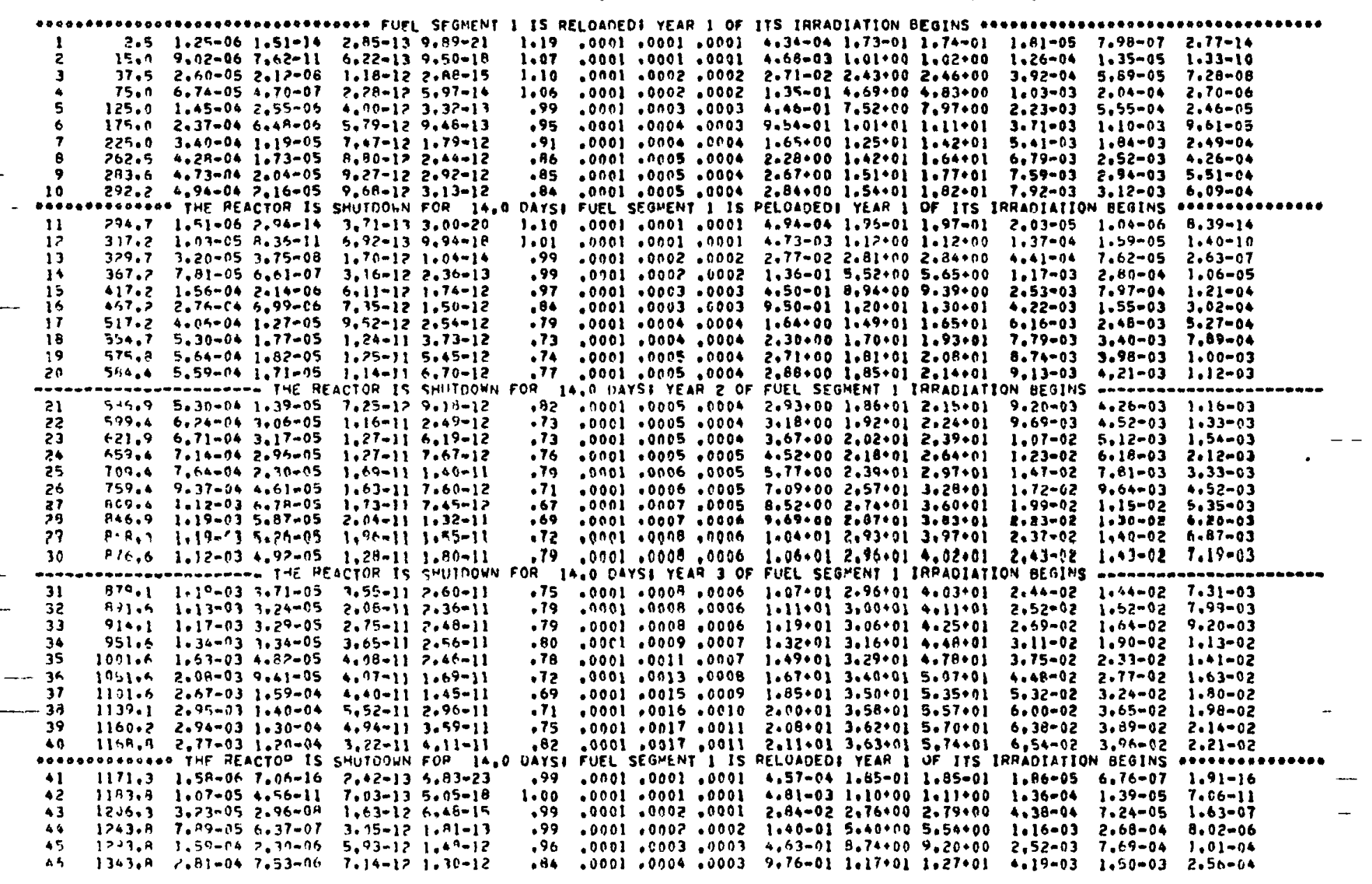




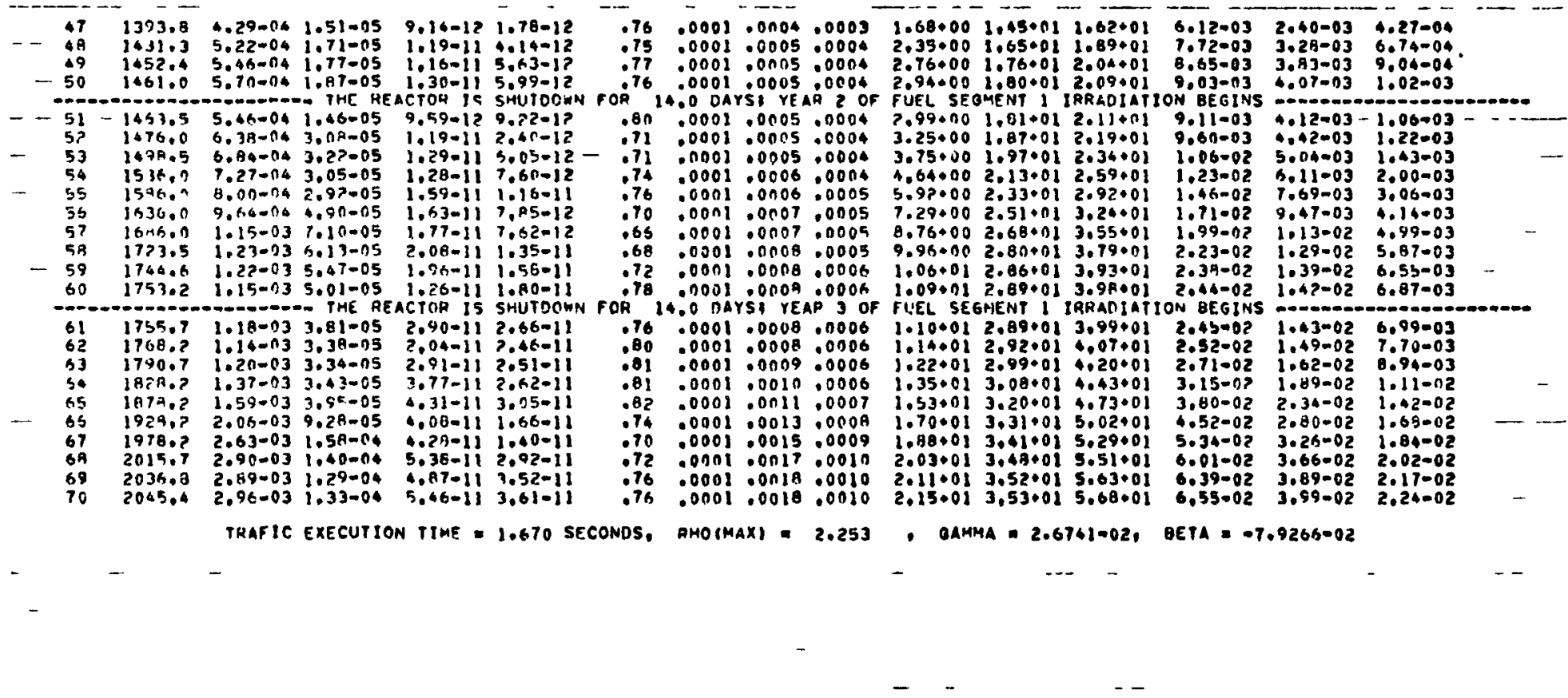




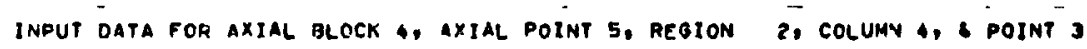

TIME TIME COOLANT COOLANT CODLANT GRAPHITE TEMFERATURES FUEL TEMPERATURES PARTICLE CHA FISSIONS

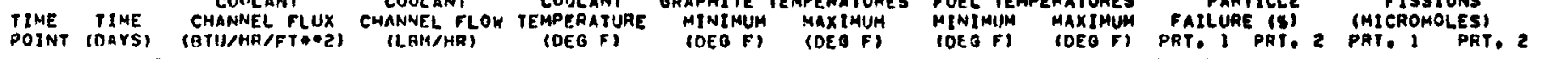

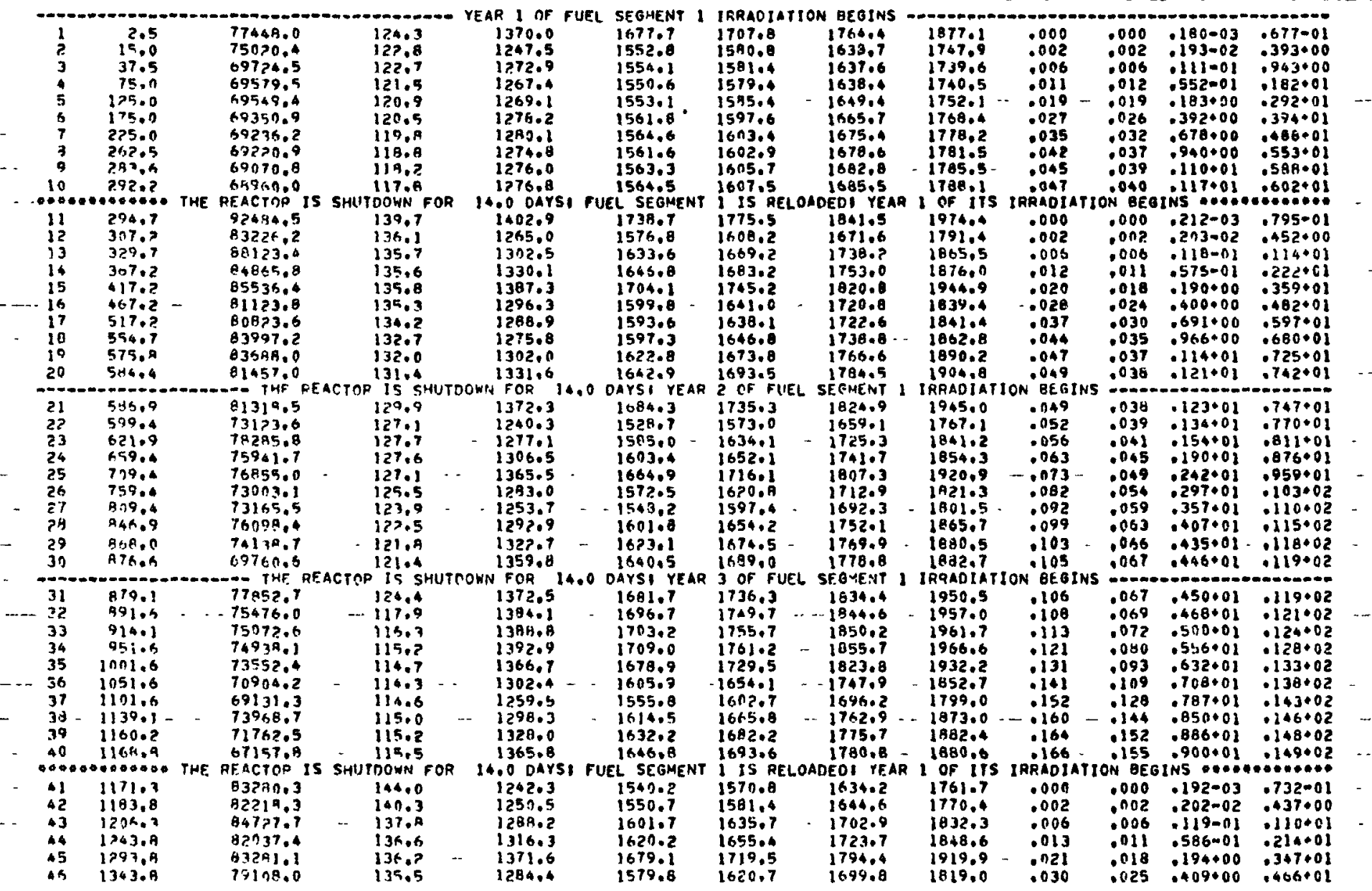




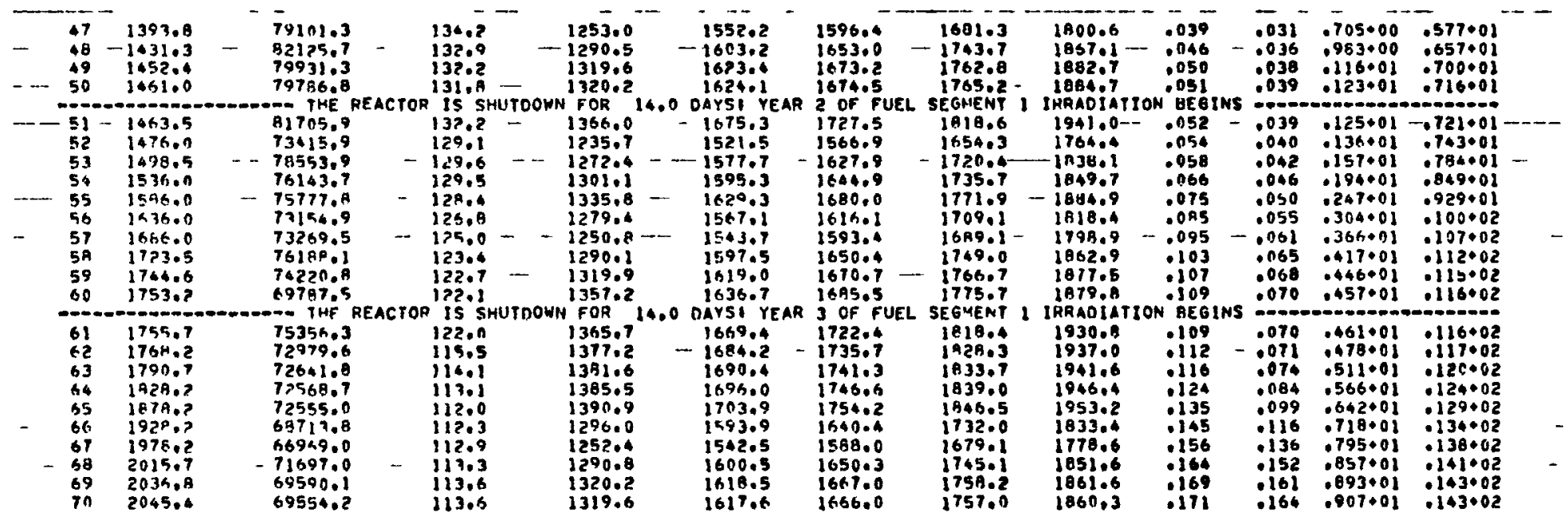


trafic evaluated fission ppoduct release from axial block a, recion 2 , column a point 3 with the reactor at full poner

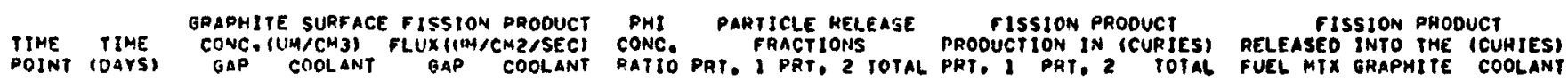

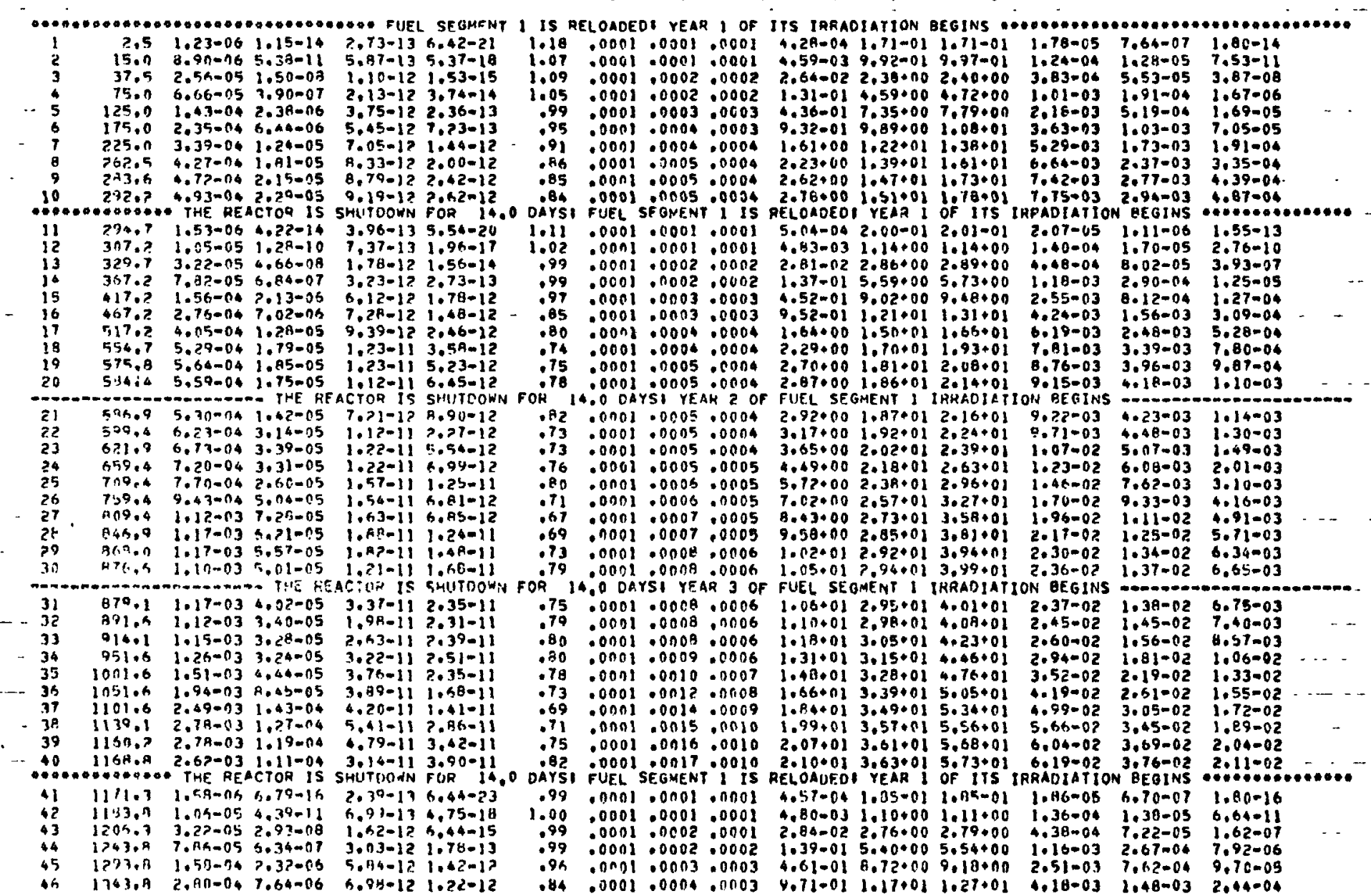




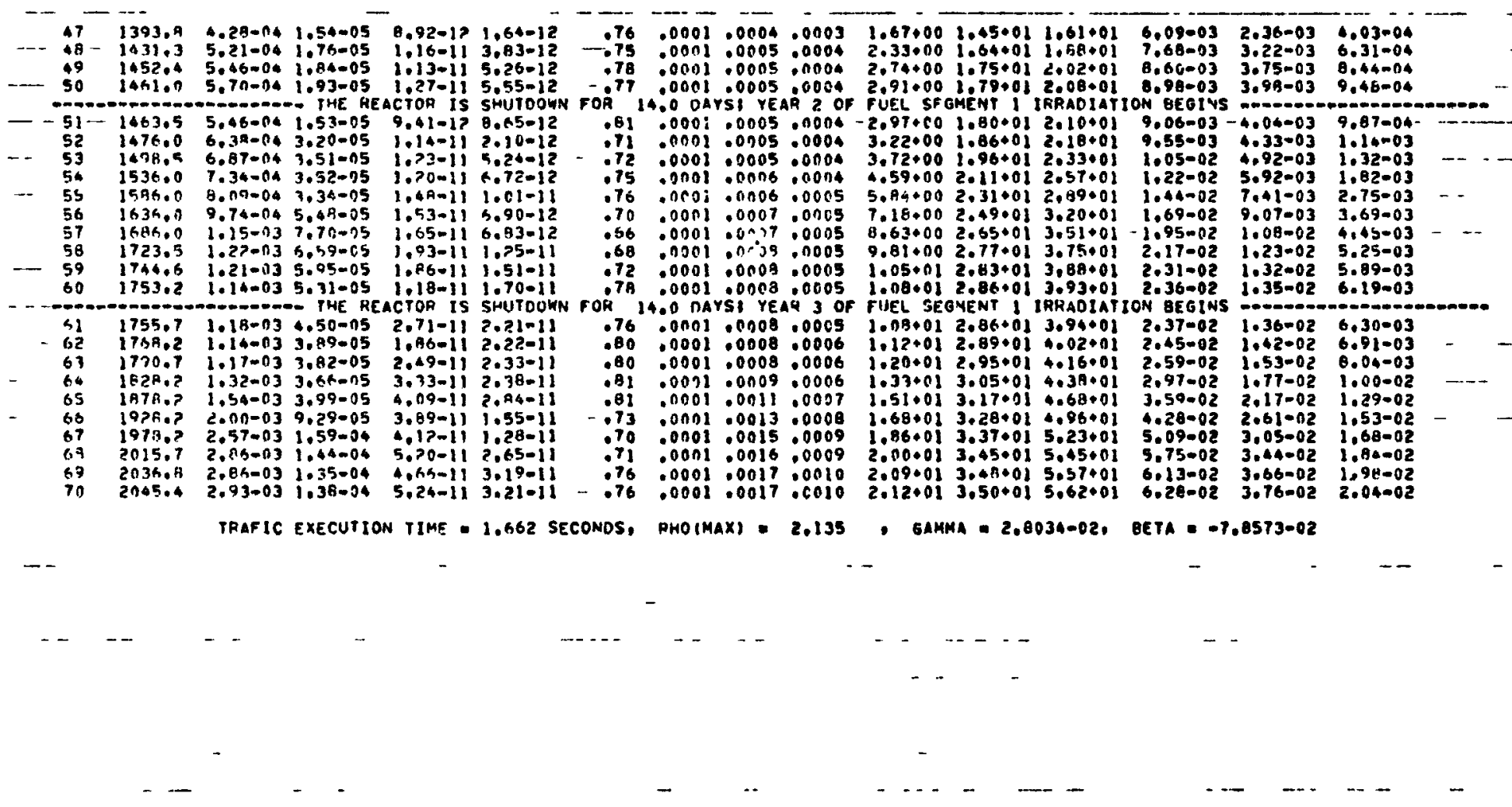




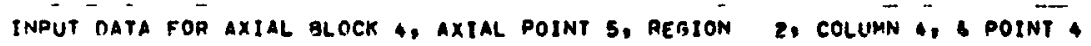

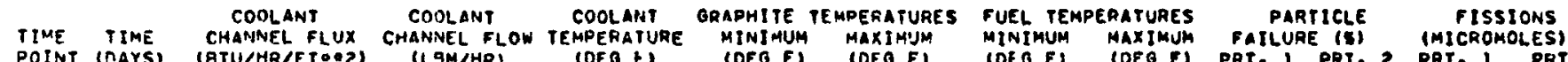

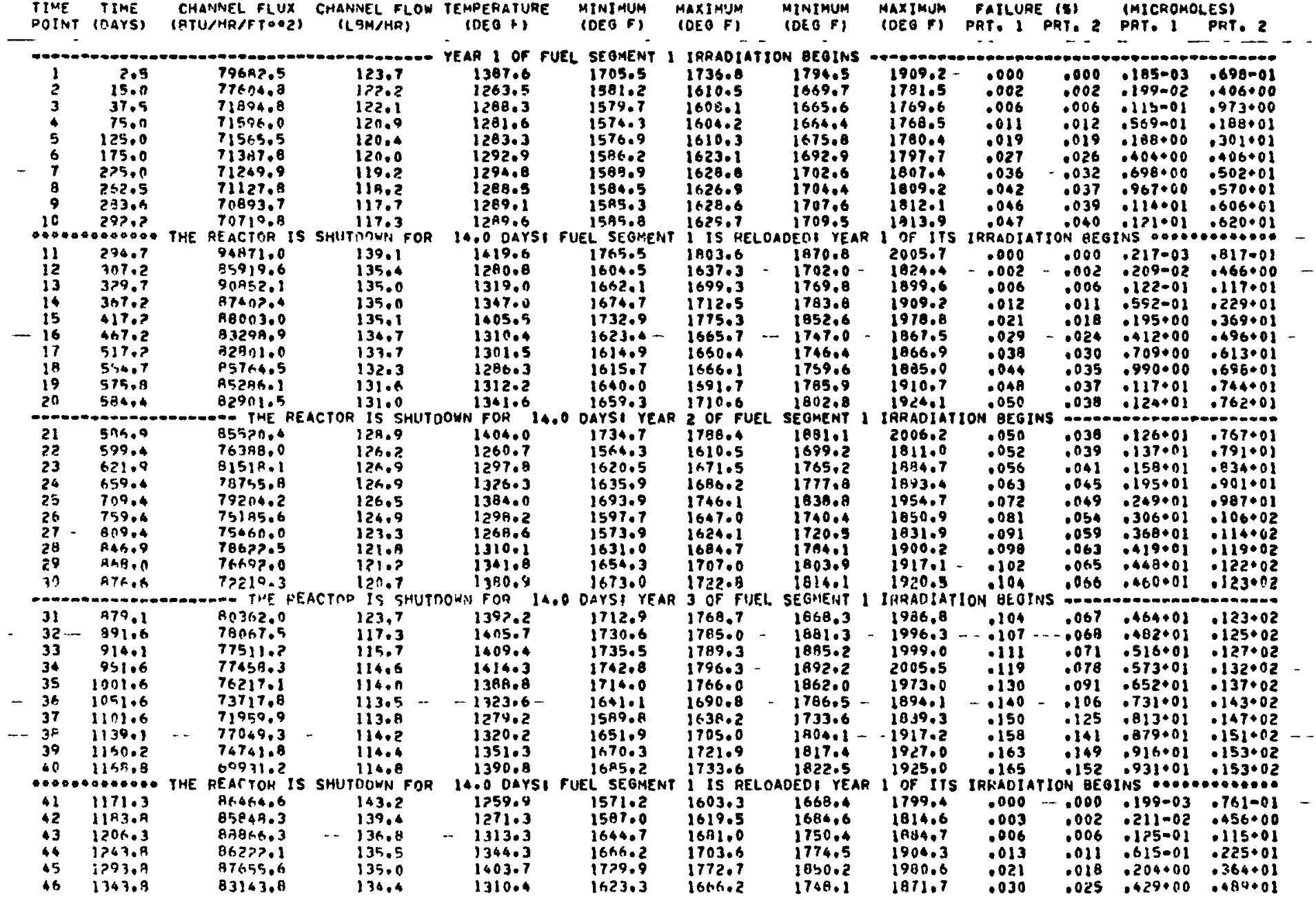




\begin{tabular}{|c|c|c|c|c|c|c|c|c|c|c|c|c|}
\hline $\begin{array}{l}47 \\
49 \\
49 \\
50 \\
0.9\end{array}$ & $\begin{array}{l}14520 \\
14610\end{array}$ & 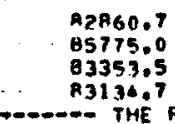 & $\begin{array}{l}133 . ? \\
332.0 \\
131.03\end{array}$ & $\begin{array}{l}1273.5 \\
4313.5- \\
1343.2\end{array}$ & $\begin{array}{l}159 \\
364 \\
166\end{array}$ & $\begin{array}{r}1837.4 \\
1693.0 \\
1713.5 \\
1719.1 \\
2 \text { of }\end{array}$ & $\begin{array}{r}1725.0 \\
17875 \\
18050 \\
1807 \\
\text { SECMENT }\end{array}$ & & $\begin{array}{r}039 \\
0.046 \\
0.050 \\
0.050\end{array}$ & 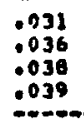 & $\begin{array}{l}739400 \\
103401 \\
121 * 01 \\
129+01 \\
129+1\end{array}$ & \\
\hline $\begin{array}{l}51 \\
52 \\
53 \\
54 \\
55 \\
56 \\
57 \\
59 \\
39 \\
30 \\
-90\end{array}$ & $\begin{array}{l}1463.5 \\
1476.0 \\
1498.05 \\
1536.0 \\
1596.0 \\
1636.0 \\
1696.0 \\
1723.5 \\
1740.5 \\
1753.2\end{array}$ & $\begin{array}{l}3 \\
8 \\
8 \\
8\end{array}$ & 87 & $\begin{array}{l}9 \\
6 \\
7 \\
7 \\
7\end{array}$ & 3 & $\begin{array}{l}0.5 \\
0.5 \\
0.1 \\
0.0 \\
0.0 \\
0.8 \\
0.6 \\
.0\end{array}$ & 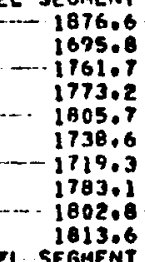 & $\begin{array}{l}0 \\
0 \\
0 \\
01 \\
0 \\
5 \\
7\end{array}$ & $\begin{array}{l}.055 \\
.059 \\
0.056 \\
0.075 \\
.075\end{array}$ & $\begin{array}{l}0.039-10 \\
0.040 \\
0.042 \\
0.046 \\
0.050 \\
0.055\end{array}$ & & $\begin{array}{l}01 \\
01 \\
02 \\
02 \\
02 \\
02\end{array}$ \\
\hline $\begin{array}{l}65 \\
66 \\
67 \\
68 \\
69 \\
76\end{array}$ & 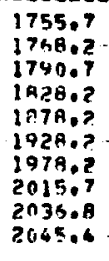 & 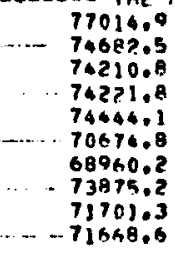 & $\begin{array}{l}i 13.7 \\
\text { lie.7 } \\
\text { 111.5 } \\
111.8 \\
112.4 \\
112.8 \\
113.8\end{array}$ & $\begin{array}{l}3378.9 \\
1391.6 \\
1395.0 \\
1399.7 \\
1307.4 \\
1310.9 \\
1266.5 \\
1306 \% 5 \\
3337 \% 0 \\
1336.4\end{array}$ & $\begin{array}{l}1690.4 \\
1706.9 \\
1711.5 \\
1718.4 \\
1729.8 \\
1618.9 \\
1566.6 \\
1627.3 \\
1605.8\end{array}$ & 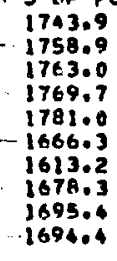 & $\begin{array}{l}17 \\
17 \\
37 \\
178\end{array}$ & & 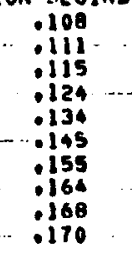 & $\begin{array}{c}0.069 \\
0071 \\
0.074 \\
0.083 \\
0998 \\
0115 \\
0135 \\
0151 \\
0160\end{array}$ & & \\
\hline
\end{tabular}




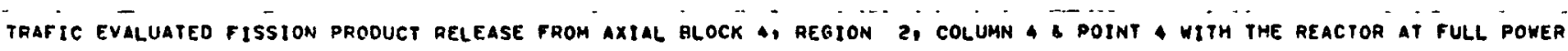

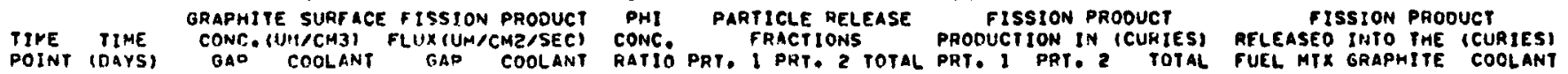

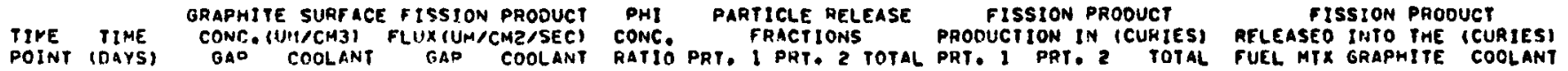

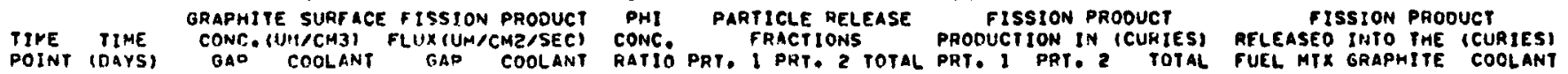

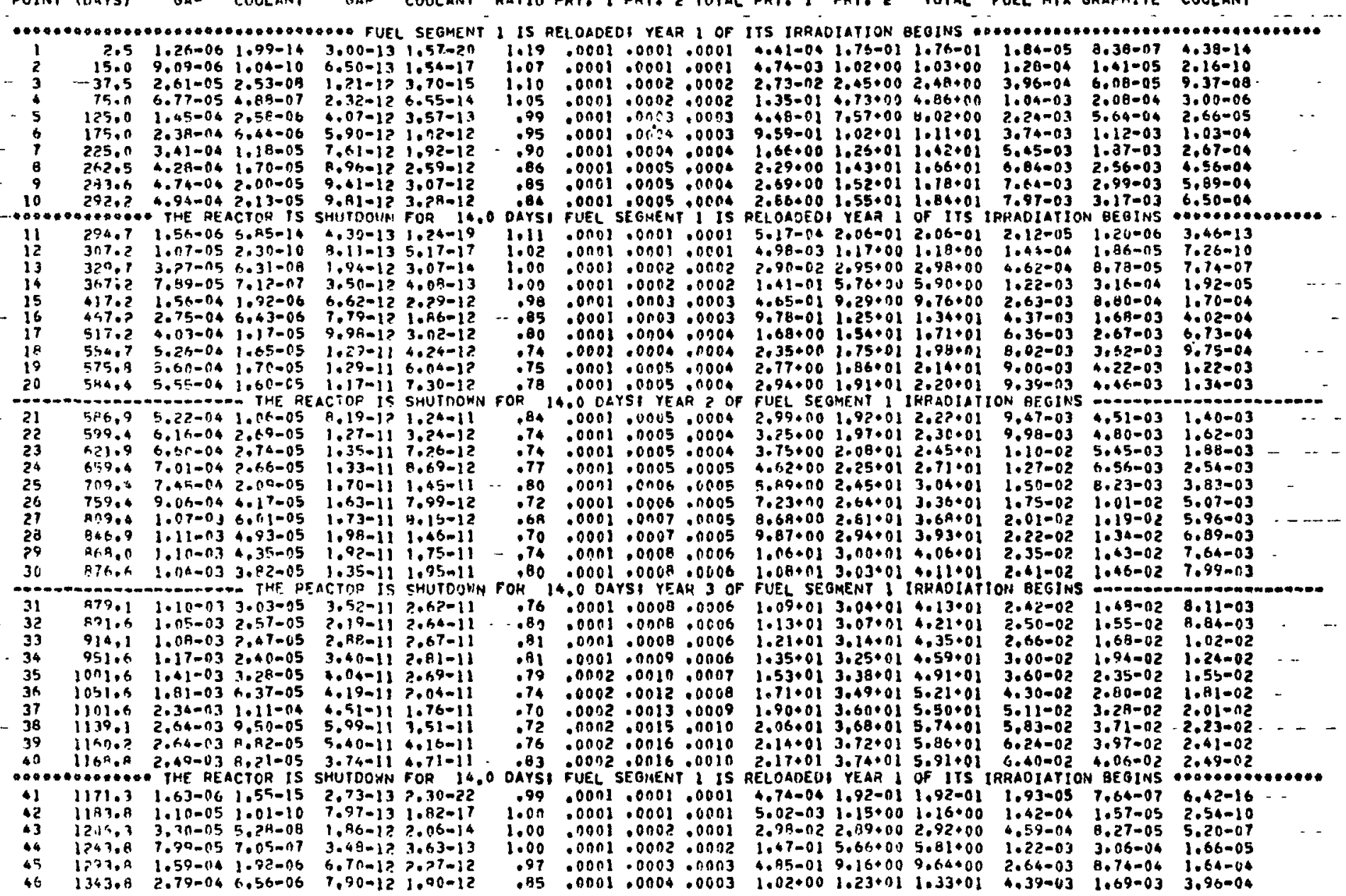




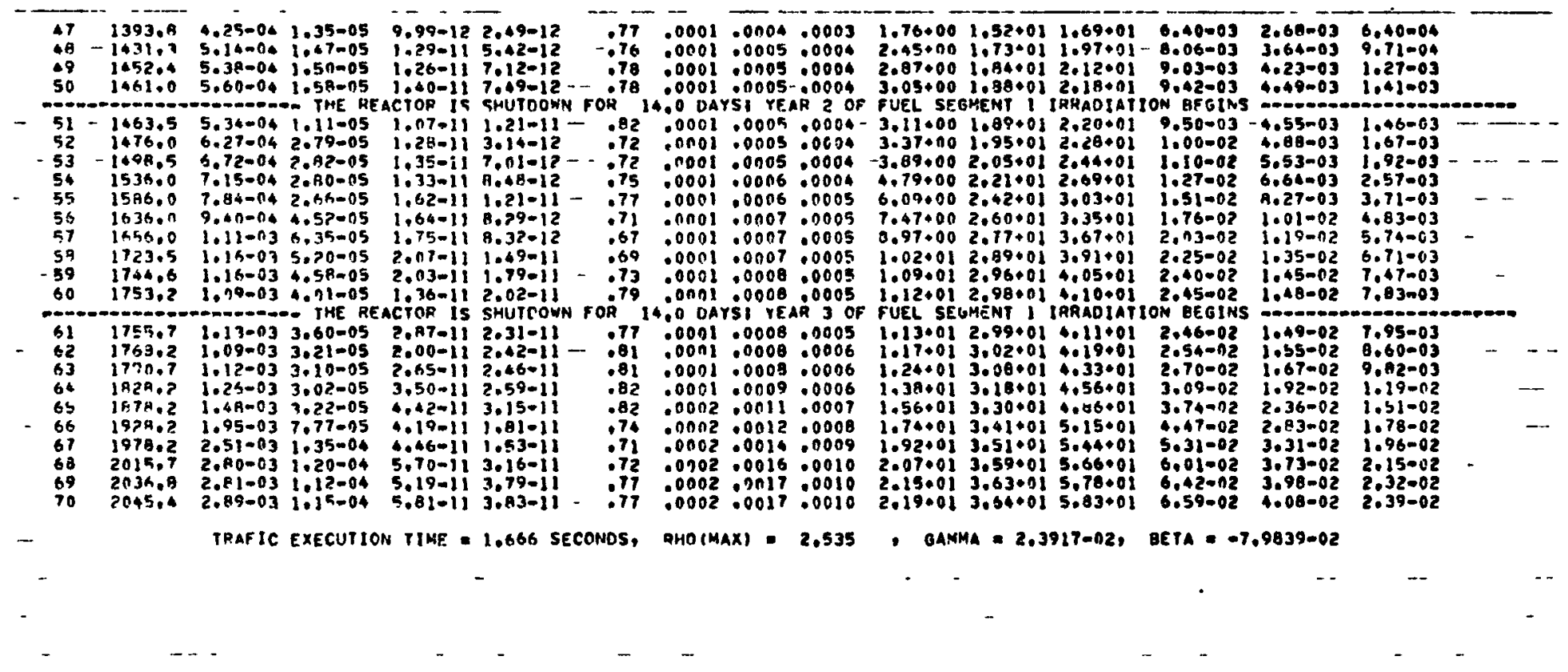


INPUT DATA FOR AXIAL BLOCK ", AXIAL POINT S, RFGION 2 , COLUHA 4, WOINT 5

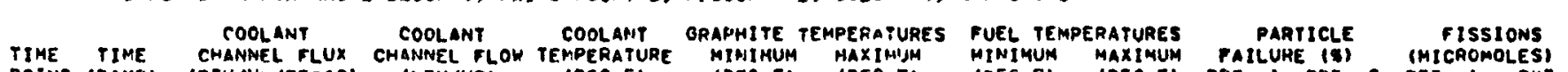

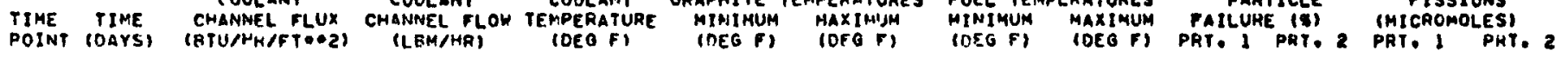

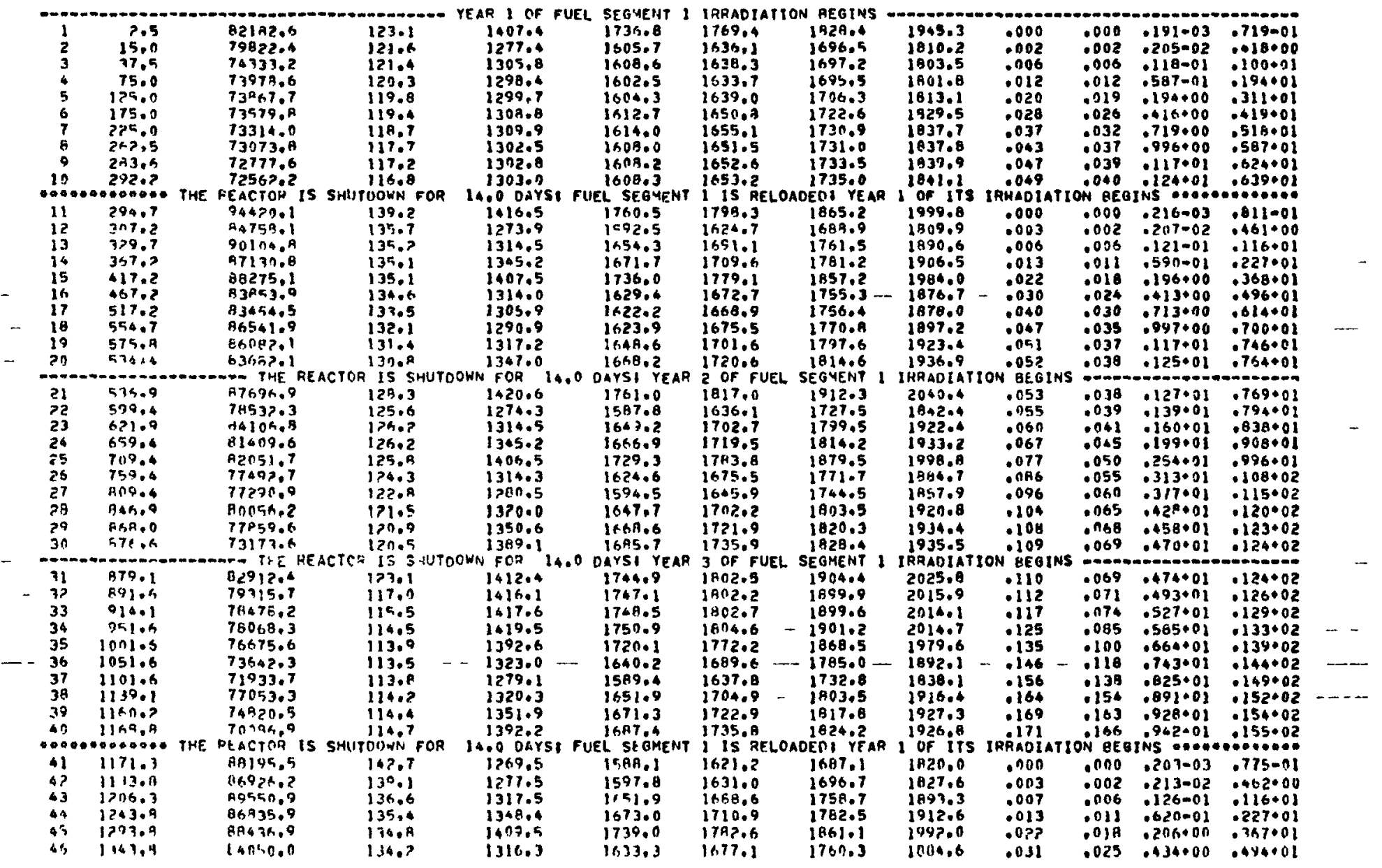




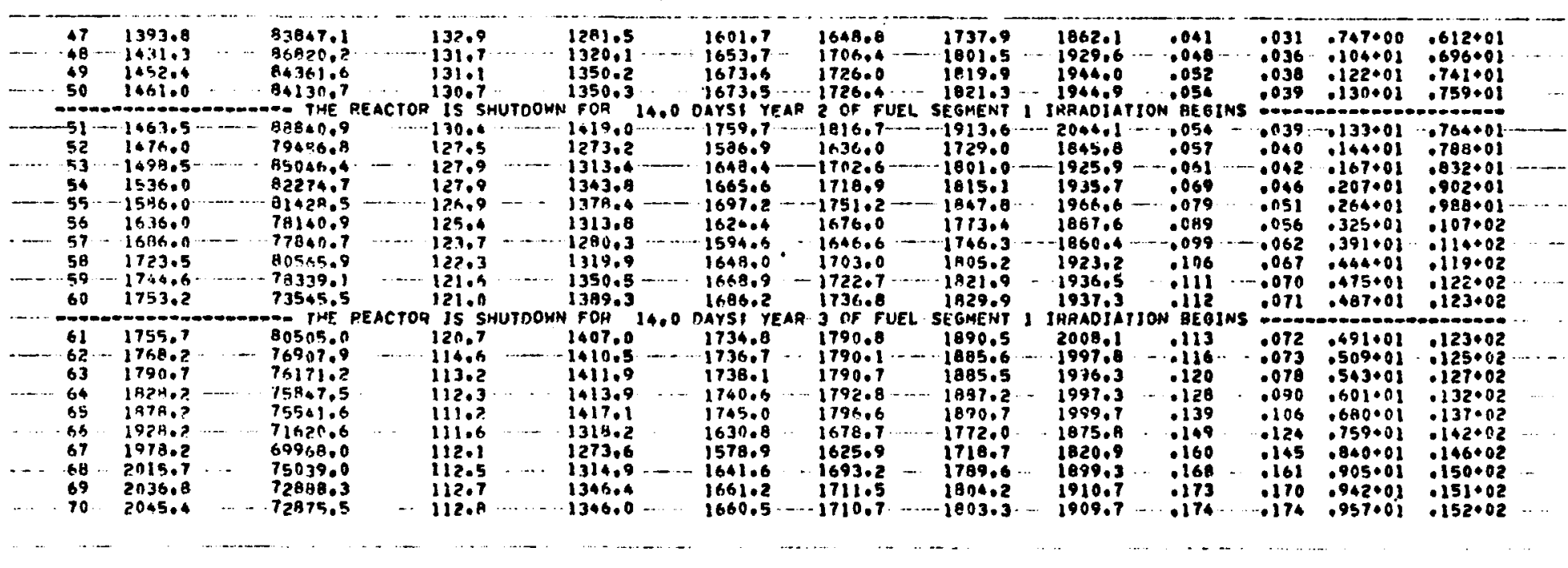




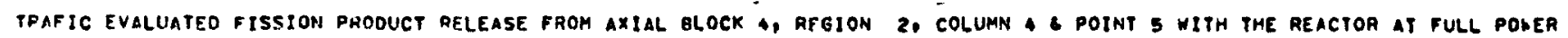

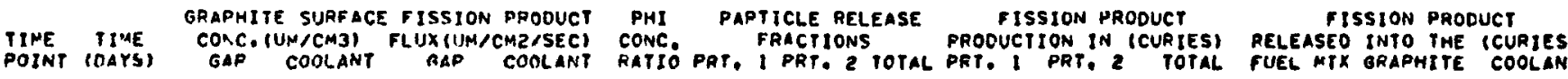

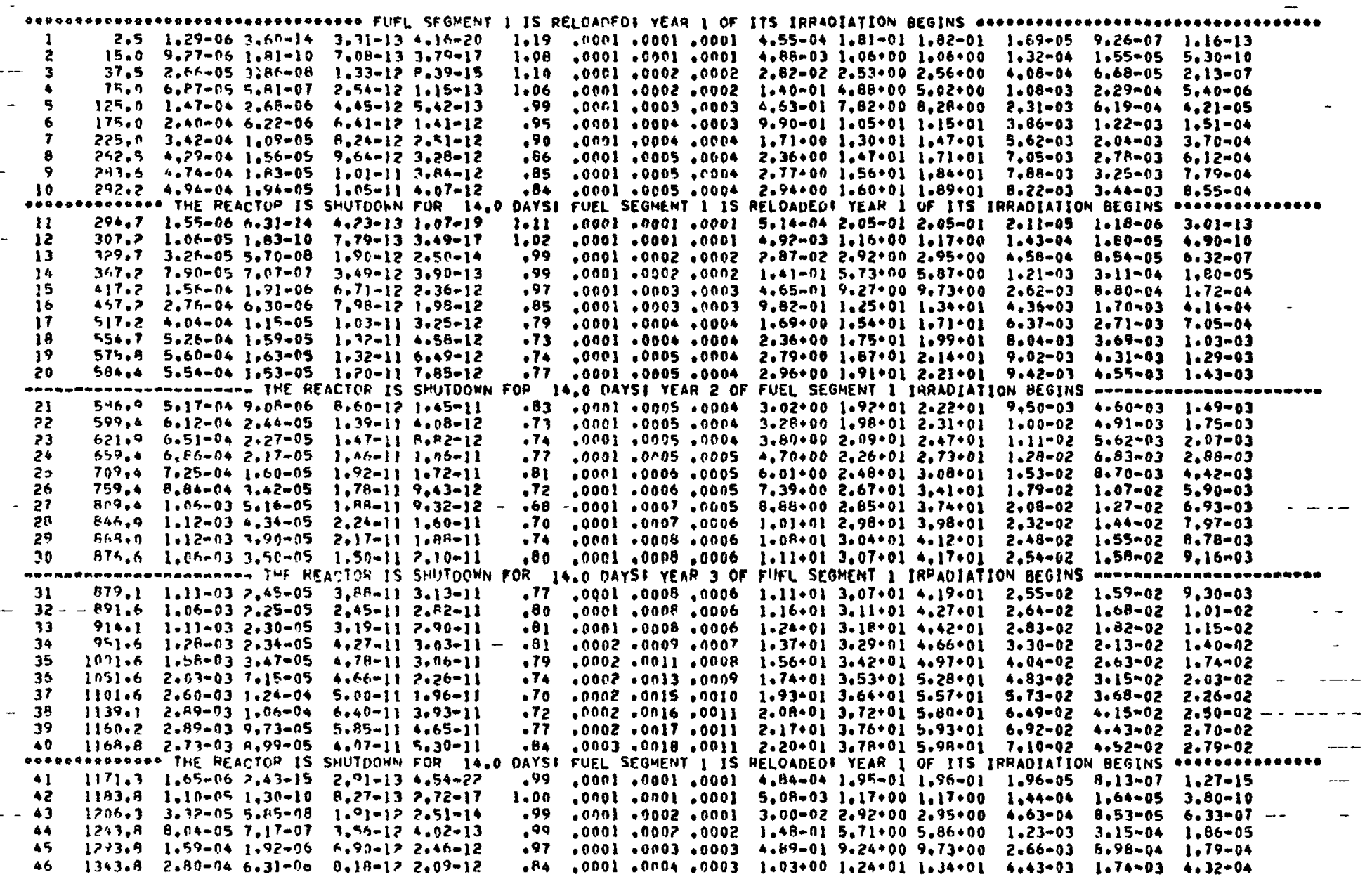




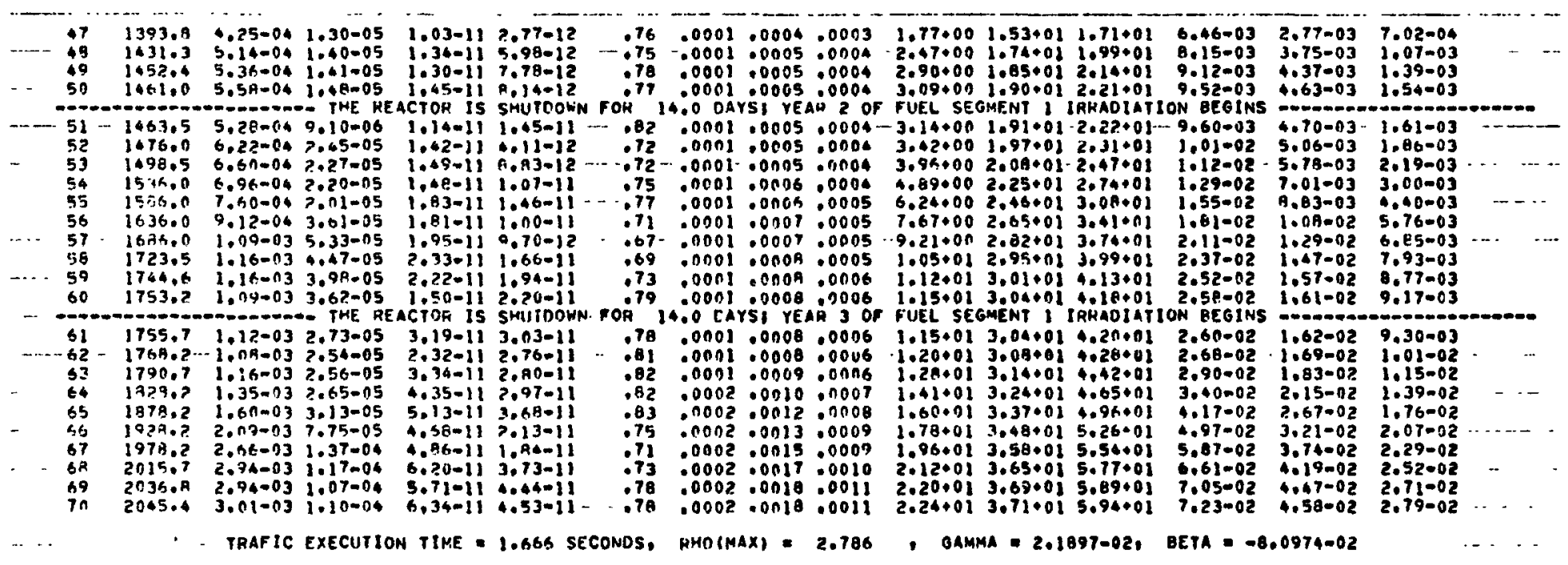

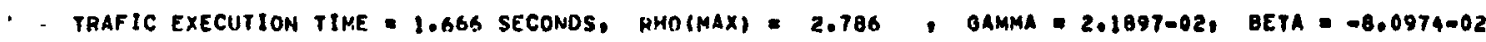




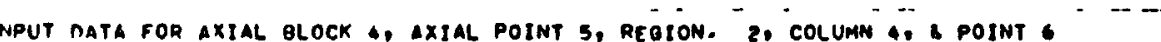

TIME TIME COOLANT COOLANT COOLANT GRADMITE TEMPERATURES FUEL TEMPERATURES PARTICLE FAT FISSIONS

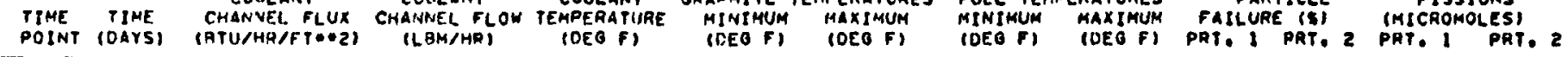

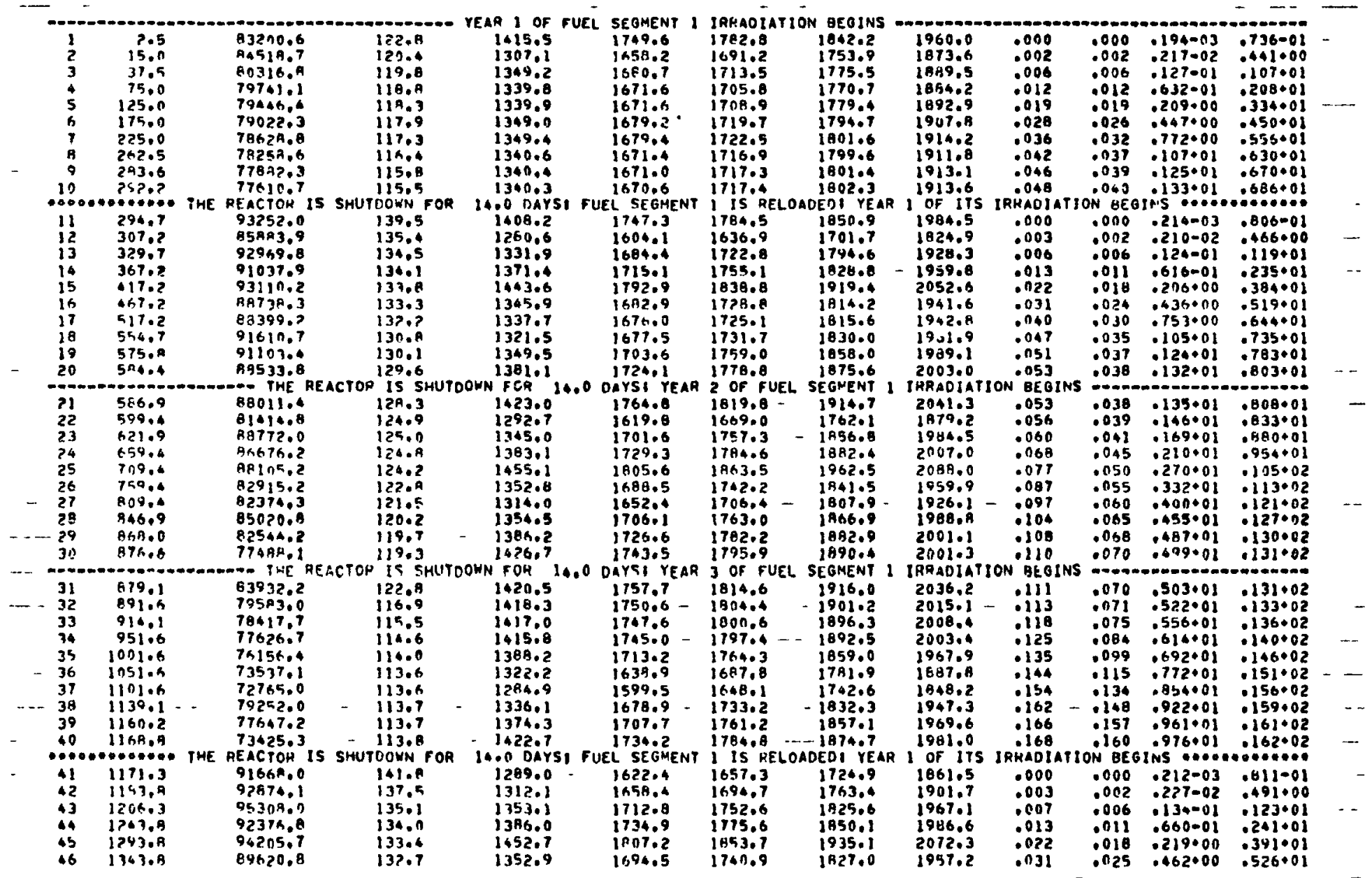




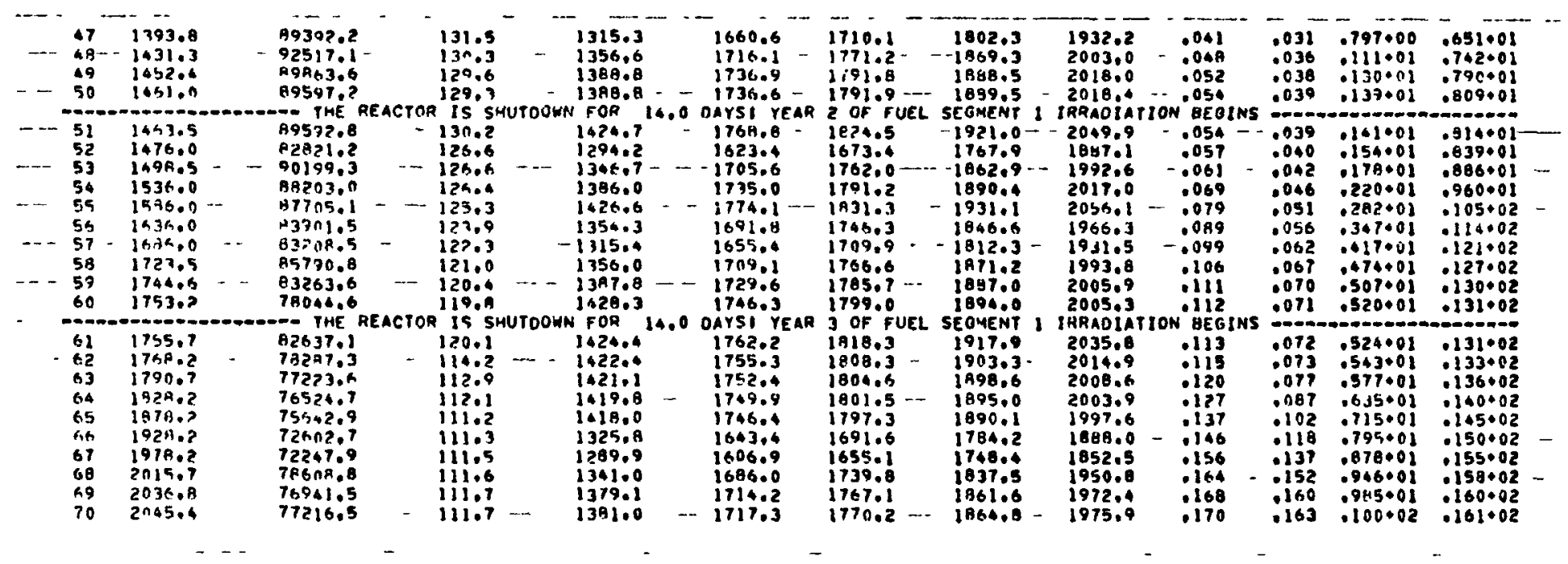




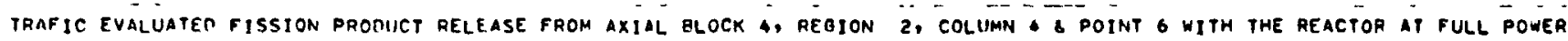

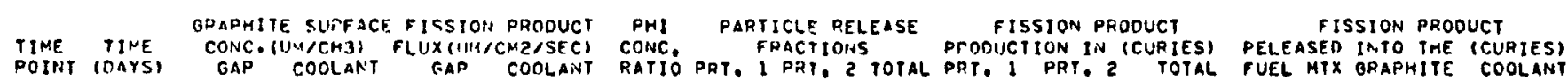

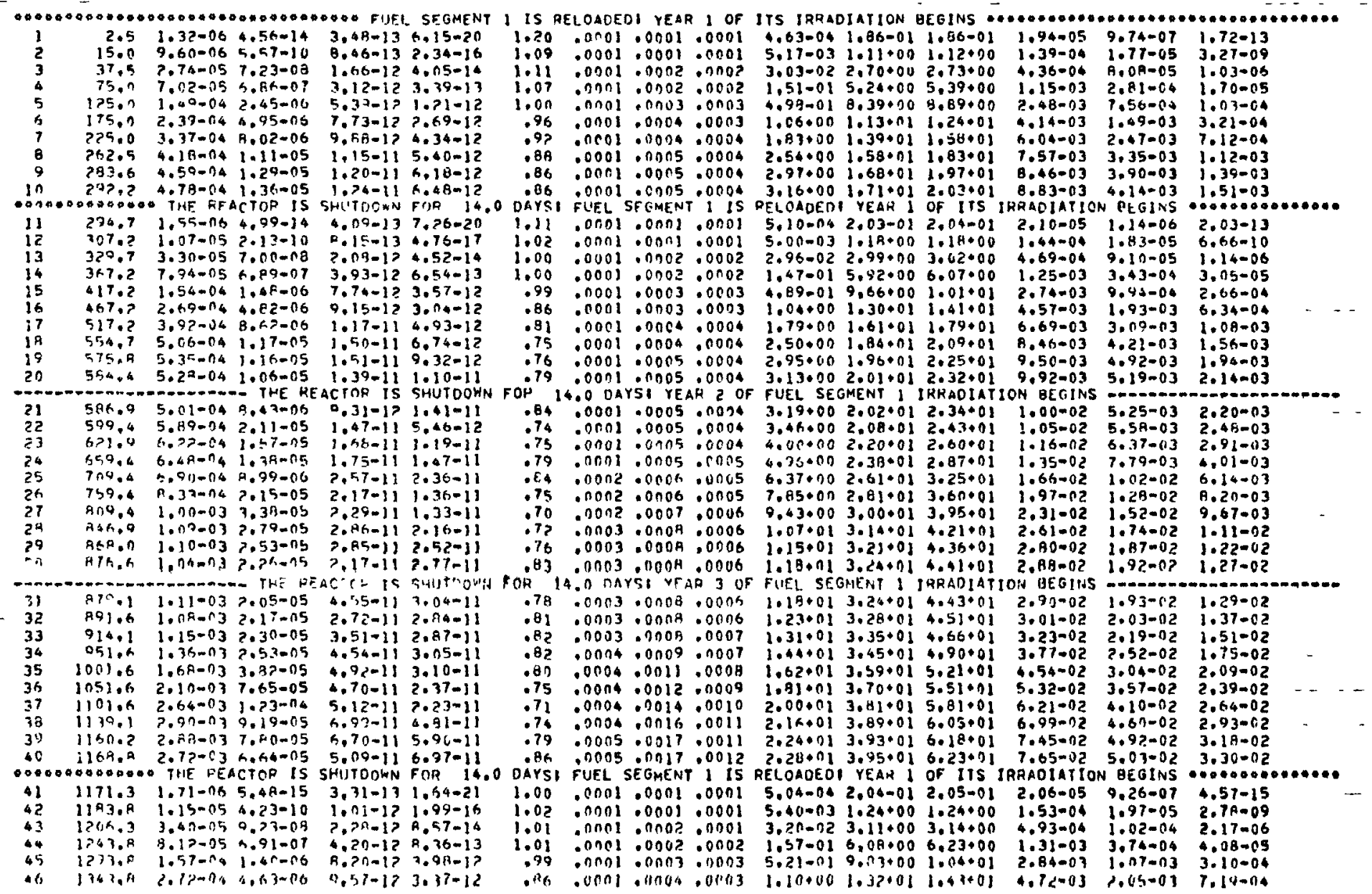




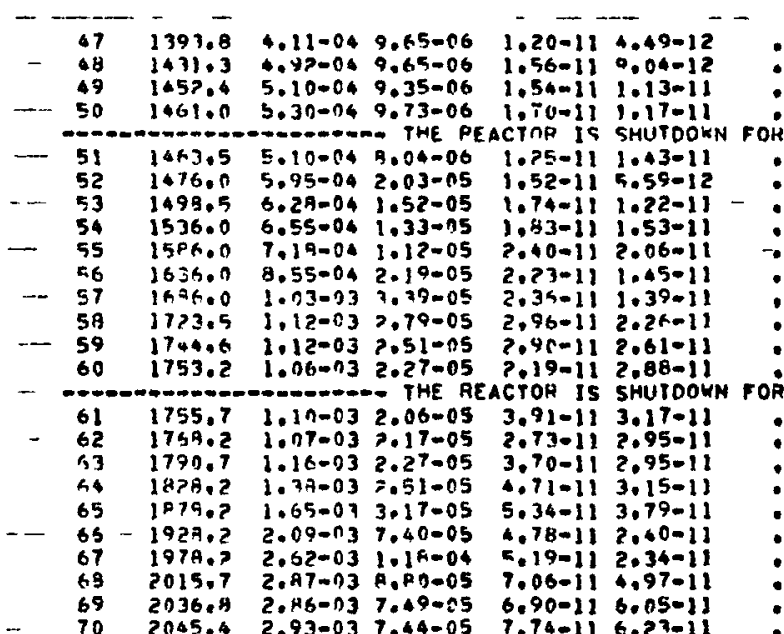

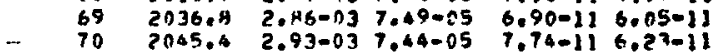
TRAFIC EXECUIION TIME $=1.672$ SECONDS, RHO(MAX) $=3.546$

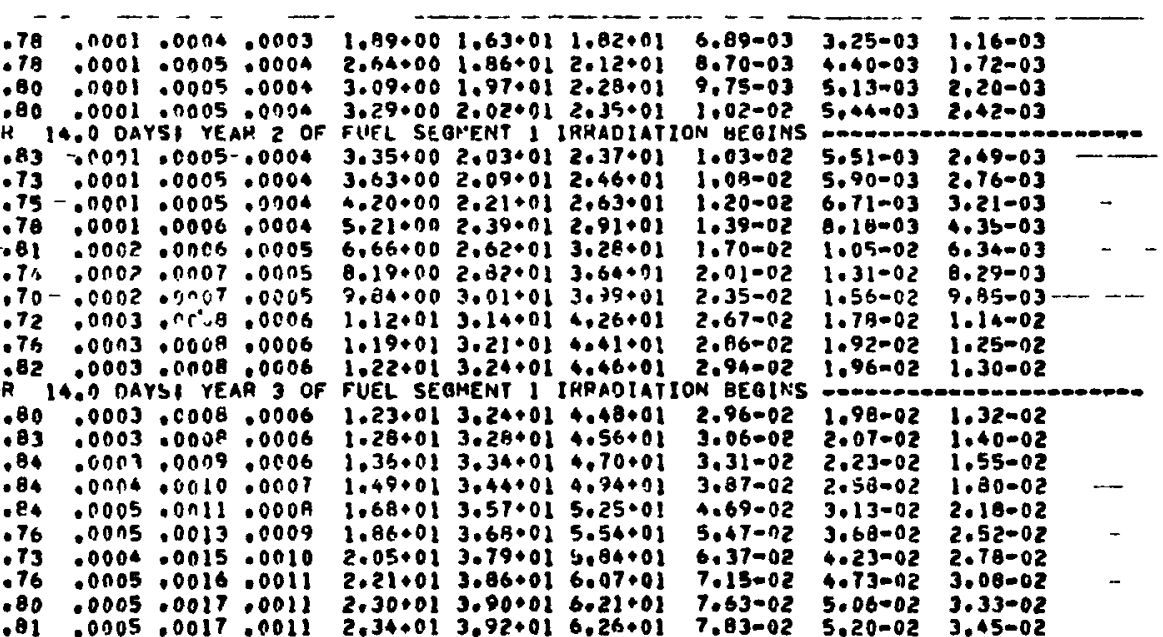

GAMMA $=1.7220-02$, EETA $=-8.2588=02$ 


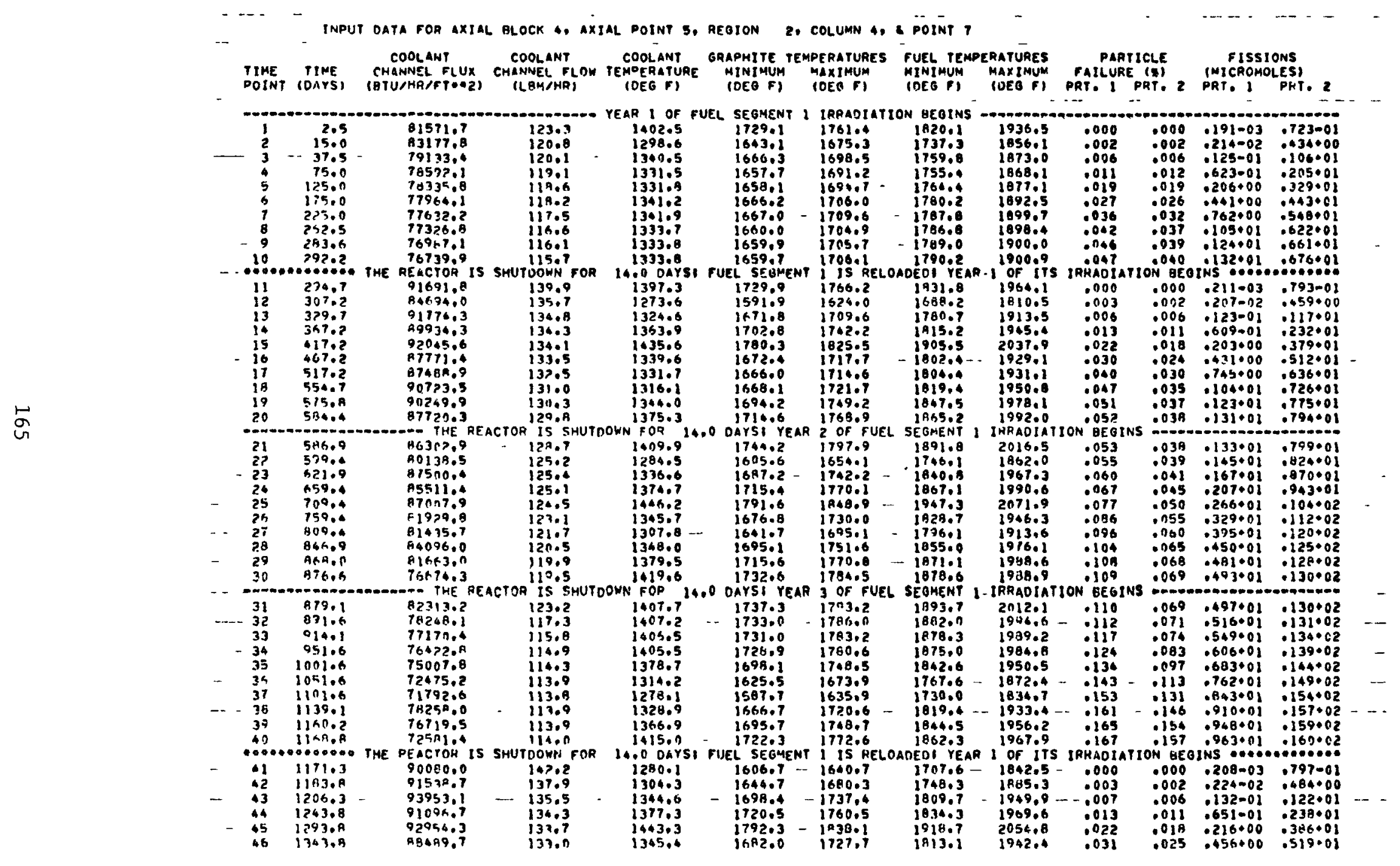




\begin{tabular}{|c|c|c|c|c|c|c|c|c|c|c|c|c|}
\hline $\begin{array}{r}47 \\
-\quad 89 \\
-\quad 50\end{array}$ & $\begin{array}{l}1393.8 \\
1431.8 \\
1452.8 \\
1461.0\end{array}$ & 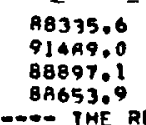 & $\begin{array}{l}131.7 \\
1309 \\
1290 \\
12909\end{array}$ & $\begin{array}{l}1300.0 \\
1350.0 \\
1382.0 \\
138201 \\
2509\end{array}$ & $\begin{array}{l}2649.3 \\
1704.7 \\
1725.7 \\
1725.6\end{array}$ & $\begin{array}{l}1698 . \overline{2} \\
1759.3 \\
1780.1 \\
1780.4 \\
08\end{array}$ & $\begin{array}{l}1789.6 \\
185600 \\
187601 \\
187706\end{array}$ & $\begin{array}{l}1918.7 \\
1989.8 \\
2000.9 \\
2100506\end{array}$ & $\begin{array}{l}.041 \\
0.040 \\
0.052 \\
0.053\end{array}$ & $\begin{array}{l}.031 \\
.036 \\
0.030 \\
.039\end{array}$ & $\begin{array}{l}.787+00 \\
.110002 \\
.129001 \\
.13701\end{array}$ & $\begin{array}{l}.643001 \\
.7332001 \\
: 779001 \\
.796001\end{array}$ \\
\hline $\begin{array}{l}-31 \\
52 \\
53 \\
50 \\
55 \\
55 \\
57 \\
58 \\
58 \\
50 \\
60\end{array}$ & 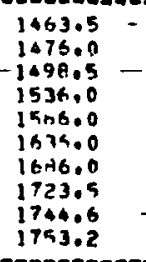 & $\begin{array}{r}81610.4 \\
-88794.8 \\
86919.5 \\
86517.0 \\
82924.0 \\
82192.0 \\
84900.9 \\
62323.7 \\
77192.3\end{array}$ & 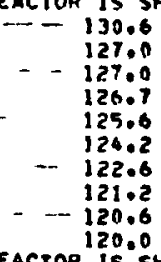 & $\begin{array}{l}1410.6 \\
1285.3 \\
1337.6 \\
1376.9 \\
1417.4 \\
1346.7 \\
1308.7 \\
1349.7\end{array}$ & 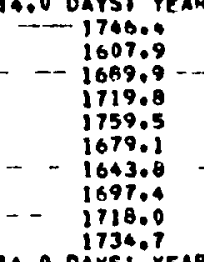 & $\begin{array}{l}1800.9-1 \\
1657.0 \\
1745.3- \\
1773.3 \\
1916.1- \\
1733.1 \\
1697.8 \\
1754.5 \\
1773.6 \\
7787.0\end{array}$ & 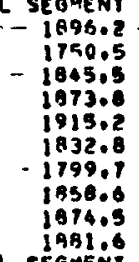 & $\begin{array}{l}2023.0 \\
1868.3 \\
1973.9 \\
1999.11 \\
2039.1 \\
1931.6 \\
1917.8 \\
1980.4 \\
1992.6 \\
1992.8\end{array}$ & $\begin{array}{l}.054 \\
.056 \\
.061 \\
060 \\
0070 \\
.086 \\
.090 \\
.105 \\
.110 \\
.111\end{array}$ & $\begin{array}{l}.039 \\
.000 \\
-0042 \\
-046 \\
.051 \\
.056 \\
.0662 \\
.062 \\
.087 \\
.070 \\
.071\end{array}$ & 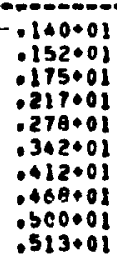 & 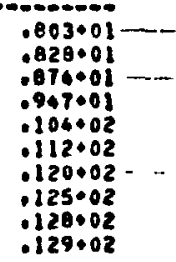 \\
\hline $\begin{array}{l}61 \\
62 \\
63 \\
64 \\
63 \\
66\end{array}$ & 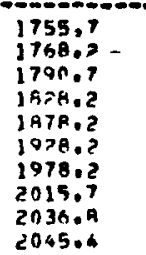 & 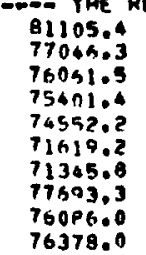 & $\begin{array}{l}120.5 \\
114.5 \\
113.5 \\
112.4 \\
111.5 \\
111.4 \\
111.9 \\
111.8 \\
111.9 \\
111.9\end{array}$ & 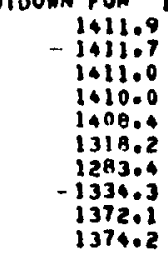 & $\begin{array}{l}1742.5 \\
1738.5 \\
1738.6 \\
1735.6 \\
1731.6 \\
1731.3 \\
1630.9 \\
1595.8 \\
1674.6 \\
1793.6 \\
1706.0\end{array}$ & 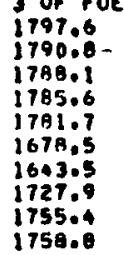 & 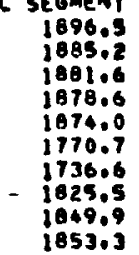 & 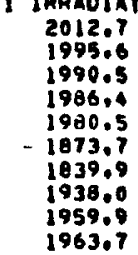 & 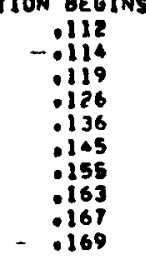 & 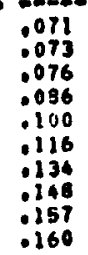 & 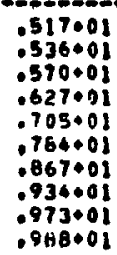 & 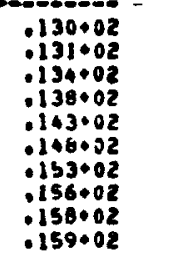 \\
\hline
\end{tabular}




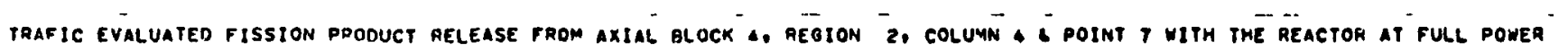

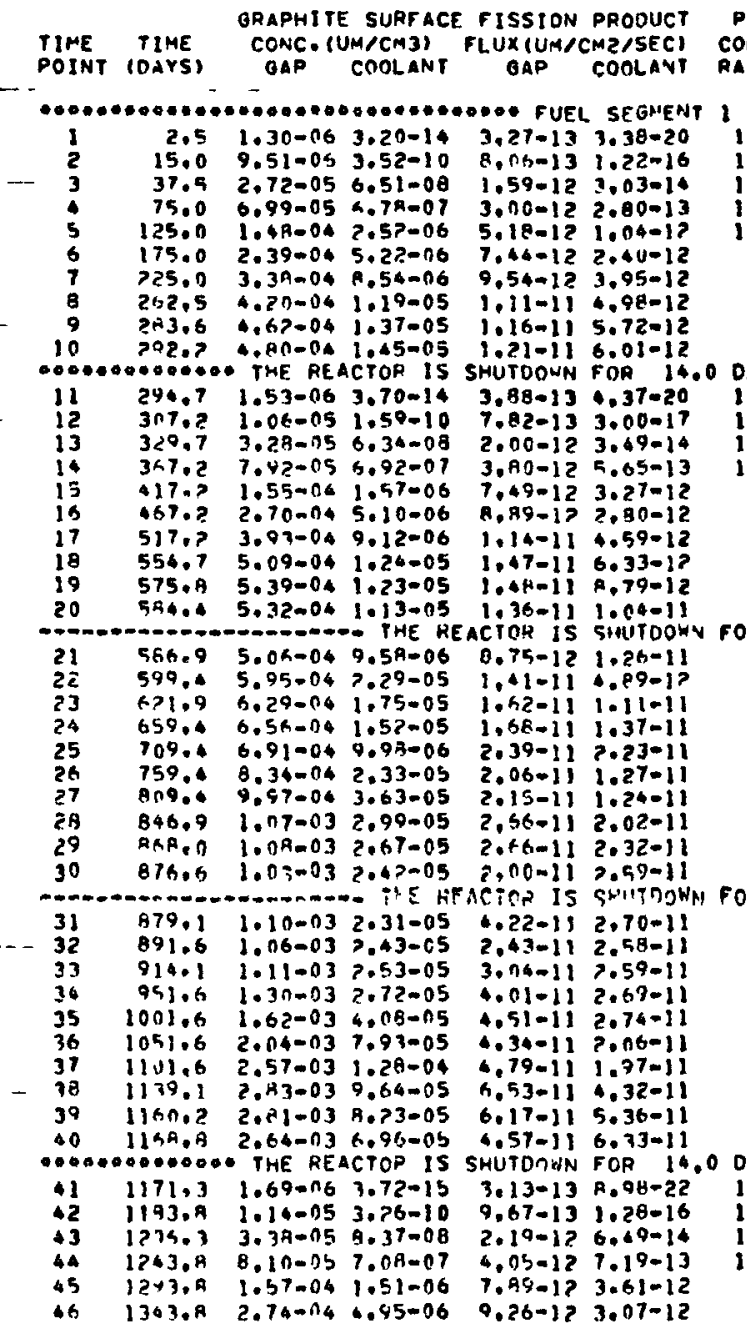

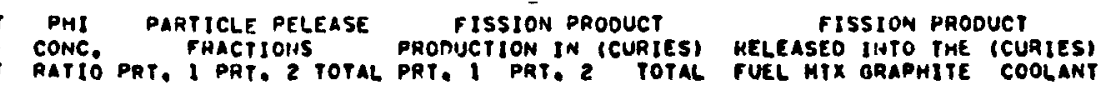

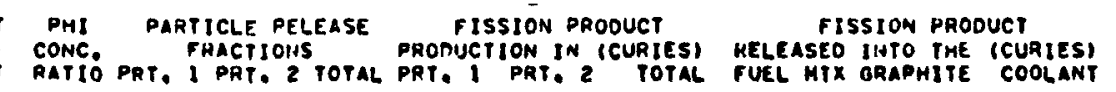

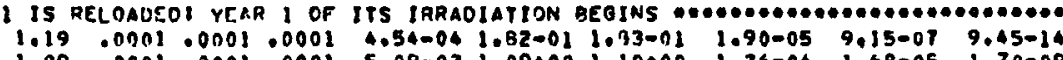

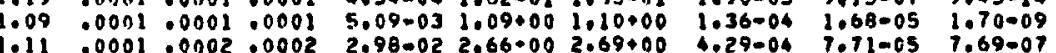

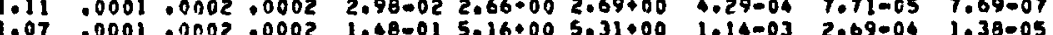

1.00 .0001 :0roj .0003 \$.91-01 8.27000 8.76000 2.05-03 $1.25-048.78-05$

.96 .0001 .0n36.0003 1.05000 1.11.01 1.220.01 4.08-03 1.43-03 2.00-04

$.92 .0001 .0004 .0004 \quad 1.81+001.37+01 \quad 1.36+01 \quad 5.95-13 \quad 2.37-03 \quad 6.33-04$

86 :0001 0015 :0004 2.50.00

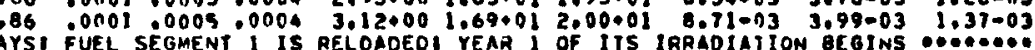

$1.11 .0001 \quad 0001.0001 \quad 5,01-042,00-012000-01 \quad 2.06-05 \quad 1.08-06 \quad 1,22-13$

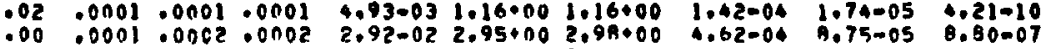

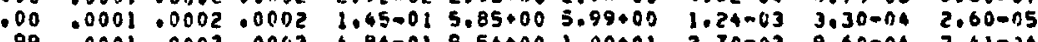

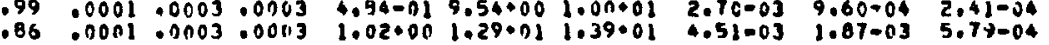

$81.0001 .0004 \quad .0004 \quad 1.77+001.60001 \quad 1.77+01 \quad 6.61-03 \quad 3.00-03 \quad 9.91-04$

$74.0001 .00040004 \quad 2.47+00 \quad 1.82+012.07+01 \quad 8.36-03 \quad 4.09-03 \quad 1.45-03$

$76.0001 .01050004 \quad 2.92 \cdot 001.94 \cdot 012.23 \cdot 01 \quad 9,38-03 \quad 4.78-03 \quad 1.80-03$

0.0001
$14.0009 Y I^{2}$

$.83 .0001 \cdot 0005.0004 \quad 3.15 \times 002.00 \times 012.3101 \quad 9.88003 \quad 5.11-03 \quad 2.05-03$

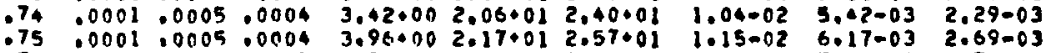

.79 .0nol .0n05 .0005 3.91000 2.35001 2.44001 1.33-02 7.54-03 3.72-03

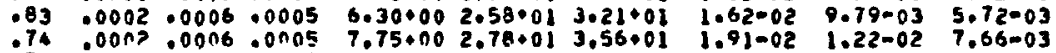

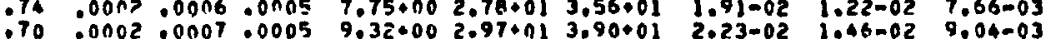

$.72 .0002 .0007 .0006 \quad 1.060013 .100014 .16001 \quad 2.51-02 \quad 1.65=02 \quad 3.04-02$ .76 .0102 .0007 .00116 1.13.01 3.17+01 4.31.01 2.69-02 1.18-0? 1.10-c2

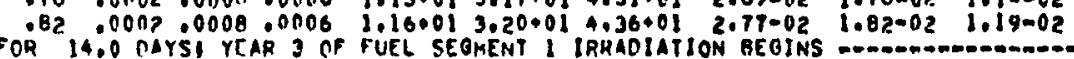
$.77 .0002 .0008 .0008 \quad 1.17 .013 .21+014.38+01 \quad 2.78-02 \quad 1.04-02 \quad 1.20-02$

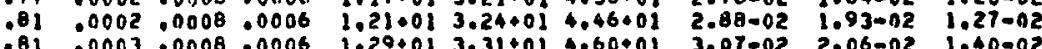

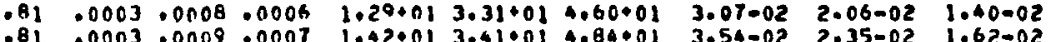
$.79 .0003 .0011 .0004 \quad 1.60+013.340015 .14001 \quad 4.26-02 \quad 2.82-02 \quad 1.92-02$ $.74 .0003 .0122 .0009 \quad 1.78 \times 013.66 \cdot 015.44 \times 01 \quad 5.00402 \quad 3.31-02 \quad 2.18=02$ $.71 .0003 .0014 .0010 \quad 1.97+013.76+015.74+01 \quad 5.45-02 \quad 3.81-02 \quad 2.40-02$ $.73 .0003 .0016 .0 n 102.13 \times 013.84 \times n 15.97001 \quad 6.59-02$ 4.27-02 $2.65-02$

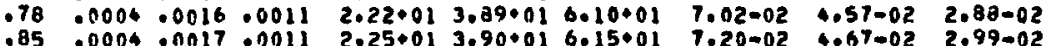
DAYS BUEL SEGMENT I IS PEIOA 1.00 .0001 .0001 .0001 4.96-04 2.01=01 2.02-01 2.02-05 8.76-07 2.51-15 $1.01 \quad 00001.0001 .0001 \quad 5.32-03 \quad 1.220001 .23+00 \quad 1.50-04 \quad 1.88-05 \quad 1.79-09$

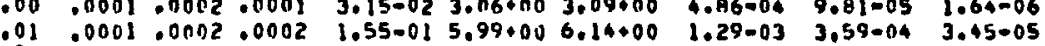
$.99 .0001 .0003 .0003 \quad 5.14+019.70+001.02+01 \quad 2.80=03 \quad 1.03-03 \quad 2.77-04$ . $0001.0004 .0003 \quad 1.08 .001 .30+01 \quad 1.41 .01 \quad 4.65-03 \quad 1.98-03 \quad 6.49=04$ 


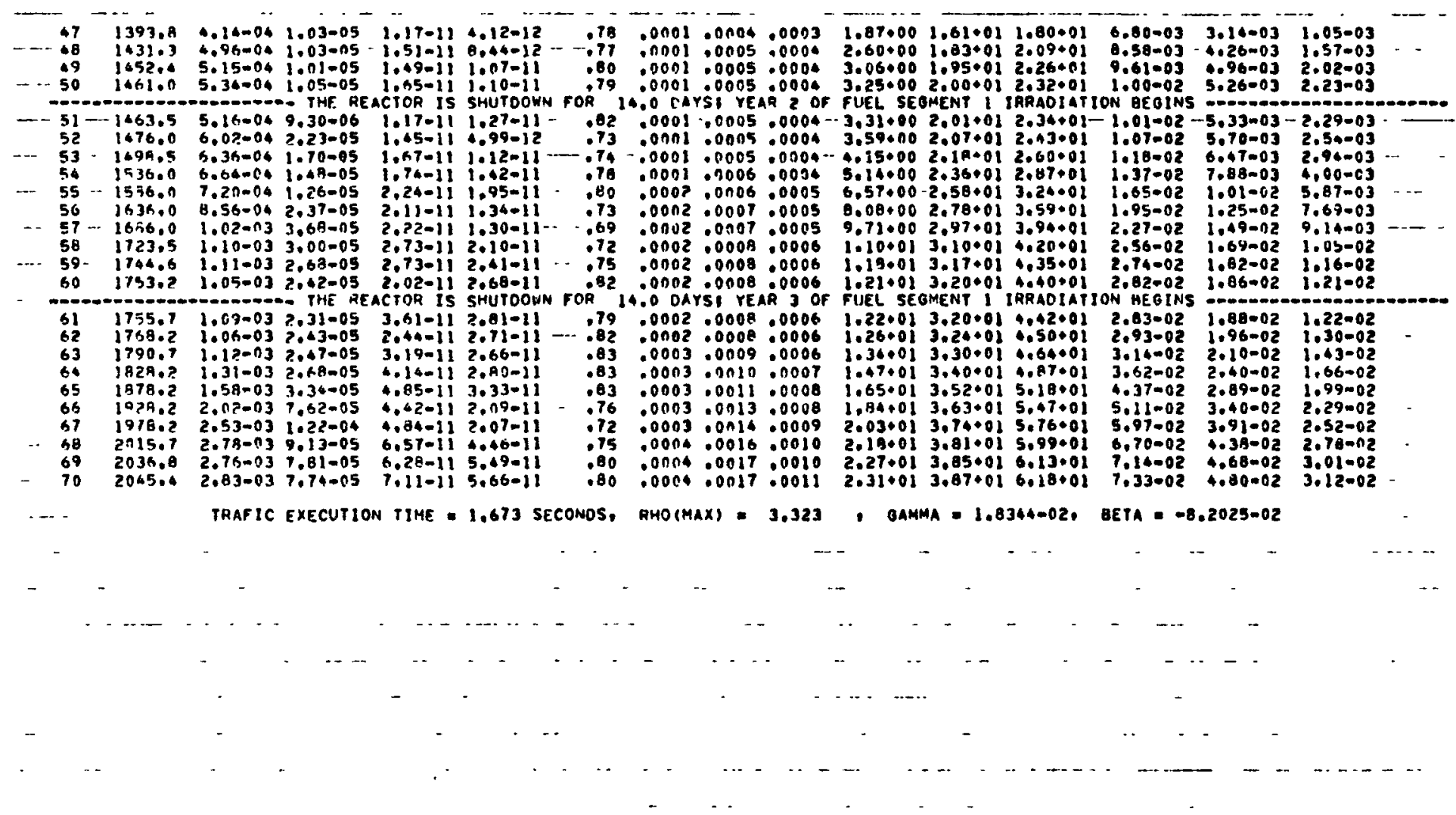




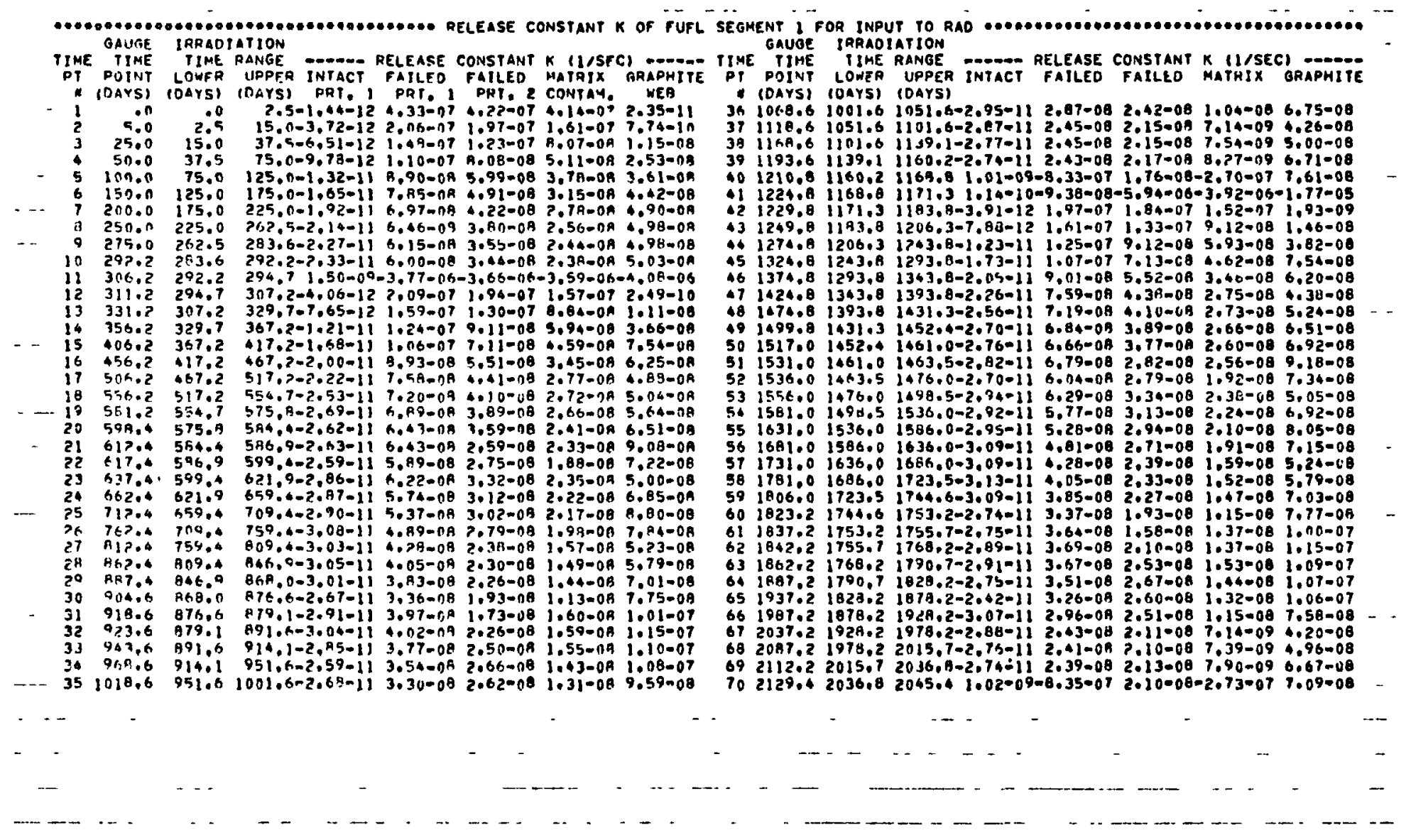




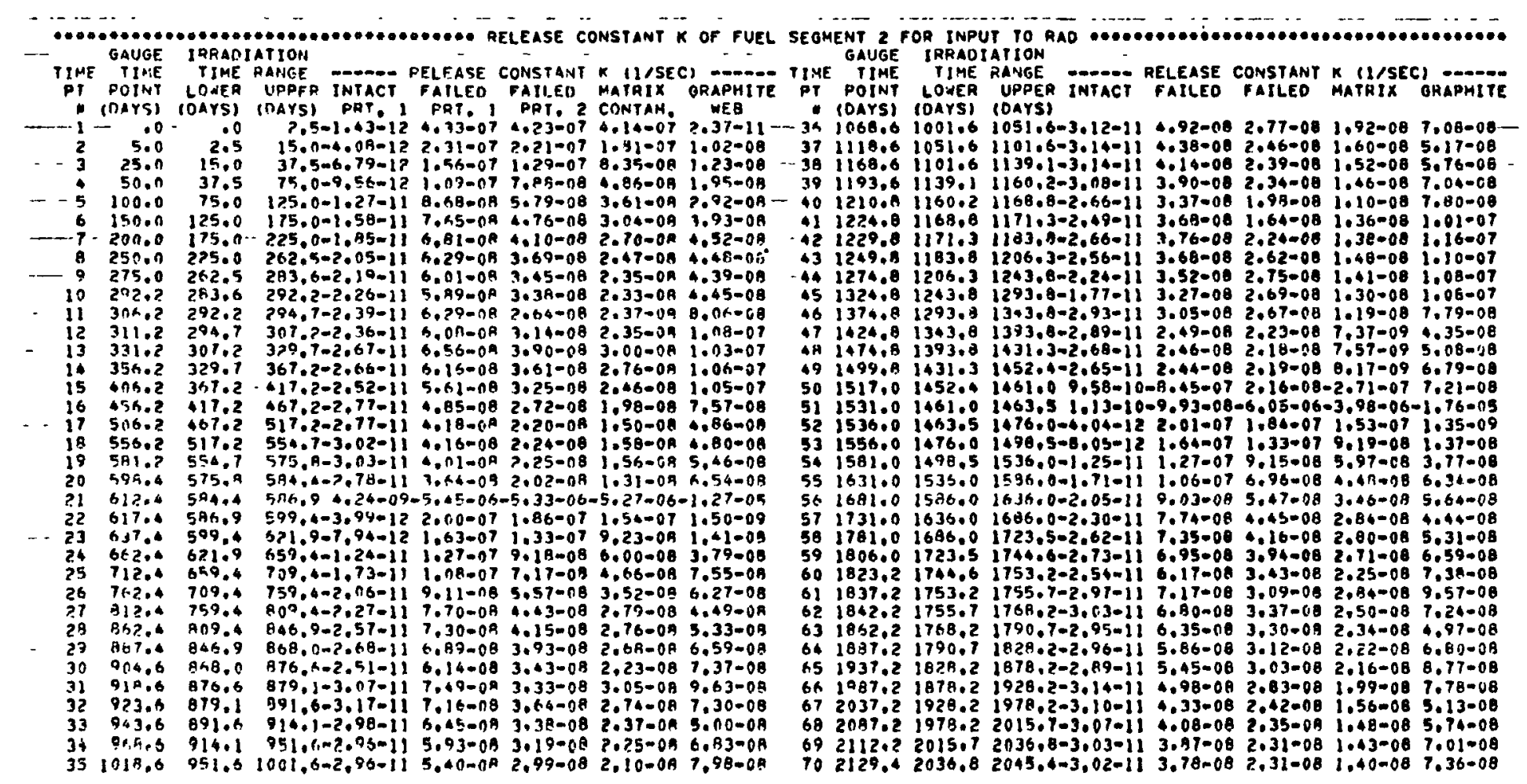




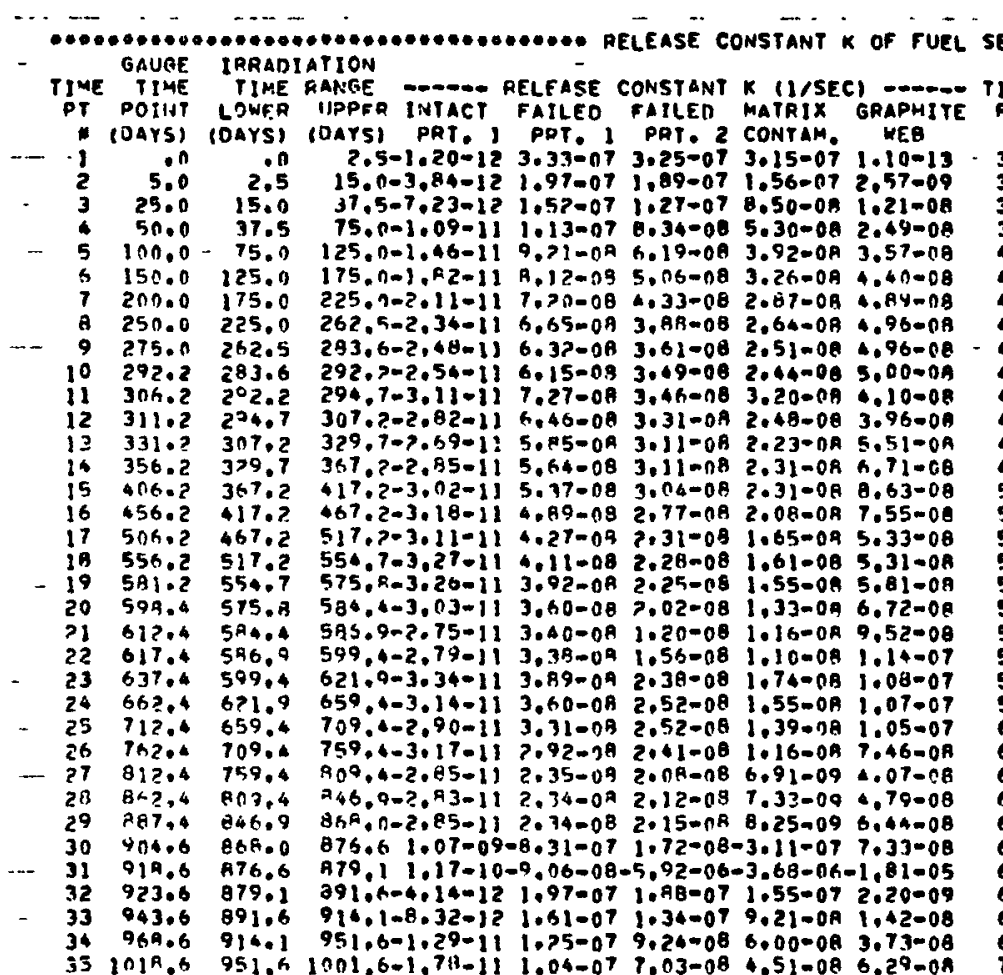

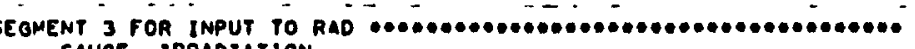
GAUBE IRRAOIATION

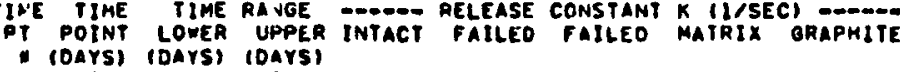

36 1068.6 1001.6 10511.6-2.13-11 8.09-08 5.51-08 3.48-06 5.55-08

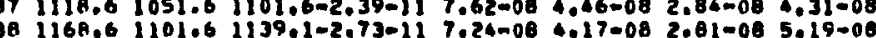
391193.61139 .1 1160.2-2,05-11 $6.04-00$ 3.95-00 2.73-08 6.52-00

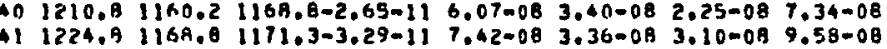

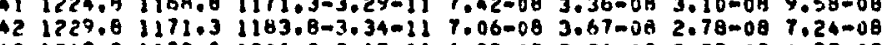
3 1269, 1103,0 1206,3-3.15-11 6,35-00 3.36-08 2.39-0B 4.,97-0B as 1274.8 1206.3 1243.8-3.16-11 5.87-08 3.16-0日 2.27-08 6.81-08

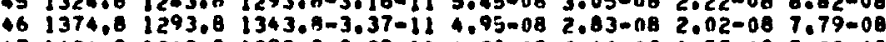
$171424,81343.8[393.8-3.29-11$ 4.28-06 2.40-06 $1.57-089.03-00$

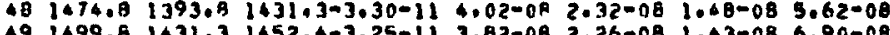

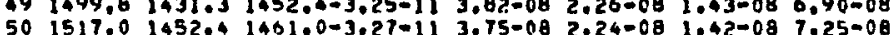
51 i531.0 1461.0 1463.5-2.95-11 3.67-08 1.51-08 1.34-08 9.69-00 $521536,01463.51476,0-2.70-113,27-08 \quad 1.84-089,94-091.16=07$ 53 1556.0 1476.0 1498.5-3.17-11 3.68-08 2.65-08 1.53-08 1.10-07

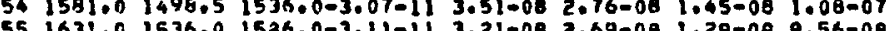

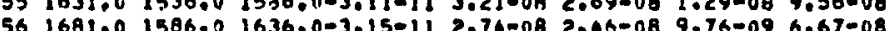

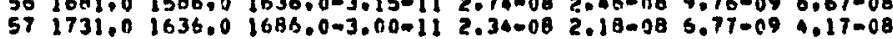
$591781.01686 .0 \quad 1723.5-2.97-11$ 2.36-08 2.17-0日 7.45-09 @.90-08 $591806,01723.5 \quad 1744.6-2.99-112.36-08$ 2.17-00 8.31-09 6.57-08 $601823.21744 .61753 .21 .111-09-8.29-071.74-08-2.85-07 \quad 7.47-08$ $611837.21753 .21755 .71 .21-10-9.00-08-5.91-06-3.74-06-1.74-05$

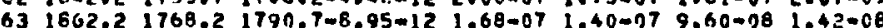

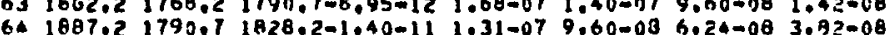
651937.2 280.2 66 19A7,2 $187 \theta .2$ 1928,2-2.32-11 9.39-08 5.A2-0B 3.67-08 6.37-08 67 2037.2 1929.2 1978.2-2.55-11 7.92-0R 4.59-08 2.89-08 4.42-08 60

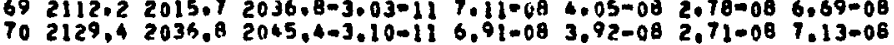
$+$

$-\cdot$ 
THE End-of-Year hetallic Fission prodict isotope production and Release in curies of oecat radiation

THE ANALYSIS WAS PEPFORMED gOR AXIAL hLOCK AND POINT :
DINEL SEGHENT POD YEAR PEODUCED IN PRT: ALL PAPTICLES
RELEASED IMTOT FUFL

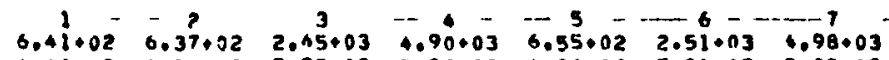 $4,40.03 \quad 4.02+03 \quad 7.97+03 \quad 9.95+03-6.80 .03 \quad 7.91 \cdot 03 \quad 9.85+03$

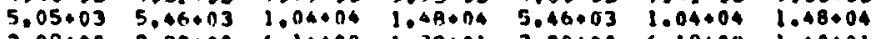

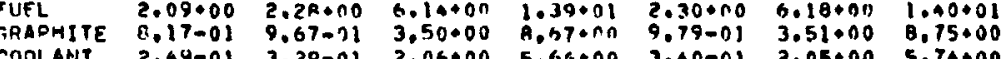

- EOUilibrium core mock-Up

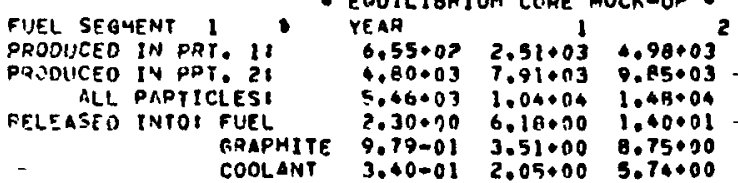

\section{FUEL STGMENT 2 " TEAB} PRODUCFO IIA PQT, I: ALL PSRTICLESS
RELEASEO INTOI FUEL

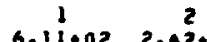
$0.33+03 \quad 7,30+03$ $4.94+03 \quad 9,72003$ $\begin{array}{cc}3 & \\ 6.39002 & 2.40 .03 \\ 4.94+03 & 8.03 \cdot 03 \\ 5.48+03 & 1.05+04 \\ 2.29+00 & 6.28000 \\ 9.78-01 & 3.61000\end{array}$ GRAPHITE

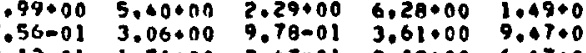

$\begin{array}{rrr}0.95+03 & 6.52+02 & 2.51 \cdot 03 \\ 1.00000 & 5.70 .03 & 7.02003\end{array}$

- eguiliarilum core mock-up.

\begin{tabular}{|c|c|c|c|c|}
\hline $\begin{array}{l}\text { FUEL SFGMENT } \\
\text { FHODINCF IN PR } \\
\text { POODULEO IN PO } \\
\text { ALL PARTI } \\
\text { EELER SED INTOI }\end{array}$ & $\begin{array}{l}2 \\
\text { T. } 11 \\
\text { T. } 21 \\
\text { CIESI } \\
\text { FUEL } \\
\text { GPAPHITE } \\
\text { COOLANT }\end{array}$ & $\begin{array}{l}Y E A R \\
6.52 \cdot 02 \\
4.74+03 \\
5.39+03 \\
2.27+00 \\
9.54-01 \\
3.35-01\end{array}$ & $\begin{array}{l}1 \\
2.51+03 \\
7,82+03 \\
1.03+04 \\
6.19+01 \\
3,56+00 \\
2,07+00\end{array}$ & $\begin{array}{l}4.9 A+03^{2} \\
9.41+03 \\
1.4 A+04 \\
1.4 A+01 \\
9.42+00 \\
6.16+00\end{array}$ \\
\hline
\end{tabular}

3

FUEL SEGITEN 3 - VEAR PRODCET IN PPT, 11 PRONUEO TLTIICLES

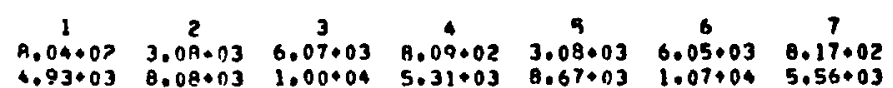
6.93003 1., $2.41+00 \quad 6.37+00 \quad 1.38+01 \quad 2.61+00 \quad 7.03000 \quad 1.63+01 \quad 2.71000$

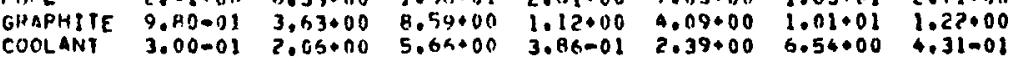

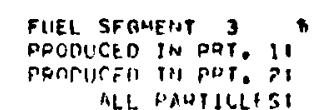

- enuillarium cofe moch-up -

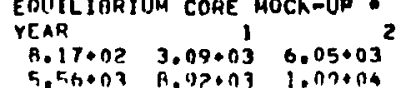


RELEASED INTOI FUEL $2.71000 \quad 7.13000 \quad 1.04001$

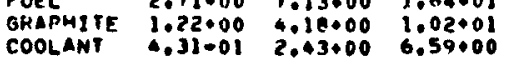

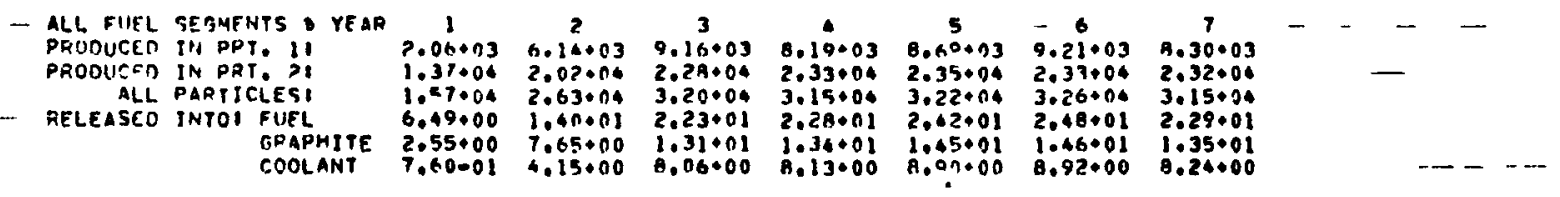

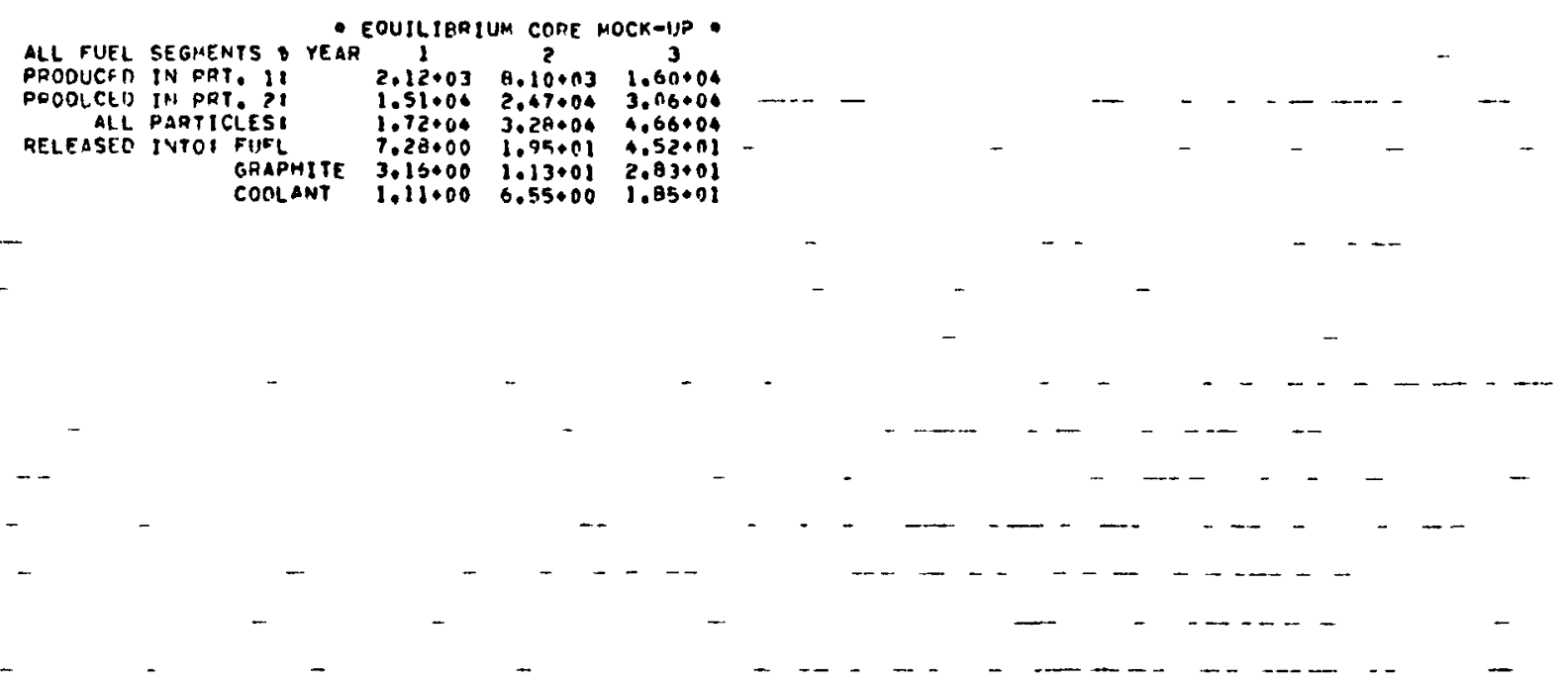




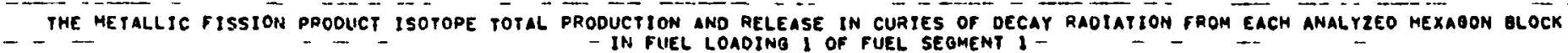

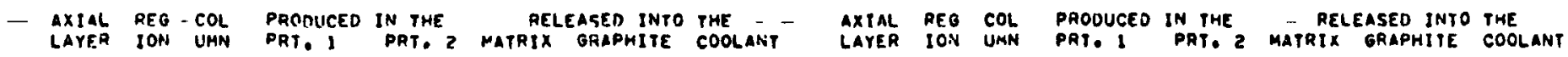

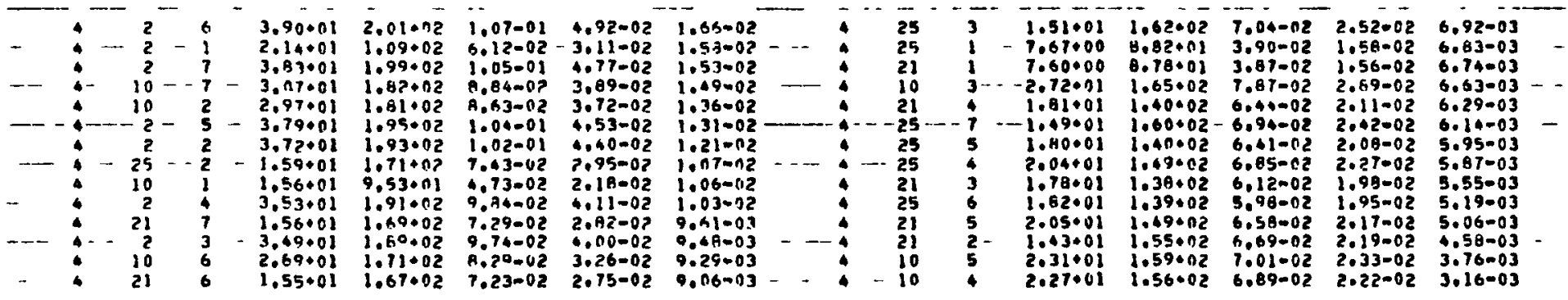

- LOADING TOTAL $6.41+02 \quad 4.40003 \quad 2.09+00 \quad 8.17-01 \quad 3.49401$ -

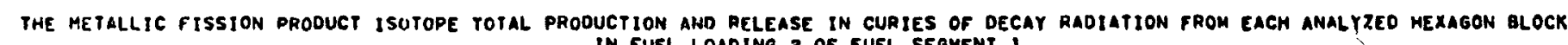
IN FUEL LOADING 2 OF FUEL SEGMENT I

\begin{tabular}{|c|c|c|c|c|c|c|c|c|c|c|c|c|c|c|c|}
\hline $\begin{array}{l}\text { IIAL } \\
\text { IYER }\end{array}$ & $\begin{array}{l}\text { REO } \\
\text { ION }\end{array}$ & $\begin{array}{l}\text { COL } \\
\text { UMN }\end{array}$ & $\begin{array}{l}\text { PRODUCEO } \\
\text { PRT, } 1\end{array}$ & $\begin{array}{l}\text { IN THE } \\
\text { PRT, } 2\end{array}$ & $\begin{array}{l}\text { RELE } \\
\text { MATRIX }\end{array}$ & $\begin{array}{l}\text { ASED INTO } \\
\text { GRAPHITE }\end{array}$ & $\begin{array}{l}\text { THE } \\
\text { COOL ANT }\end{array}$ & $\begin{array}{l}\text { AXIAL } \\
\text { LAYER }\end{array}$ & $\begin{array}{l}\text { REO } \\
\text { ION }\end{array}$ & $\begin{array}{l}\text { COL } \\
\text { UHAN }\end{array}$ & $\begin{array}{l}\text { PHOOUCEO } \\
\text { PRT. I }\end{array}$ & $\begin{array}{l}\text { IN THE } \\
\text { PRT, ? }\end{array}$ & ATRIX & $\begin{array}{l}\text { SEO INTO } \\
\text { RAPHITE }\end{array}$ & $\begin{array}{l}\text { THE } \\
\text { COOLANT }\end{array}$ \\
\hline $\begin{array}{l}: \\
\vdots \\
\vdots \\
\vdots \\
:\end{array}$ & $\begin{array}{r}2 \\
2 \\
2 \\
10 \\
2 \\
2 \\
10 \\
? \\
2 \\
10 \\
10 \\
2 \\
25 \\
21 \\
21\end{array}$ & $\begin{array}{l}6 \\
7 \\
5 \\
7 \\
2 \\
2 \\
4 \\
3 \\
6 \\
3 \\
1 \\
2 \\
6 \\
7\end{array}$ & $\begin{array}{l}2.82 \cdot 02 \\
2.78 \cdot 02 \\
2.70+02 \\
2.37+02 \\
2.71+02 \\
2.31+02 \\
2.61+07 \\
2.58 \cdot 02 \\
2.28+02 \\
2,19+02 \\
1.53 \cdot 02 \\
1.33+02 \\
1.32+02 \\
1.30+02\end{array}$ & $\begin{array}{l}4,62+02 \\
4.60+02 \\
4.50+02 \\
4,43+02 \\
4,48+02 \\
4.43+02 \\
4.49+02 \\
4.44002 \\
4.22+102 \\
4.15+02 \\
2.47+02 \\
3.09+02 \\
3.67+02 \\
3.64+02\end{array}$ & 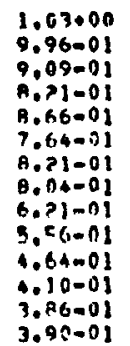 & $\begin{array}{l}6.81=01 \\
6.54-01 \\
5.05-01 \\
5.33-01 \\
5.54-01 \\
6.91-01 \\
5.17=01 \\
5,00=01 \\
3.93-01 \\
3.46-01 \\
3.16-01 \\
2.64-01 \\
2.55-01 \\
2.49-01\end{array}$ & 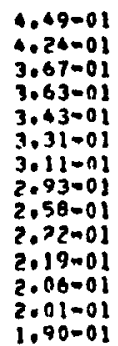 & $:$ & $\begin{array}{l}25 \\
10 \\
10 \\
10 \\
25 \\
21 \\
21 \\
25 \\
25 \\
21 \\
25 \\
21 \\
21 \\
25\end{array}$ & $\begin{array}{l}3 \\
5 \\
1 \\
1 \\
5 \\
2 \\
1 \\
1 \\
6 \\
6 \\
3 \\
5\end{array}$ & $\begin{array}{l}1.31+02 \\
1.93+02 \\
1.080 .02 \\
1.22+02 \\
1.23+02 \\
1.52+02 \\
1.19+02 \\
1.050 .02 \\
6.34+01 \\
6.30+01 \\
1.33+02 \\
1.28002 \\
1.28+02 \\
1.26+02\end{array}$ & 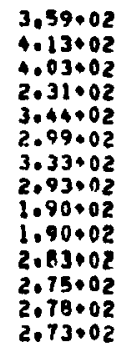 & 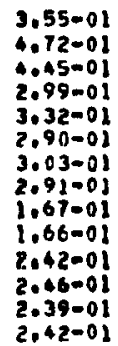 & $\begin{array}{l}2.33-01 \\
2.82-01 \\
2.56-01 \\
2.00=01 \\
1.96-01 \\
1.74-01 \\
1.70-01 \\
1.04-01 \\
1.02-01 \\
1.02-01 \\
1.19-01 \\
1.10-01 \\
1.10-01 \\
1.09-01\end{array}$ & $\begin{array}{l}1.82-01 \\
1.67-01 \\
1.43-01 \\
1.41=01 \\
1.39=01 \\
1.23-01 \\
1.13-01 \\
1.07-01 \\
7.36-02 \\
7.31=02 \\
6.37=02 \\
5.66-02 \\
5.26-02 \\
5.0602\end{array}$ \\
\hline
\end{tabular}

LOAOING TOTAL $\quad 4.90+03 \quad 9.95+03 \quad 1.39+01 \quad 9,67+00 \quad 5.66+00$ 
THE METALLIC FISSION PRODUCT ISOTOPE TOTAL PRODUCTION AND RELEASE IN CUPIES OF DECAY RAOIATION FROM EACH ANALYZEO HEXAGON BLOCK IN FUEL LOAOING 3 OF SUEL SEGMENT I

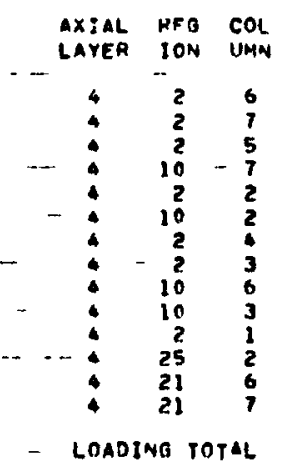

PRODUCED IN THE RELEASED INTO THF AXIAL REG COL PPT. I PRT. 2 MATRIX GRAPHITE COOLAMT LAYER ION UMN

PRODUCEO IN THE

RELEASED INIO THE $0.0803 \quad 4.54+02 \quad 1.04+00 \quad 6,04-01 \quad 4.58-01$ $4,35=01$ $2.00+02 \quad 0.41+02 \quad 9.18-01 \quad 5,95-01 \quad 3.15-01$ $2.40 .02 \quad 4.37+02 \quad a_{0} 15.01 \quad 5.30-01 \quad 3.61-01$ 3.50 3.65402 4.010. $2.63+n 2 \quad 4.36+02 \quad 0.12-01 \quad 5.07=01 \quad 3.00=01$ $2.31+02 \quad 4.18 .02 \quad 6.21-01 \quad 3.94-01 \quad 2.60-01$ $2.22+02 \quad 4.1100$ ? $5.50-01 \quad 3.44=01 \quad 2.24001$

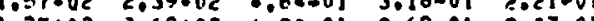

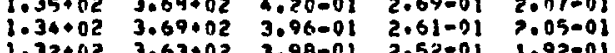
$4.93003 \quad 9.85 \cdot 03 \quad 1.40+01 \quad 8,75+00 \quad 5.74+00$

\begin{tabular}{|c|c|c|c|c|}
\hline $\begin{array}{l}1.34 \cdot 02 \\
1.95+02 \\
1.90 \cdot 02 \\
1.26 \cdot 02 \\
1.24 \cdot 02 \\
1.52 \cdot 02 \\
1.21 \cdot 02 \\
1.45 \cdot 02 \\
6.44 \cdot 01 \\
6.34+01 \\
1.36+02 \\
1.20 \cdot 02 \\
1.29+02 \\
1.36+02\end{array}$ & 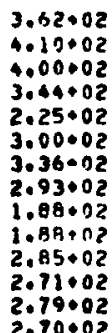 & 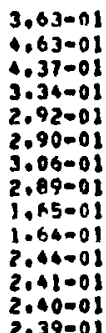 & $\begin{array}{l}2.39-01 \\
2.80-01 \\
2.57-01 \\
2.02-01 \\
1.96-01 \\
1.96-01 \\
1.78001 \\
1.02-01 \\
1.02-01 \\
1.01001 \\
1.23-01 \\
1.12001 \\
1.12-01\end{array}$ & $\begin{array}{l}1.07-01 \\
1.69-01 \\
1.47-01 \\
1.44-01 \\
1.39=01 \\
1.22-01 \\
1.21=01 \\
1.05=01 \\
7.33-02 \\
7.29-02 \\
6.74-02 \\
5.52=02 \\
5.43-02 \\
5.01-02\end{array}$ \\
\hline
\end{tabular}

- equilibrium core hock-up for SEGMENt 1.

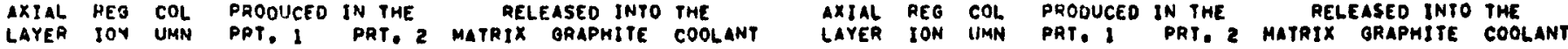

$\begin{array}{rrr}- & 2 & 6 \\ -\quad 4 & 2 & 7 \\ 10 & 5 \\ 4 & 7 & 2 \\ 10 & 2 \\ 2 & 4 \\ 7 & 3 \\ -4 & 6 \\ 11 & 3 \\ 2 & 1 \\ -4 & 21 & 6 \\ -4 & 21 & 7\end{array}$

loading total $\begin{array}{lllll}2.48+02 & 4.54+02 & 1.04+00 & 6.94-01 & 0.50-01 \\ 2.80+02 & 4.51+02 & 1.01+00 & 6.67-01 & 6.35-01\end{array}$ $\begin{array}{ccccc}2.86+02 & 4.51+02 & 1.01+00 & 8.67-11 & 4.35-01 \\ 2.8 n+02 & 4.41+02 & 9.18-01 & 5.855-01 & 3.75-01\end{array}$

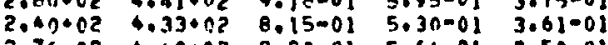
$2,75+02 \quad 4,4 C+02$ R. $A 0=01 \quad 5,64-101$ 1.50-n $2.33+02 \quad 4.33+02 \quad 7.53-01$ 4.63-01 3.23-01

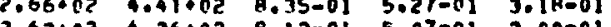

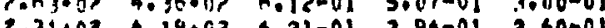
3)

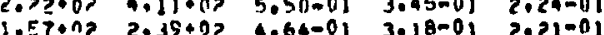
$1.35002 \quad 3.69+02 \quad 4.20-01 \quad 2.69-01 \quad 2.07-01$ $\begin{array}{lllll}1.36 \cdot 02 & 3.69 \cdot 02 & 3.96-01 & 2.61-01 & 2.05-01 \\ 1.32 \cdot 02 & 3.63 \cdot 02 & 3.08-01 & 2.52-01 & 1.92-01\end{array}$ $-$

$4.98003 \quad 9.85 \times 03 \quad 1.40001 \quad 0.75 \times 00 \quad 5.74+00$

-4
$\vdots$
$-\quad \vdots$
$-\quad \vdots$
$-\quad i$

$\begin{array}{rr}25 & 3 \\ 10 & 5 \\ 10 & 4 \\ 25 & 7 \\ 10 & 1 \\ 21 & 5 \\ 21 & 2 \\ 25 & 4 \\ 25 & 1 \\ 21 & 1 \\ 25 & -6 \\ 21 & 4 \\ 21 & -3 \\ 25 & 5\end{array}$

$\begin{array}{lllll}1.34+02 & 3.62+02 & 3.63-01 & 2.39-01 & 1.07-01 \\ 1.95 \cdot 02 & 4.10002 & 4.63-01 & 2.00-01 & 1.69-01\end{array}$ $\begin{array}{lllll}1.95002 & 4.10002 & 4.63-01 & 2.800-01 & 1.69-01 \\ 1.90002 & 4000002 & 0.37-01 & 2.57=01 & 1.47-01\end{array}$ $1.26+02 \quad 3.46+02 \quad 3.34-01 \quad 2.02-01 \quad 1.46=01$ $1.24 .02 \quad 2.25+02 \quad 2.92-01 \quad 1.96-01 \quad 1.39-01$ $1.52002 \quad 3.00602 \quad 2.90-01 \quad 1.74-01$ 1.22-01 1.21.02 3.36002 3.06-01 1.78-01 1.21-01 1.45002 2.93002 $2.09-01$ 1.62-01 1.05-01 $6.39+01$ i. $3.36002 \quad 2.85002$ 2.44-01 $1.23-110.74-02$ $1.28+02 \quad 2,71.02 \quad 2.42-01$ 1.12-01 5.52-02

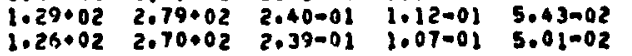
$-\ldots$ 


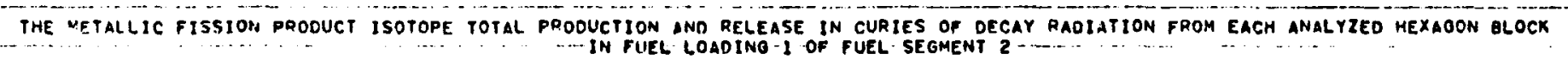

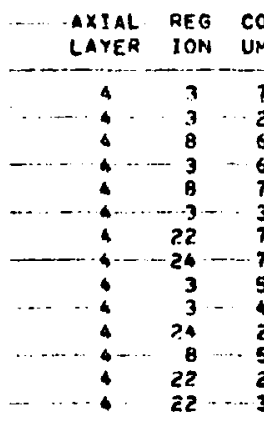

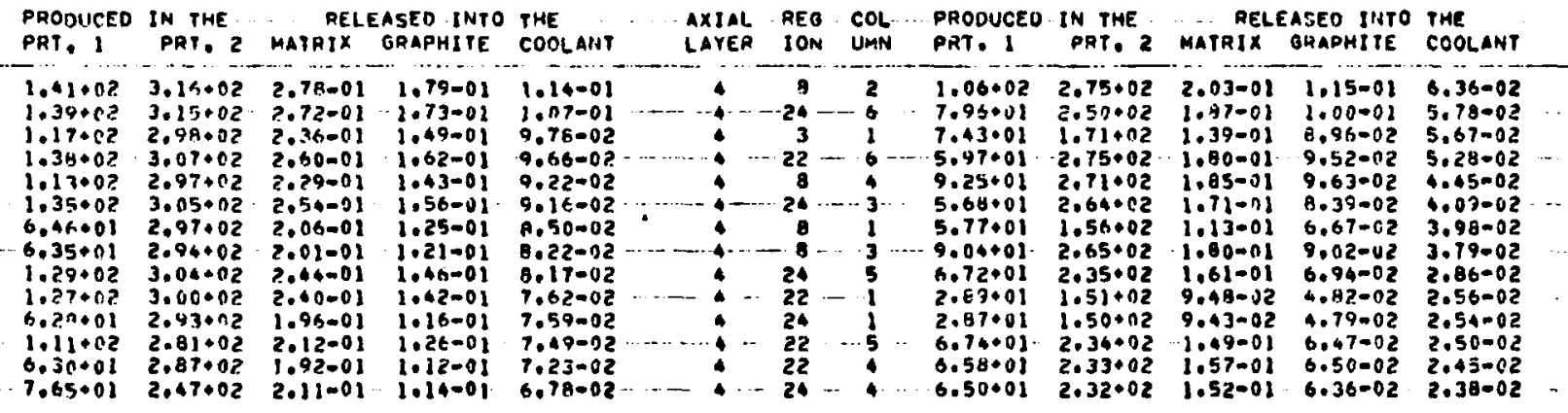

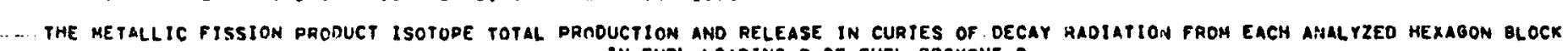
IN FUEL LOROING 2 OF FIEL SEGMENT 2

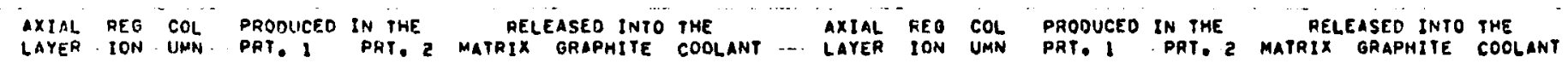

2,90+02 4.00+02 $1.19+00$ H.11-01 5.39-0

$2.36+02 \quad 4.79+02 \quad 1.12 .00 \quad 7.58-02 \quad 4.94-01$

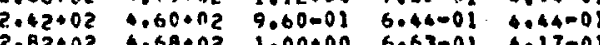

$\begin{array}{lllll}2.02+02 & 4.68+02 & 1.00000 & 6.43-01 & 4.17=01\end{array}$

$\begin{array}{lllll}2.36+02 & 4.59+02 & 0,90-01 & 5.92-01 & 4.03-01 \\ 2.78+02 & 4.36+02 & 0.60+01 & 6.29-0 . & 3.00-01\end{array}$

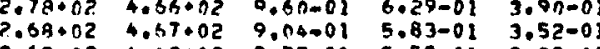

$.65+02$
$2.63+02$

$2.32+02 \quad 4.390 .02 \quad 6.92-01 \quad 4.46-01 \quad 2.90-01$

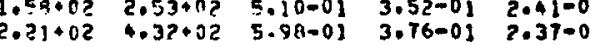

$1.33+02 \quad 3.56+02 \quad 4.07-01 \quad 2.65-01 \quad 2.00-01$

$\begin{array}{lllll}1.31+02 & 3.56+02: 3.79-01 & 2.50-01 & 1.98-01 \\ 1.30+02 & 3.53+02 & 3.52-01 & 2.45-01 & 1.90-01\end{array}$

LOAOING TOTAL

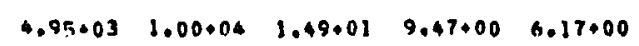

\begin{tabular}{|c|}
\hline $\begin{array}{r}8 \\
22 \\
6 \\
8 \\
22 \\
24 \\
24 \\
22 \\
22 \\
24 \\
22 \\
24 \\
24 \\
22\end{array}$ \\
\hline
\end{tabular}

$1.94+02-4.29 \cdot 02-4.95-01-2.99-01-1.13-01$ $1.29+02 \quad 3.49+02 \quad 3.40-01 \quad 2.21-01 \quad 1.12=01$ $1.90+02 \quad 4.18002 \quad 4.65-01$ 2.75-01 1.52-01 $1.24002 \quad 2.36002 \quad 3.210012 .16-01 \quad 1.51001$ $\begin{array}{lllll}1.24+02 & 3.33+02 & 3.23-01 & 1.93-01 & 1.39-01 \\ 1.19+02 & 3.23 \cdot 02 & 2.95-102 & 1.69-01 & 1.14001\end{array}$ $\begin{array}{lllll}1.19+02 & 3.23002 & 2.95-01 & 1.69-01 & 1.14001 \\ 1.50002 & 2.03602 & 2.65-01 & 1.51-01 & 1.02-01\end{array}$

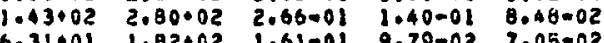
6.31001 1.98+02 1.01-n1 9.79-02 7.25-02 $\begin{aligned} & 6.27+01 \\ & 1.31+02\end{aligned} \quad 1.02+02 \quad 1.61-01 \quad 9.73-02 \quad 7.00=02$ $1.25+02 \quad 2.72,02 \quad 2,35-01 \quad 1.09-01 \quad 5.42=02$ $\begin{array}{lllll}1.25+02 & 2.62+02 & 2.36-01 & 1.06-01 & 5.07-02 \\ 1.23+02 & 2.61 \cdot 02 & 2.33=01 & 1.02-01 & 4.65=02\end{array}$ 
THE METALLIC FISSION PRODIJCT ISOTOPE TOTAL PRODUCTION ANO RELEASE IN CURIES OF deCAY RADIATION FROM EACH ANALTZED HEXAGON BLOCK AXIAL PEG COL PRODUCED IN THE
LAYER ION UMN PRT. I PRT, 2 MATRIX GPIOPHITE COOLANT AXIAL REG COL PROOUCED IN THE PELEASEO INTO THE
LAYER ION UMN PRT, I PRT, 2 MATRIX ORAPHITE COOLANT

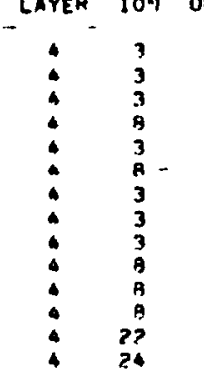

LOAOING TOTAL

(1.,

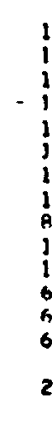

$2.51+03 \quad 7.02 .03 \quad 6.19000 \quad 3.56000 \quad 2.07+00$

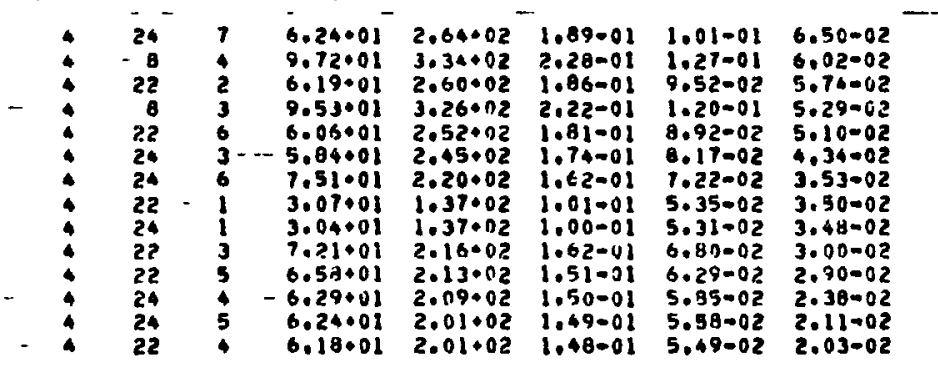

- equiligrium core mockmup for segment 2 -

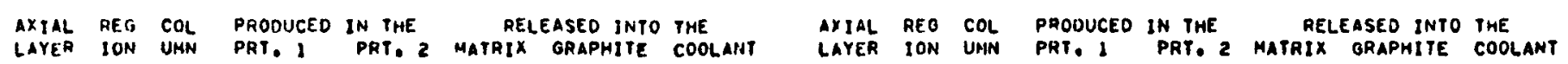

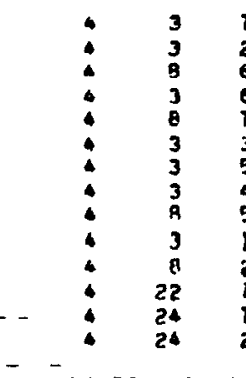

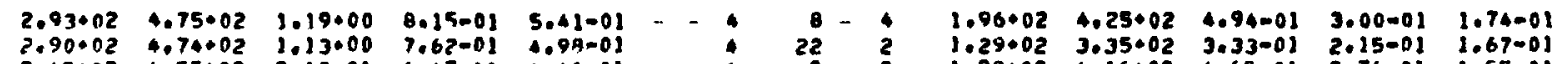

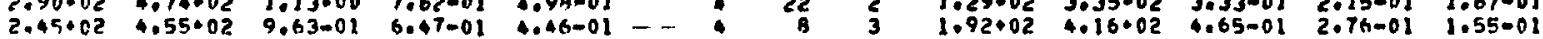
$2.86005 \quad 4.66002 \quad 1.01+00 \quad 6.66-01 \quad 0.20-01$ $2,38 \cdot 02 \quad 4.54+02 \quad 9,90-01 \quad 3,92-01 \quad 4.03-01$ $2.87002 \quad 9.61002 \quad 9,00-01 \quad 6.30-01 \quad 3.92-01$ $2.71 \cdot 02 \quad 4.51 \cdot n 2 \quad 9.04001 \quad 5.84-02 \quad 3.52-01$ $2.33+02 \quad 4.33002$ 6. $30-01 \quad 5.59-01 \quad 3.30=01$

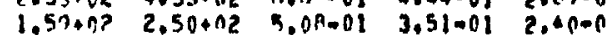
$2.23+12 \quad 4.26002 \quad 5.94001 \quad 3.75-01 \quad 2.26-01$ $1.33+02 \quad 3.44+02 \quad 4.00-01 \quad 2.60-01 \quad 2.04-01$ $\begin{array}{lllll}1.31+C 2 & 3.43+02 & 3.72-01 & 2.44-01 & 1.93-11 \\ 1.34002 & 3.41+02 & 3.7 k-01 & 2.42-01 & 1.08-01\end{array}$ $2.42-01 \quad 1.88-01$

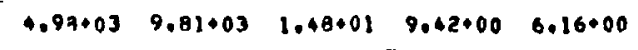
$1.25+02 \quad 2.33+02 \quad 3.18-01 \quad 2.14=01 \quad 1.50-01$ $1.240023 .24002 \quad 3.16-01 \quad 1.92-01 \quad 1.40-01$ $1.19 .02 \quad 3.160 .02 \quad 2.91-01$ 1.68-01 $1.16-01$ $1.41002 \quad 2.68002 \quad 2.57-01 \quad 1.34-01 \quad 0.23-02$ $6.27001 \quad 1.76+02 \quad 1.57=01 \quad 9.47=02 \quad 6.01-02$ $6.23+01 \quad 1.75002 \quad 1.57-01 \quad 9.42-122 \quad 6.77-02$ $1.10402 \quad 2.67+02 \quad 2.33-01 \quad 1.17001 \quad 6.34002$ $\begin{array}{lllll}1.23+02 & 2.61002 & 2,2 \beta-01 & 1.05-01 & 5.16-02 \\ 1.33002 & 2.51+02 & 2.28-01 & 1.00-01 & 4.72-02\end{array}$ $\begin{array}{lllll}1.23+02 & 2.51+02 & 2.28=01 & 1.000-01 & 4.72-02 \\ 1.21+02 & 2.50+02 & 2.25=01 & 9.67-02 & 4.32=02\end{array}$ 


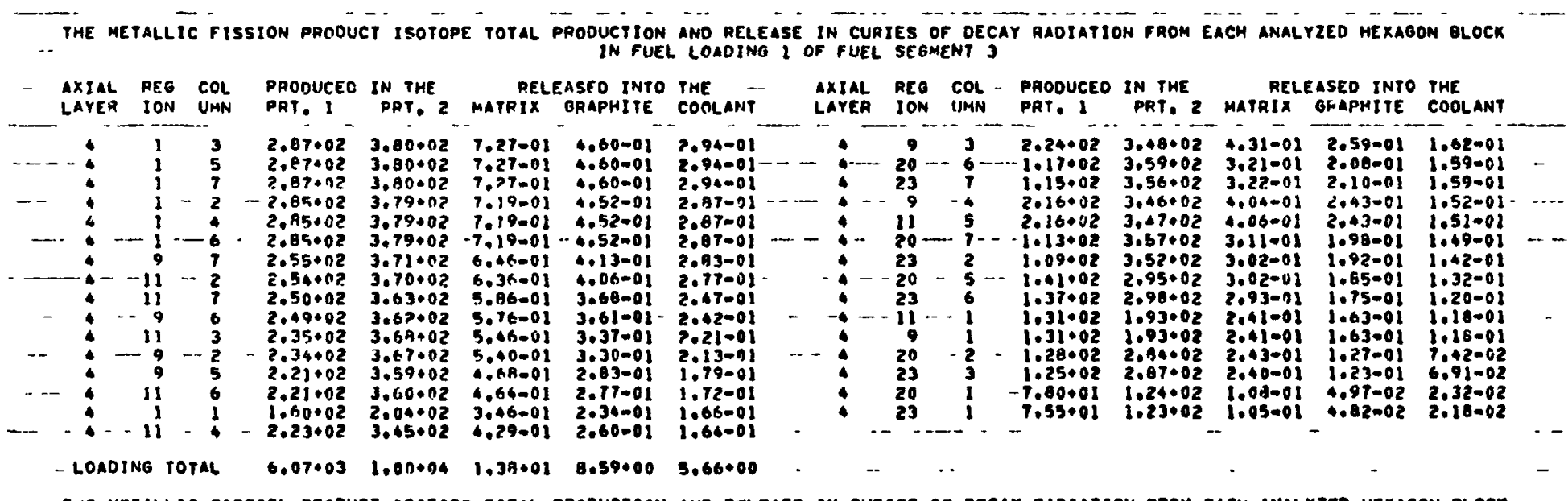
PHE METALLIC FISSION PROOUCT ISOTOPE TOTAL PRODUCTION ANR RELEASE IN CURJES OF OEC AY
IN FUEL LOAOING 2 OF FUEL SEOMENT 3

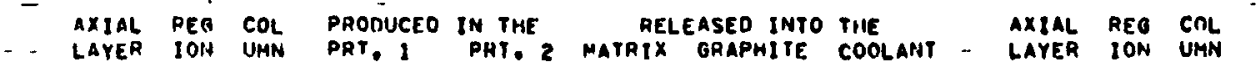

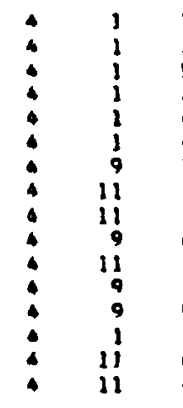

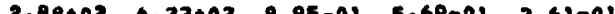

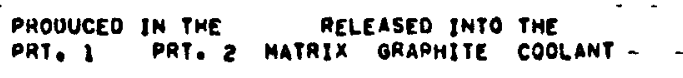

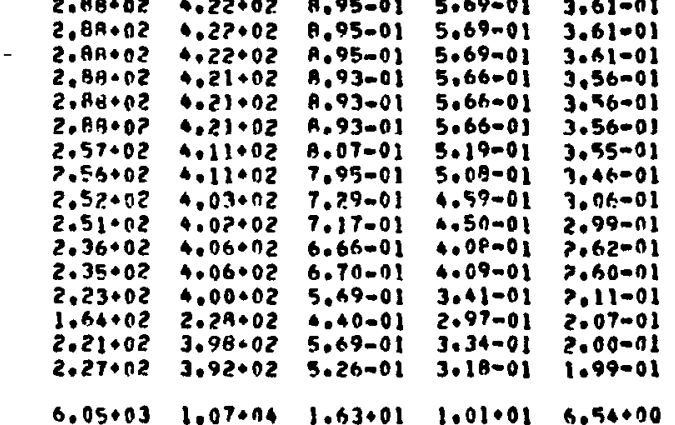

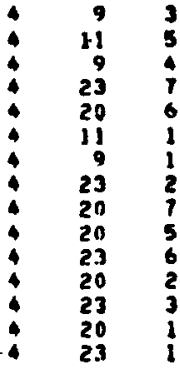

$2.29002 \quad 3.09002 \quad 3.25-02 \quad 3.12-01 \quad 1.90-01$ $2.10 \cdot 02 \quad 3,92002 \quad 4.07-01 \quad 2,92-01 \quad 1,78-01$

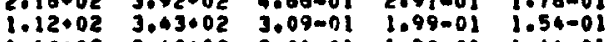

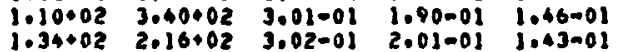

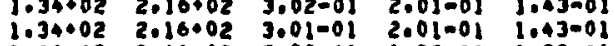

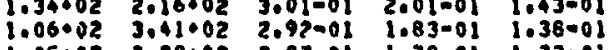
$1.05 .02 \quad 3.38 .02 \quad 2.07=01 \quad 1.78-01 \quad 1.33-01$ $1.28 \cdot 02 \quad 2.03 * 02 \quad 2.57-01 \quad 1.45-01 \quad 9.68-02$

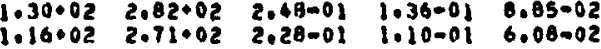

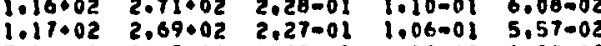

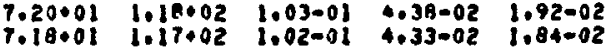

LOAOINB TOTAL

$6.05 \times 03 \quad 1.07004 \quad 1.63 \times 01 \quad 1.01001 \quad 6.54 \times 00$ 


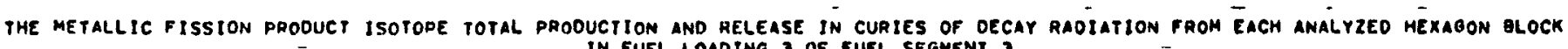
IN FUEL LOADING 3 OF FUEL SEGMENT 3

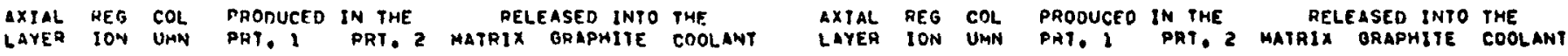

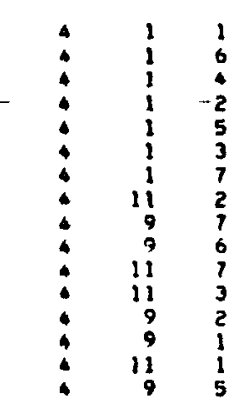

LOADINB TOYAL $\begin{array}{llllll}2.36+01 & 1.30+12 & 7.58-02 & 0.26-02 & 2.37-02 \\ 0.09001 & 2.36+02 & 3.20-01 & 0.23-02 & 2.033-02\end{array}$ $\begin{array}{lllll}0.09+01 & 2.36+02 & 1.24-01 & 6.23-02 & 2.23-02 \\ 4.09+01 & 2,3+02 & 1.24-01 & 6.23-02 & 2.23-02\end{array}$ . $\therefore 07001$ 2.3602 1.73-01 6.30-02 $2.035=02$ $4.07+012.36+02 \quad 1.23-71 \quad 6.20-02 \quad 2.21-02$ $4.07+01 \quad 2,36.02 \quad 1.23-n 1 \quad 6,20-02$ 2.21-02 3.510012023002 1.10-01 $5042-02$ 20.20-02 3.5101 2.?

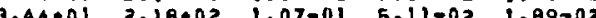
$3.20+01 \quad 2.17+02 \quad 1.04-01 \quad 0.93-02 \quad 1.67=02$ $3.16 .01 \quad 2.16002 \quad 1.02-01 \quad 9.75=02 \quad 1.63=02$ $1 .+40+01 \quad 1.17+02 \quad 6.05-02 \quad 3.14-02 \quad 1.52-02$

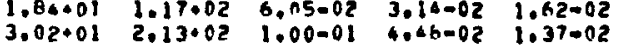

A. $17+02 \quad 5.56+03 \quad 2.71+00 \quad 1.22+00 \quad 4.31-01 \quad-$

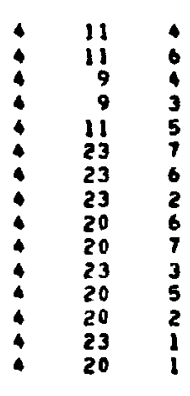
$3.11 .01^{--} 2.10 .02 \quad 1.01=01 \quad 4.44-02 \quad 1.33-02$ $\begin{array}{lllll}2.98+01 & 2.10+02 & 9.83-02 & 4.02-02 & 1.25-02\end{array}$

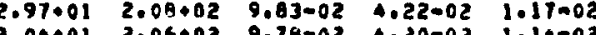

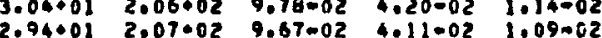
$1.28+01 \quad 1.50+12 \quad 6.59-12 \quad 2.34-02 \quad B .14-03$ $1.68+01 \quad 1.33+02 \quad 6.25=02 \quad 2.14-02 \quad 8.03=03$ $1.24001 \quad 1.50 \cdot 02 \quad 6.39-02 \quad 2.31-02 \quad 7.86-03$ $1.20001 \quad 1.43 .02 \quad 6,11=02 \quad 2.17-02 \quad 7.81=03$ $1.51+01 \quad 1.27+02 \quad 5.93-02$ 2.030-02 $5.16=03$ $\begin{array}{lllll}1.55001 & 1.30002 & 5.19-02 & 1.81 .02 & 5.12-03\end{array}$ $1.40 .01 \quad 1.240112 \quad 5.51-02 \quad 1.53-02 \quad 3.13-03$ $\begin{array}{lllll}9.75+00 & 5.73+01 & 2.82-02 & 6.92-03 & 9.51-04 \\ 6.79+00 & 5.45001 & 2.57-02 & 6.14-03 & 8.20-04\end{array}$

- equilibaivy cope mock-up for Segment 3 .

axial REg COL
- laYer ION UMA PRODUCEO IN THE RELEASEO INTO THE
PRT, I PRT, 2 MATRIX GRAPHITE COOLANT AXIAL REG COL PRODUCEO IN THE M RELEASED INTO THE
LAYER ION UMN PRT, I PRT. 2 MATRIX GRAPHITE COOLANT $2.80+02 \quad 4.37+02 \quad 9.01-01 \quad 5.75-01$ $2.00+02 \quad 4.37+02 \quad 9.01=01 \quad 5.75-01 \quad 3.54-01$

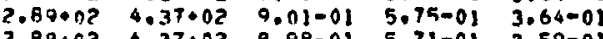

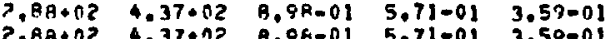

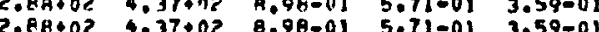
2.5700 ? 4.26002 a. $12-01 \quad 5.24-013.58-01$ $2,54002 \quad 0.25 \cdot 02 \quad 8.00-01 \quad 5.13=01 \quad 3.49-01$ $2.52+1250.17+12 \quad 1.14001 \quad 4.64=023.09=01$ $2.51 .02 \quad 4.17002 \quad 7.27-01$ 4.55-01 3.010.01 2.34002 40.20002 b. 2. $1.64002 \quad 2.35002$ 5.744-01 3.00-01 2.13-01 $\begin{array}{lllll}2.2 A+02 & 6.06+02 & 5.31-01 & 3.23-01 & 2.01-01 \\ 2.21+02 & 4.11002 & 5.73-01 & 3.38-01 & 2.01-01\end{array}$

$6.05 \cdot 03 \quad 1.09004 \quad 1.64 .01 \quad 1.07 .01 \quad 6.59+00$

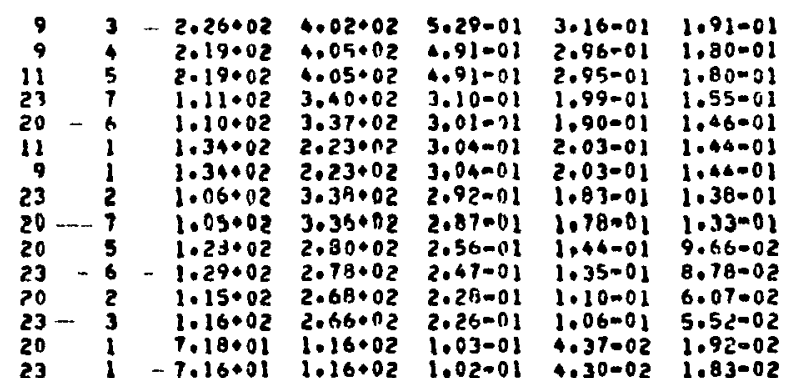

TOTAL EXECUTION TIME $=986.034$ SECONOS 


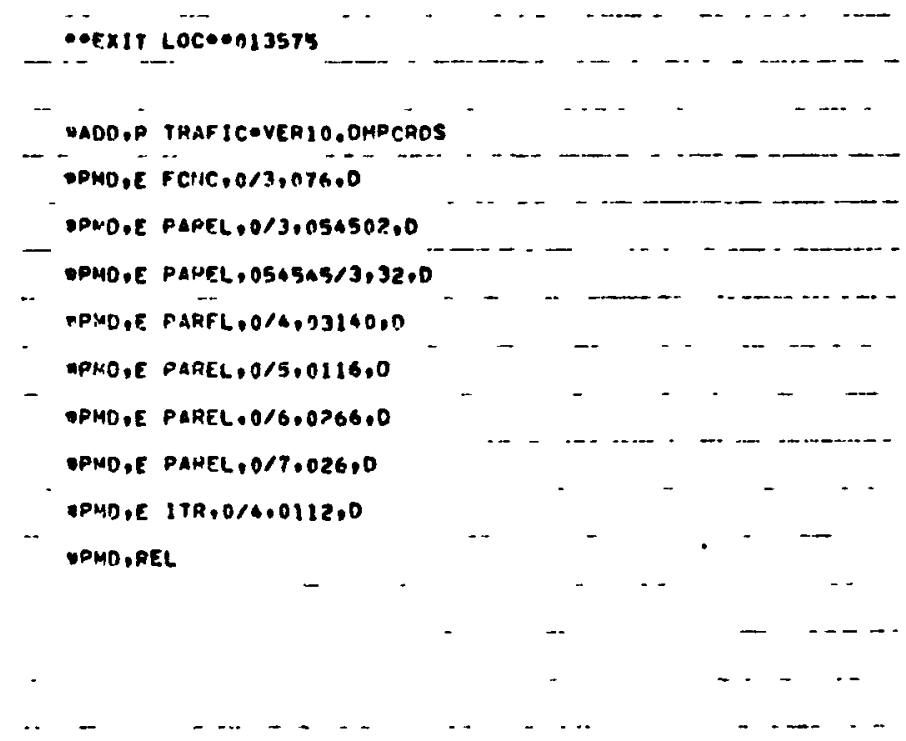




\section{REFERENCES}

1. Appe1, J., and B. Roos, "A Study of the Release of Radioactive Metallic Isotopes from High Temperature Gas-Cooled Reactors," Nuclear Science and Engineering: 34, 201-213 (1968).

2. Smith, P. D., and R. G. Steinke, "COPAR, A Program to Compute Release of Metallic Fission Products from Coated Particles," General Atomic Report GA-A14034, July 1977.

3. Saeger, J., "HEXT, A Special Purpose Heat Conduction Code for the HTGR Core," General Atomic Informal Report GAMD-10534, March 3, 1971.

4. Alberstein, D., P. D. Smith, and M. J. Haire, "Metallic Fission Product Release from the HTGR Core," General Atomic Report GA-A13258 (GA-LTR-20), May 15, 1975.

5. Shewmon, P. G., Diffusion in Solids, McGraw-Hill Book Company, New York, 1963, pp. 189-196.

6. Smith, P. D., "An Approximate Closed Form Solution to the Fission Product Diffusion Equation in One-Dimensional Slab Geometry," General Atomic Report GA-A13196, Nov. 1, 1974.

7. Treybal, Robert E., Mass-Transfer Operations, 2nd ed., McGraw-Hi11 Book Company, New York, 1968, p. 62 .

8. Bird, R. B., W. E. Stewart, and E. N. Lightfoot, Transport Phenomena, J. Wiley and Sons, New York, 1960, p. 511.

9. Wagner, M. R., "GAUGE, A Two-Dimensional Few Group Neutron DiffusionDepletion Program for a Uniform Triangular Mesh," General Atomic Report GA-8307, March 15, 1968.

10. Dorsey, J. P., R. Froehlich, and F. Todt, "BUG-2/BUGTRI, Two-Dimensional Multigroup Burnup Codes for Rectangular and Hexagonal Geometry," General Atomic Report GA-8272, August 22, 1969.

11. Hudritsch, W. W., "RANDI, A Zero-Dimensional Computer Program for Calculating HTGR Activities," General Atomic Report GA-A14091, March, 1977.

12. Alberstein, D., et. al., "HTGR Accident Initiation and Progression Analysis Status Report," General Atomic Report GA-A13617 Volume V, February, 1976. 


\section{ACKNOWLEDGEMENTS}

The TRAFIC program as described herein has been under continuing development at General Atomic for about four years. Many individuals have made significant contributions to its development. A partial list is given below:

1. Jon Haire and Lee Rovner were instrumental in defining the need and the specifications for a core survey program of this type.

2. John Shi did many of the derivations and programmed the first operating version of the code.

3. Dave Alberstein performed many of the initial trial runs and gave us valuable feedback from a user's viewpoint.

4. Bob Steinke performed a major cleanup of TRAFIC and reduced its running time from eight seconds per case to two seconds per case.

5. Bob Steinke was also the original developer of the COPAR program which is now used as a particle source subroutine.

6. Richard Archibald programed the TSORT program, which serves as the interface between the core physics codes and SURVEY. He also initiated the SURVEY development.

7. Debra Georghiou completed the SURVEY development and has made numerous modifications to SURVEY. She also programmed and repeatedly improved the many data interfaces between SURVEY, TRAFIC, RANDI, and various postprocessors.

8. Finally, Debra Georghiou was instrumental in helping to locate some persistent numerical problems in both TRAFIC and COPAR, and she provided valuable assistance in a major reprogramming of the solution methods in both of these programs.

The author extends his grateful appreciation to all of these individuals and to all others who have participated in this effort. 